\title{
EL COMERCIO ELECTRÓNICO
}

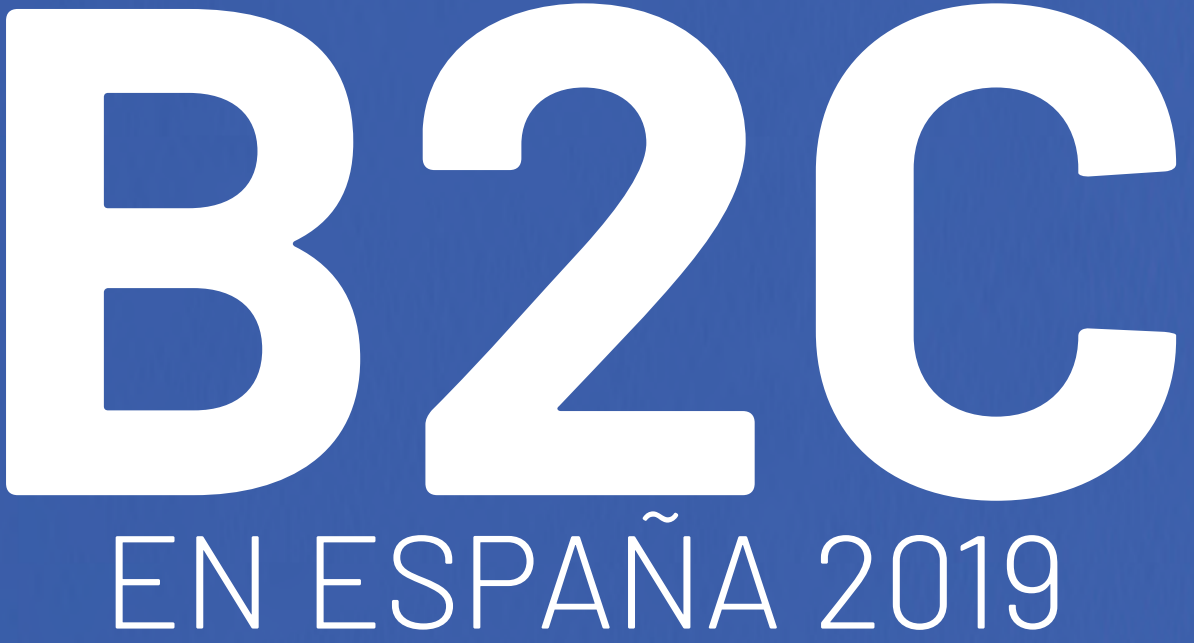

EDICIÓN

2020

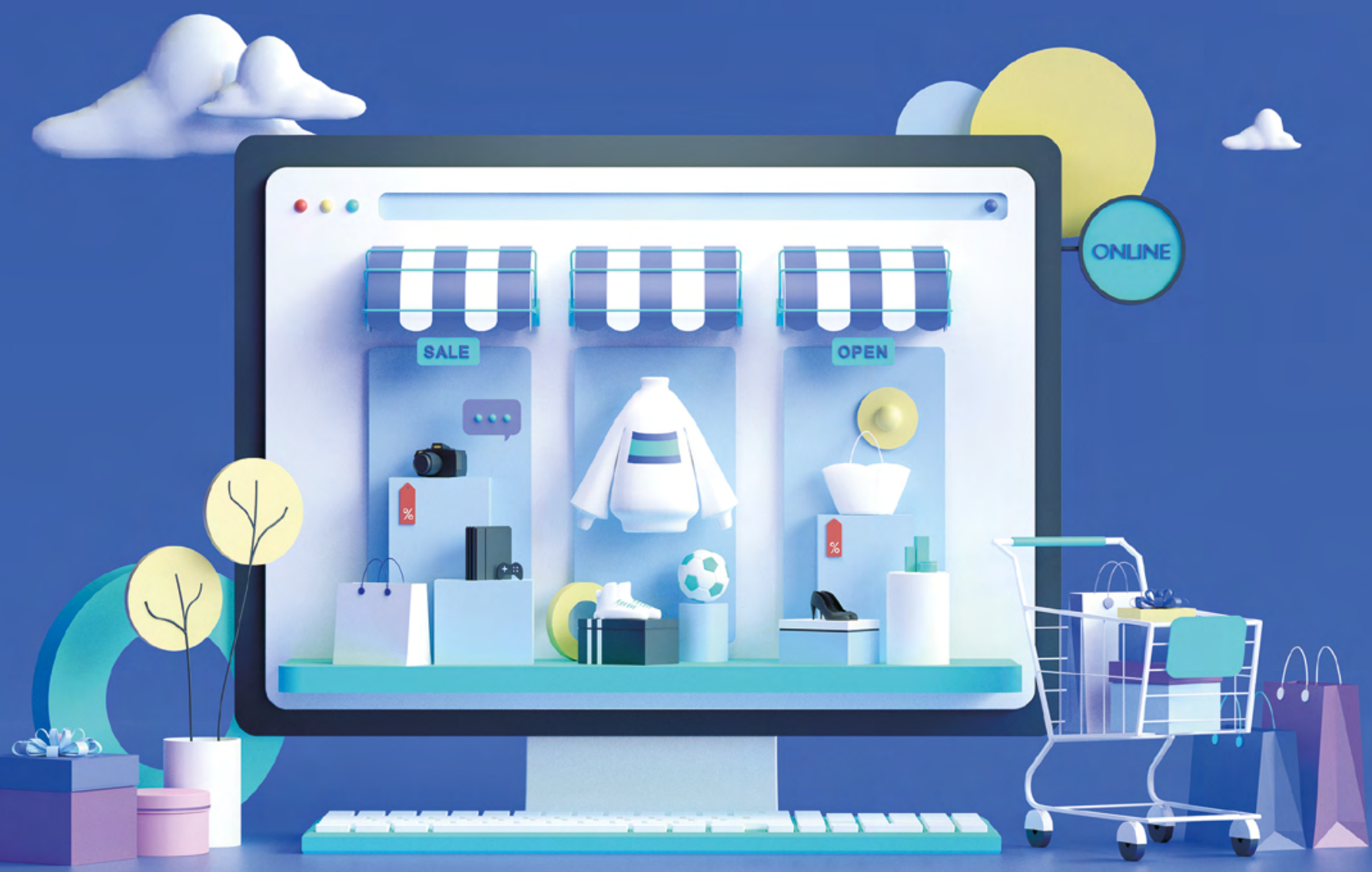




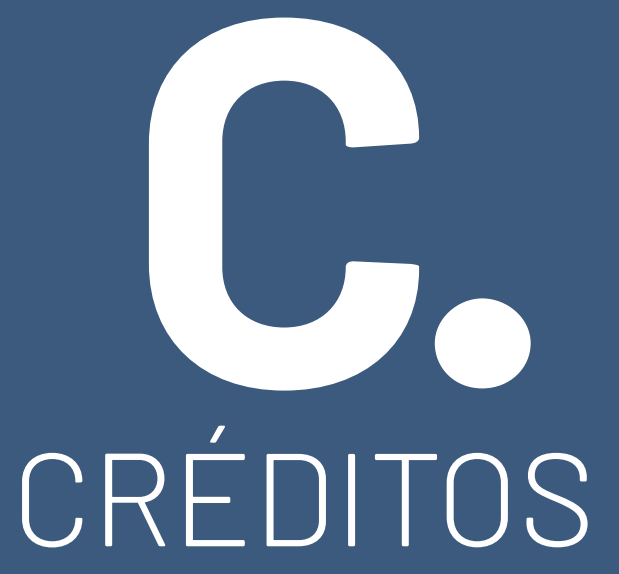

Este informe ha sido elaborado por el equipo de Estudios del ONTSI

(Observatorio Nacional de las Telecomunicaciones y de la Sociedad de la Información):

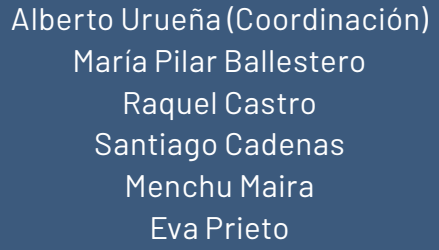

Edita:

Secretaría General Técnica. Centro de Publicaciones

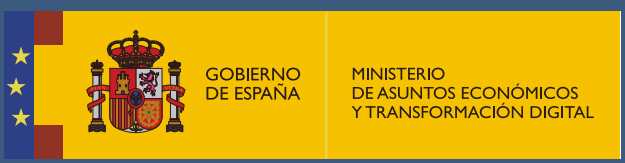

ISSN: 2695-5830

DOI: 10.30923/2695-5830-2020

E-NIPO: 094-20-090-0

\section{Sugerencia para citar este informe:}

Observatorio Nacional de las Telecomunicaciones y de la Sociedad de la Información (2020). El comercio electrónico B2C en España: 2019 (Ed. 2020). Madrid: Secretaría General Técnica, Centro de Publicaciones. <http://doi.org/10.30923/2695-5830-2020>

Reservados todos los derechos. Se permite su copia y distribución por cualquier medio siempre que se mantenga el reconocimiento de sus autores, no se haga uso comercial de las obras y no se realice ninguna modificación de las mismas. 
1. INTRODUCCIÓN

2. RESUMEN EJECUTIVO

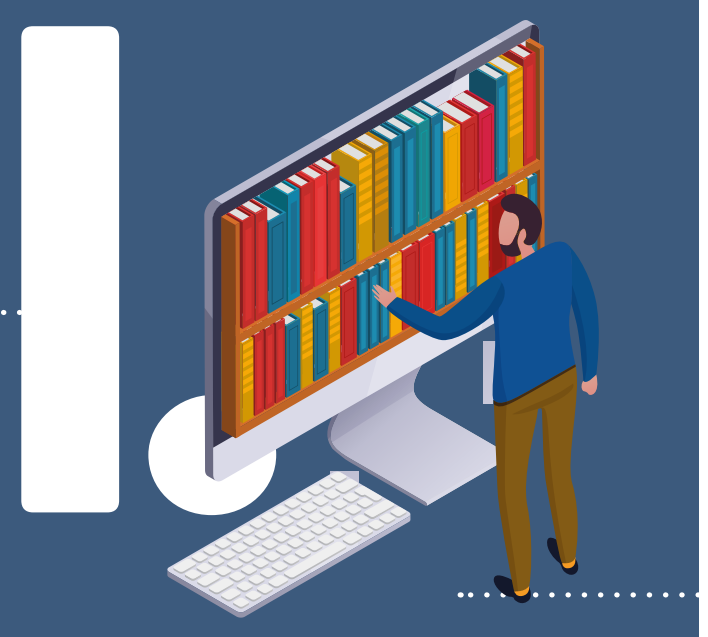

3. DATOS GENERALES DEL ESTUDIO

3.1. VOLUMEN DE NEGOCIO DEL COMERCIO ELECTRÓNICO

3.2. CARACTERIZACIÓN DE USUARIOS DE INTERNET: INTERNAUTAS COMPRADORES Y NO COMPRADORES

4. HÁBITOS DEL COMERCIO ELECTRÓNICO

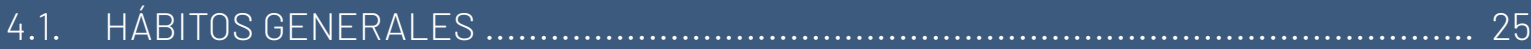

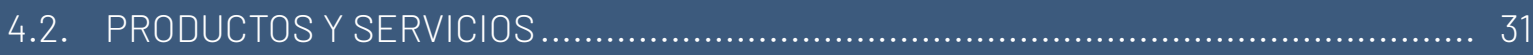

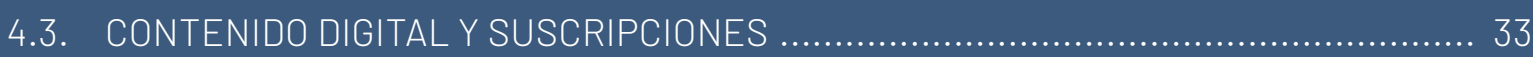

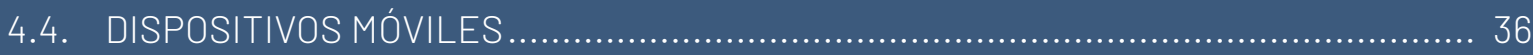

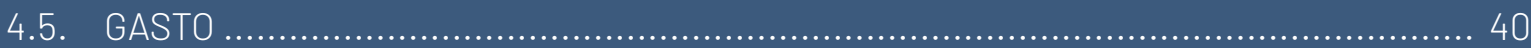

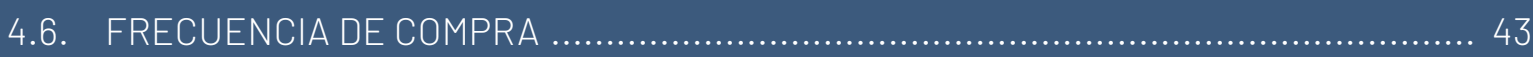

4.7. COMERCIO ELECTRÓNICO ENTRE PARTICULARES C2C .................................. 45

5. EXPERIENCIA DE COMPRA ONLINE

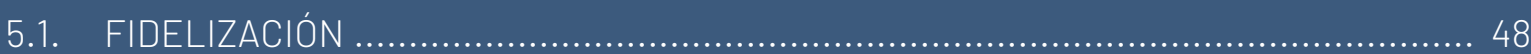

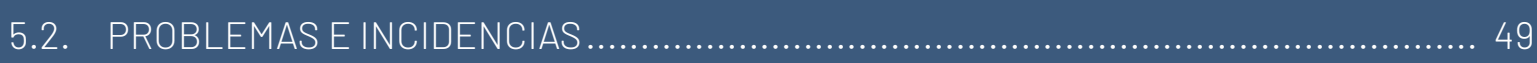

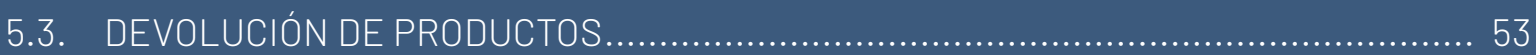

\section{LOGISTICA Y DISTRIBUCIÓN}

7. FRENOS E IMPULSORES DEL COMERCIO ELECTRÓNICO

7.1. ANÁLISIS DESDE LA PERSPECTIVA DE LOS NO COMPRADORES ........................... 60

7.2. ANÁLISIS DESDE LA PERSPECTIVA DE LOS COMPRADORES ............................... 62

8. HÁBITOS DE COMPRA ONLINE DURANTE EL CONFINAMIENTO

8.1. CARACTERIZACIÓN DE LA COMPRA DURANTE EL CONFINAMIENTO.....

8.2. FRENOS E IMPULSORES DE LA COMPRA ONLINE DURANTE EL CONFINAMIENTO 72

8.3. EFECTOS DEL CONFINAMIENTO EN LOS HÁBITOS DE CONSUMO ONLINE.

9. METODOLOGIA

9.1. CAMBIOS RESPECTO A LA EDICIÓN ANTERIOR ........................................... 78

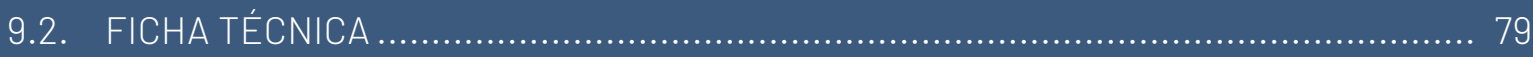

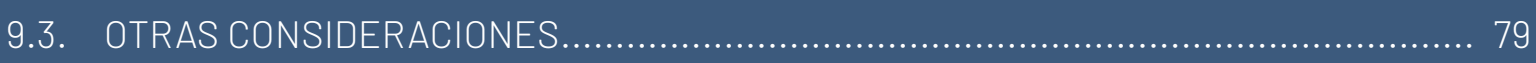

ÍNDICE DE TABLAS

ÍNDICE DE FIGURAS 


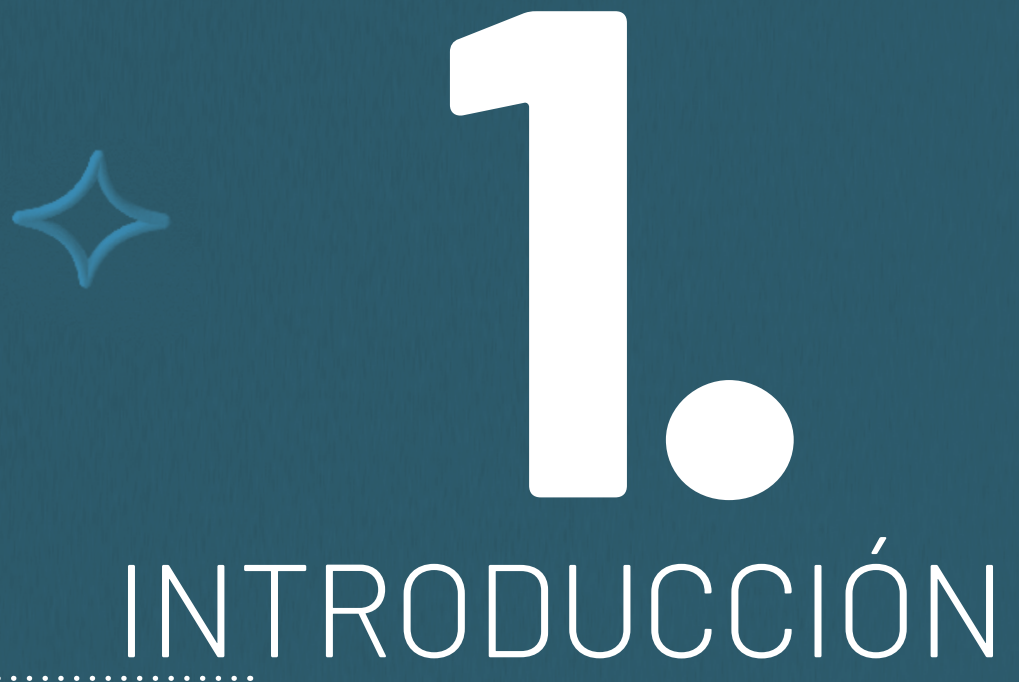

4

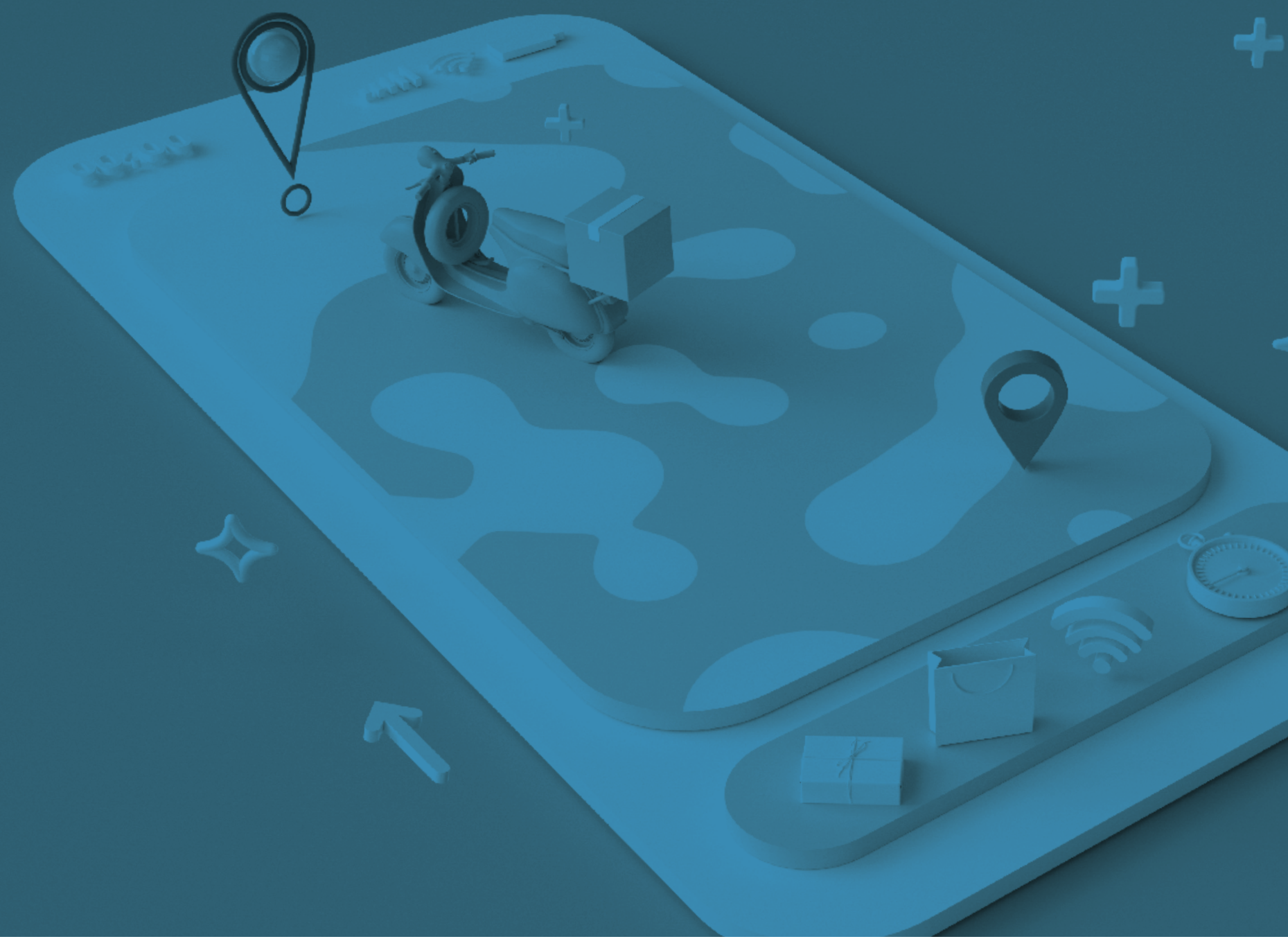




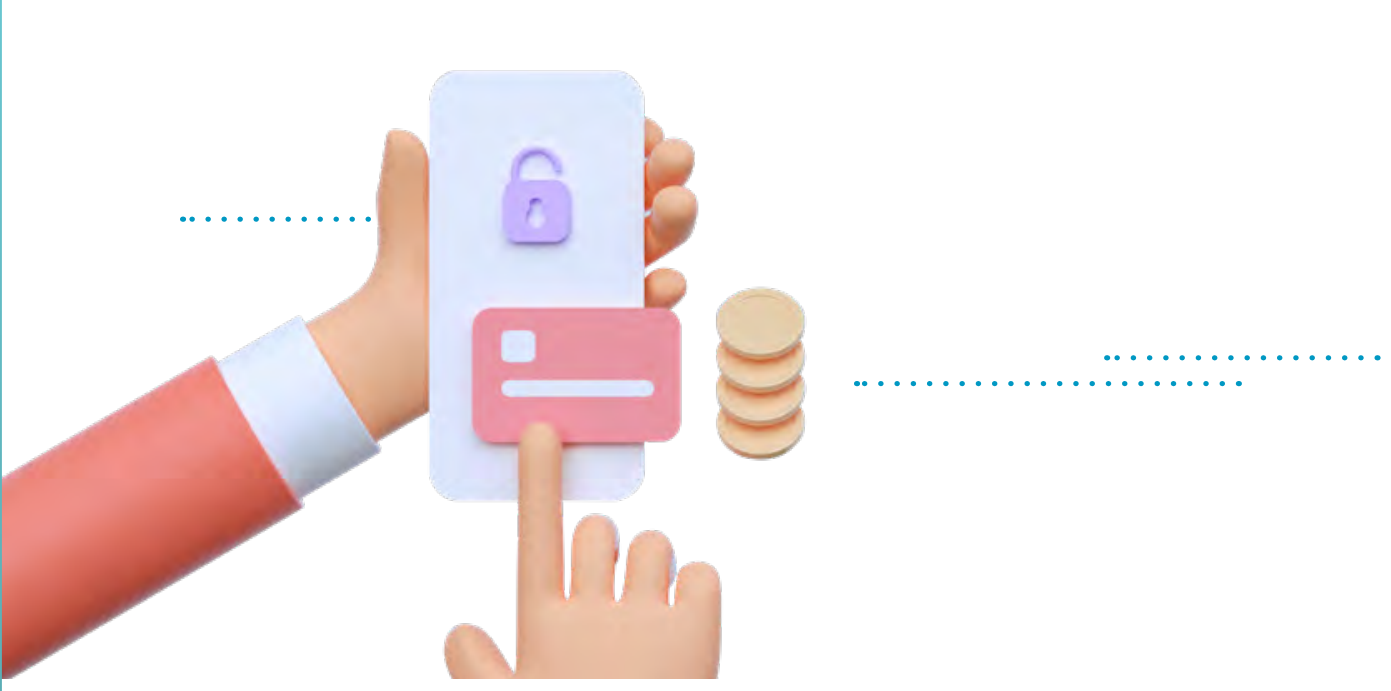

El Observatorio Nacional de las Telecomunicaciones y de la Sociedad de la Información (ONTSI) de Red.es, pone a disposición de los ciudadanos y la sociedad en general, la duodécima edición del estudio «El Comercio Electrónico B2C en España 2019 (Ed. 2020)» con la finalidad de mostrar la realidad del comercio electrónico en España durante el año 2019. El estudio es una herramienta que permite dimensionar el sector y caracterizar a los usuarios del comercio electrónico y sus hábitos de consumo.

Dadas las circunstancias derivadas de la pandemia ocasionada por la COVID-19, esta edición ha incorporado una batería de preguntas realizadas expresamente relacionadas con el comportamiento de la población durante los meses de marzo a mayo de 2020 que duró el estado de alarma nacional. Con ello se ofrece una valoración del impacto de esta situación excepcional en los hábitos de consumo a través de Internet.

El universo contemplado por el estudio es la población internauta de 16 a 74 años (34.910.798 individuos en 2019, según datos del INE: Encuesta sobre equipamiento y uso de tecnologías de información y comunicación en los hogares). La muestra utilizada ha sido de 2.900 personas lo que permite asegurar para un nivel de confianza del $95 \%(p=q=50 \%)$, un margen de error de $\pm 1,82 \%$. La muestra se ha segmentado generando cuotas proporcionales por género, edad, y tamaño de hábitat según los datos de la encuesta del INE citada anteriormente.

Antes de dar paso al análisis de los resultados, el estudio incluye un resumen ejecutivo que permite una rápida aproximación a los principales indicadores y resultados, con respecto a la evolución del comercio electrónico y el comportamiento de los compradores.

El tercer capítulo muestra una panorámica general del sector con referencias al volumen de ventas que se realizan por medios electrónicos, el gasto medio de los compradores, el perfil del comprador y no comprador online o la evolución del número de compradores que existen en España.

El cuarto capítulo integra información sobre los hábitos de compra en nuestro país. Se orienta a conocer cómo compran los internautas en España, y el tipo de productos que compran. El quinto capítulo aborda la experiencia de compra online que valora la satisfacción de los clientes de comercio electrónico y los aspectos que dan lugar a esa satisfacción. Por su parte, el sexto capítulo recoge algunas referencias a los procesos de distribución en el comercio electrónico.

Para terminar el estudio se incluyen dos capítulos adicionales: el primero, sobre el futuro del comercio electrónico, donde se hace un análisis de su posible evolución; el segundo, sobre los hábitos de compra online durante el estado de alarma nacional. 


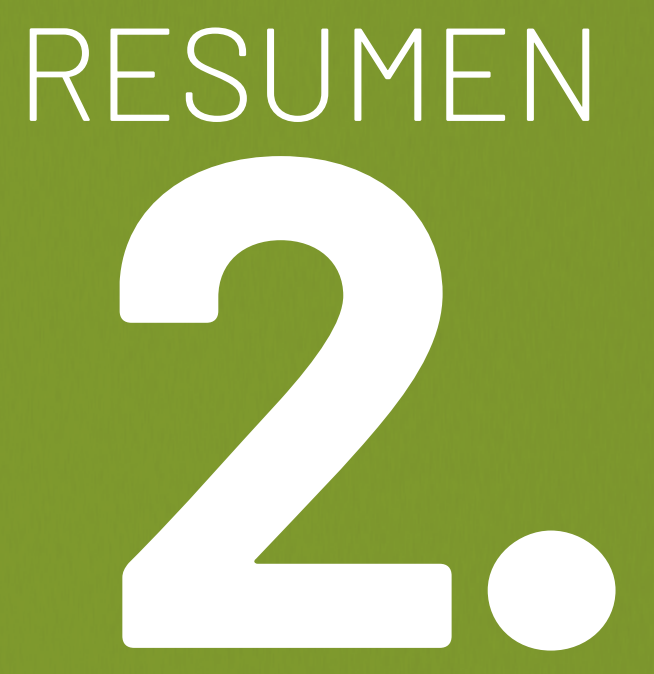

EJECUTIVO

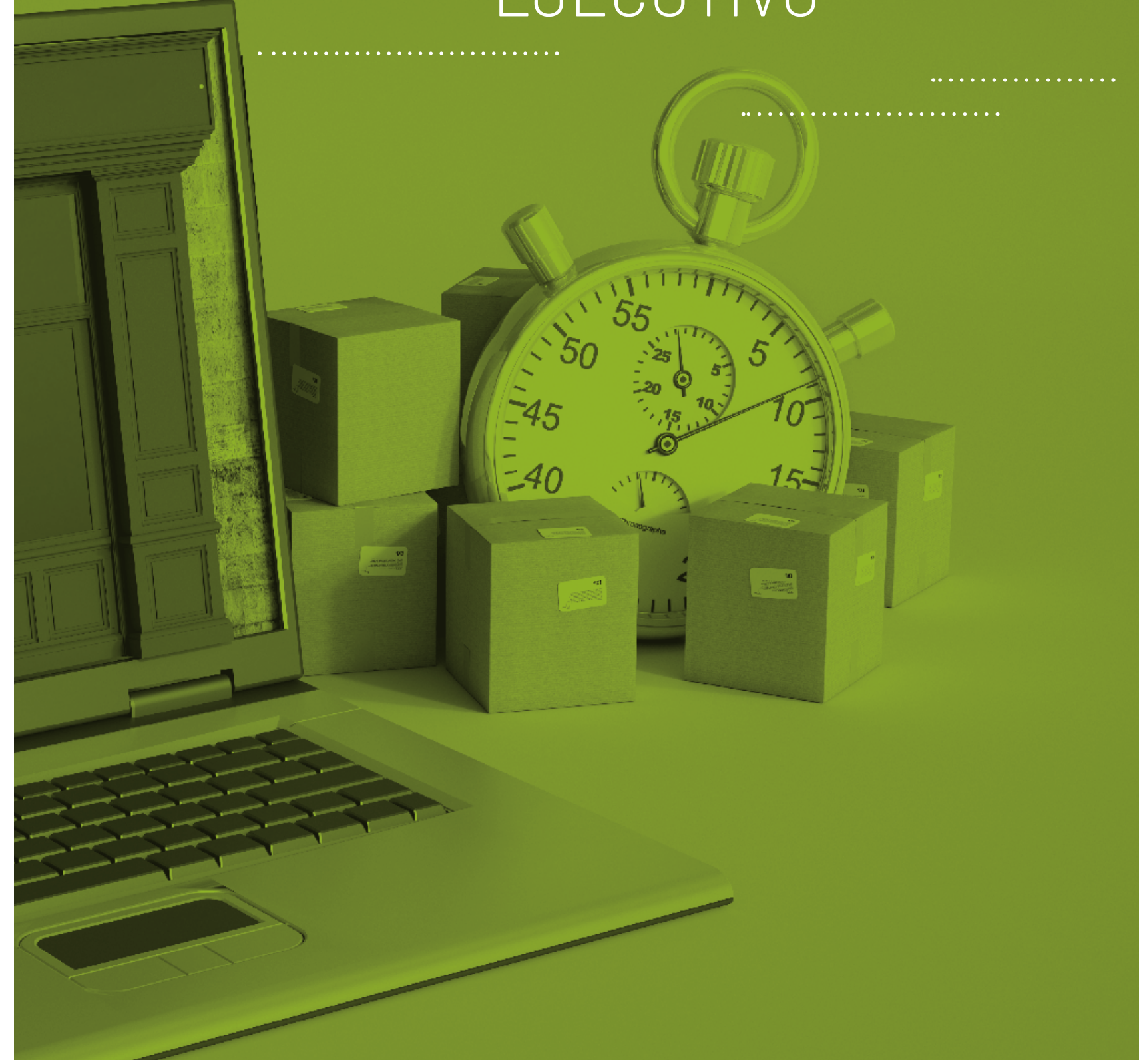




\section{DATOS GENERALES DEL COMERCIO ELECTRÓNICO EN ESPAÑA}

En 2019, las ventas realizadas a través de Internet superaron por primera vez los 50.000 millones de euros, siguiendo la tendencia creciente desde que se tienen registros. Las cifras revelan que el sector crece un $21,4 \%$ respecto al año anterior y un 210\% en los últimos 5 años.

A lo largo del año, cada comprador gasta una media de 2.076 euros en compras electrónicas, habiéndose duplicado la cifra desde 2015 (1.016 euros). El gasto anual promedio por comprador se ha incrementado en 156 euros respecto a 2018.

El número de personas que compran a través de Internet también crece, sumándose 2,6 millones de internautas a la compra online hasta los 24,3 millones, lo que supone un crecimiento del $12,2 \%$ respecto al año anterior. En este sentido, el porcentaje de internautas compradores se sitúa en un $76,4 \%$ del total de internautas (4,4 puntos porcentuales más con respecto a 2018).

El 23,6\% de los internautas (unos 7 millones) no realiza ninguna compra en Internet durante 2019, de ellos, unos 5 millones no había comprado nunca online anteriormente.

\section{PERFIL DEL}

\section{COMPRADOR ONLINE}

El comprador en España puede ser hombre o mujer de forma indistinta. Con una edad media de 44 años, el 23,5\% de los compradores online tiene entre 35 y 44 años, mientras un 22,5\% tiene entre 45 y 54 años. Las personas de 25 a 34 años son los que compran de forma más intensiva y superan las 3 compras mensuales.

Además, un $53,7 \%$ cuenta con estudios universitarios, el 60,5\% permanece activo laboralmente y la mayoría de los compradores tienen un nivel de ingresos entre los 900 y los 2.500 euros al mes.

De media, los compradores realizan casi 30 compras anuales por Internet. La población activa de entre 25 y 44 años, con estudios superiores e ingresos mensuales superiores a $2.500 €$ son quienes compran con mayor frecuencia.

\section{POR OUÉ SE}

COMPRA ONLINE

El motivo principal por el que se elige comprar online es la comodidad, así lo manifiestan el 63,3\% de los encuestados. Al 51,3\% le motivaron los precios, al 50,4\% la rapidez y el ahorro de tiempo que implica la compra a través de medios electrónicos, y el $36,6 \%$ de los compradores utiliza este canal por la facilidad para comprar y obtener información. 


\section{QUÉ SE COMPRA ONLINE}

En términos de número de compradores, las categorías de productos más demandados en 2019 son ropa, calzado y complementos $(59,2 \%)$, reservas de alojamiento y paquetes turísticos $(52,1 \%)$, entradas a espectáculos y eventos $(49,0 \%)$, billetes de transporte $(45,3 \%)$, y comida a domicilio $(38,5 \%)$. Las mujeres jóvenes son quienes más compras realizan dentro de las categorías de venta mayoritarias.

En términos de volumen de gasto, el turismo y el transporte son líderes en venta online. Las reservas de alojamiento y paquetes turísticos representan en 2019 el 18,9\% del gasto total, alcanzando los 9.524 millones de euros. Por su parte, con un total de 6.069 millones de euros, los billetes de transporte suponen el $12 \%$ del gasto total.

El porcentaje de consumidores online de productos exclusivamente digitales crece del $3,7 \%$ al $11,8 \%$ en 2019 y dobla el porcentaje de compradores que solo adquiere productos físicos.

Cada vez son más los internautas que se suscriben a algún servicio o contenido digital de pago. En 2019, se incrementa el porcentaje de este tipo de suscripciones 10,5 puntos porcentuales. En particular, se han disparado las suscripciones a las plataformas audiovisuales en streaming. El 94,1\% de los internautas con acceso a servicios o contenidos digitales de pago está suscrito a alguna de ellas. En lo que se refiere a la suscripción a videojuegos, los hombres duplican a las mujeres en este tipo de contenidos.

Llama la atención que los juegos de azar, concursos, apuestas y loterías son los actos de compra online que se realizan con mayor frecuencia.

\section{HÁBITOS DE COMPRA ONLINE EN ESPAÑA}

El 86,5\% de los internautas busca información en Internet sobre los productos que le interesan siendo una práctica muy extendida entre la población. Antes de comprar los consumidores se informan de forma exhaustiva. La decisión de compra se fundamenta en el conocimiento de los bienes que se quieren adquirir, que se complementa en unos casos con la información derivada de la experiencia de conocidos sobre el producto (27,5\%), o bien con aquella adquirida al visitar la tienda física para ver o probar el producto, e informarse cara a cara con el/la dependiente/a $(22,5 \%)$.

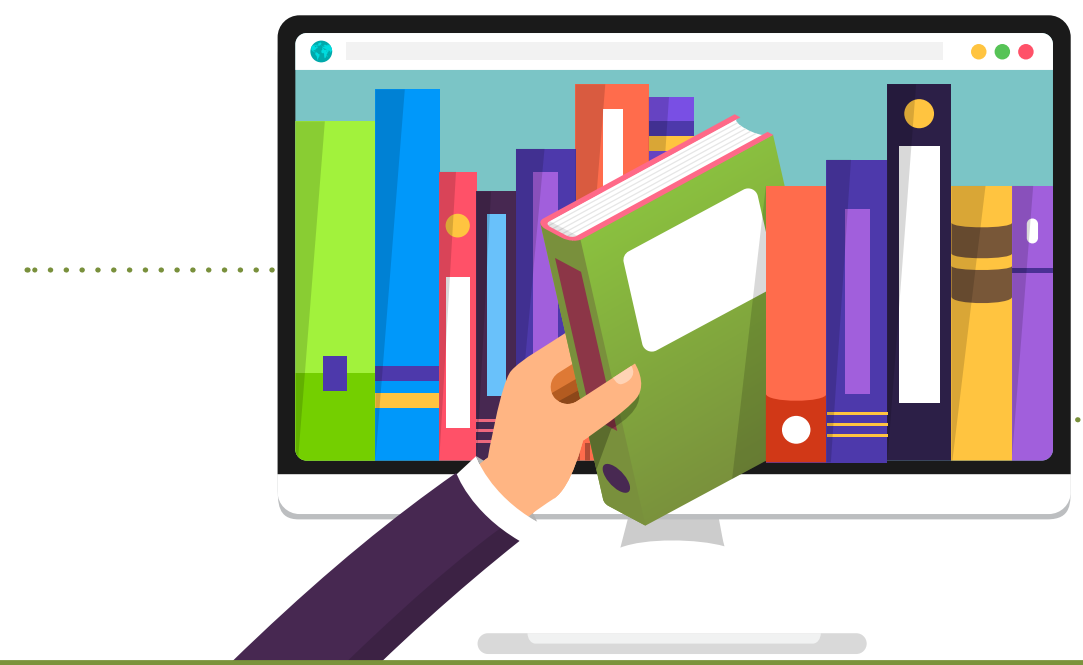


La omnicanalidad se abre paso en la experiencia de compra online, de forma que ganan peso como canal preferente las tiendas y empresas que venden tanto en Internet como en tienda física $(52,3 \%)$.

En torno a 17 millones de consumidores compran en marketplaces de forma habitual (70\%). Su motivación se basa principalmente en la variedad de productos y marcas que pueden encontrar a través de estos canales, así como los precios y opiniones que generan los usuarios. La alternativa preferida por el $40 \%$ de los compradores online es la compra directa en los sitios de los proveedores de bienes y servicios. Destaca, igualmente, que el 69,4\% de los internautas utilizan las herramientas online de compraventa entre particulares.

Entre los distintos dispositivos analizados, el smartphone crece como medio habitual de compra de forma significativa (13,5 p.p.) al utilizarlo un 62,8\% de la población en 2019 . El teléfono inteligente se sitúa por primera vez a menos de 10 puntos del ordenador, cuya popularidad decrece, aunque siga siendo el medio preferente para realizar las compras (72\%). Las mujeres son las que usan con mayor frecuencia el teléfono inteligente, ganando terreno su uso entre los internautas de 25 a 44 años.

La mayoría de los internautas compradores (82,3\%) se encargan personalmente de la recepción 0 recogida de los paquetes de sus compras online.

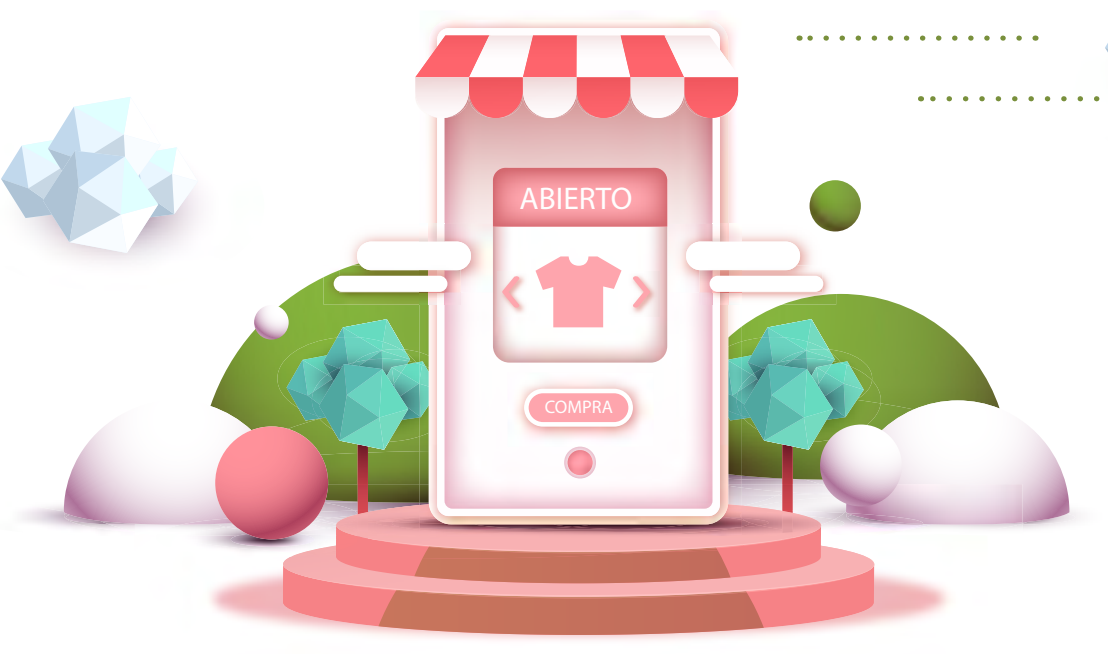

\section{SATISFACCIÓN DEL CONSUMIDOR}

23 millones de internautas, el 96,1\% de los compradores online, afirman haber repetido sus compras en los mismos sitios web. La fidelidad de los clientes con las tiendas online se fundamenta en los precios (61,7\%), las garantías que ofrecen (48,3\%) y la variedad de productos que disponen (42,4\%).

Los envíos gratuitos son la clave para la satisfacción de los consumidores. El 74,4\% lo valora como un aspecto relevante. El tiempo de entrega $(62,9 \%$ ) y la posibilidad de seguimiento del envío $(60,9 \%)$, son otros dos de los factores que favorecen la satisfacción.

En torno a 4 millones de personas, un 18,1\% de compradores online, han tenido algún problema con su compra a lo largo de 2019. El proceso de entrega es el que concentra la mayoría de las incidencias. De esta forma, el 39,9\% de los compradores afectados por estos problemas afirma que alguno de los productos que adquirió no le llegó; el 36,9\% coincide en que algún producto fue entregado con retraso y el $32,5 \%$ afirma que ha recibido productos estropeados o con desperfectos. 


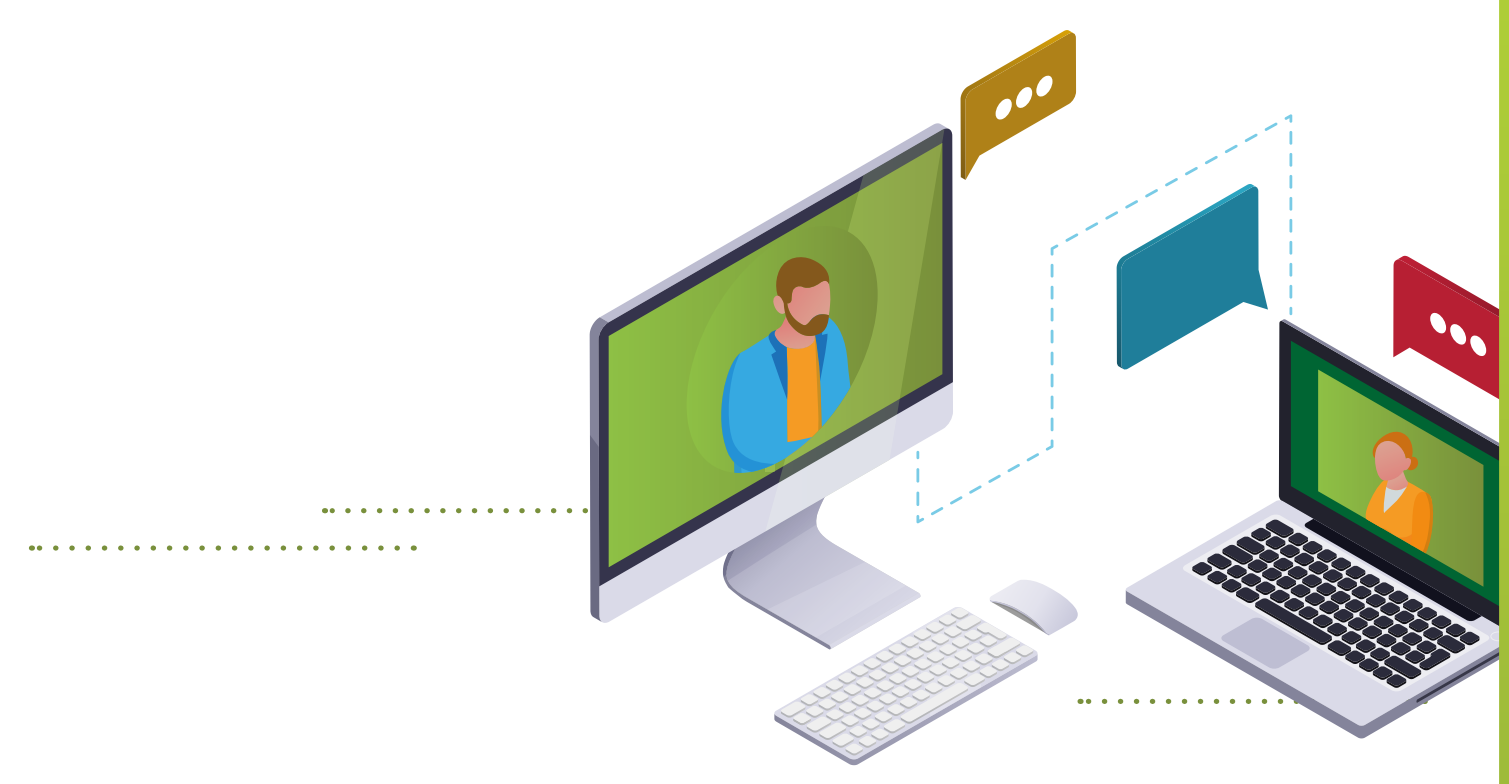

El $83,1 \%$ de los compradores que ha sufrido alguna incidencia formula alguna reclamación durante 2019, siendo los hombres más propensos a reclamar. Por rango de edad, los mayores de 55 años son los que más reclaman, frente a los más jóvenes que reclaman en menor medida. La gran mayoría de las reclamaciones planteadas en 2019 se han hecho a través del servicio de atención al cliente del sitio web donde se realizó la compra o a través de contacto directo vía redes sociales.

En 2019, crece el volumen de compradores que devuelven las compras realizadas a través de Internet en 3,6 puntos porcentuales hasta alcanzar el 37\%. Por categorías, la ropa, el calzado y los complementos son los productos que más se devuelven, afectando a un tercio $(33,5 \%)$ de los compradores. También indican que han devuelto sus compras un 15,9\% de los compradores de productos deportivos y fitness y un $15,6 \%$ de los compradores de electrodomésticos, muebles, hogar, bricolaje y jardín.

\section{EL FUTURO DEL COMERCIO ELECTRÓNICO}

La posibilidad de que los no compradores se conviertan en compradores en el futuro es elevada. El 74,8\% de quienes no han comprado en 2019, pero sí lo habían hecho en el pasado, afirman que sí comprarán de nuevo en el futuro. Entre los internautas que nunca han comprado online, el 38,3\% afirman que probable o seguramente lo haga en un futuro. Todo ello indica que existe margen de crecimiento del comercio electrónico en España en los próximos años.

Una de las razones principales esgrimidas por los no compradores para no comprar es que prefieren acudir a la tienda física $(41,1 \%)$, porcentaje que muestra la relevancia que debe tener en el futuro la posibilidad de combinar canales en las relaciones con los clientes.

Persiste un $21 \%$ de no compradores que indican que la razón de no comprar por medios electrónicos se debe a que perciben el canal como inseguro, lo que muestra el recorrido que tienen acciones de sensibilización o los sellos de calidad y códigos éticos de confianza online.

Cabe resaltar que los sellos de confianza online son tenidos en cuenta por el $40 \%$ de los compradores a la hora de comprary, que la valoración de la seguridad de los medios de pago ha crecido 9 puntos porcentuales a lo largo del año 2019. 


\section{COMPRA ONLINE Y CONFINAMIENTO}

En esta edición del estudio se ha incluido el análisis del comportamiento de la población durante los meses de marzo a mayo de 2020, con el fin de poder valorar el impacto de la COVID-19 en los hábitos de consumo a través de Internet.

La pandemia ha supuesto un importante impulso para el comercio electrónico. La compra online llegó casi al 75\% de los internautas durante el estado de alarma nacional.

En los tres meses de restricciones de movilidad derivados del estado de alarma se ha concentrado prácticamente el mismo número de compradores que en todo 2019. El análisis permite identificar que no han sido las mismas personas las que han comprado por medios electrónicos. Se constatan, así, ciertos cambios interesantes en la conducta. De un lado, el 47,2\% de los consumidores online durante el confinamiento no había comprado por Internet en 2019. Y por otro, entre las personas que venían realizando compras online durante 2019 , algo más de un $16 \%$ no ha comprado por Internet durante el período de marzo a mayo de 2020.

Además, el 29,7\% de los compradores online asegura haber incrementado su actividad de compra, mientras que el 35,3\% de ellos continúa comprando vía online con la misma frecuencia que antes.

La mayoría de los internautas han realizado compras mensuales o semanales, mientras que el $23,5 \%$ ha comprado de forma espontánea durante el confinamiento. El gasto medio se sitúa entre 101 y 500 euros durante este período.

Los internautas que no han comprado a través de Internet afirman no haberlo hecho para reducir el gasto a compras esenciales (36,9\%) o para preservar la salud de los trabajadores $(29,4 \%)$. Mientras que los que sí han realizado alguna compra online durante el estado de alarma ha sido por seguridad ante el contagio (46,1\%).

El 48,7\% de los internautas compradores a través de Internet durante el confinamiento continuarán haciéndolo, mientras que un $43,8 \%$ optará por el consumo en pequeños comercios próximos a sus domicilios.

Los productos más comprados en este periodo han sido ropa, calzado y complementos (38,5\%), alimentación, bebidas y productos de limpieza del hogar $(30,5 \%)$ y salud y cuidado personal $(27,2 \%)$.

El mayor incremento en ventas con relación a 2019 tuvo lugar en los productos de alimentación, bebida y limpieza del hogar, con una subida de casi 7 puntos porcentuales. Por el contrario, el descenso más significativo de compradores por categoría durante este período se observa en la reserva de alojamiento y paquetes turísticos, con una reducción del $52,1 \%$ al $3,6 \%$, lo que afectará sin duda al volumen global del gasto en el futuro, cuya tendencia se verá marcada por la caída del turismo. 


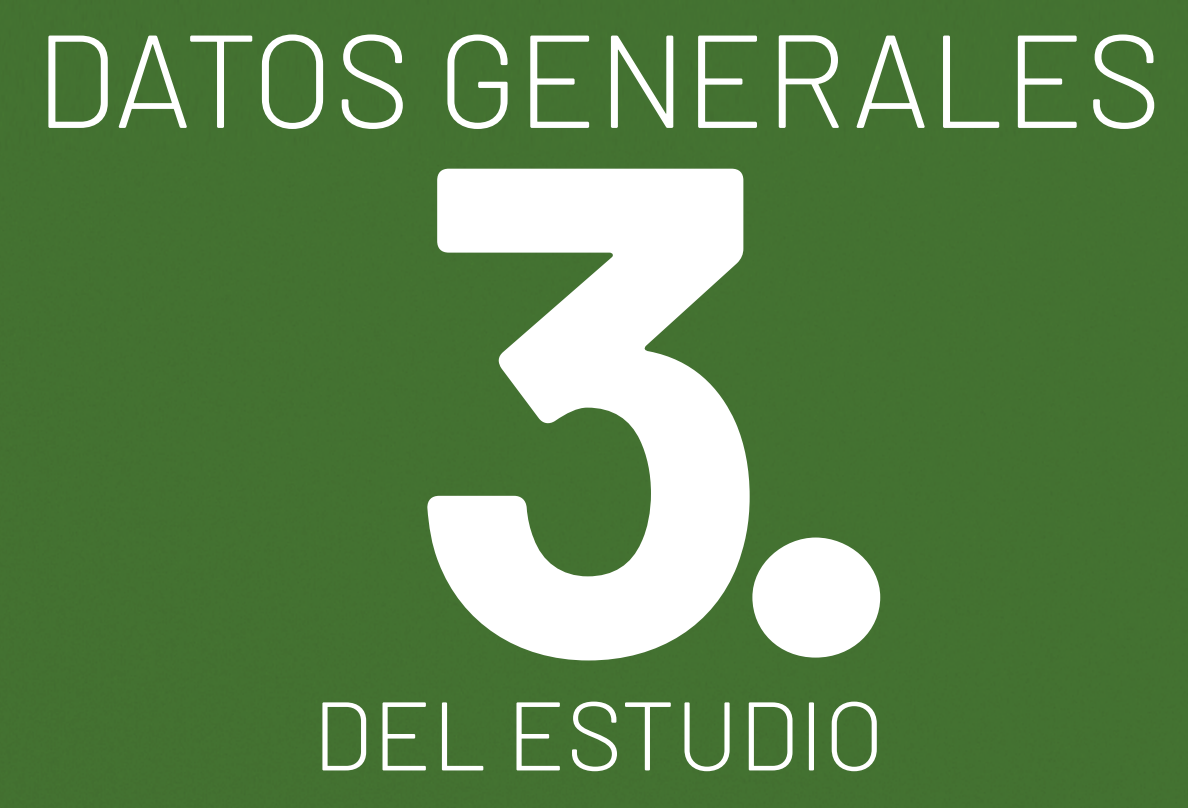

DEL ESTUDIO

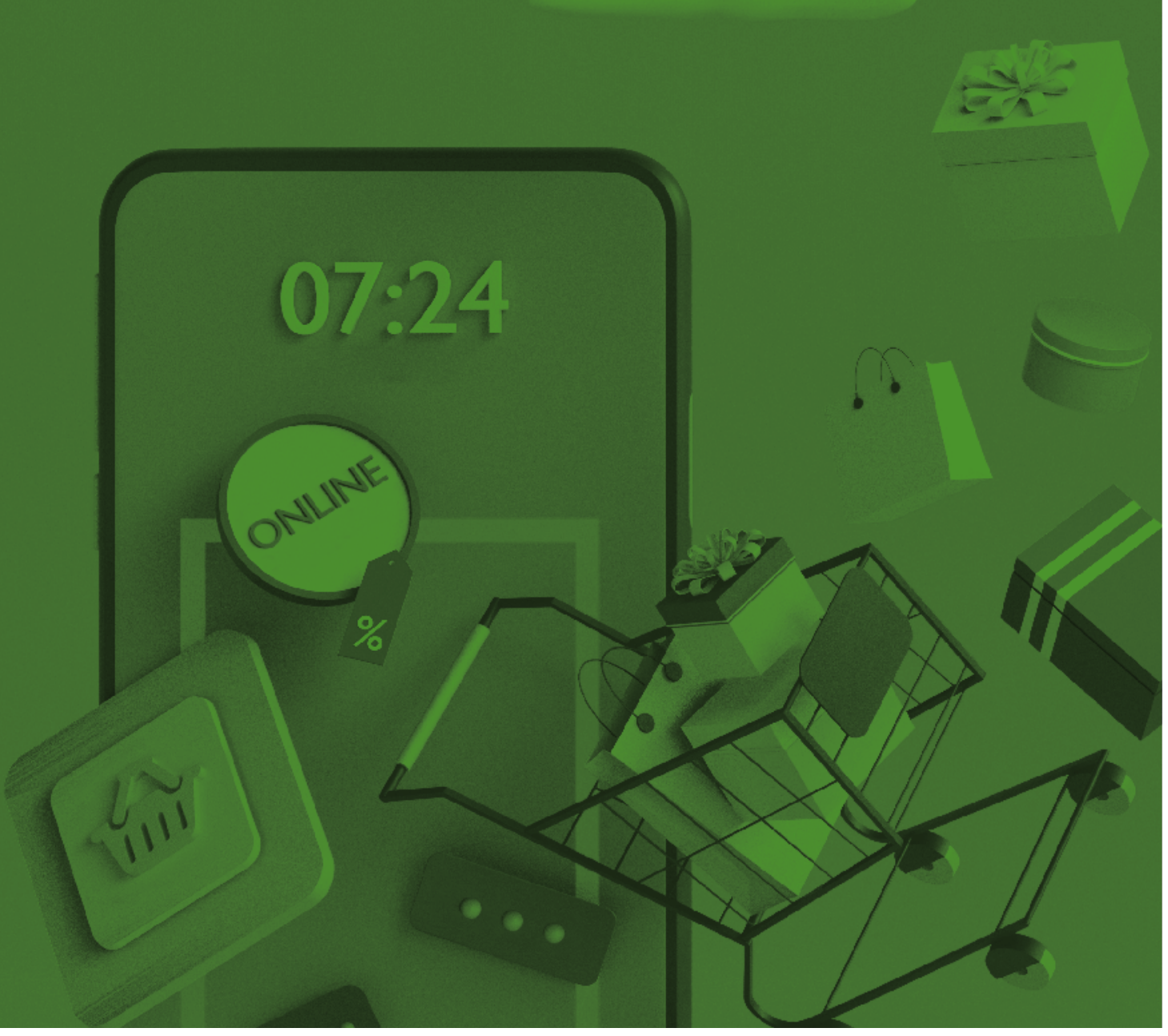




\section{1. \\ VOLUMEN DE NEGOCIO \\ DEL COMERCIO ELECTRÓNICO \\ El comercio electrónico supera los $\mathbf{5 0 . 0 0 0}$ millones de euros y sigue batiendo récords}

FIGURA 3. 1. VOLUMEN DE NEGOCIO DEL COMERCIO ELECTRÓNICO B2C EN ESPAÑA (EVOLUCIÓN 2009-2019)(MILLONES €)

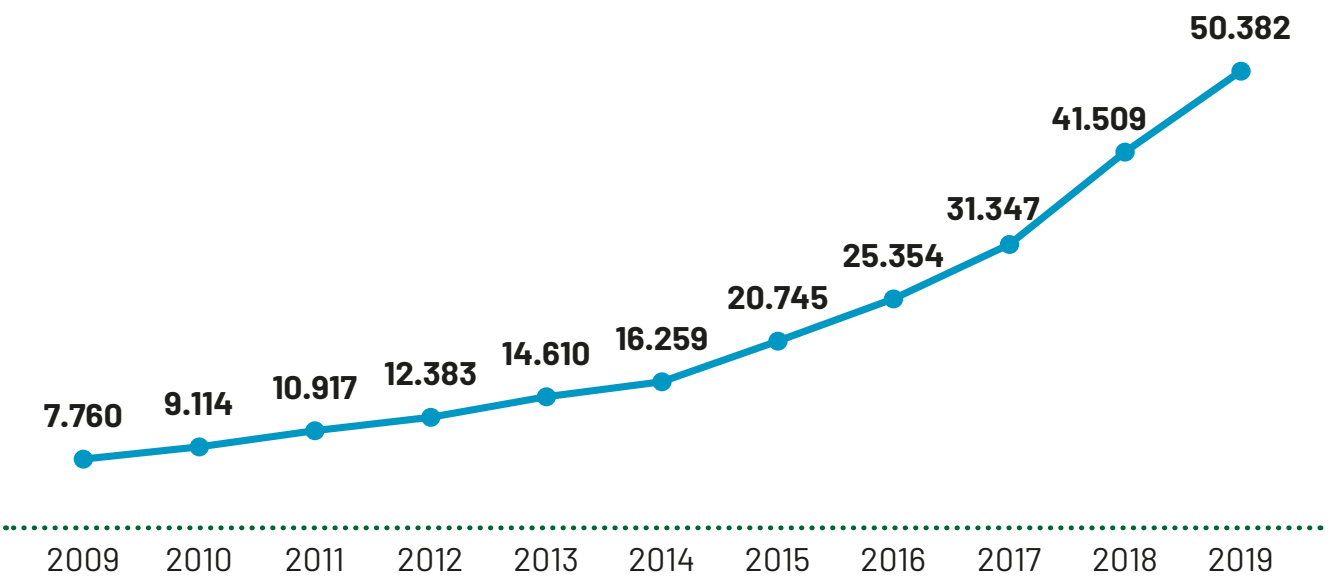

Fuente: panel hogares, ONTSI (2008-2017), encuesta INE y Encuesta online de comercio electrónico, ONTSI. (2018-2019).

El comercio electrónico entre empresas y consumidores (B2C) superó los 50 mil millones de euros en España en 2019, lo que supone un 21,4\% más (8.873 millones de euros) respecto al dato registrado en 2018.

\section{En los últimos 4 años, el gasto medio en comercio electrónico se ha incrementado en 1.000 euros por persona}

FIGURA 3. 2. GASTO MEDIO ANUAL POR INTERNAUTA COMPRADOR EN COMERCIO ELECTRÓNICO B2C EN ESPAÑA (EVOLUCIÓN 2009-2019)(€)

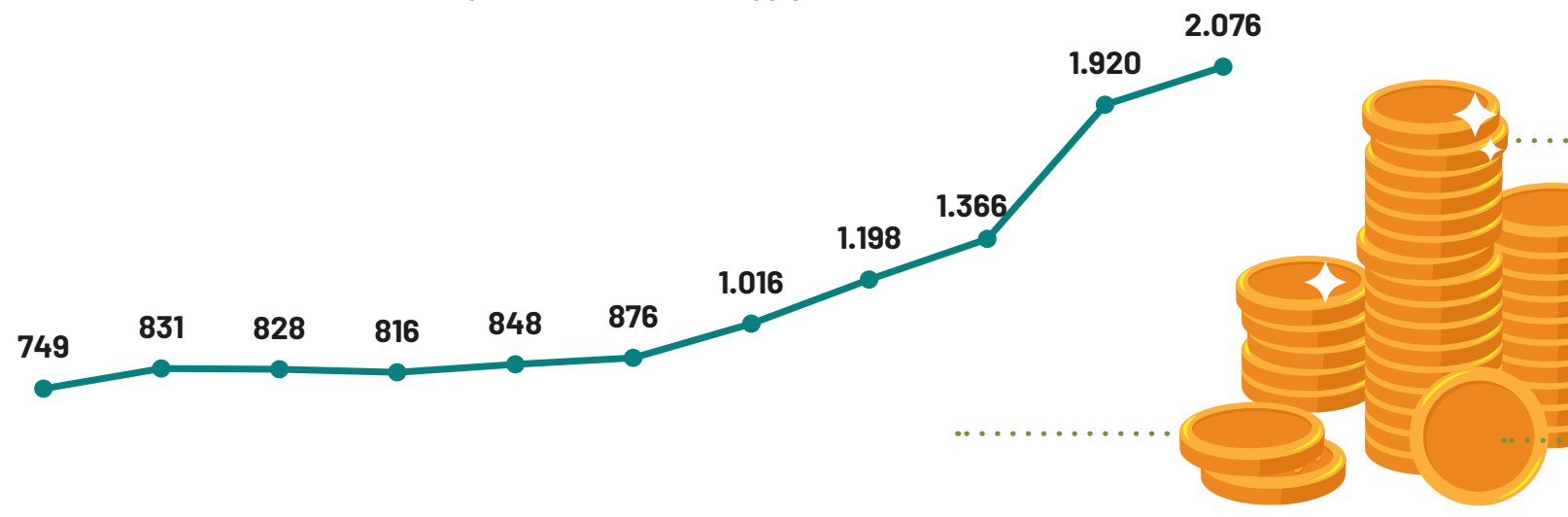



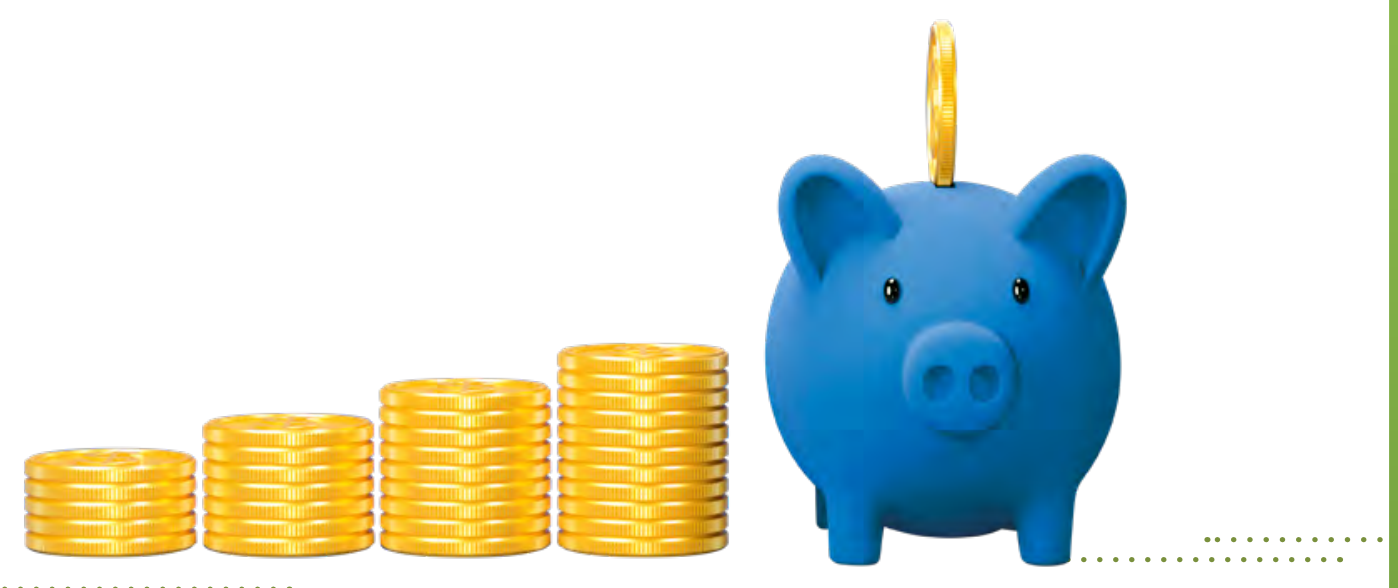

A lo largo de 2019, los usuarios compradores han gastado una media de 2.076 euros en los canales de compra online, lo que supone un crecimiento del 4,9\% en relación con 2018, año en el que el gasto medio en comercio electrónico fue de 1.920 euros. Esta cifra implica un incremento de 1.000 euros por persona en los últimos 4 años.

\title{
24,3 millones de personas compraron online durante 2019, un $12,2 \%$ más que el año anterior
}

FIGURA 3. 3. INTERNAUTAS EN ESPAÑA (EVOLUCIÓN 2009-2019) (\%)

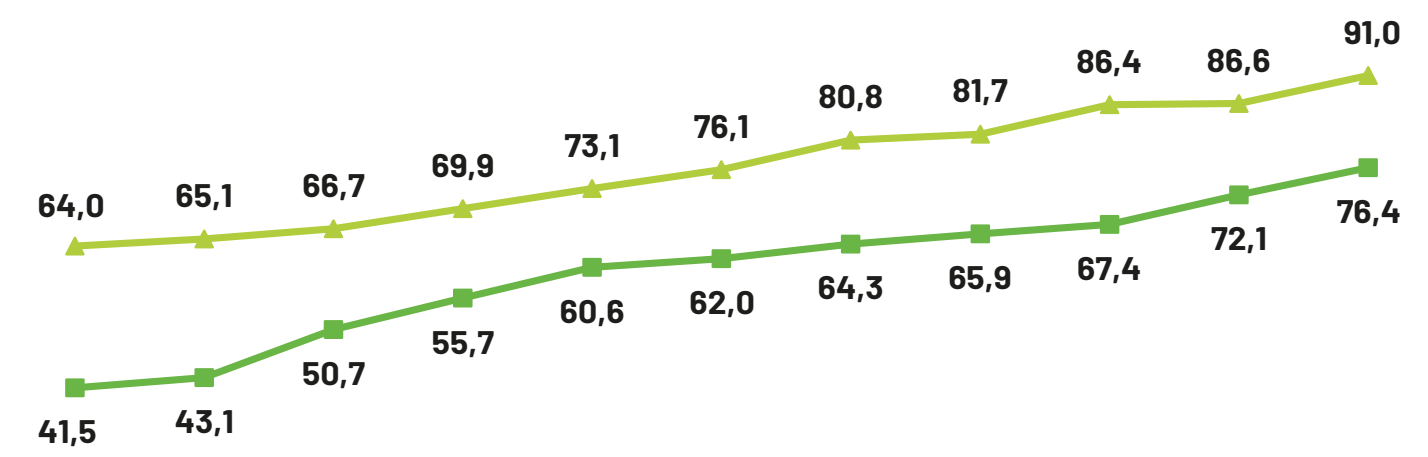

- Internautas / Población total (16 y + años)*

- Compradores online / Total internautas

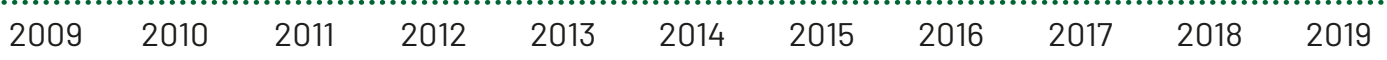

\begin{abstract}
Base: total internautas. / Fuente: panel hogares, ONTSI (2008- 2017), encuesta INE (Encuesta sobre Equipamiento y Uso de TIC en los Hogares 2019) y Encuesta online de comercio electrónico, ONTSI(2018-2019). / * El porcentaje total de internautas de 2018 y 2019, ha sido extraído de la «Encuesta sobre Equipamiento y Uso de Tecnologías de Información y Comunicación en los hogares» del INE, considerando la población entre 16 y 74 años, a diferencia de años anteriores en los que el propio panel de hogares del ONTSI era fuente del estudio y determinaba el porcentaje de población internauta, incluyendo a la población de 15 años y más.
\end{abstract}

Respecto a 2018, el número de compradores a través de canales de comercio electrónico en 2019 ha crecido un $12,2 \%$. El porcentaje de internautas compradores alcanza el $76,4 \%$ sobre el total de internautas, equivalente a 24,3 millones de personas.

\begin{tabular}{|c|c|}
\hline$\%$ internautas & $91,0 \%$ (31 millones de personas) \\
\hline$\%$ internautas compradores & $76,4 \%$ (24,3 millones de personas) 1 \\
\hline Gasto medio anual por comprador & $2.076 €$ \\
\hline Volumen total de gasto & 50.382 millones $€$ \\
\hline
\end{tabular}




\section{2. \\ CARACTERIZACIÓN DE USUARIOS DE INTERNET: INTERNAUTAS COMPRADORES Y NO COMPRADORES}

INTERNAUTAS

\section{El 76,4\% de los internautas compraron por Internet en 2019}

TABLA 3. 1. DISTRIBUCIÓN DE INTERNAUTAS POR PERFIL SOCIODEMOGRÁFICO (\%)

\begin{tabular}{|c|c|c|c|c|}
\hline & & INTERNAUTAS & COMPRADORES & NO COMPRADORES \\
\hline \multicolumn{2}{|l|}{ TOTAL } & 91,0 & 76,4 & 23,6 \\
\hline GÉNERO & $\begin{array}{l}\text { Hombres } \\
\text { Mujeres }\end{array}$ & $\begin{array}{l}49,5 \\
50,5\end{array}$ & $\begin{array}{l}50,4 \\
49,6\end{array}$ & $\begin{array}{l}46,5 \\
53,5\end{array}$ \\
\hline EDAD & $\begin{array}{l}16-24 \text { años } \\
25-34 \text { años } \\
35-44 \text { años } \\
45-54 \text { años } \\
55-64 \text { años } \\
65-74 \text { años }\end{array}$ & $\begin{array}{r}12,5 \\
15,5 \\
22,2 \\
22,4 \\
17,5 \\
9,9\end{array}$ & $\begin{array}{r}13,3 \\
17,0 \\
23,5 \\
22,5 \\
15,6 \\
8,2\end{array}$ & $\begin{array}{r}10,0 \\
10,6 \\
18,1 \\
22,2 \\
23,8 \\
15,3\end{array}$ \\
\hline $\begin{array}{l}\text { TAMAÑO DE } \\
\text { HÁBITAT }\end{array}$ & $\begin{array}{l}\text { Menos de } 10.000 \text { habitantes } \\
\text { De } 10.000 \text { a } 20.000 \text { habitantes } \\
\text { De } 20.000 \text { a } 50.000 \text { habitantes } \\
\text { De } 50.000 \text { a } 100.000 \text { habitantes } \\
\text { Más de } 100.000 \text { habitantes y } \\
\text { capitales de provincia }\end{array}$ & $\begin{array}{r}18,4 \\
11,3 \\
15,4 \\
12,8 \\
42,2\end{array}$ & $\begin{array}{r}17,5 \\
11,5 \\
15,1 \\
13,0 \\
42,9\end{array}$ & $\begin{array}{l}21,2 \\
10,5 \\
16,4 \\
12,2 \\
39,7\end{array}$ \\
\hline $\begin{array}{l}\text { NIVEL DE } \\
\text { ESTUDIOS }\end{array}$ & $\begin{array}{l}\text { Sin estudios } \\
\text { Primaria } \\
\text { Secundaria (ESO) } \\
\text { Secundaria (Bachillerato) } \\
\text { Formación profesional } \\
\text { Estudios superiores }\end{array}$ & $\begin{array}{r}0,5 \\
3,2 \\
4,1 \\
17,4 \\
25,1 \\
49,7\end{array}$ & $\begin{array}{r}0,4 \\
2,1 \\
3,2 \\
16,5 \\
24,1 \\
53,7\end{array}$ & $\begin{array}{r}1,2 \\
6,7 \\
6,9 \\
20,5 \\
28,1 \\
36,6\end{array}$ \\
\hline $\begin{array}{l}\text { NIVEL DE } \\
\text { INGRESOS EN } \\
\text { EL HOGAR }\end{array}$ & $\begin{array}{l}\text { Menos de } 900 \text { euros } \\
\text { Entre } 900 \text { y } 1.599 \text { euros } \\
\text { Entre } 1.600 \text { y } 2.499 \text { euros } \\
\text { Entre } 2.500 \text { y } 2.999 \text { euros } \\
3.000 \text { euros o más }\end{array}$ & $\begin{array}{r}11,5 \\
27,8 \\
31,2 \\
15,2 \\
14,3\end{array}$ & $\begin{array}{r}9,1 \\
27,0 \\
30,1 \\
16,7 \\
17,0\end{array}$ & $\begin{array}{r}19,3 \\
30,2 \\
34,5 \\
10,2 \\
5,7\end{array}$ \\
\hline OCUPACIÓN & $\begin{array}{l}\text { Estudiante } \\
\text { Ocupado/a por cuenta ajena } \\
\text { Ocupado/a por cuenta propia } \\
\text { Labores del hogar } \\
\text { Parado/a } \\
\text { Jubilado/a }\end{array}$ & $\begin{array}{r}8,9 \\
50,7 \\
6,6 \\
16,0 \\
4,0 \\
13,7\end{array}$ & $\begin{array}{r}9,5 \\
53,4 \\
7,1 \\
15,0 \\
3,5 \\
11,6\end{array}$ & $\begin{array}{r}7,1 \\
42,3 \\
5,1 \\
18,9 \\
5,8 \\
20,8\end{array}$ \\
\hline
\end{tabular}

Base: total internautas, compradores y no compradores por variables sociodemográficas. / Fuente: Encuesta online de comercio electrónico, ONTSI.

Aunque no hay apenas diferencias por género, los datos muestran un porcentaje ligeramente superior de mujeres internautas. Los porcentajes de internautas más elevados se encuentran entre las personas de 35 a 54 años, los que viven en grandes ciudades, los que tienen estudios superiores y aquellos que disponen de ingresos medios mensuales en el hogar de entre 900 y 2.500 euros. En lo que a actividad laboral se refiere, la mitad de la población internauta está empleada por cuenta ajena $(50,7 \%)$. 
En cuanto a compradores y no compradores en 2019, un 76,4\% de los internautas declara hacer compras por vía online, representando aproximadamente 24 millones de personas en el país, mientras que 7 millones de internautas reconocen no haber realizado ninguna compra a través de Internet, lo que supone el $23,6 \%$ de los internautas.

\section{En pareja y con hijos, el perfil de hogar mayoritario del internauta en España}

FIGURA 3. 4. ¿CUÁL ES LA SITUACIÓN EN SU HOGAR? (\%)

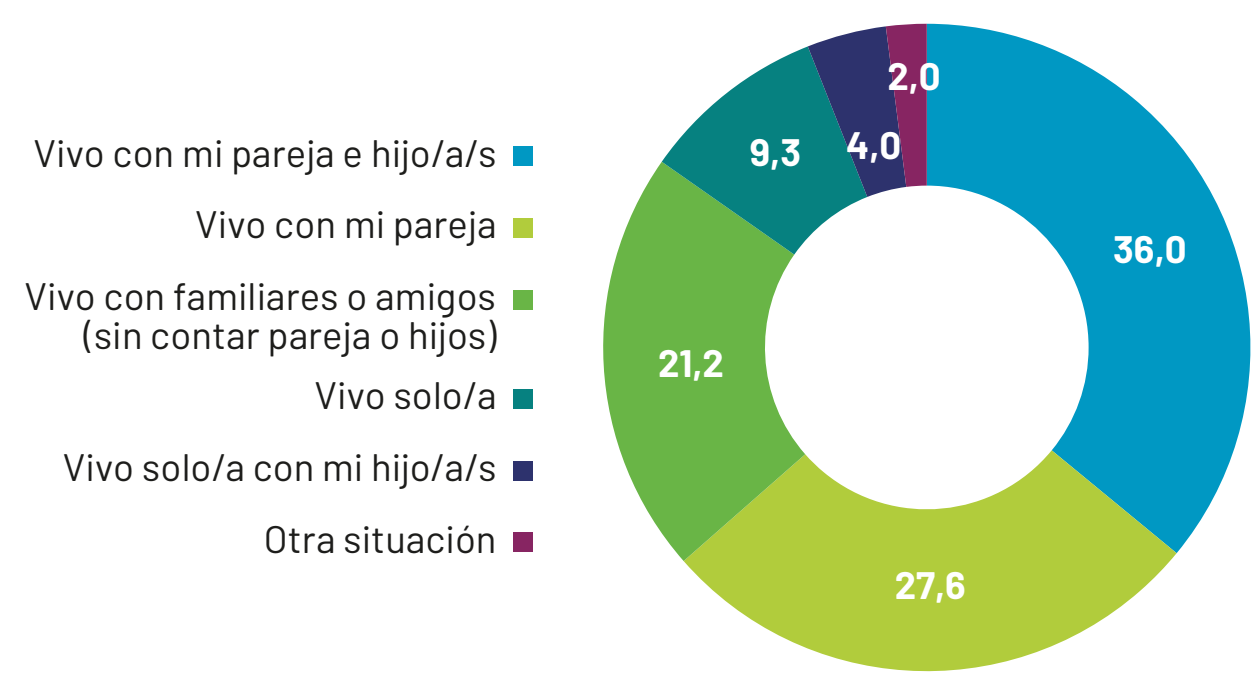

Base: total internautas. / Fuente: Encuesta online de comercio electrónico, ONTSI.

Se observa una importante diversidad de situaciones en el hogar de los internautas españoles. La mayoría de usuarios de Internet vive en pareja (63,6\%), y de ellos, el grupo más representativo es el de los internautas que además de pareja también tienen hijos (36\% sobre el total). Aquellos que viven con familiares o amigos son el tercer grupo más voluminoso $(21,2 \%)$, y en cuarto lugar se encuentran quienes viven solos $(9,3 \%)$.

\section{Más del $50 \%$ de los internautas comparte la responsabilidad de las compras en el hogar con otra persona}

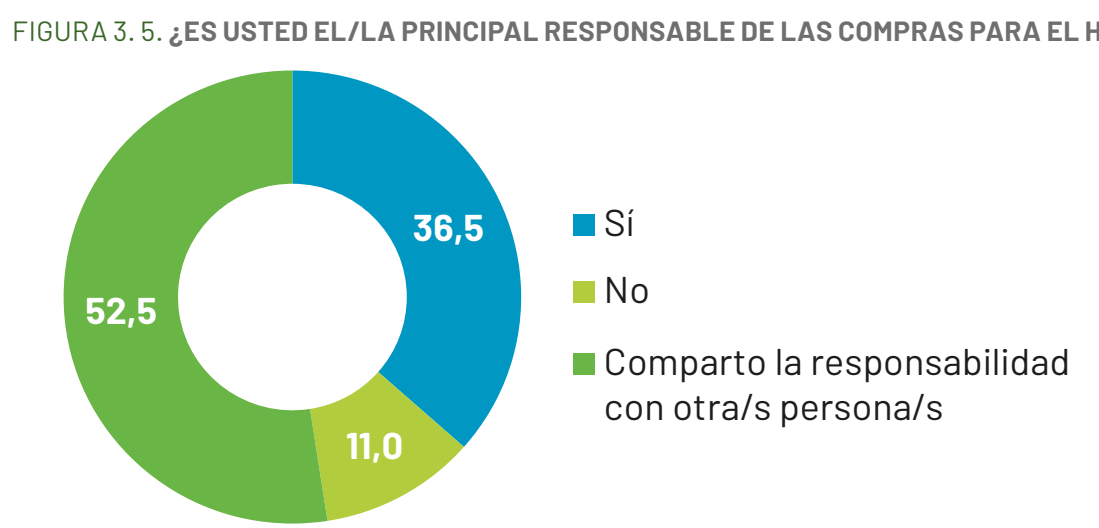

Base: total internautas. / Fuente: Encuesta online de comercio electrónico, ONTSI.

El 52,5\% de los usuarios de Internet afirma compartir la responsabilidad de las compras para el hogar con otra persona, mientras que un 36,5\% dice ser responsable único de las compras.

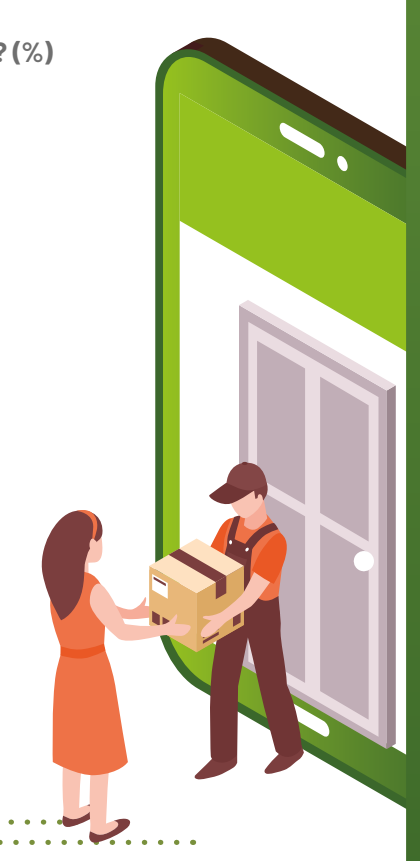




\section{9 de cada 10 personas de entre 16 y 34 años se conectan a Internet varias veces al día}

TABLA 3. 2. ¿CON OUÉ FRECUENCIA ACCEDE A INTERNET? POR GÉNERO Y GRUPOS DE EDAD (\%)

\begin{tabular}{|c|c|c|c|c|c|c|c|c|c|}
\hline & \multirow[b]{2}{*}{ TOTAL } & \multicolumn{2}{|c|}{ GÉNERO* } & \multicolumn{6}{|c|}{ EDAD* } \\
\hline & & Hombres & Mujeres & $\begin{array}{l}16-24 \\
\text { años }\end{array}$ & $\begin{array}{c}25-34 \\
\text { años }\end{array}$ & $\begin{array}{c}35-44 \\
\text { años }\end{array}$ & $\begin{array}{l}45-54 \\
\text { años }\end{array}$ & $\begin{array}{l}55-64 \\
\text { años }\end{array}$ & $\begin{array}{l}65-74 \\
\text { años }\end{array}$ \\
\hline Varias veces al día & 76,3 & 74,2 & 78,4 & 90,3 & 92,6 & 82,6 & 73,3 & 61,6 & 52,6 \\
\hline $\begin{array}{c}\text { Diariamente, al menos } 5 \text { dias } \\
\text { por semana }\end{array}$ & 17,9 & 19,9 & 15,9 & 7,8 & 6,1 & 12,3 & 19,9 & 28,6 & 37,9 \\
\hline $\begin{array}{r}\text { Todas las semanas, pero no } \\
\text { diariamente }\end{array}$ & 4,5 & 4,3 & 4,6 & 1,4 & 1,1 & 3,8 & 4,7 & 7,5 & 8,9 \\
\hline $\begin{array}{r}\text { Al menos una vez al mes, pero } \\
\text { no todas las semanas }\end{array}$ & 0,7 & 0,8 & 0,5 & 0,3 & 0,0 & 0,3 & 1,2 & 1,4 & 0,7 \\
\hline $\begin{array}{r}\text { Muy ocasionalmente (menos } \\
\text { de una vez al mes) }\end{array}$ & 0,7 & 0,8 & 0,6 & 0,3 & 0,2 & 0,9 & 0,9 & 1,0 & 0,0 \\
\hline
\end{tabular}

Base: total internautas. / Base: total internautas por categorías género y edad. / Fuente: Encuesta online de comercio electrónico, ONTSI.

Durante 2019, el 76,3\% de los internautas reconoce que accede a Internet varias veces al día. Hay un uso más intensivo de Internet entre la población menor de 35 años y mujeres. Se observa que la población más joven es la que más veces accede a Internet, con una frecuencia mayoritariamente diaria y repetida a lo largo del día, mientras que los mayores de 65 años son mayoría entre quienes acceden una vez al día o al menos 5 días a la semana. Un dato a destacar es que tan solo el 1,4\% de los internautas accede una vez al mes o con una frecuencia menor.

\section{La mayoria de compradores online accede varias veces al dia o diariamente a Internet}

TABLA 3. 3. ¿CON QUÉ FRECUENCIA ACCEDE A INTERNET? POR COMPRADORES Y NO COMPRADORES ONLINE(\%)

\begin{tabular}{|c|c|c|}
\hline & \\
\hline & COMPRADORES & NO COMPRADORES \\
\hline Varias veces al día & 80,5 & 48,2 \\
\hline Diariamente, al menos 5 días por semana & 16,3 & 28,6 \\
\hline Todas las semanas, pero no diariamente & 2,7 & 16,1 \\
\hline Al menos una vez al mes, pero no todas las semanas & 0,5 & 1,9 \\
\hline Muy ocasionalmente (menos de una vez al mes) & 0,0 & 5,3 \\
\hline
\end{tabular}

Base: total internautas compradores y no compradores. / Fuente: Encuesta online de comercio electrónico, ONTSI.

Los internautas que compran por vía online acceden a Internet con mayor frecuencia que los no compradores. El $80,5 \%$ de los compradores online accede varias veces al día a Internet frente al $48,2 \%$ de los no compradores.

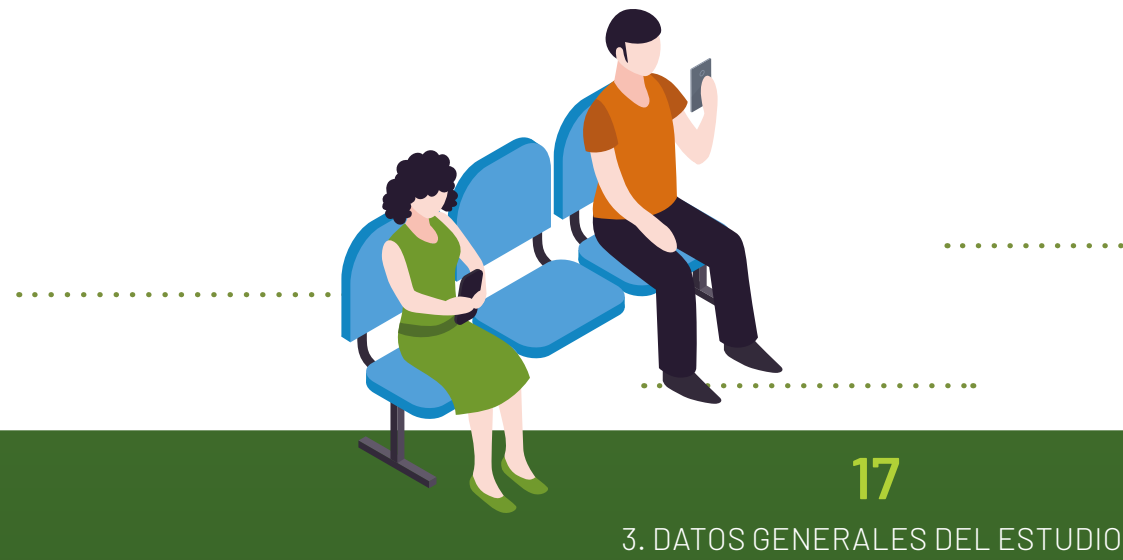




\section{Perfil mayoritario del consumidor online en España: alrededor de 40 años, estudios superiores, urbano y económicamente activo}

FIGURA 3. 6. DISTRIBUCIÓN DE INTERNAUTAS COMPRADORES POR PERFIL SOCIODEMOGRÁFICO (\%)
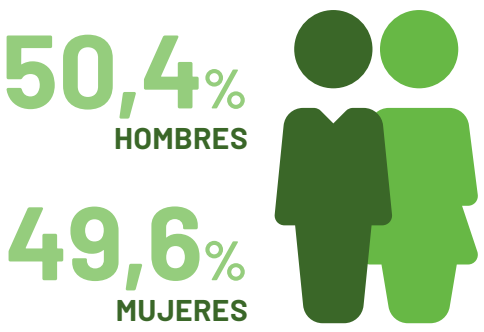

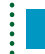

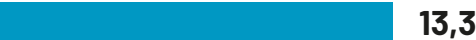

25-34 años

35-44 años

45-54 años

55-64 años

65-74 años

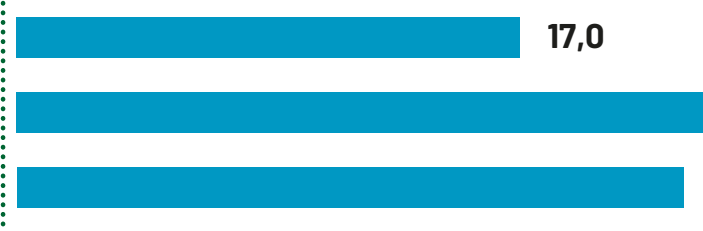

23,5

22,5

8,2
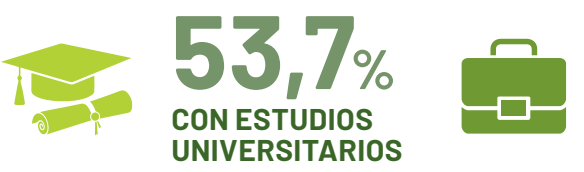

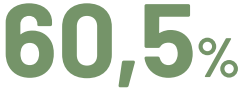

OCUPADOS

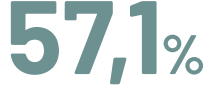

CON NIVEL DE INGRESOS ENTRE 900 Y $2.500 €$ AL MES

Base: total internautas compradores online. / Fuente: Encuesta online de comercio electrónico, ONTSI.

Al igual que sucede con el perfil de usuario de Internet, el grueso de los consumidores online se concentra entre internautas de 35 a 54 años, quienes suman el 46\%. En este caso, hay más hombres que mujeres, pero la diferencia es menor a 1 punto porcentual (50,4\% vs. 49,6\%).

Durante 2019, se aprecia que la mayoría de los compradores online trabaja, el 60,5\%, siendo también lo más común que cuenten con estudios universitarios (53,7\%). Además, el nivel de ingresos mensuales de sus hogares en ese año se sitúa entre 900 y 2.499 euros en el $57,1 \%$ de los internautas que compran por Internet.

FIGURA 3. 7. DISTRIBUCIÓN DE INTERNAUTAS COMPRADORES POR GÉNERO (\%)
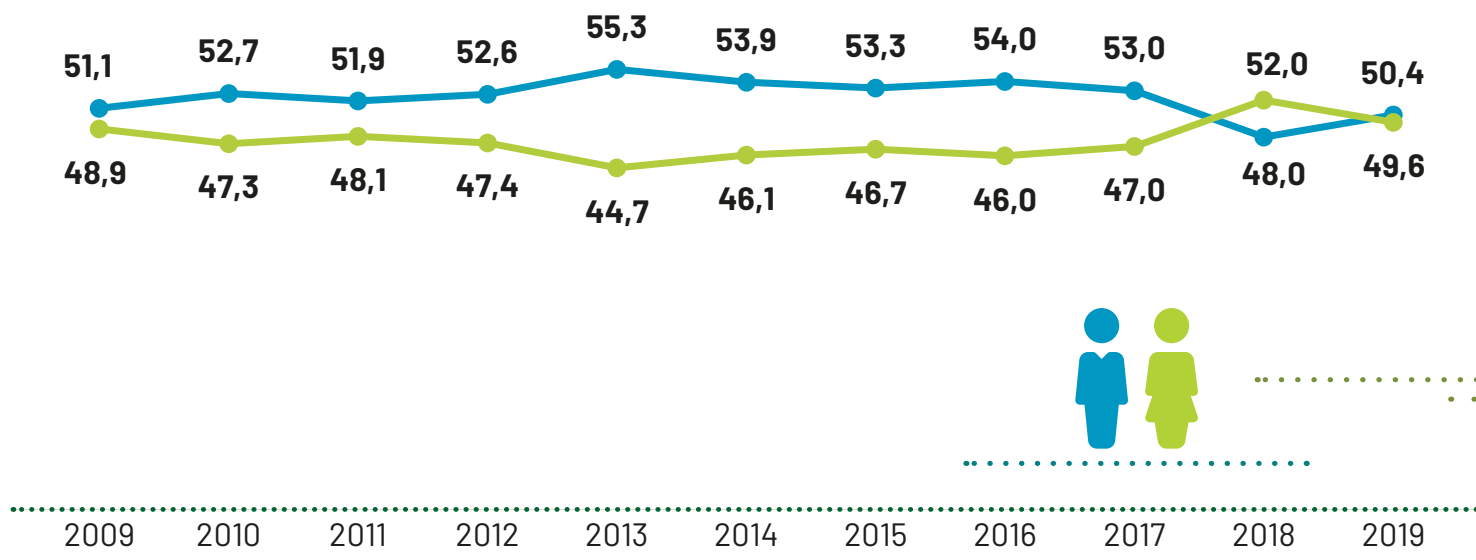
Tras un incremento de 5 p.p. entre 2017 y 2018, el porcentaje de mujeres que compran online cae del $52 \%$ al $49,6 \%$, dejando prácticamente igualado el número de internautas compradores entre hombres y mujeres. En 2019, el porcentaje de hombres vuelve a ser superior, aunque la diferencia es inferior a 1 p.p.: 12,2 millones de hombres frente a 12 millones de mujeres.

\section{Uno de cada tres compradores tiene ingresos mensuales superiores a los 2.499 euros frente al $15,9 \%$ de los no compradores}

TABLA 3. 4. INTERNAUTAS COMPRADORES Y NO COMPRADORES ONLINE POR VARIABLES SOCIODEMOGRÁFICAS RELATIVAS AL HOGAR Y LA CONVIVENCIA (\%)

\begin{tabular}{|c|c|c|c|}
\hline & & COMPRADORES & NO COMPRADORES \\
\hline \multirow{5}{*}{$\begin{array}{l}\text { NIVEL DE INGRESOS } \\
\text { EN EL HOGAR }\end{array}$} & Menos de 900 euros & 9,1 & 19,3 \\
\hline & Entre 900 y 1.599 euros & 27,0 & 30,2 \\
\hline & Entre 1.600 y 2.499 euros & 30,1 & 34,5 \\
\hline & Entre 2.500 y 2.999 euros & 16,7 & 10,2 \\
\hline & 3.000 euros o más & 17,0 & 5,7 \\
\hline \multirow{6}{*}{$\begin{array}{l}\text { SITUACIÓN EN EL } \\
\text { HOGAR }\end{array}$} & Vivo solo/a & 9,1 & 9,7 \\
\hline & Vivo con mi pareja & 27,2 & 28,9 \\
\hline & $\begin{array}{l}\text { Vivo con familiares o amigos } \\
\text { (no pareja o hijos) }\end{array}$ & 21,8 & 19,4 \\
\hline & Vivo con mi pareja e hijo/a/s & 36,2 & 35,1 \\
\hline & Vivo solo/a con mi hijo/a/s & 4,0 & 4,0 \\
\hline & Otra situación & 1,8 & 2,9 \\
\hline \multirow{3}{*}{$\begin{array}{l}\text { RESPONSABILIDAD } \\
\text { SOBRE LA COMPRA }\end{array}$} & Sí & 37,8 & 32,2 \\
\hline & No & 10,2 & 13,9 \\
\hline & Comparto la responsabilidad & 52,0 & 54,0 \\
\hline
\end{tabular}

Base: total internautas compradores y no compradores. / Fuente: Encuesta online de comercio electrónico, ONTSI.

Un factor decisivo a la hora de analizar la compra online es el nivel de ingresos. La mitad de los no compradores disponen de menos de 1.600 euros al mes, mientras que entre los compradores este porcentaje se sitúa en el 36,1\%. Por otro lado, uno de cada tres compradores tiene ingresos mensuales superiores a los 2.499 euros frente al 15,9\% de los no compradores.

\section{La mayor parte de internautas compradores comparte la responsabilidad de las compras del hogar con otra persona}

FIGURA 3. 8. DISTRIBUCIÓN COMPRADORES ONLINE POR RESPONSABILIDAD EN LA COMPRA Y GÉNERO (\%)

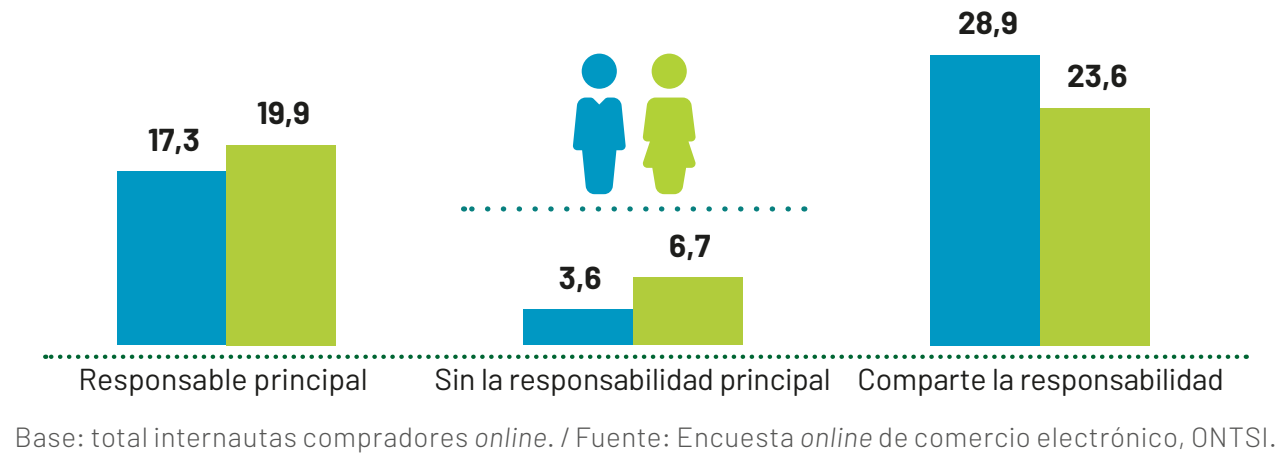


La mayoría de los compradores online afirma compartir responsabilidad sobre las compras del hogar, siendo más habitual este hábito entre los hombres. Sin embargo, las mujeres compradoras online declaran con mayor frecuencia ser las responsables principales de las compras para el hogar (19,9\%).

\section{7 de cada 10 compradores online realiza compra de forma mensual o trimestral}

FIGURA 3. 9. ¿CON QUÉ FRECUENCIA COMPRÓ POR INTERNET DURANTE 2019? (\%)
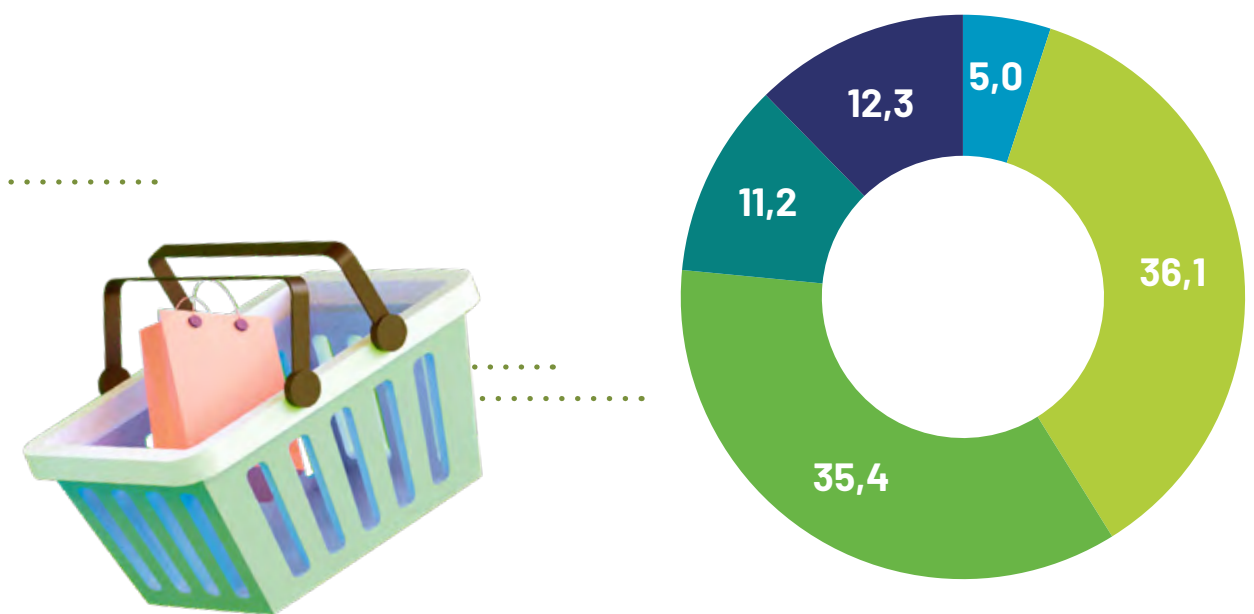

- Semanalmente

Mensualmente

- Una vez cada 3 meses

- Una vez cada 6 meses

- Con menor frecuencia

Base: total internautas compradores online. / Fuente: Encuesta online de comercio electrónico, ONTSI.

El 36,1\% de los internautas compradores online realiza las compras a través de Internet de forma mensual, mientras que un 35,4\% compra una vez cada 3 meses durante el 2019. Por el contrario, solo un $5 \%$ de los compradores lleva a cabo su compra online de manera semanal.

\section{2,1 millones de internautas son nuevos compradores online en 2019}

FIGURA 3. 10. DISTRIBUCIÓN DE LOS INTERNAUTAS COMPRADORES ONLINE POR MOMENTO DE COMPRA (ANTIGUOS Y NUEVOS) (\%)

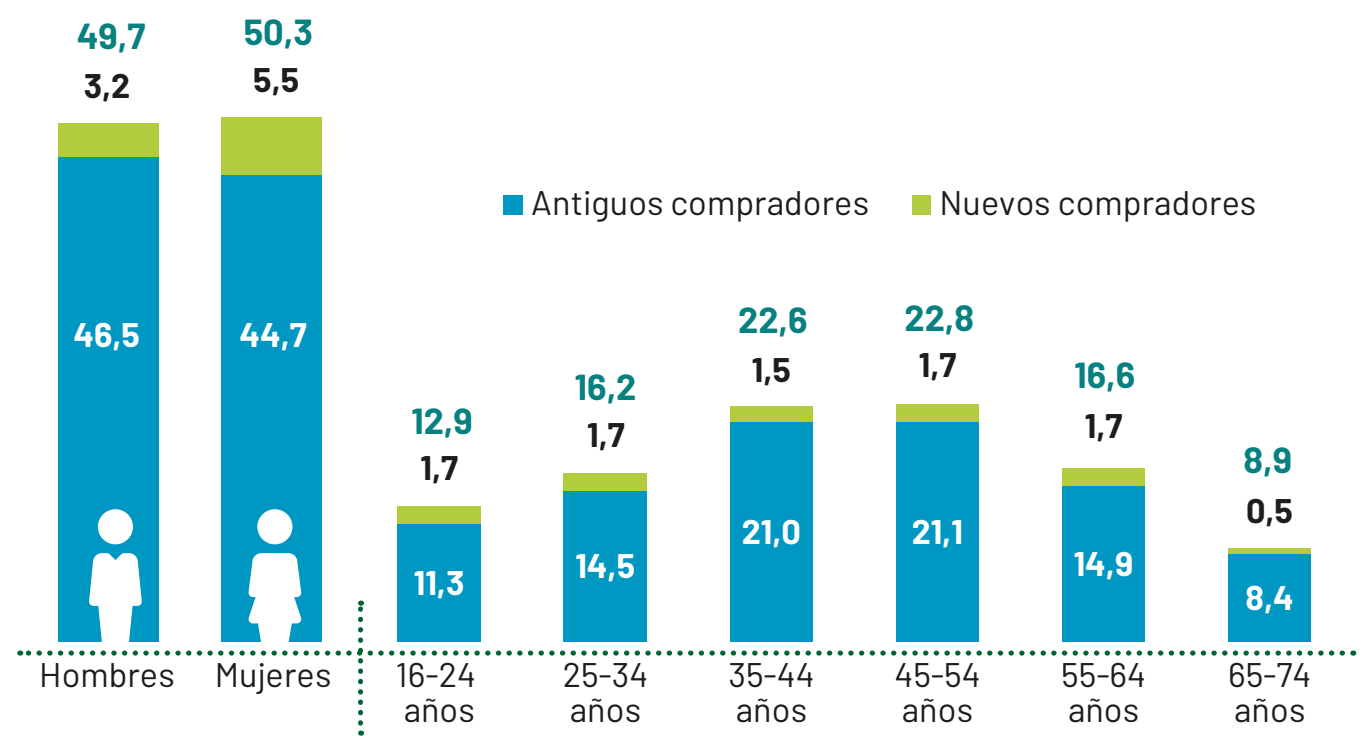


Más de 2 millones de españoles han comprado por primera vez online en 2019, quienes representan un $8,8 \%$ del total de compradores. La mayor parte son mujeres, el 63,3\%. En cuanto a la edad, se observa un incremento similar de nuevos compradores en todos los rangos, a excepción de los mayores de 65 años que suman muy pocos compradores online y representan tan solo el 0,5\% del total.

NO COMPRADORES

\section{1 de cada 4 internautas no ha realizado ninguna compra a través de Internet en 2019, y la mayoria no ha comprado online nunca}

FIGURA 3. 11. DISTRIBUCIÓN DE INTERNAUTAS NO COMPRADORES POR PERFIL SOCIODEMOGRÁFICO (\%)
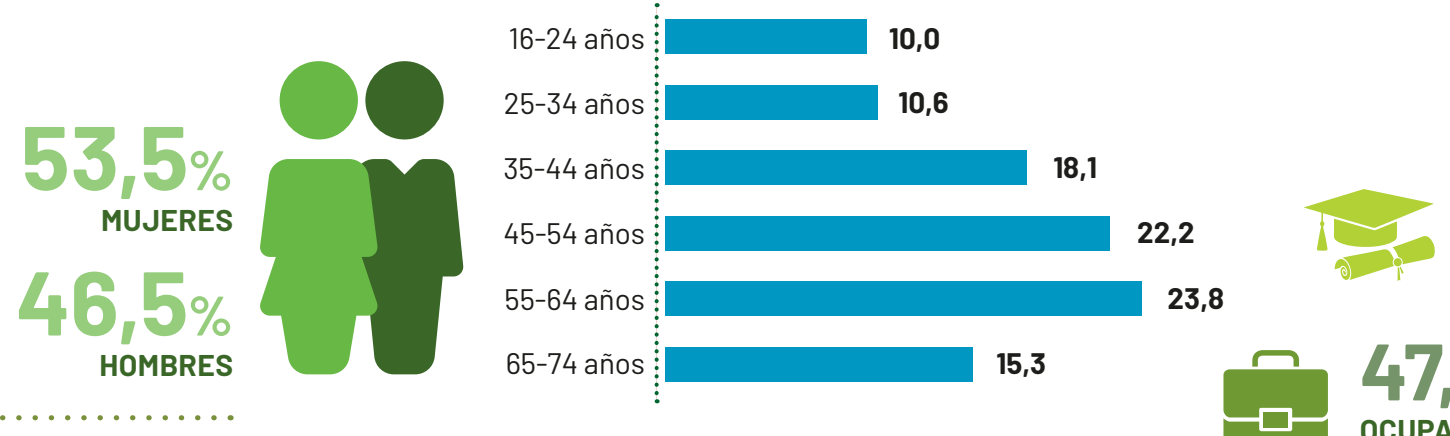
$36,6 \%$ CONESTUDIOS UNIVERSITARIOS ..................
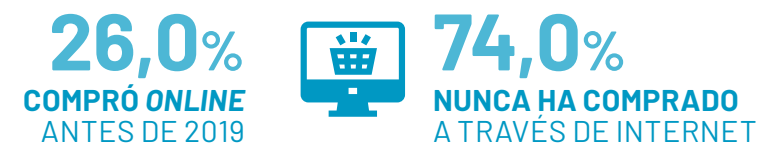

$64,7 \%$

CON NIVEL DE INGRESOS

ENTRE 900 Y $2.500 €$ AL MES

Base: total internautas no compradores online. / Fuente: Encuesta online de comercio electrónico, ONTSI.

En 2019, un 23,6\% de los internautas no ha efectuado ninguna compra de bienes o contratación de servicios a través de Internet, lo que equivale a 7,3 millones de personas en España. El 74\% de los internautas que no han comprado online en 2019, casi 5,4 millones de personas, afirma no haber comprado nunca a través de Internet. Esta cifra equivale al 17,5\% del total de usuarios de Internet en España.

\section{3 de cada 10 hombres no compradores realizaron alguna compra a través de Internet antes de 2019}

TABLA 3. 5. INTERNAUTAS QUE NO COMPRARON EN 2019 PERO SI EN AÑOS ANTERIORES, POR GÉNERO Y GRUPOS DE EDAD (\%)

\begin{tabular}{|c|c|c|c|c|c|c|c|c|c|}
\hline & \multirow[b]{2}{*}{ TOTAL } & \multicolumn{2}{|c|}{ GÉNERO* } & \multicolumn{6}{|c|}{ EDAD* } \\
\hline & & Hombres & Mujeres & $\begin{array}{l}16-24 \\
\text { años } \\
\end{array}$ & $\begin{array}{c}25-34 \\
\text { años }\end{array}$ & $\begin{array}{c}35-44 \\
\text { años }\end{array}$ & $\begin{array}{c}45-54 \\
\text { años }\end{array}$ & $\begin{array}{c}55-64 \\
\text { años }\end{array}$ & $\begin{array}{c}65-74 \\
\text { años } \\
\end{array}$ \\
\hline Compró antes del 2019 & 26,0 & 28,6 & 23,6 & 32,4 & 22,0 & 29,3 & 22,7 & 24,4 & 25,8 \\
\hline
\end{tabular}

Base: total internautas no compradores online. / Base: total internautas no compradores online por categorías género y edad. / Fuente: Encuesta online de comercio electrónico, ONTSI.

El 26\% de los no compradores online en 2019 sí lo habían sido en años anteriores. Se aprecian mayores porcentajes de no compradores que sí lo habían sido con anterioridad entre los hombres y en el estrato de edad de 16 a 24 años. 


\section{La intención de compra para los próximos meses se acerca al $50 \%$ entre los internautas que no han realizado ninguna compra en 2019}

FIGURA 3. 12. A PESAR DE NO HABER REALIZADO COMPRAS A TRAVÉS DE INTERNET EN EL AÑO 2019, ¿TIENE INTENCIÓN DE HACERLO EN LOS PRÓXIMOS MESES? (\%)

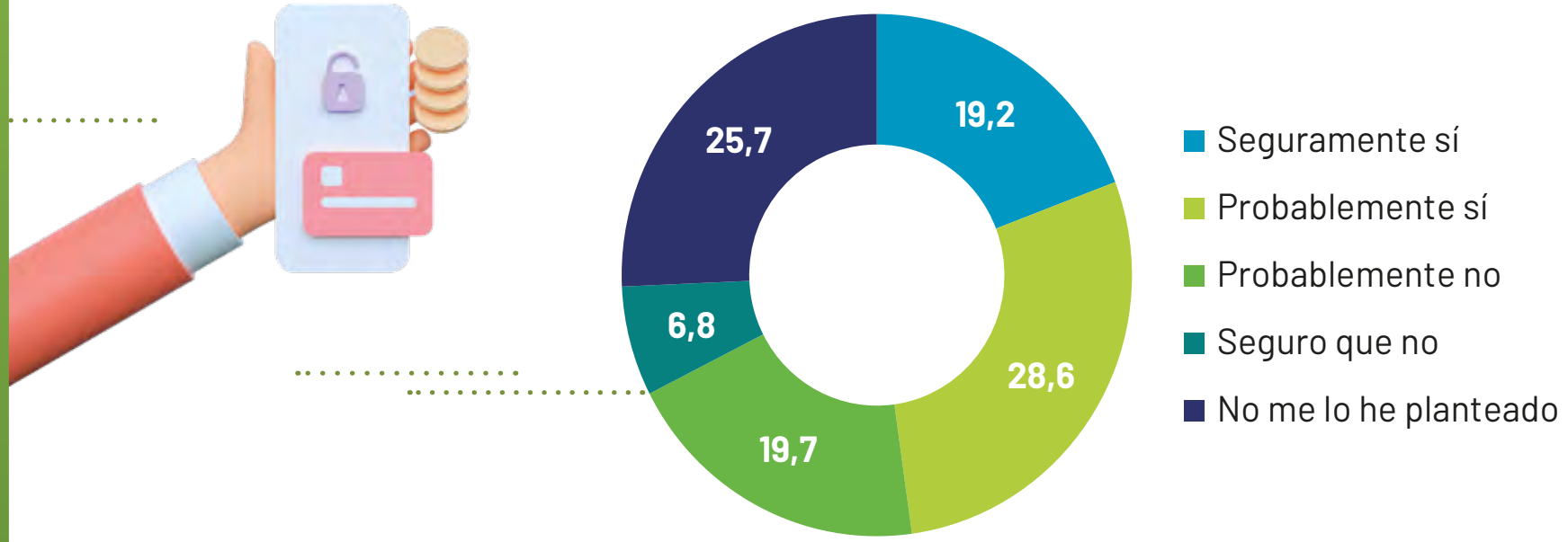

Base: total internautas no compradores online. / Fuente: Encuesta online de comercio electrónico, ONTSI.

Entre los internautas que no han comprado a través de Internet en 2019, el 47,8\% declara que tiene intención de realizar alguna compra online durante los próximos meses. Por el contrario, un 19,7\% dice que probablemente no compre online y el 6,8\% asegura que no realizará ninguna compra a través de Internet.

\section{Las mujeres y los jóvenes no compradores tienen mayor predisposición a realizar una compra online en el futuro}

TABLA 3. 6. INTENCIÓN DE COMPRA ONLINE EN LOS PRÓXIMOS MESES DE LOS NO COMPRADORES POR GÉNERO Y GRUPOS DE EDAD (\%)

\begin{tabular}{|c|c|c|c|c|c|c|c|c|c|}
\hline & \multirow[b]{2}{*}{ TOTAL } & \multicolumn{2}{|c|}{ GÉNERO* } & \multicolumn{6}{|c|}{ EDAD* } \\
\hline & & Hombres & Mujeres & $\begin{array}{l}16-24 \\
\text { años }\end{array}$ & $\begin{array}{c}25-34 \\
\text { años }\end{array}$ & $\begin{array}{c}35-44 \\
\text { años }\end{array}$ & $\begin{array}{c}45-54 \\
\text { años }\end{array}$ & $\begin{array}{l}55-64 \\
\text { años }\end{array}$ & $\begin{array}{l}65-74 \\
\text { años }\end{array}$ \\
\hline Seguramente sí & 19,2 & 18,7 & 19,6 & 28,6 & 33,3 & 31,1 & 10,7 & 10,1 & 12,7 \\
\hline Probablemente sí & 28,6 & 26,9 & 30,2 & 45,7 & 33,3 & 23,0 & 33,3 & 24,7 & 22,2 \\
\hline Probablemente no & 19,7 & 19,2 & 20,1 & 17,1 & 9,5 & 20,3 & 25,3 & 16,9 & 25,4 \\
\hline Seguro que no & 6,8 & 8,2 & 5,5 & 0,0 & 2,4 & 2,7 & 6,7 & 11,2 & 12,7 \\
\hline No me lo he planteado & 25,7 & 26,9 & 24,6 & 8,6 & 21,4 & 23,0 & 24,0 & 37,1 & 27,0 \\
\hline
\end{tabular}

Base: total internautas no compradores online. /*Base: total internautas no compradores online por categoría de género y edad. / Fuente: Encuesta online de comercio electrónico, ONTSI.

Las mujeres internautas no compradoras muestran una mayor intención de compra online que los hombres, ya que el 49,8\% de ellas declara que probable o seguramente realizará una compra online en el futuro, frente al $45,6 \%$ de los hombres. Los varones, en cambio, tienen más claro que no realizarán ninguna compra online en los próximos meses, ya que el $8,2 \%$ de internautas no compradores está seguro de que no lo hará, frente al 5,5\% de mujeres. 


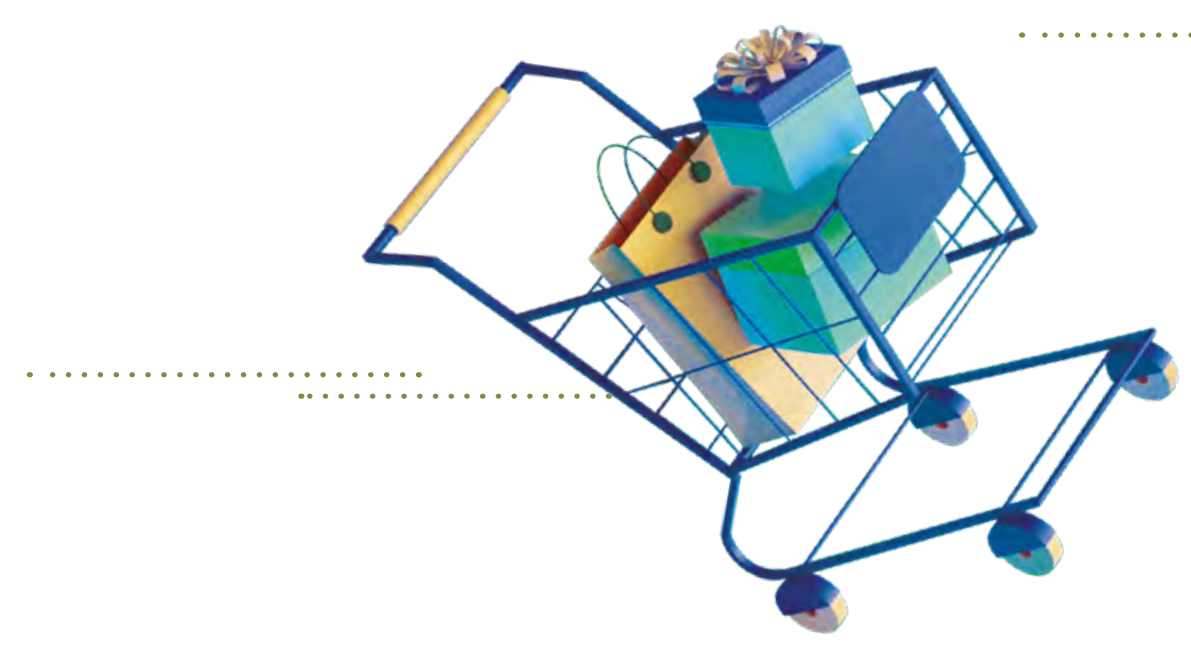

En relación con la edad, la población joven es la que muestra mayor intención de compra online. De hecho, 3 de 4 jóvenes internautas no compradores de entre 16 y 34 años afirma que realizará una compra online en el futuro. Entre los adultos y adultos mayores, en cambio, la mayoría no se lo ha planteado aún.

\section{La experiencia de compra previa impulsa la intencionalidad de compra}

FIGURA 3. 13. ¿TIENE INTENCIÓN DE COMPRAR A TRAVÉS DE INTERNET EN LOS PRÓXIMOS MESES? POR PERFIL DE COMPRA ONLINE ANTERIOR A 2019 (\%)

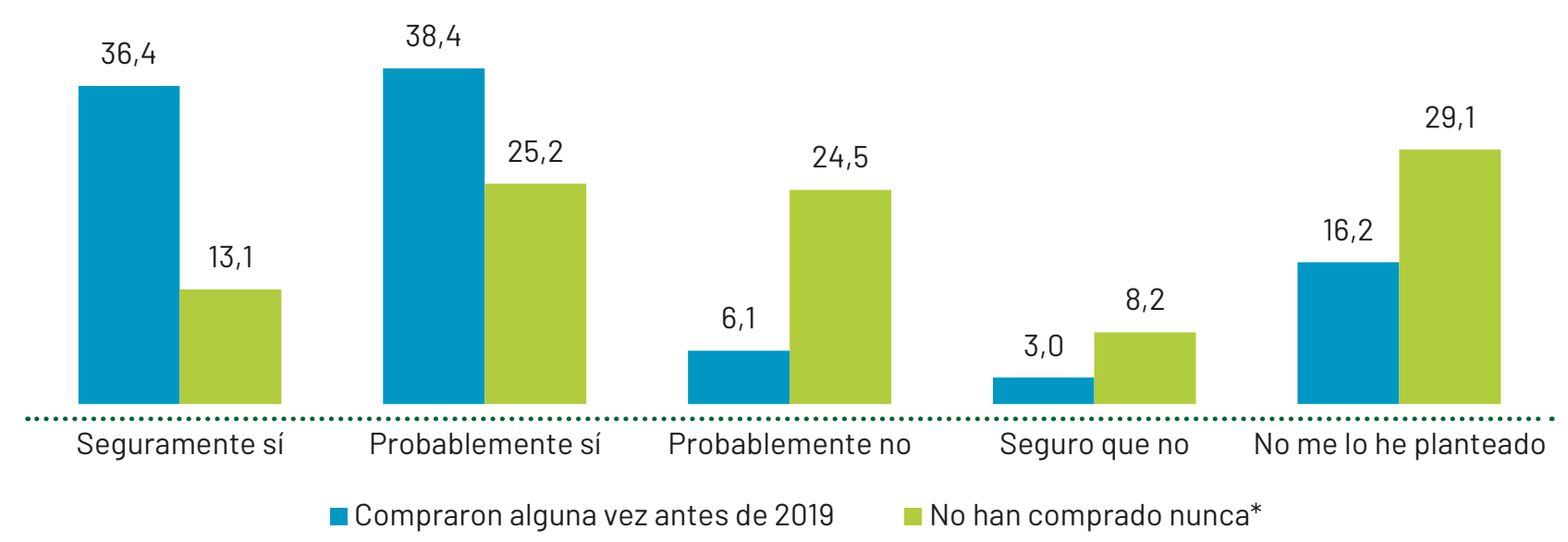

Base: total internautas no compradores online, que lo hicieron antes de 2019. / Base*: total internautas que no han comprado nunca. / Fuente: Encuesta online de comercio electrónico, ONTSI.

Cuando un internauta prueba la compra online es muy probable que repita, pues aproximadamente tres de cada cuatro internautas que compraron online con anterioridad a 2019 declara que comprará por esta vía en los próximos meses. Por otro lado, del total de internautas que nunca ha comprado online, el 38,3\% (aproximadamente 2 millones de personas) afirma que segura 0 probablemente comprará online en un futuro. Mientras que un $29,1 \%$ no se lo ha planteado y casi un tercio declara que es probable o seguro que no vaya a realizar compras a través de Internet en los próximos meses. 


\section{HÁBITOS}
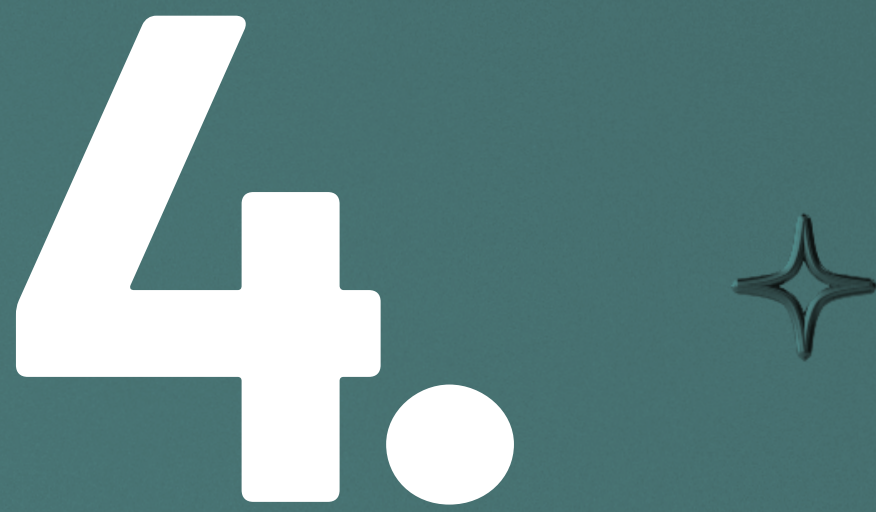

DEL COMERCIO ELECTRÓNICO

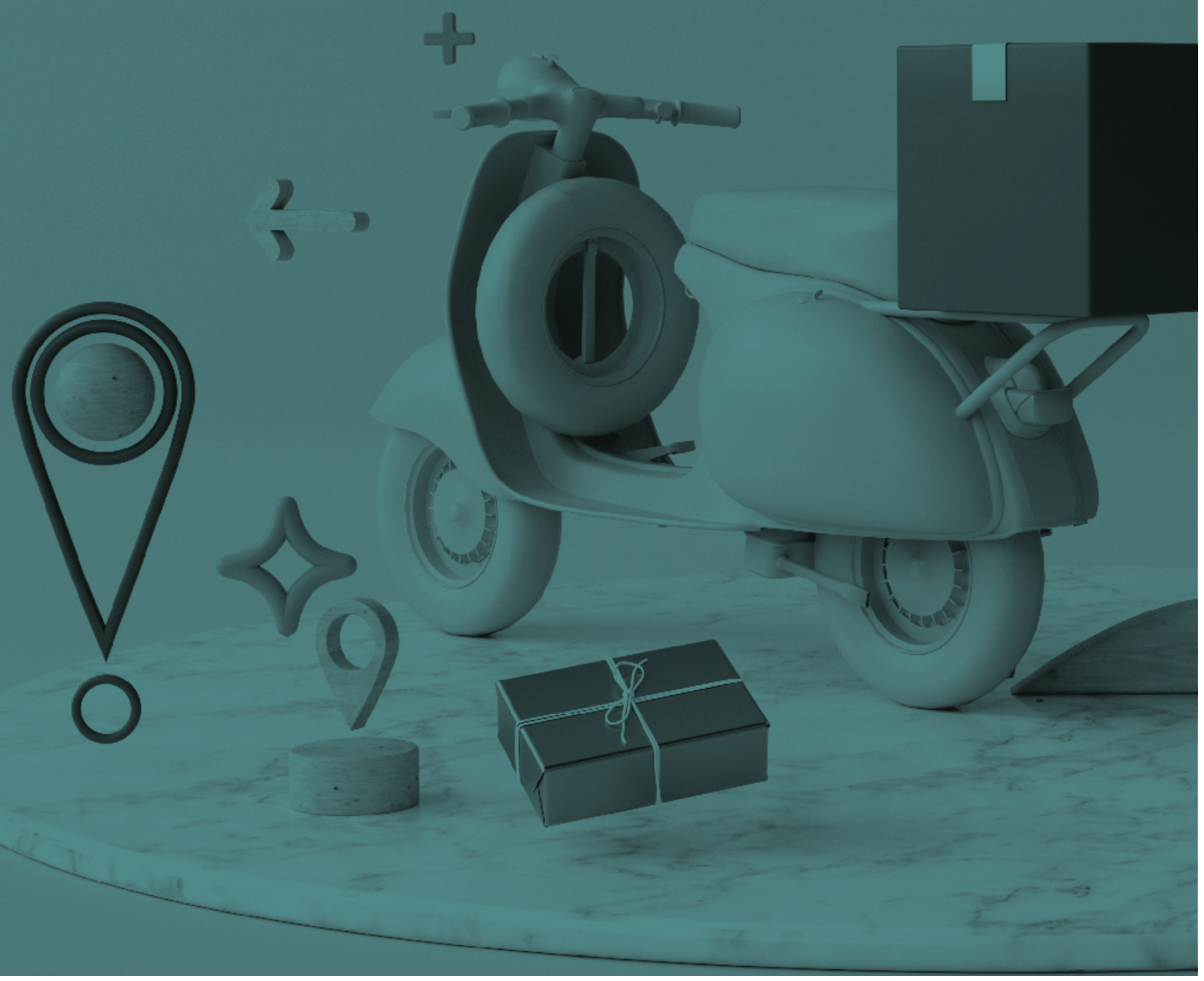




\section{1. HÁBITOS GENERALES}

\section{ACCIONES PREVIAS}

A LA COMPRA ONLINE

\section{El 86,5\% de los internautas se informa en Internet antes de comprar}

FIGURA 4.14 ¿CUÁL DE LAS SIGUIENTES ACCIONES REALIZA GENERALMENTE ANTES DE HACER COMPRAS ONLINE? (\%) (RESPUESTA MÚLTIPLE)

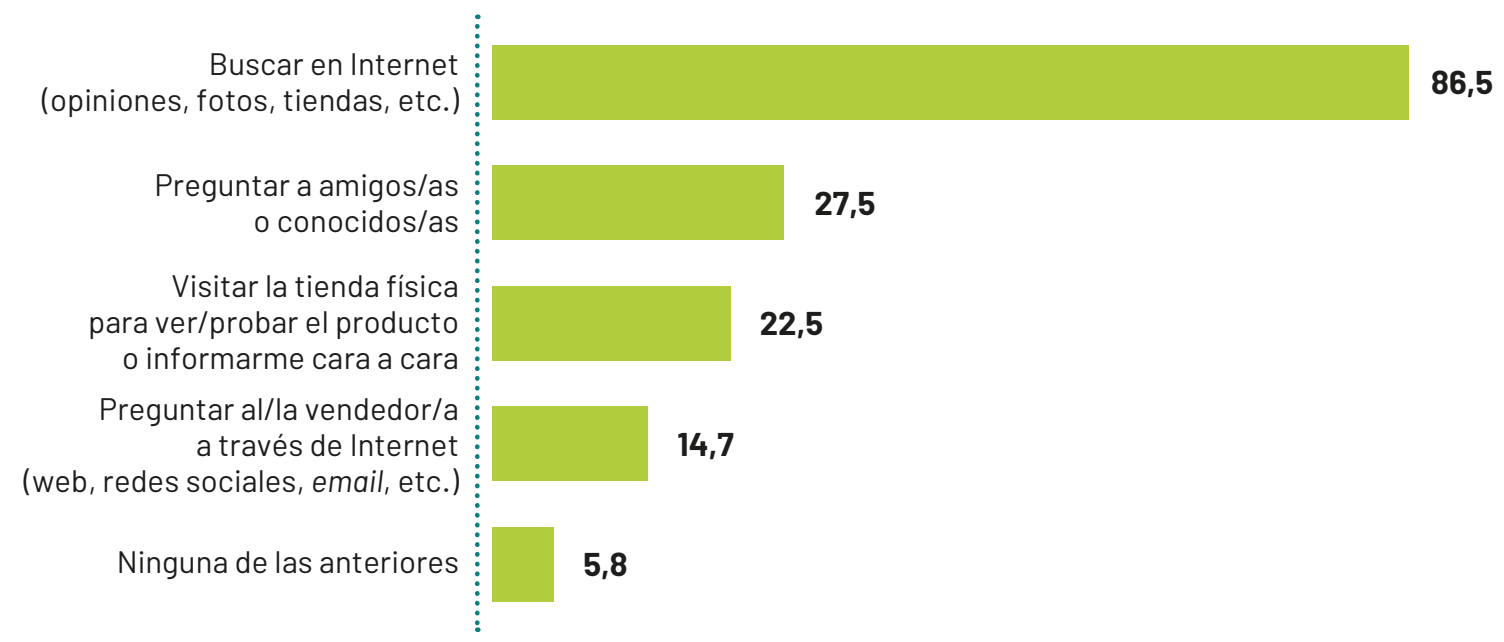

Base: total internautas. / Fuente: Encuesta online de comercio electrónico, ONTSI.

La inmensa cantidad de información disponible a través de Internet favorece que sus usuarios comparen y busquen opiniones de otros compradores sobre los productos y las empresas antes de realizar una compra. El 86,5\% de los internautas rastrea opiniones en la Red antes de adquirir productos o servicios.

Por otro lado, también es habitual, aunque en menor medida, la búsqueda de información entre amigos y conocidos, un hábito presente en el 27,5\% de internautas. Así como un 22,5\% que se acerca a la tienda física directamente para ver y probar el producto antes de realizar la compra.

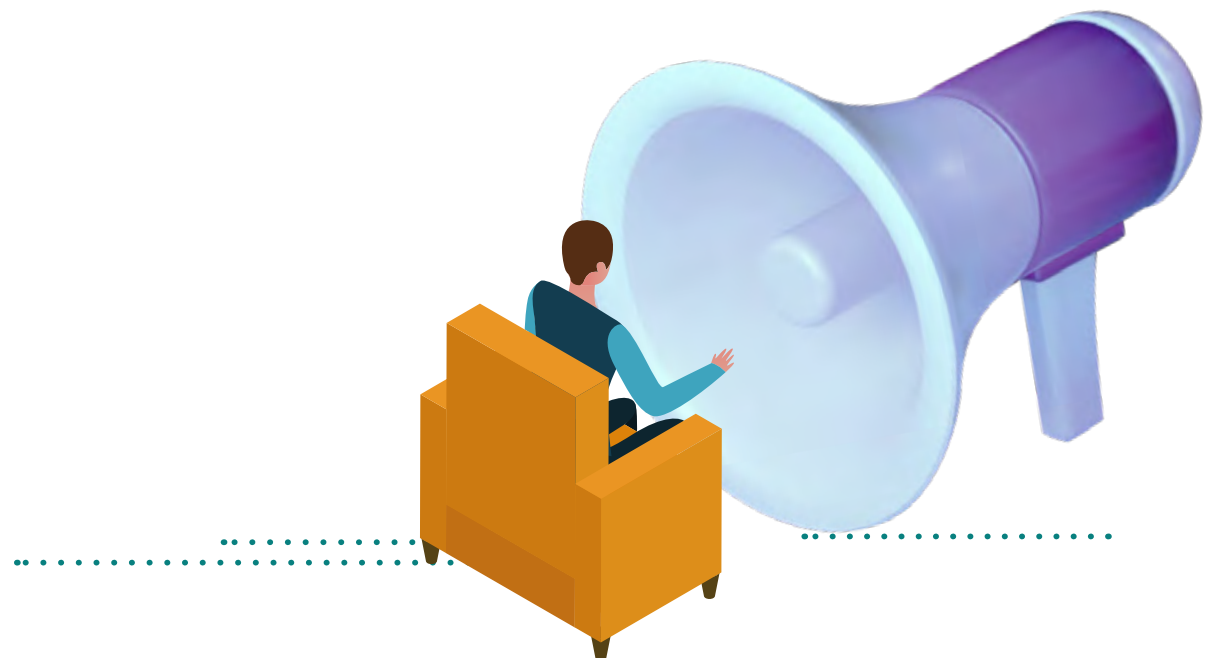




\section{Preguntar a amigos y conocidos y visitar tiendas físicas antes de la compra online, hábitos más frecuentes entre los menores de 24 años}

TABLA 4. 7. SEGÚN GÉNERO Y EDAD ¿CUÁL DE LAS SIGUIENTES ACCIONES REALIZA GENERALMENTE ANTES DE HACER COMPRAS ONLINE? POR GÉNERO Y GRUPOS DE EDAD (\%)(RESPUESTA MÚLTIPLE)

\begin{tabular}{|c|c|c|c|c|c|c|c|c|c|}
\hline & \multirow{2}{*}{ TOTAL } & \multicolumn{2}{|c|}{ GÉNERO* } & \multicolumn{6}{|c|}{ EDAD* } \\
\hline & & Hombres & Mujeres & $\begin{array}{l}16-24 \\
\text { años }\end{array}$ & $\begin{array}{c}25-34 \\
\text { años }\end{array}$ & $\begin{array}{c}35-44 \\
\text { años }\end{array}$ & $\begin{array}{c}45-54 \\
\text { años }\end{array}$ & $\begin{array}{c}55-64 \\
\text { años }\end{array}$ & $\begin{array}{c}65-74 \\
\text { años } \\
\end{array}$ \\
\hline Buscar en Internet & 86,5 & 85,5 & 87,6 & 87,1 & 90,6 & 90,0 & 86,0 & 81,2 & 80,7 \\
\hline Preguntar a amigos/as o conocidos/as & 27,5 & 23,7 & 31,2 & 42,8 & 34,3 & 25,9 & 22,1 & 19,7 & 25,2 \\
\hline Visitar la tienda física para ver/probar el producto & 22,5 & 21,9 & 23,1 & 24,3 & 22,4 & 22,2 & 23,1 & 21,9 & 20,4 \\
\hline Preguntar al vendedor/ra a través de Internet & 14,7 & 15,6 & 13,9 & 16,9 & 12,6 & 17,8 & 13,0 & 12,1 & 16,9 \\
\hline Ninguna & 5,8 & 6,7 & 4,9 & 4,0 & 2,4 & 3,5 & 6,8 & 9,2 & 11,3 \\
\hline
\end{tabular}

Base: total internautas compradores. /*Base: total internautas compradores por categoría de género y edad. / Fuente: Encuesta online de comercio electrónico, ONTSI.

\section{DISPOSITIVOS DE COMPRA ONLINE}

\section{$72,0 \%$} ORDENADOR
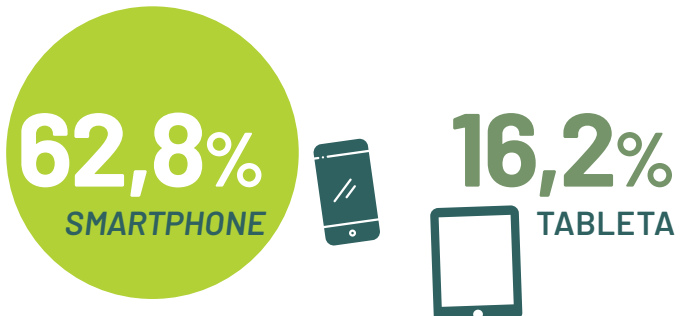
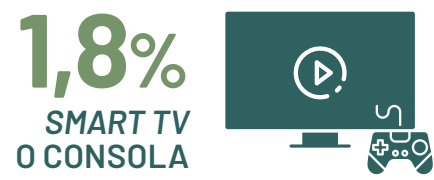

\section{El ordenador y el smartphone siguen siendo los dispositivos predominantes a la hora de realizar una compra online}

El ordenador es el dispositivo más utilizado en las compras online (72\% de internautas), 9,2 p.p por encima del smartphone (62,8\%). La diferencia con el resto de dispositivos es significativa: a través de las tabletas se realiza un 16,2\% de las compras online y a través de la smart TV o consola un 1,8\%.

FIGURA 4. 15. DISPOSITIVOS UTILIZADOS PARA COMPRAS ONLINE, POR GÉNERO (\%) (RESPUESTA MÚLTIPLE)

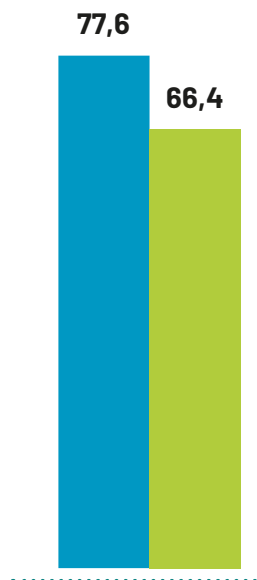

Ordenador

69,7

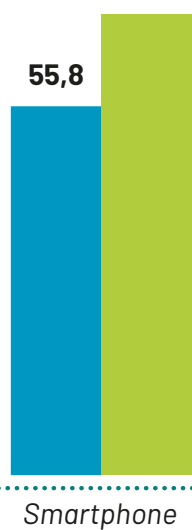

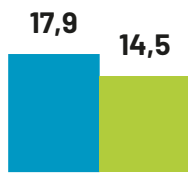

Tableta

4,5
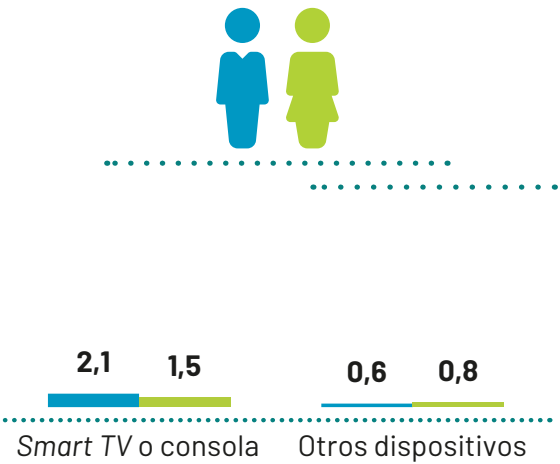
El uso del smartphone es la principal diferencia entre hombres y mujeres en cuanto a dispositivo preferido para la compra online, con un uso más intensivo entre las mujeres, que lo utilizan casi 14 p.p. más que los hombres, mientras que entre ellos predomina el uso del ordenador, la tableta y la smart TV o consola.

\section{El smartphone gana peso entre los internautas de 25 a 44 años como dispositivo preferente para realizar compras online}

FIGURA 4. 16. DISPOSITIVOS UTILIZADOS PARA COMPRAS ONLINE, POR GRUPOS DE EDAD (\%) (RESPUESTA MÚLTIPLE)

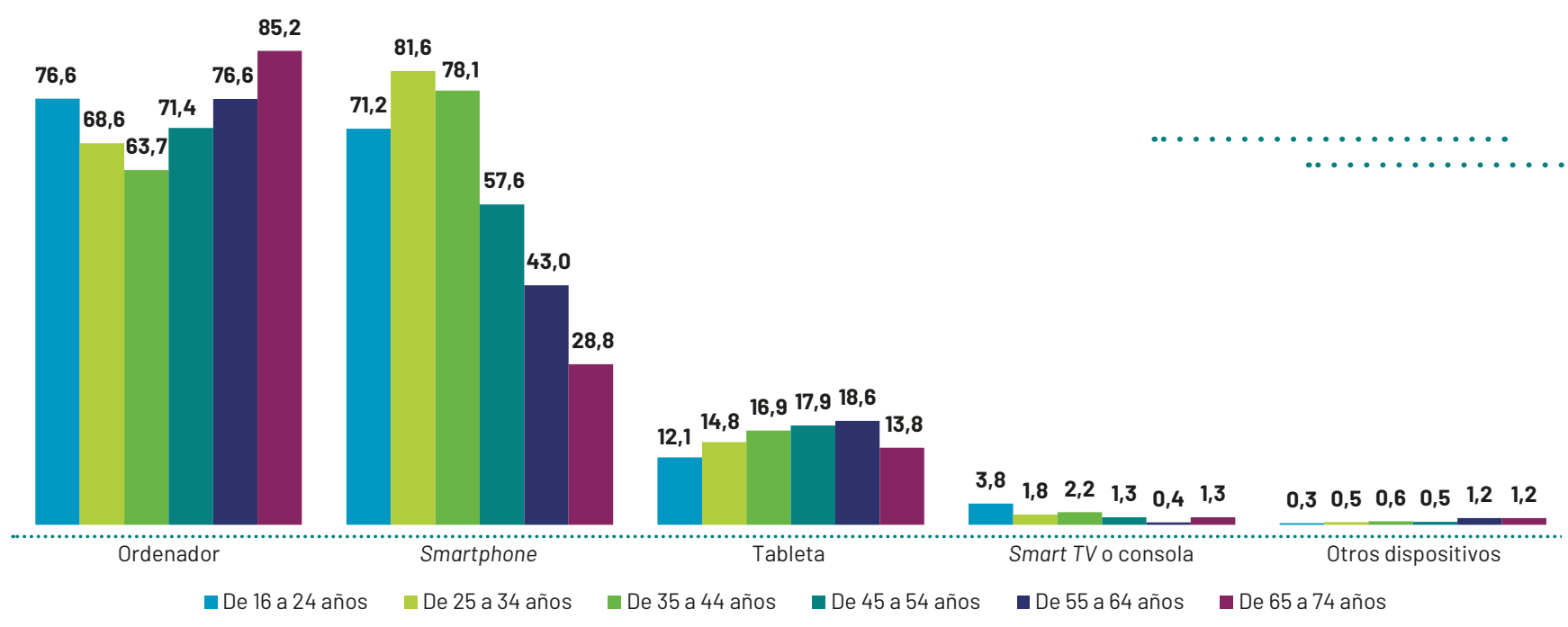

Base: total internautas compradores online por categoría de edad. / Fuente: Encuesta online de comercio electrónico, ONTSI.

El uso del ordenador como dispositivo para comprar online desciende en todas las franjas de edad respecto a 2018. Por el contrario, el smartphone gana adeptos en 2019: el uso entre los jóvenes de entre 25 y 34 años se incrementa 16,2 p.p. y entre los usuarios de 35 a 44 años aumenta 13,3 p.p. respecto al año anterior.

Los jóvenes son quienes más utilizan el smartphone para comprar, mientras que el ordenador está más generalizado entre los mayores de 45 años. La tableta se utiliza poco en todas las edades, aunque es más común entre los internautas de 55 a 64 años. En el caso de las consolas y smart TV se observa mayor porcentaje de usuarios entre los 16 y 24 años, aunque todavía las cifras son bajas.

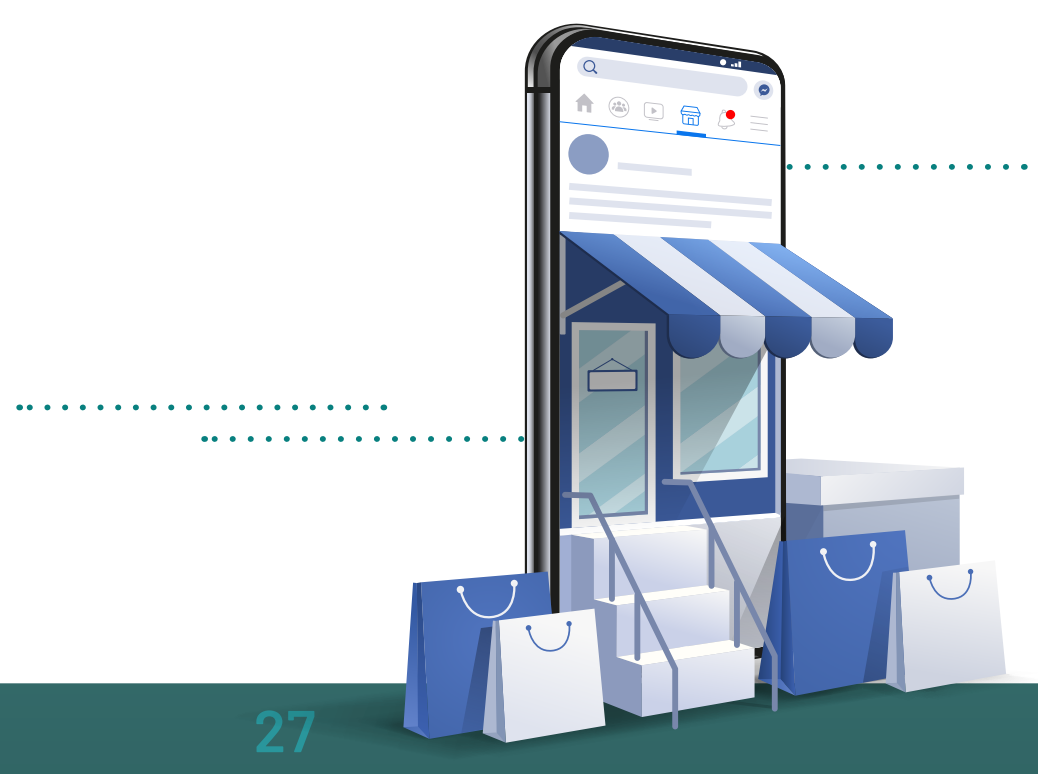




\section{SITIOS DE COMPRA}

\section{7 de cada 10 internautas prefieren comprar en portales con múltiples vendedores o marketplaces}

FIGURA 4. 17. ¿DÓNDE SUELE COMPRAR EN INTERNET? (\%) (RESPUESTA MÚLTIPLE)

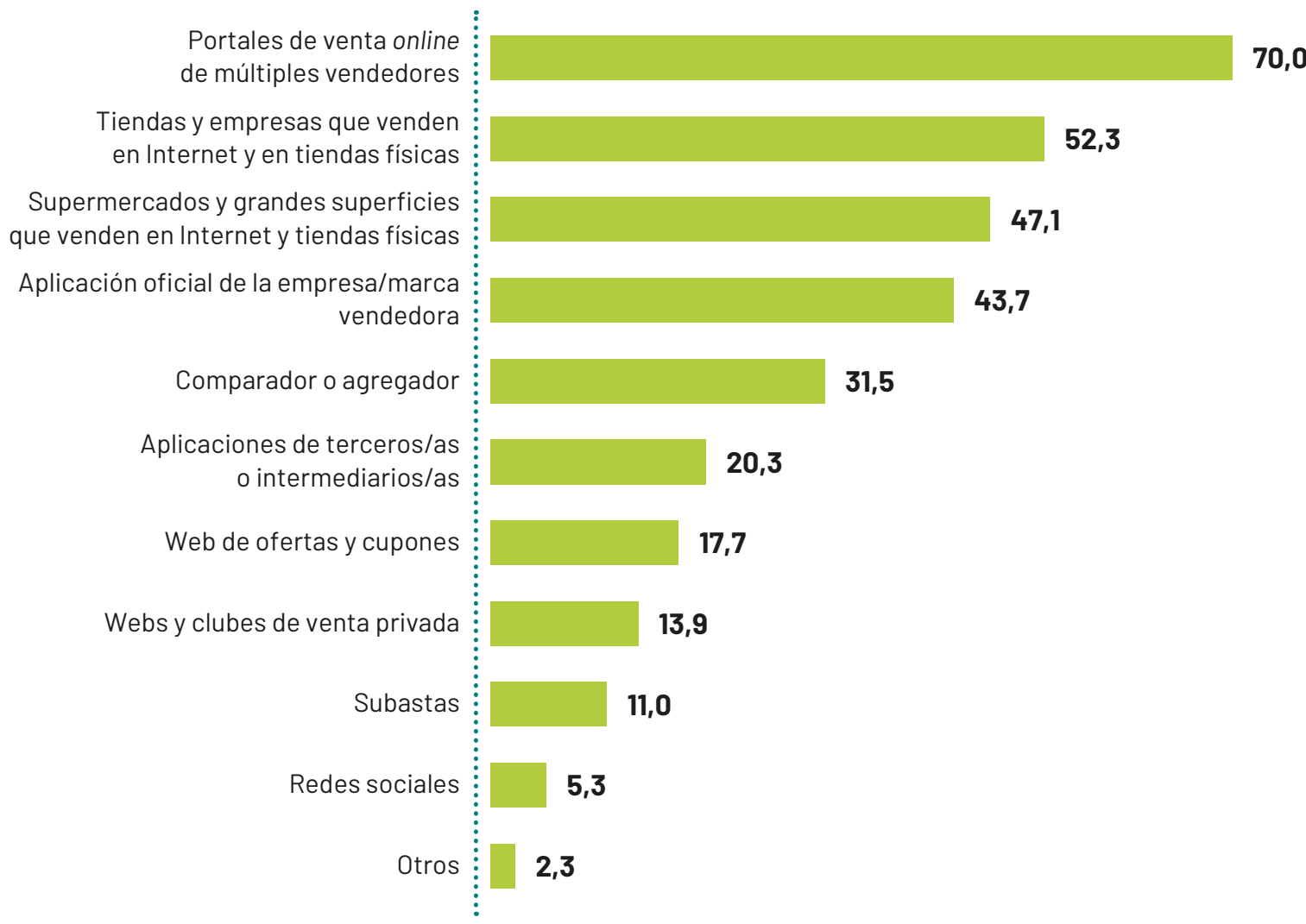

Base: total internautas compradores online. / Fuente: Encuesta online de comercio electrónico, ONTSI.

En 2019, se mantiene la preferencia mayoritaria por la compra en portales de múltiples vendedores. Concretamente, siete de cada diez internautas realizan compras a través de este tipo de sitio web, los conocidos como marketplaces.

Las tiendas y empresas que venden tanto en Internet como en tienda física ganan peso entre los internautas al pasar de 46\% a 52,3\%. Les siguen, en tercer lugar, los supermercados y grandes superficies que venden en la Red y en tienda física (47,1\%) y las aplicaciones oficiales de empresas y marcas $(43,7 \%)$.

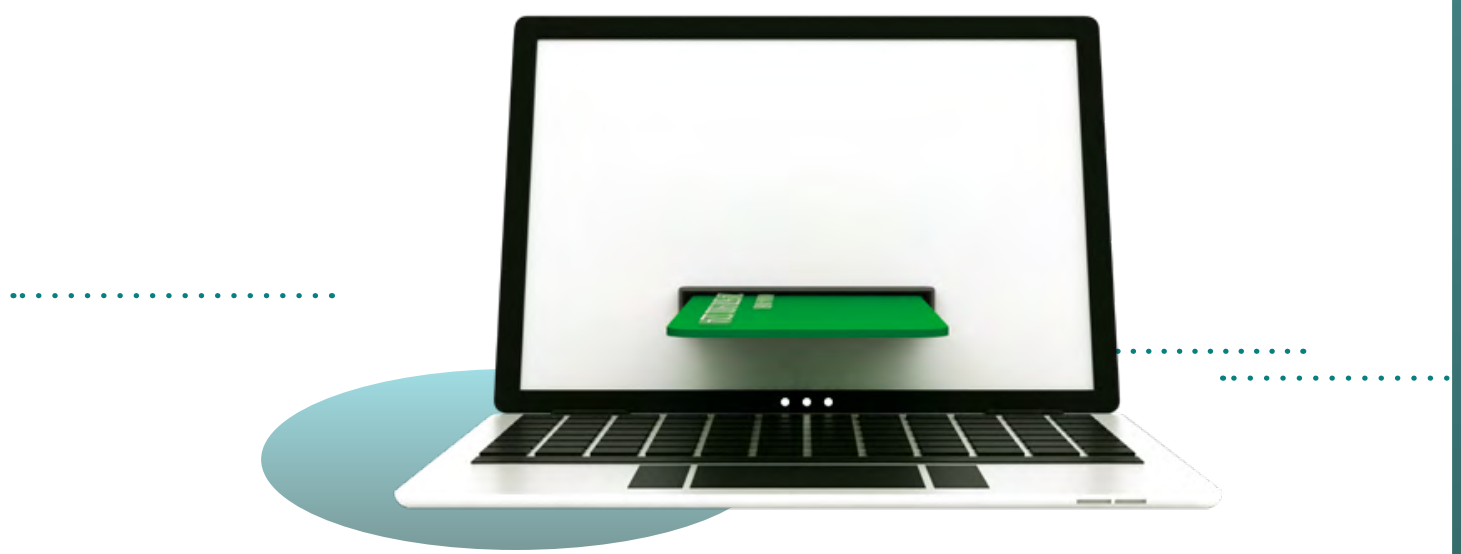




\section{Los usuarios se decantan por comprar en los marketplaces por la variedad de productos, mejores precios y la presencia de opiniones de otros compradores}

FIGURA 4. 18. ¿QUÉ MOTIVOS LE LLEVAN A RECURRIR A UN MARKETPLACE PARA SUS COMPRAS ONLINE? (\%) (RESPUESTA MÚLTIPLE)

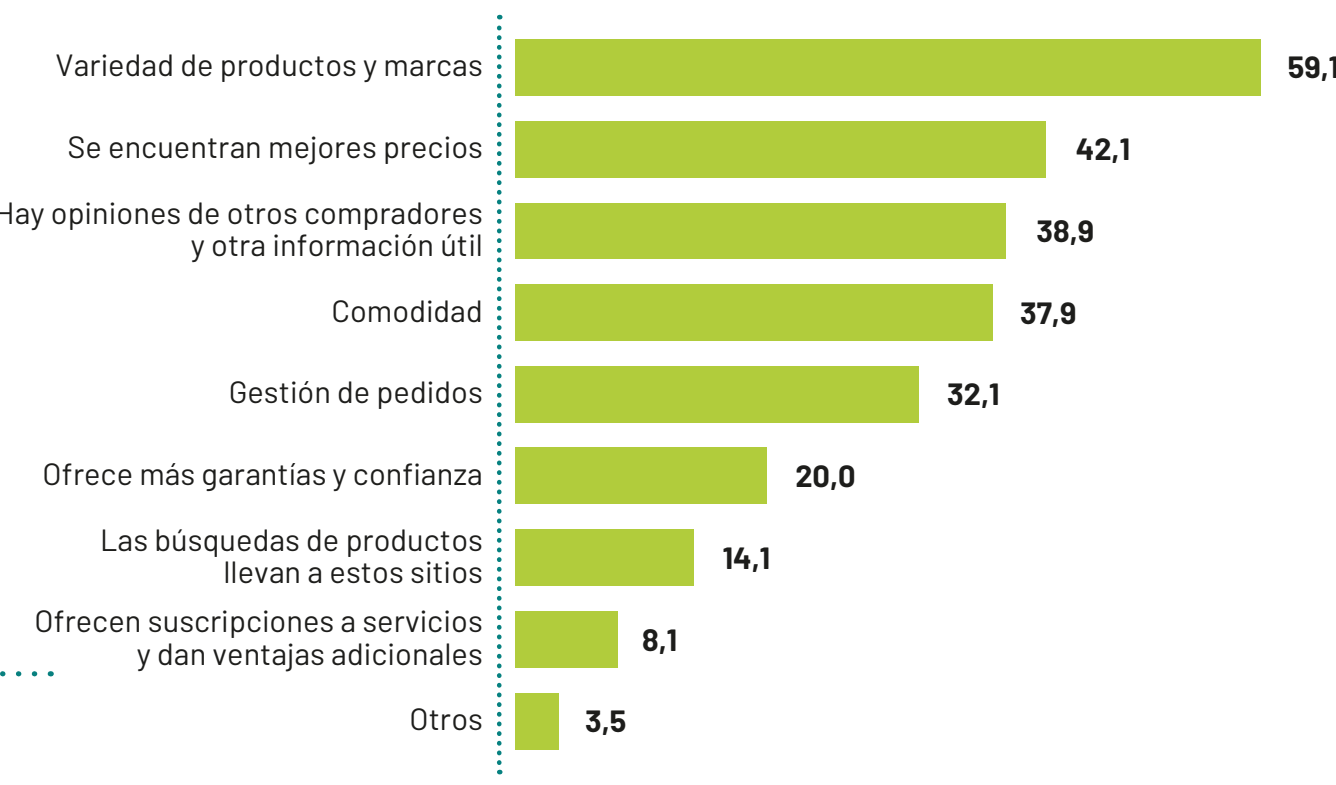

Base: internautas compradores online que utilizan marketplace. / Fuente: Encuesta online de comercio electrónico, ONTSI.

Los tres factores que atraen más consumidores a los marketplaces, en detrimento de otro tipo de sitios de compra, son la variedad de productos y marcas $(59,1 \%)$, el precio (42,1\%) y las opiniones e información útil de otros compradores (38,9\%). La comodidad que ofrecen $(37,9 \%)$ es otro factor decisivo.

\section{La compra directa al proveedor es la principal alternativa a los marketplaces}

FIGURA 4. 19. ¿POR OUÉ MOTIVOS NO RECURRE A UN MARKETPLACE PARA SUS COMPRAS ONLINE? (\%) (RESPUESTA MÚLTIPLE)

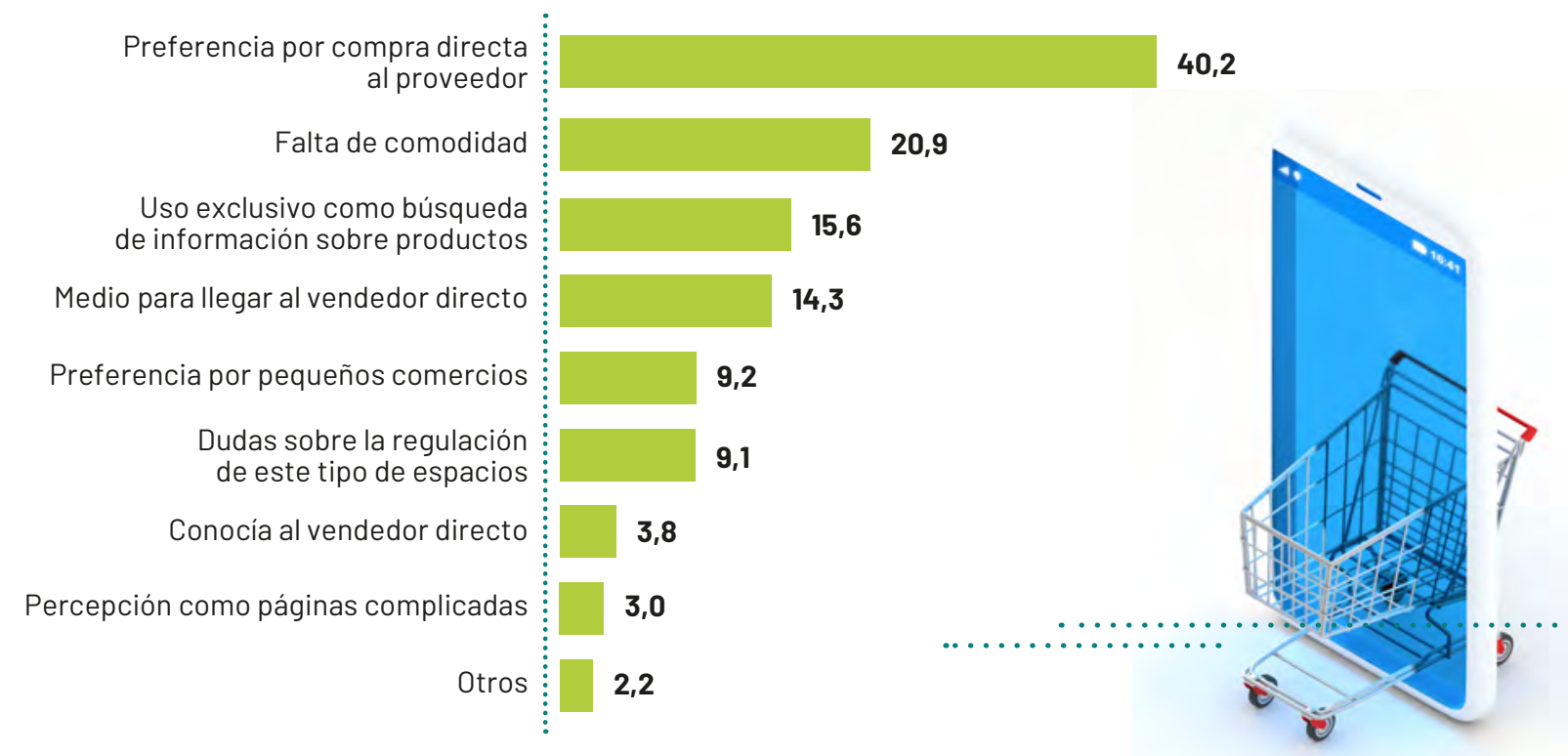


Entre los usuarios que rechazan comprar en marketplaces, cuatro de cada diez dicen que prefieren hacerlo directamente en el sitio del proveedor. Un 20,9\% de esos usuarios los rechaza porque perciben falta de comodidad al utilizarlos, mientras que un $15,6 \%$ solo los utiliza como una herramienta que les ayuda a buscar información sobre el producto, o para llegar al vendedor directo $(14,3 \%)$, pero no como un sitio donde comprar.

\section{FORMAS DE PAGO}

\section{Un $85,2 \%$ de los compradores utiliza la tarjeta de crédito o débito como forma de pago en compras online}

FIGURA 4. 20. ¿OUÉ FORMAS DE PAGO SUELE UTILIZAR EN SUS COMPRAS ONLINE? (\%)(RESPUESTA MÚLTIPLE)

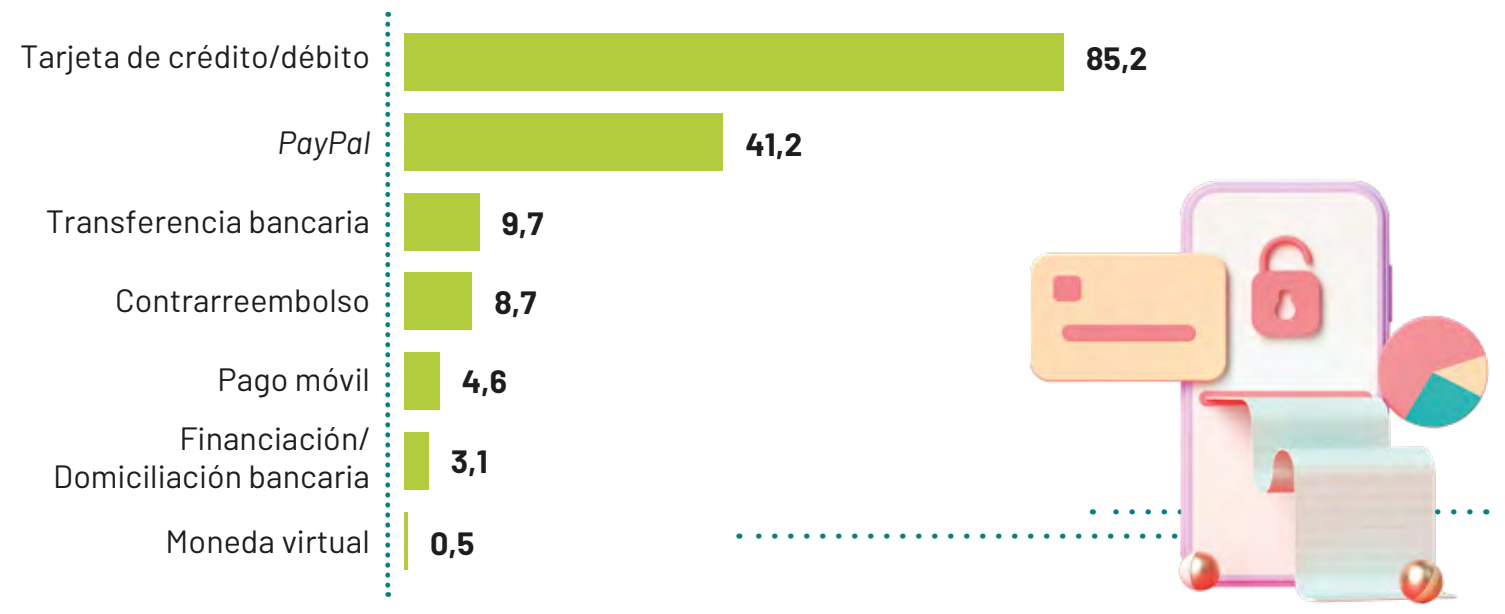

Base: total internautas compradores online. / Fuente: Encuesta online de comercio electrónico, ONTSI.

El uso de tarjeta de crédito/débito sigue predominando un año más entre todas las formas de pago para las compras online, siendo utilizado por el 85,2\% de los internautas compradores. La segunda forma más habitual de pago es a través de PayPal, utilizado por el 41,2\%. Lejos de estas cifras se sitúan los pagos por transferencia bancaria (9,7\%), contrarreembolso $(8,7 \%)$ o a través de servicios de pago móvil (4,6\%).

\section{El pago con tarjeta de crédito o débito predomina entre los mayores de 55 años, mientras que el pago a través de PayPal predomina entre los internautas de 25 a 44 años}

TABLA 4. 8. USO DE PAYPAL Y TARJETA COMO FORMA DE PAGO ONLINE, POR GÉNERO Y GRUPOS DE EDAD (\%)

\begin{tabular}{|c|c|c|c|c|c|c|c|c|c|}
\hline & \multirow{2}{*}{ TOTAL } & \multicolumn{2}{|c|}{ GÉNERO* } & \multicolumn{6}{|c|}{ EDAD* } \\
\hline & & Hombres & Mujeres & $\begin{array}{l}16-24 \\
\text { años }\end{array}$ & $\begin{array}{c}25-34 \\
\text { años }\end{array}$ & $\begin{array}{c}35-44 \\
\text { años }\end{array}$ & $\begin{array}{c}45-54 \\
\text { años }\end{array}$ & $\begin{array}{c}55-64 \\
\text { años }\end{array}$ & $\begin{array}{c}65-74 \\
\text { años }\end{array}$ \\
\hline Tarjeta de crédito/débito & 85,2 & 86,4 & 83,9 & 85,0 & 86,7 & 83,1 & 84,3 & 86,9 & 87,0 \\
\hline PayPal & 41,2 & 43,6 & 38,8 & 30,6 & 45,9 & 46,3 & 42,3 & 37,5 & 39,0 \\
\hline
\end{tabular}

Base: total internautas compradores online. /*Base: internautas compradores online por género y edad. / Fuente: Encuesta online de comercio electrónico, ONTSI.

Mujeres y hombres utilizan de manera similar la tarjeta de crédito/débito como método de pago, con 2,5 p.p. de diferencia. En el caso de uso de PayPal, la diferencia es algo mayor, 4,8 puntos a favor de los hombres.

Con relación a la edad de los usuarios, cabe destacar que el uso de PayPal está más generalizado entre los internautas de 25 a 44 años; más del 45\% pagan con este método. 


\section{2. PRODUCTOS Y SERVICIOS \\ Moda, turismo y ocio son las categorias líderes en las compras online en 2019}

TABLA 4. 9. BIENES Y SERVICIOS ADOUIRIDOS POR INTERNET (\% Y № ABSOLUTO DE INTERNAUTAS COMPRADORES)

\section{CATEGORÍA DE BIENES Y SERVICIOS MÁS ADOUIRIDOS}

Ropa, calzado y complementos

Reserva de alojamiento y paquetes turísticos

Entradas para espectáculos y eventos (cine, teatro, arte, deportes, ferias, etc.) Billetes de transporte (avión, tren, autobús, barco, taxi, metro...)

Comida a domicilio de restaurantes

Ocio, restaurantes, servicios personales y experiencias

Salud y cuidado personal (cosmética, perfumería, farmacia, parafarmacia, etc.)

Electrodomésticos, muebles, hogar, bricolaje y jardín

Teléfonos móviles, smartphones y accesorios relacionados Deporte y fitness (ropa deportiva, accesorios y otros productos)

Alimentación, bebidas y productos de limpieza del hogar Ordenadores, tabletas, accesorios y otros productos de electrónica (sonido, fotografía y vídeo) Juguetes y juegos de mesa

Libros, cómics, revistas y periódicos en formato físico Servicios de Internet y telefonía (conexión a Internet, alojamiento web, tarifas y recarga móviles, etc.)

Descarga o servicio online de películas, música y videojuegos Material de oficina, papelería e imprenta

Mascotas (comida, higiene, complementos, animales, etc.) Formación y cursos online Libros, cómics, revistas y periódicos en formato electrónico (incluyendo descarga y suscripción

Joyería, bisutería y relojes

Películas, música y videojuegos para recibirlos en formato físico

Servicios financieros (fondos de inversión, acciones, banca, etc.) y seguros (hogar, salud coche, etc.)

Programas, software y aplicaciones para móvil o tableta Juegos de azar, concursos, apuestas y lotería

Vehículos de motor (incluyendo alquiler y compra de vehículos, repuestos y accesorios, y vehículos eléctricos

Artículos de coleccionismo y antigüedades

Contenido de pago en redes sociales, profesionales y de citas (Linkedin, Meetic, Tinder InfoJobs, etc.)

Otros

\begin{tabular}{|c|c|}
\hline $\begin{array}{l}\text { PORCENTAJE } \\
\text { COMPRADORES }\end{array}$ & $\begin{array}{l}\text { NUMERO DE } \\
\text { COMPRADORES }\end{array}$ \\
\hline 59,2 & 14.364 .099 \\
\hline 52,1 & 12.646 .006 \\
\hline 49,0 & 11.892 .427 \\
\hline 45,3 & 10.995 .418 \\
\hline 38,5 & 9.332 .617 \\
\hline 33,6 & 8.152 .996 \\
\hline 32,4 & 7.873 .037 \\
\hline 30,5 & 7.393 .735 \\
\hline 30,3 & 7.361 .930 \\
\hline 24,6 & 5.967 .177 \\
\hline 23,7 & 5.753 .218 \\
\hline 22,6 & 5.477 .793 \\
\hline 22,2 & 5.389 .242 \\
\hline 20,4 & 4.947 .679 \\
\hline 19,7 & 4.769.716 \\
\hline 18,5 & 4.479 .141 \\
\hline 17,7 & 4.306 .341 \\
\hline 16,2 & 3.940 .767 \\
\hline 15,0 & 3.640 .973 \\
\hline 14,3 & 3.480 .276 \\
\hline 13,6 & 3.309 .284 \\
\hline 12,1 & 2.945 .284 \\
\hline 12,1 & 2.928.170 \\
\hline 11,1 & 2.704 .042 \\
\hline 9,8 & 2.373 .033 \\
\hline 6,7 & 1.617 .986 \\
\hline 4,9 & 1.192 .468 \\
\hline 2,6 & 641.065 \\
\hline 1,4 & 342.221 \\
\hline
\end{tabular}

Base: total internautas compradores online. / Fuente: Encuesta online de comercio electrónico, ONTSI.

Los productos más comprados en 2019 son ropa, calzado y complementos (un 59,2\%), seguidos de reservas de alojamientos y paquetes turísticos (52,1\%). Las entradas para espectáculos y eventos $(49 \%)$ y los billetes de transporte $(45,3 \%)$, también adquieren protagonismo entre los bienes y servicios más demandados. 
Por el contrario, los contenidos de pago en redes sociales $(2,6 \%)$, los artículos de coleccionismo y antigüedades $(4,9 \%)$ y los vehículos de motor $(6,7 \%)$, se posicionan como los bienes y servicios menos demandamos por los internautas.

\section{Las mujeres y los jóvenes son quienes más compras realizan dentro de las categorias de venta mayoritarias}

TABLA 4. 10. BIENES Y SERVICIOS ADQUIRIDOS POR INTERNET (\%) .

\begin{tabular}{|c|c|c|c|c|c|c|c|c|}
\hline \multirow[b]{2}{*}{ TOTAL } & \multicolumn{2}{|c|}{ GÉNERO* } & \multicolumn{6}{|c|}{ EDAD* } \\
\hline & Hom. & Muj. & $\begin{array}{l}16-24 \\
\text { años }\end{array}$ & $\begin{array}{c}25-34 \\
\text { años }\end{array}$ & $\begin{array}{l}\begin{array}{c}35-44 \\
\text { años }\end{array}\end{array}$ & $\begin{array}{c}45-54 \\
\text { años }\end{array}$ & $\begin{array}{c}55-64 \\
\text { años }\end{array}$ & $\begin{array}{l}65-74 \\
\text { años }\end{array}$ \\
\hline 59,2 & 48,7 & 69,8 & 66,0 & 65,4 & 62,0 & 61,7 & 49,4 & 38,8 \\
\hline 52,1 & 50,5 & 53,7 & 46,3 & 55,0 & 51,4 & 54,4 & 50,2 & 54,7 \\
\hline 49,0 & 44,8 & 53,3 & 48,8 & 57,0 & 50,7 & 48,3 & 43,0 & 41,1 \\
\hline 45,3 & 42,6 & 48,0 & 48,8 & 52,2 & 42,1 & 42,4 & 42,5 & 47,6 \\
\hline 38,5 & 31,9 & 45,1 & 47,5 & 55,6 & 46,6 & 32,0 & 24,6 & 9,2 \\
\hline 33,6 & 31,7 & 35,5 & 37,5 & 42,1 & 36,4 & 29,6 & 27,9 & 23,0 \\
\hline 32,4 & 22,9 & 42,1 & 29,4 & 40,4 & 35,0 & 30,7 & 25,6 & 31,4 \\
\hline 30,5 & 32,7 & 28,2 & 16,2 & 30,4 & 33,2 & 29,5 & 33,0 & 43,5 \\
\hline 30,3 & 35,2 & 25,4 & 31,3 & 29,6 & 34,1 & 32,9 & 24,2 & 24,1 \\
\hline 24,6 & 25,4 & 23,7 & 24,3 & 31,1 & 24,2 & 28,8 & 20,0 & 9,9 \\
\hline 23,7 & 22,2 & 25,3 & 18,6 & 24,6 & 28,9 & 23,6 & 19,3 & 23,6 \\
\hline 22,6 & 27,2 & 17,8 & 24,5 & 24,2 & 20,7 & 22,2 & 22,3 & 23,1 \\
\hline 22,2 & 20,4 & 24,0 & 12,9 & 26,7 & 36,7 & 21,4 & 9,5 & 12,7 \\
\hline 20,4 & 19,0 & 21,8 & 21,8 & 21,2 & 21,2 & 18,6 & 20,5 & 18,5 \\
\hline 19,7 & 21,7 & 17,6 & 20,0 & 21,7 & 19,0 & 19,4 & 17,7 & 21,1 \\
\hline 18,5 & 19,0 & 17,9 & 28,5 & 23,6 & 19,6 & 15,0 & 11,8 & 10,3 \\
\hline 17,7 & 16,3 & 19,2 & 18,3 & 18,7 & 17,2 & 19,1 & 16,5 & 15,1 \\
\hline 16,2 & 14,2 & 18,3 & 13,9 & 21,1 & 20,6 & 13,7 & 12,5 & 11,6 \\
\hline 15,0 & 10,7 & 19,4 & 16,5 & 25,8 & 15,2 & 13,7 & 9,5 & 3,7 \\
\hline 14,3 & 14,1 & 14,5 & 13,7 & 13,6 & 15,6 & 16,3 & 11,9 & 12,4 \\
\hline 13,6 & 9,5 & 17,9 & 21,5 & 19,2 & 12,0 & 11,9 & 9,3 & 7,3 \\
\hline 12,1 & 14,3 & 9,9 & 12,4 & 17,3 & 14,5 & 12,4 & 6,4 & 4,6 \\
\hline 12,1 & 16,6 & 7,6 & 6,0 & 9,0 & 11,1 & 13,9 & 14,9 & 21,4 \\
\hline 11,1 & 14,0 & 8,3 & 11,0 & 11,0 & 11,8 & 11,0 & 11,0 & 10,3 \\
\hline 9,8 & 13,2 & 6,3 & 5,0 & 10,4 & 10,6 & 11,1 & 8,0 & 13,6 \\
\hline 6,7 & 9,2 & 4,1 & 4,1 & 5,8 & 6,6 & 6,4 & 7,5 & 11,9 \\
\hline 4,9 & 7,7 & 2,1 & 2,9 & 4,0 & 4,8 & 5,3 & 5,3 & 8,4 \\
\hline 2,6 & 3,4 & 1,9 & 3,9 & 3,3 & 1,7 & 3,5 & 1,9 & 0,8 \\
\hline 1,4 & 1,3 & 1,5 & 1,3 & 0,5 & 0,5 & 1,2 & 2,5 & 4,6 \\
\hline
\end{tabular}

Entradas para espectáculosy eventc

Ropa, calzado y complementos ferias, etc

Billetes de transporte (avión, tren, autobús, barco, taxi, metro, etc.)

Comida a domicilio de restaurantes

Ocio, restaurantes, servicios personales y experiencias Salud y cuidado personal (cosmética, perfumería, farmacia, etc.)

Electrodomésticos, muebles, hogar, bricolaje y jardín

Teléfonos móviles, smartphones y accesorios relacionados Deporte y fitness (ropa deportiva, accesorios y otros productos)

Alimentación, bebidas y productos de limpieza del hoga

Ordenadores, tabletas, accesorios y otros productos de electrónica

Juguetes y juegos de mesa

Libros, cómics, revistas y periódicos en formato físico

Servicios de Internet y telefonía

Descarga o servicio online de películas, música y videojuegos Material de oficina, papelería e imprenta

Mascotas (comida, higiene, complementos, animales, etc.)

Formación y cursos online

Libros, cómics, revistas y periódicos en formato electrónico (incluyendo descarga y suscripción)

Joyería, bisutería y relojes

Películas, música y videojuegos para recibirlos en formato físico

Servicios financieros y seguros

Programas, software y aplicaciones para móvil o tableta Juegos de azar, concursos, apuestas y lotería

Vehículos de moto

Artículos de coleccionismo y antigüedades

Contenido de pago en redes sociales, profesionales y de citas

Otros

Base: total internautas compradores online. /*Base: internautas compradores online por género y edad. / Fuente: Encuesta online de comercio electrónico, ONTSI.

Por edades, los más jóvenes (16-24 años) son quienes más consumen productos de moda (ropa, calzado y complementos). El segmento de 25 a 34 años sobresale en el pago por entretenimiento y cultura, así como en turismo y transporte (reservas de alojamientos y paquetes turísticos, entradas a espectáculos y billetes de transporte). Encargar comida a domicilio también es algo que predomina entre los más jóvenes, sobre todo entre personas de 25 a 34 años. 


\section{3. \\ CONTENIDO DIGITAL Y \\ SUSCRIPCIONES}

Más de la mitad de los consumidores online está suscrito a algún proveedor de servicios o contenidos digitales de pago

FIGURA 4. 21. ¿ESTÁ SUSCRITO A ALGÚN SERVICIO O CONTENIDO DIGITAL (VÍDEO, MÚSICA, VIDEOJUEGOS, ETC.)? (\%)
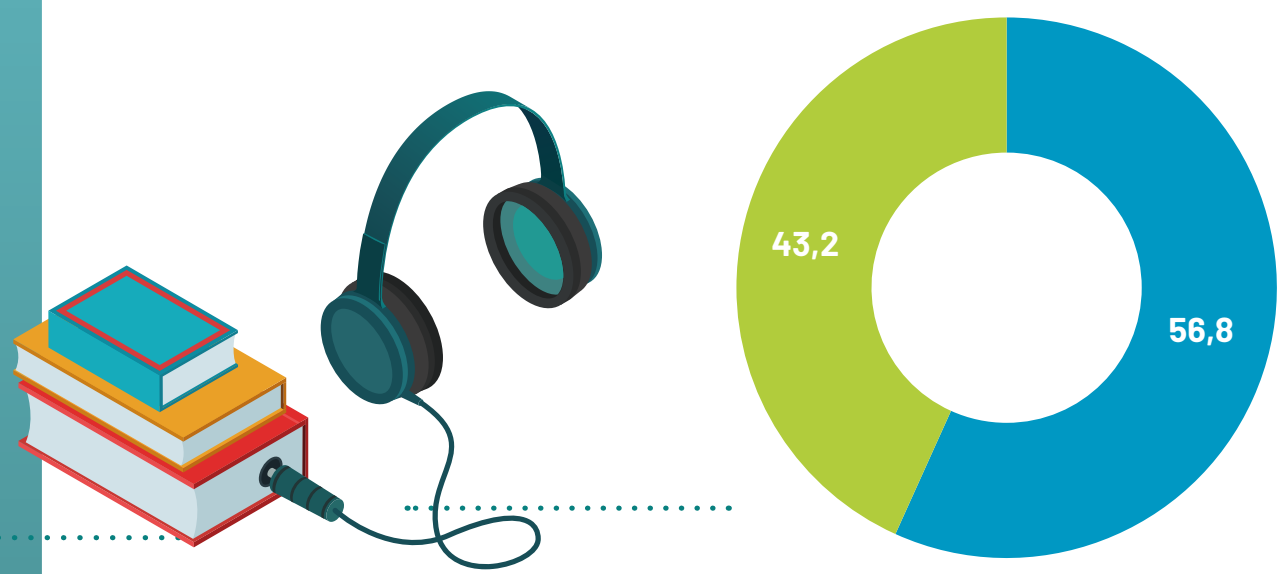

$\square$ Sí $\square$ No

Base: total internautas compradores online. / Fuente: Encuesta online de comercio electrónico, ONTSI.

Cada vez son más los internautas que se suscriben a algún servicio o contenido digital de pago. En 2019, se incrementa este tipo de suscripciones 10,5 puntos porcentuales hasta el $56,8 \%$ de los internautas compradores.

\section{Aumentan las suscripciones a plataformas audiovisuales en streaming}

FIGURA 4. 22. ¿A OUUÉ SERVICIOS DIGITALES ESTÁ SUSCRITO Y A TRAVÉS DE QUÉ DISPOSITIVOS ACCEDE? (\%) (RESPUESTA MÚLTIPLE)

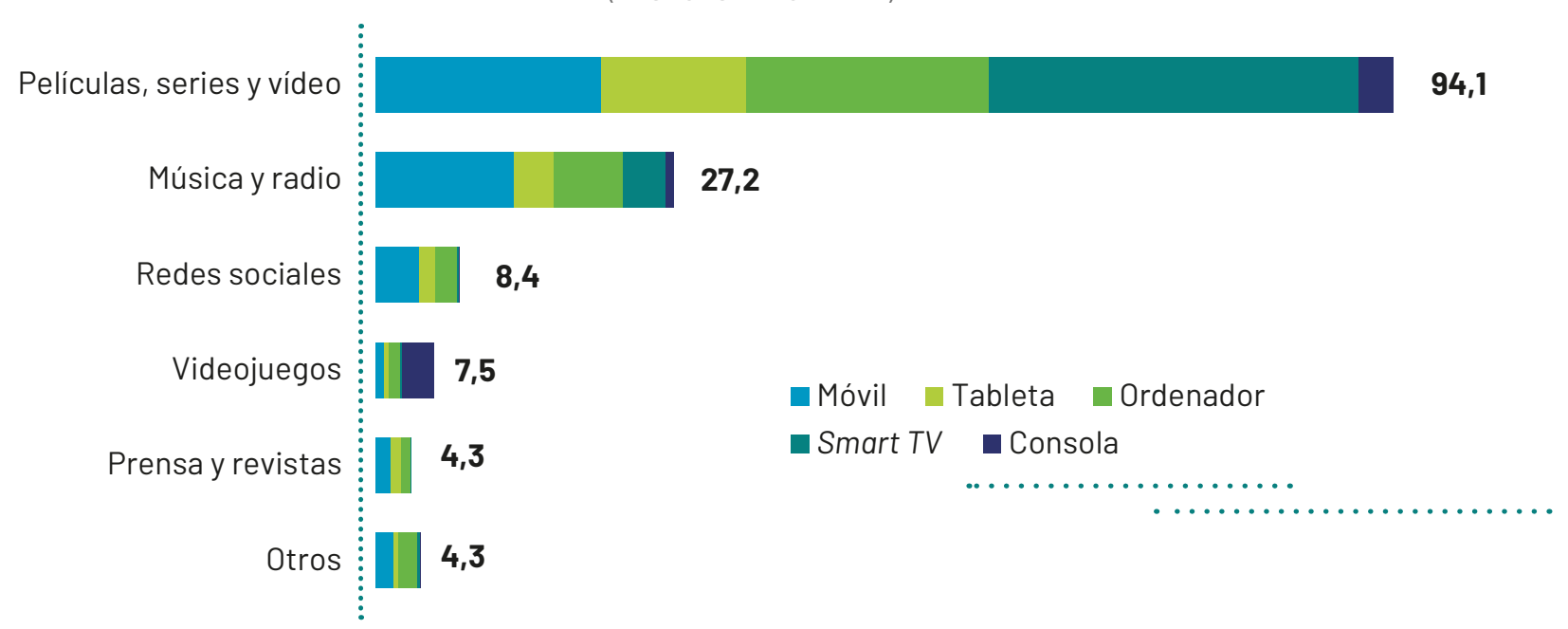


En el año 2019, los servicios o contenidos digitales más demandados son las plataformas audiovisuales en streaming, con una cantidad inmensa de usuarios, ya que el $94,1 \%$ de los internautas compradores online suscritos a servicios o contenidos digitales disfruta de servicios de alguna de estas plataformas. Detrás quedan los servicios digitales de música y radio, con un $27,2 \%$ de las suscripciones. La suscripción en redes sociales $(8,4 \%)$ y los videojuegos $(7,5 \%)$ son otros de los servicios que cuentan con seguidores entre los internautas compradores que contratan estos servicios.

En cuanto a los dispositivos más utilizados para acceder a las suscripciones y contenidos digitales, el teléfono móvil tiene una gran presencia en la mayoría de los servicios. Es el dispositivo predominante tanto para los servicios de música y radio $(46,5 \%)$ como para las redes sociales $(52,7 \%)$. En cuanto al acceso a películas, series y videos, hay un predominio claro en el uso de las smart TV (36,3\%), aunque el 23,8\% utiliza el ordenador y el 22,2\% un smartphone para consumir contenidos en streaming.

El acceso a los videojuegos se realiza principalmente a través de las consolas (54,3\%), seguido de los ordenadores $(18,7 \%)$ y los smartphones $(14,8 \%)$.

\section{El porcentaje de hombres con suscripciones de videojuegos duplica al de mujeres}

TABLA 4. 11. SUSCRIPCIONES A SERVICIOS Y CONTENIDOS DIGITALES, POR GÉNERO Y GRUPOS DE EDAD (\%)

\begin{tabular}{|c|c|c|c|c|c|c|c|c|c|}
\hline & \multirow{2}{*}{ TOTAL } & \multicolumn{2}{|c|}{ GÉNERO* } & \multicolumn{6}{|c|}{ EDAD* } \\
\hline & & Hombres & Mujeres & $\begin{array}{r}16-24 \\
\text { años }\end{array}$ & $\begin{array}{c}25-34 \\
\text { años }\end{array}$ & $\begin{array}{c}35-44 \\
\text { años }\end{array}$ & $\begin{array}{c}45-54 \\
\text { años }\end{array}$ & $\begin{array}{c}55-64 \\
\text { años } \\
\end{array}$ & $\begin{array}{l}65-74 \\
\text { años }\end{array}$ \\
\hline TOTAL & 56,8 & 56,7 & 56,8 & 68,3 & 66,6 & 60,7 & 47,2 & 47,0 & 55,0 \\
\hline Películas, series y vídeo & 94,1 & 93,7 & 94,4 & 92,6 & 96,4 & 92,6 & 95,3 & 94,6 & 92,1 \\
\hline Música y radio & 27,2 & 26,0 & 28,4 & 34,2 & 35,0 & 24,4 & 28,1 & 20,9 & 12,7 \\
\hline Redes sociales & 8,4 & 8,7 & 8,1 & 7,9 & 7,2 & 6,8 & 10,5 & 10,9 & 7,1 \\
\hline Videojuegos & 7,5 & 10,2 & 4,9 & 7,0 & 9,7 & 11,0 & 7,6 & 3,0 & 0,0 \\
\hline Prensa y revistas & 4,3 & 5,5 & 3,3 & 1,7 & 2,2 & 2,8 & 3,6 & 10,4 & 10,3 \\
\hline Otros & 4,3 & 5,2 & 3,4 & 3,9 & 3,2 & 4,2 & 5,8 & 4,0 & 4,7 \\
\hline
\end{tabular}

Base: total internautas compradores online suscritos a servicios o contenidos digitales. / Base: total internautas compradores online suscritos a servicios o contenidos digitales por categoría de género y edad. / Fuente: Encuesta online de comercio electrónico, ONTSI.

No hay grandes diferencias en cuanto a las suscripciones a servicios y contenidos digitales por género, salvo en el caso de las suscripciones a videojuegos, donde el porcentaje de hombres es del $10,2 \%$ frente al 4,9\% de mujeres.

Por otra parte, la edad marca cierta diferencia entre algunas de las preferencias de consumo: Ios más jóvenes tienden a tener más suscripciones, predominando las de música y radio, mientras que los perfiles más adultos prefieren suscribirse a redes sociales, prensa y revistas. Sin embargo, la edad no parece ser un factor diferencial para el consumo de contenidos audiovisuales en streaming: en todas las franjas de edad se supera el $90 \%$ de suscripciones a plataformas audiovisuales. 


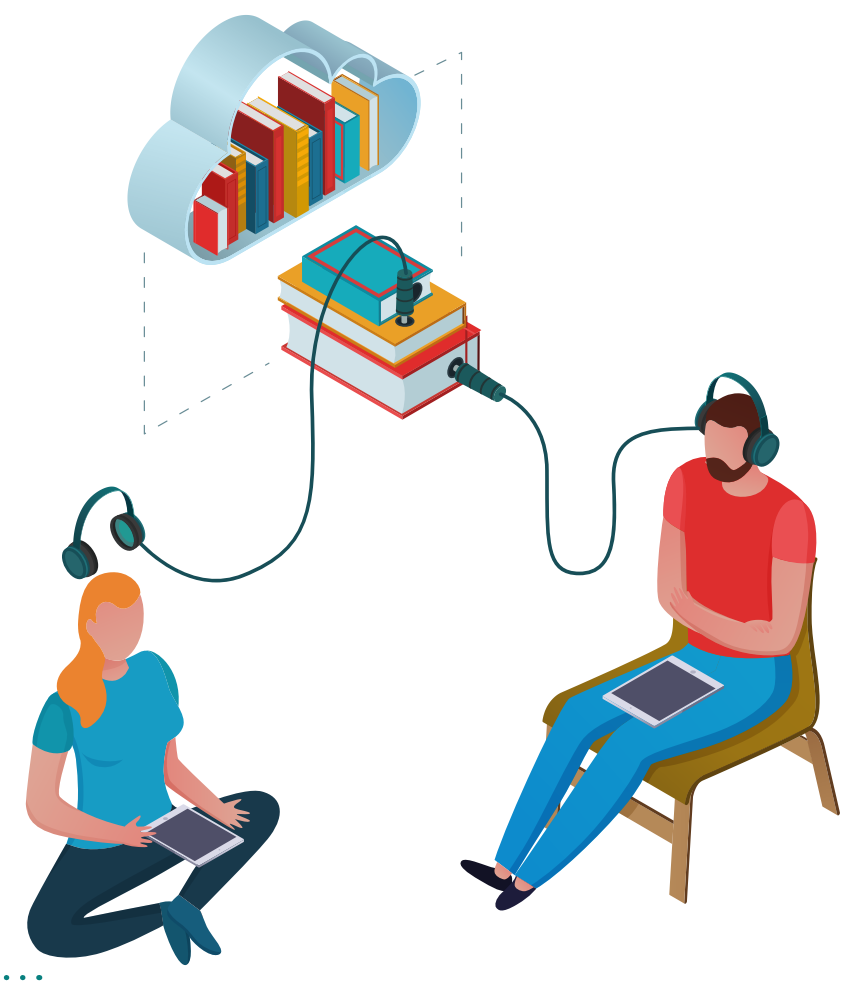

\section{6 de cada 10 internautas comparte la suscripción de contenido audiovisual en streaming con terceras personas}

FIGURA 4. 23. SERVICIOS Y CONTENIDOS DIGITALES OUE SE COMPARTEN CON TERCERAS PERSONAS (\%)

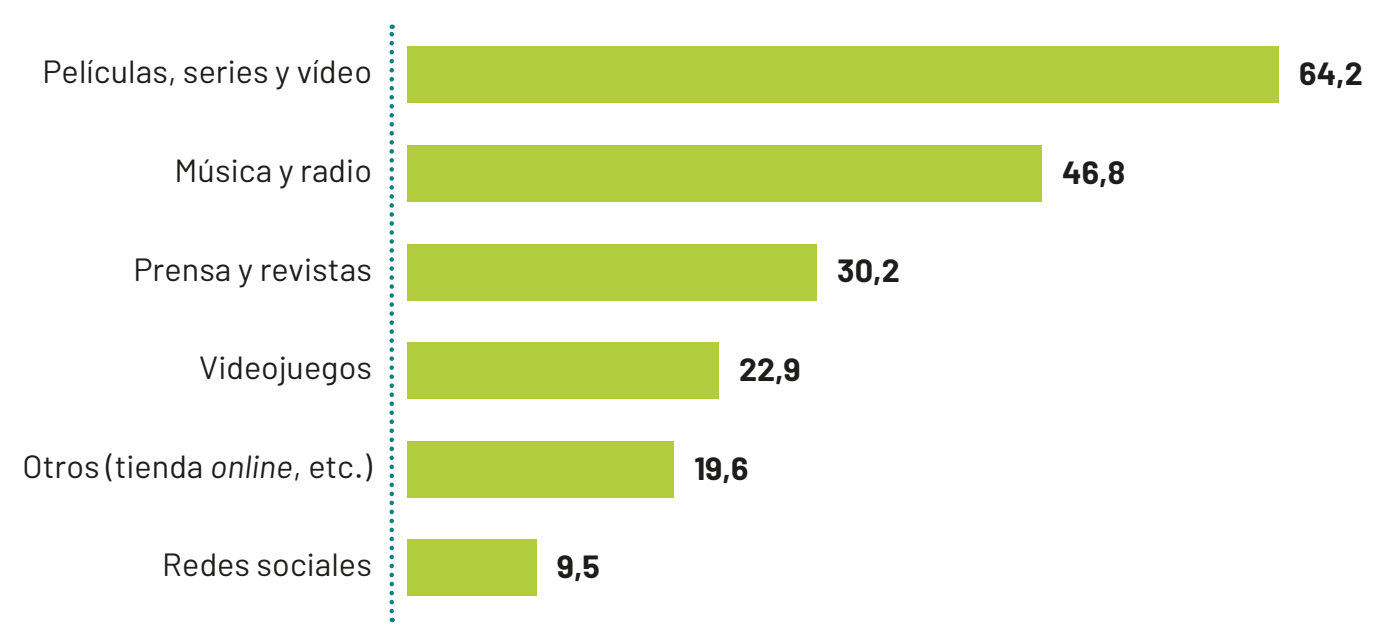

Base: total internautas compradores online suscritos a servicios o contenidos digitales. / Fuente: Encuesta online de comercio electrónico, ONTSI.

Las suscripciones a plataformas de películas, series y vídeos son mayoría y también las que más se comparten: casi dos tercios de los usuarios comparten sus cuentas con terceros. Le siguen las suscripciones de música y radio, así como las de prensa y revistas, y videojuegos. 


\section{4. \\ DISPOSITIVOS MÓVILES}

\section{Las mujeres son las que más utilizan el smartphone para realizar compras online}

FIGURA 4. 24. COMPRA DE PRODUCTOS O SERVICIOS A TRAVÉS DE INTERNET USANDO DISPOSITIVOS MÓVILES, POR GÉNERO Y GRUPOS DE EDAD (\%)

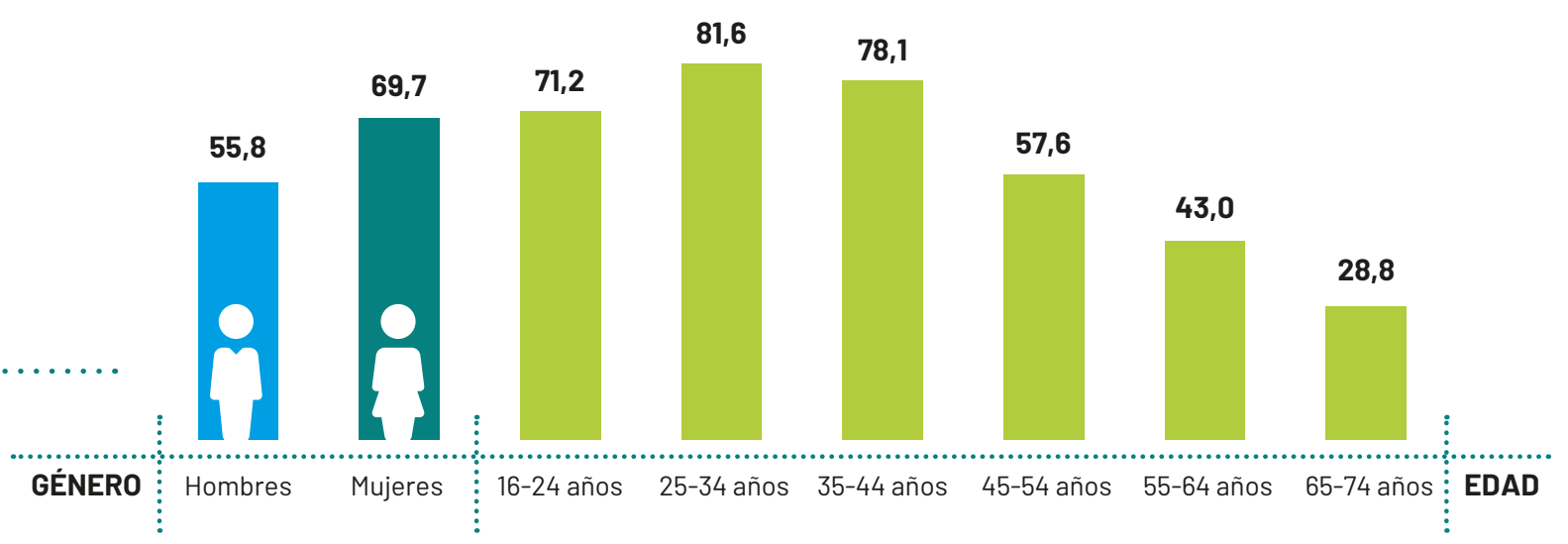

Base: total internautas compradores online por género y edad. / Fuente: Encuesta online de comercio electrónico, ONTSI.

En 2019, los smartphones mantienen el crecimiento anual y se posicionan como el dispositivo preferido para realizar compras online $(62,8 \%$ de los internautas compradores, lo que supone un incremento de 1,1 puntos porcentuales con respecto al año anterior), junto con el ordenador(72\%).

Casi el 70\% de las mujeres utiliza dispositivos móviles para comprar online, frente al 55,8\% de hombres. En cuanto a la edad, los jóvenes de entre 25 y 34 años son quienes mayor uso hacen del móvil para comprar en Internet.

\section{Cerca del $40 \%$ de los compradores online realiza casi todas sus compras a través de smartphone}

FIGURA 4. 25. ¿OUÉ PORCENTAJE REPRESENTAN LAS COMPRAS MÓVILES SOBRE EL TOTAL DE LAS COMPRAS QUE REALIZA A TRAVÉS DE INTERNET? (\%)

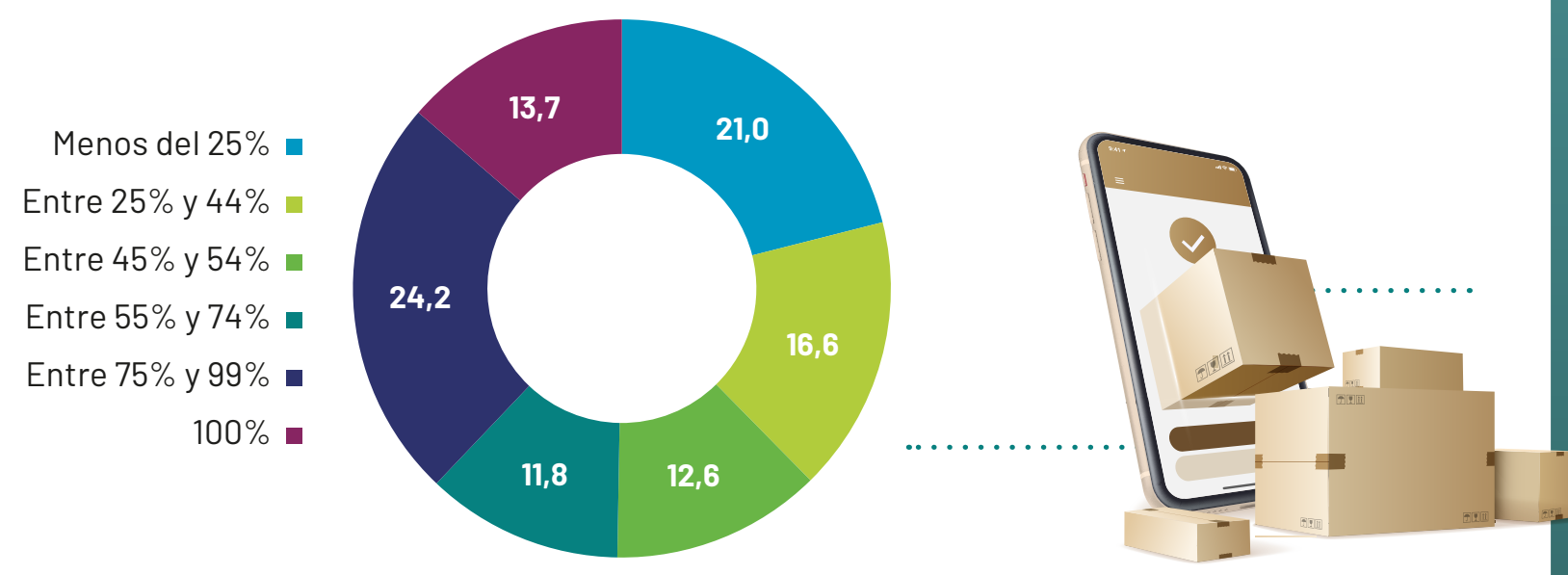


La compra online a través de smartphones se segmenta entre un 37,9\% de usuarios que lo usa para casi todas sus compras (entre el 75 y $100 \%$ ) y un $21 \%$ que lo utiliza para menos de un cuarto de sus adquisiciones. En el medio, queda un $41 \%$ que realiza entre un $25 \%$ y un $75 \%$ de sus compras con el móvil.

\section{La comodidad es la razón principal por la cual los internautas realizan sus compras a través del smartphone}

FIGURA 4. 26. ¿CUÁLES SON LAS PRINCIPALES RAZONES POR LAS QUE REALIZA COMPRAS ONLINE A TRAVÉS DE MÓVIL? (\%) (RESPUESTA MÚLTIPLE)

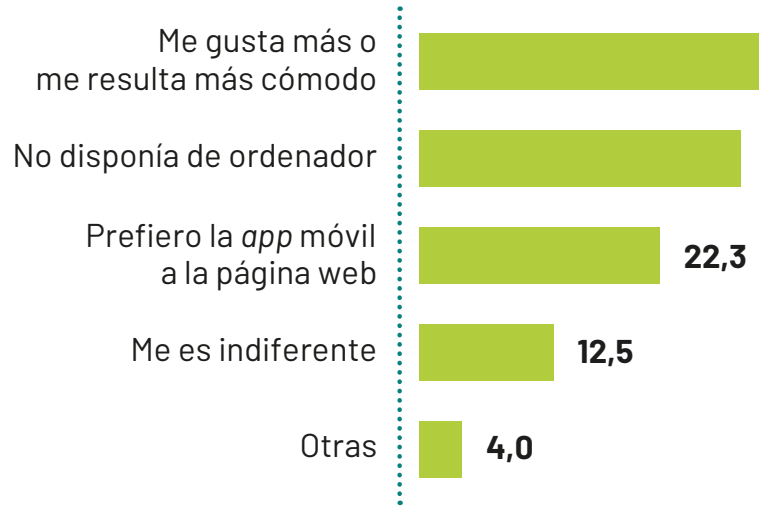

57,8

29,9

Base: compradores online que compran con teléfono móvil. / Fuente: Encuesta online de comercio electrónico, ONTSI.

«Me gusta más o me resulta más cómodo», principales factores que atraen a los internautas a utilizar sus móviles para comprar online. Por otra parte, casi un 30\% usa el smartphone porque no dispone de ordenador y dos de cada diez compradores prefieren acceder a la aplicación móvil antes que a la página web.

\section{La comodidad o la preferencia a usar más el ordenador son los factores principales para no realizar compras a través del smartphone}

FIGURA 4. 27. ¿POR OUÉ RAZONES NO REALIZA COMPRAS ONLINE A TRAVÉS DE MÓVIL O PREFIERE NO HACERLO? (\%) (RESPUESTA MÚLTIPLE)
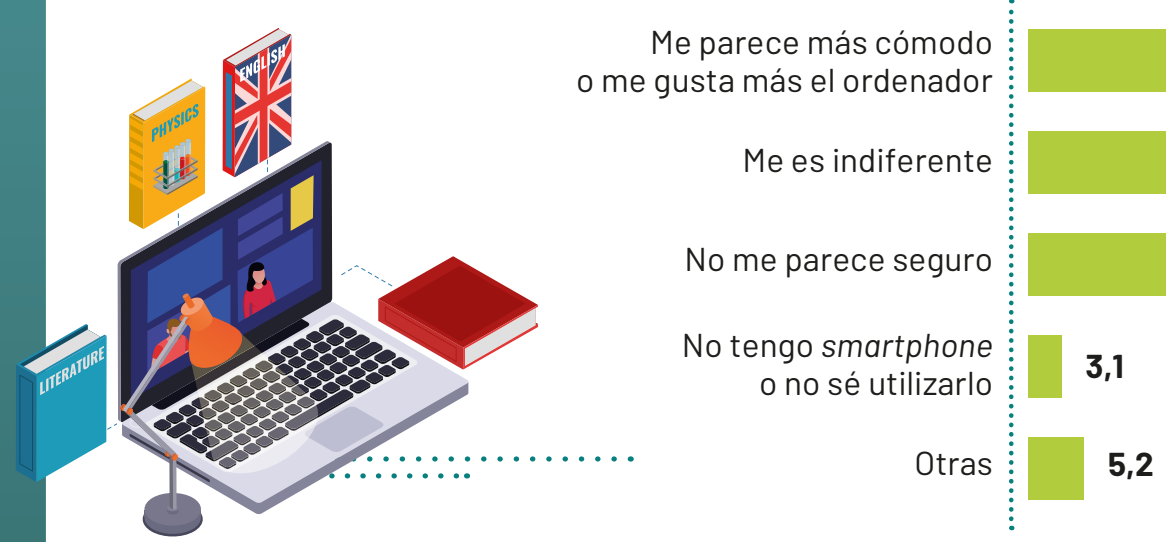

Base: compradores online que no compran con teléfono móvil. / Fuente: Encuesta online de comercio electrónico, ONTSI.

La comodidad o simple gusto por un dispositivo sobre el otro es también la principal razón por la cual se utiliza el ordenador en lugar de un smartphone. Para el 68,7\% de los compradores este factor es decisivo, mientras que el 20,5\% afirma que le resulta indiferente. 
En tercer lugar, se prioriza la seguridad: el 17,7\% afirma que no les parece seguro realizar las compras online a través de los dispositivos móviles.

\section{COMPRA DE APLICACIONES}

\section{Ligero descenso de la compra de aplicaciones móviles en 2019: solo 1 de cada 10 internautas ha adquirido al menos una}

Un 11,8\% de los internautas ha adquirido alguna aplicación de pago durante 2019, cifra que implica un descenso de 1,4 puntos porcentuales respecto al año anterior.

FIGURA 4. 28. ¿PARA OUÉ TIPO DE DISPOSITIVO ADOUIRIÓ ALGUNA APLICACIÓN DE PAGO?(\%)
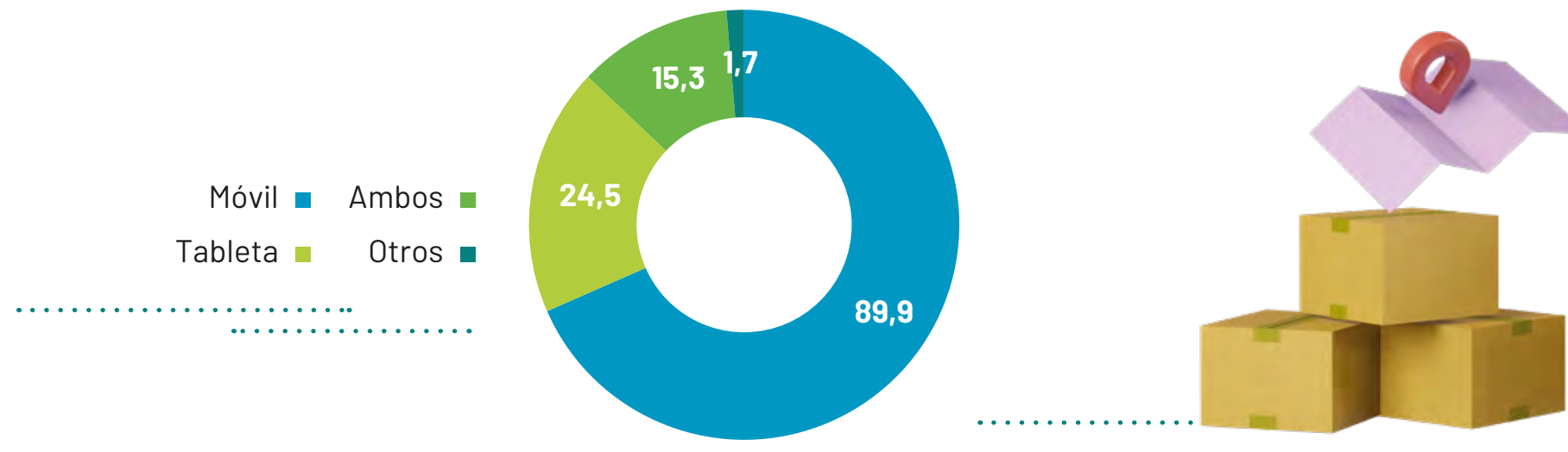

Base: internautas compradores online que adquirieron alguna aplicación de pago. / Fuente: Encuesta online de comercio electrónico, ONTSI.

La gran mayoría(el 89,9\%) de los internautas que adquieren una aplicación de pago, la compra para el smartphone, mientras que un 24,5\% la destina para la tableta. Por otra parte, los internautas que compran aplicaciones para ambos dispositivos representan el 15,3\%.

\section{Hombre y menor de 35 años, el perfil de consumidor de aplicaciones móviles de pago}

TABLA 4. 12. APLICACIONES ADOUIRIDAS SEGÚN DISPOSITIVOS, POR GÉNERO Y GRUPOS DE EDAD (\%)

\begin{tabular}{|c|c|c|c|c|c|c|c|c|c|}
\hline & \multirow{2}{*}{ TOTAL } & \multicolumn{2}{|c|}{ GÉNERO* } & \multicolumn{6}{|c|}{ EDAD* } \\
\hline & & Hombres & Mujeres & $\begin{array}{c}16-24 \\
\text { años }\end{array}$ & $\begin{array}{c}25-34 \\
\text { años }\end{array}$ & $\begin{array}{c}35-44 \\
\text { años }\end{array}$ & $\begin{array}{c}45-54 \\
\text { años }\end{array}$ & $\begin{array}{c}55-64 \\
\text { años }\end{array}$ & $\begin{array}{l}65-74 \\
\text { años }\end{array}$ \\
\hline TOTAL & 11,8 & 14,0 & 9,6 & 13,5 & 15,9 & 13,6 & 9,9 & 9,3 & 6,9 \\
\hline Aplicaciones para smartphone & 10,6 & 12,8 & 8,4 & 12,9 & 15,2 & 11,4 & 8,7 & 8,1 & 6,4 \\
\hline Aplicaciones para tableta & 2,9 & 3,3 & 2,5 & 1,8 & 3,0 & 4,2 & 2,4 & 2,6 & 2,5 \\
\hline $\begin{array}{r}\text { Aplicaciones para ambos } \\
\text { dispositivos }\end{array}$ & 1,8 & 2,4 & 1,2 & 1,1 & 2,3 & 2,1 & 1,2 & 2,0 & 2,2 \\
\hline $\begin{array}{r}\text { Aplicaciones para otrotipo de } \\
\text { dispositivos }\end{array}$ & 0,2 & 0,3 & 0,1 & 0,3 & 0,0 & 0,2 & 0,1 & 0,6 & 0,0 \\
\hline
\end{tabular}

Base: total internautas compradores online. /*Base: internautas compradores online por género y edad. / Fuente: Encuesta online de comercio electrónico, ONTSI.

En la compra de aplicaciones se advierte una diferencia en el porcentaje de hombres y mujeres de casi 5 p.p. entre quienes compran a través del móvil. Un 14\% de los hombres que hacen compras con su smartphone opta por adquirir aplicaciones, frente al 9,6\% de las mujeres. A su vez, se comprueba que hay mayor propensión a la compra de aplicaciones entre la población joven. 


\section{Las aplicaciones de pago de juegos y entretenimiento son las más compradas por los internautas}

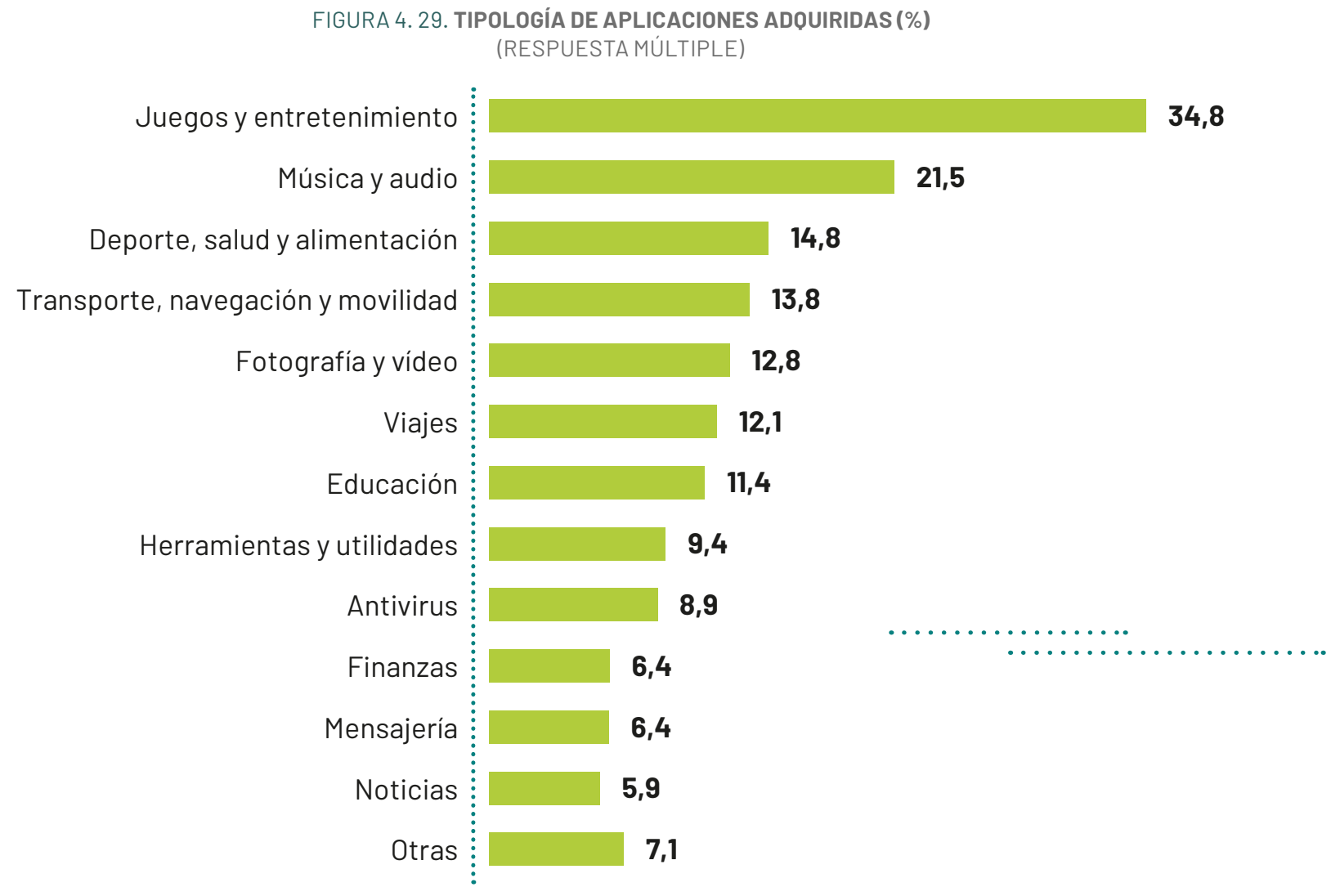

Base: internautas compradores online que adquirieron alguna aplicación de pago. / Fuente: Encuesta online de comercio electrónico, ONTSI.

En cuanto a la tipología de aplicaciones de pago, el 34,8\% compra juegos y aplicaciones de entretenimiento, seguida por las de música y audio (21,5\%).

Otras aplicaciones de pago que cabe destacar son las de deporte, salud y alimentación (14,8\%), transporte, navegación y movilidad (13,8\%), fotografía y vídeo (12,8\%) o las de viajes $(12,1 \%)$.

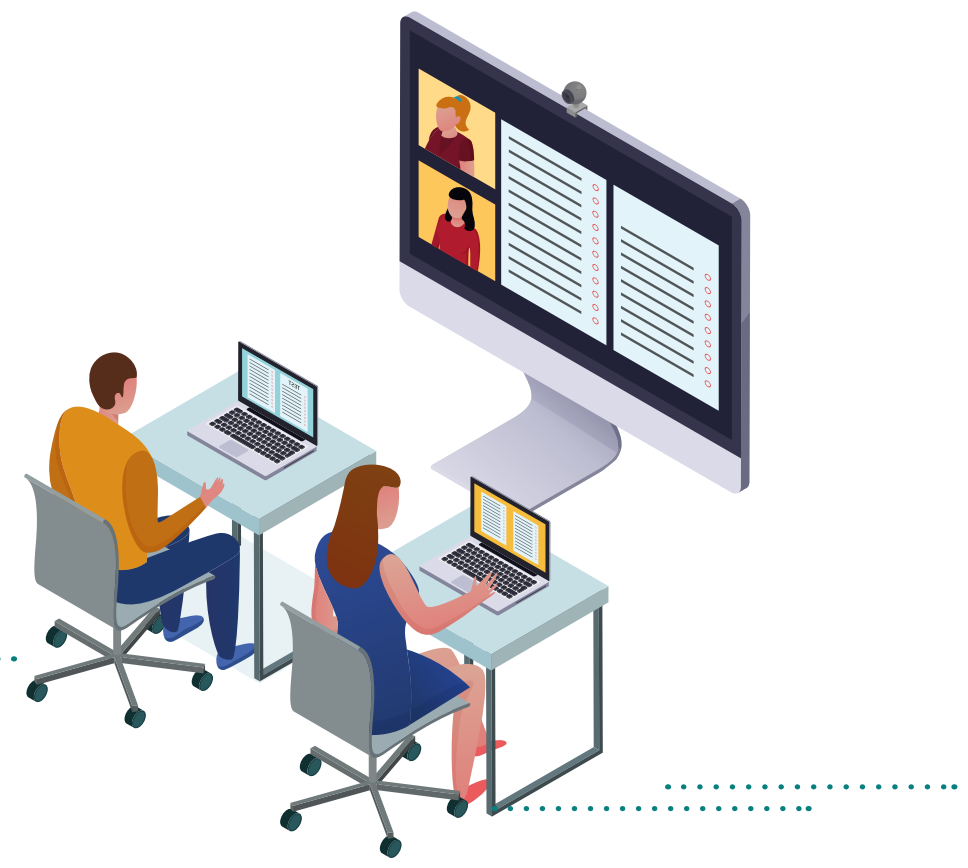




\section{5. \\ GASTO \\ El gasto medio anual de los internautas en 2019 se sitúa en 2.076 euros}

FIGURA 4. 30. ¿CUÁL FUE EL GASTO TOTAL APROXIMADO EN SUS COMPRAS POR INTERNET EN 2019? (2017-2019)(\%)

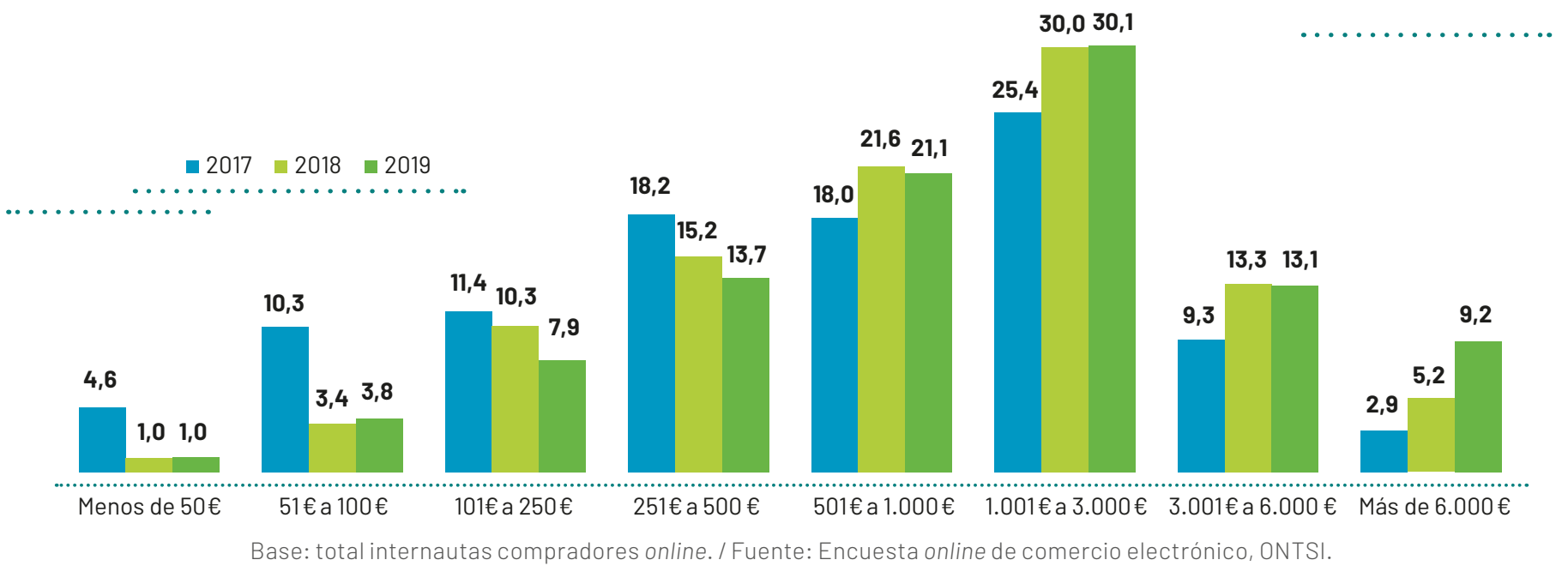

A lo largo de 2019 los internautas han gastado una media de $2.076 €$, lo que supone un incremento de un $8,1 \%$ respecto a 2018. Al igual que en años anteriores, se observa que el gasto en compras online oscila principalmente entre los $1.001 €$ y los $3.000 €$, seguido de un gasto medio mayor a $500 €$ pero menor o igual a $1.000 €$. Los internautas con un gasto inferior a $50 €$ anuales representan apenas el 1\%. Los compradores que gastan más de 6.000 euros al año en Internet, prácticamente se han duplicado desde 2018 y triplican la cifra de 2017.

\section{El gasto medio anual de las mujeres y hombres tiende a igualarse}

FIGURA 4. 31. EVOLUCIÓN DEL GASTO MEDIO ANUAL EN COMPRAS ONLINE, POR GÉNERO (2009-2019)(€)

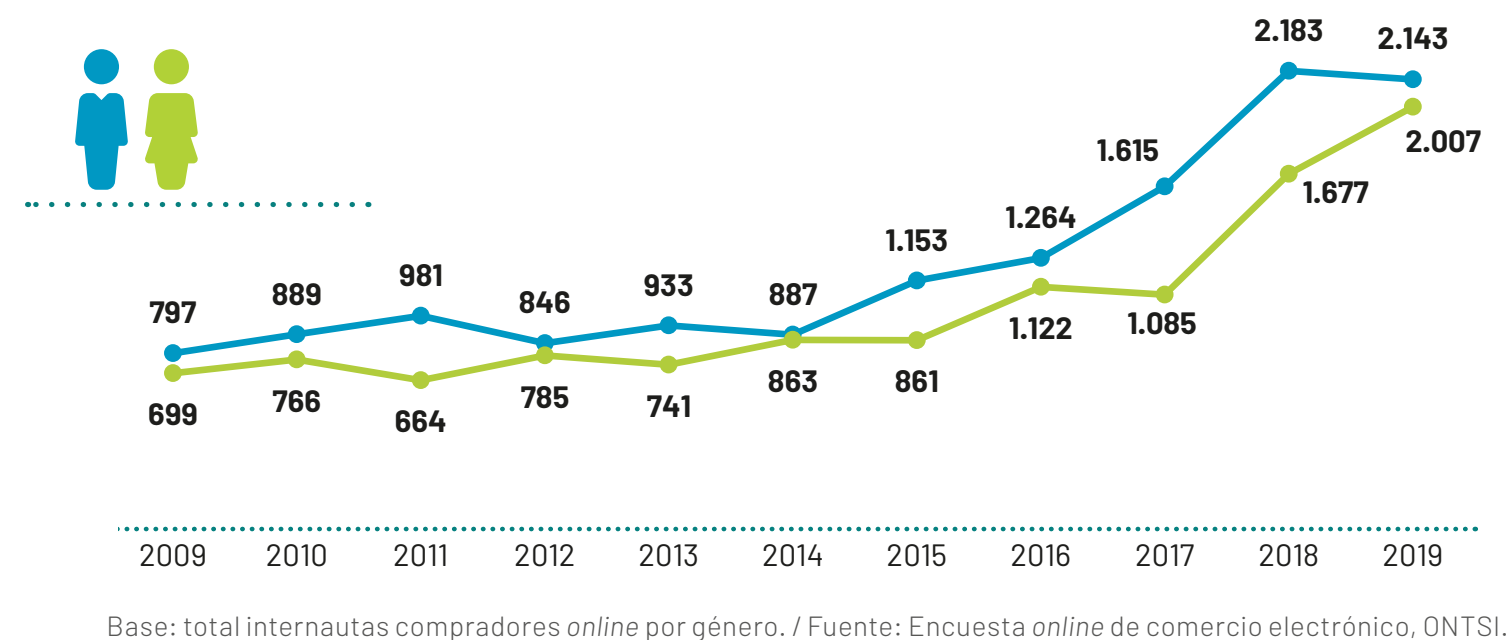

Base: total internautas compradores online por género. / Fuente: Encuesta online de comercio electrónico, ONTSI. 
A pesar de que los hombres han gastado de media más que las mujeres durante 2019 (2.143 € frente a $2.007 €$ ), se observa un incremento sostenido desde 2017 del gasto medio en las compras online de las mujeres. El gasto medio de los hombres, en cambio, experimenta una leve reducción en comparación a 2018, el primer descenso desde 2014.

\section{El perfil de consumidor online que más gasta se sitúa entre los 35 y 44 años}

TABLA 4. 13. ¿CUÁL FUE EL GASTO TOTAL APROXIMADO EN SUS COMPRAS POR INTERNET EN 2019? (2017-2019)(\%)

\begin{tabular}{|c|c|c|c|c|c|c|c|}
\hline & \multirow{2}{*}{ TOTAL } & \multicolumn{6}{|c|}{ EDAD } \\
\hline & & $16-24$ años & $25-34$ años & 35-44 años & 45-54 años & 55-64 años & 65-74 años \\
\hline Gasto medio 2018 (€) & 1.920 & 1.937 & 2.096 & 2.288 & 1.765 & 1.745 & 1.628 \\
\hline Gasto medio 2019(€) & 2.076 & 1.491 & 2.267 & 2.423 & 2.071 & 1.808 & 2.152 \\
\hline Incremento (\%) & 8,1 & $-23,0$ & 8,1 & 5,9 & 17,3 & 3,6 & 32,2 \\
\hline
\end{tabular}

Base: total internautas compradores online por edad. / Fuente: Encuesta online de comercio electrónico, ONTSI.

En cuanto a la edad, se observa que los internautas de 35 a 44 años son los que más gastan de media al año en Internet (2.423 €). Les siguen los usuarios de entre 25 y 34 años, con un gasto medio de $2.267 €$ y el grupo de los mayores de 65 años, con $2.152 €$ gastados durante 2019 .

En relación con años anteriores, se observa un incremento del gasto medio anual en todas las franjas de edad, con excepción de los más jóvenes, donde se reduce un 23\% con respecto al 2018. El mayor incremento se observa entre los mayores de 65 años, donde el gasto medio aumenta un $32,2 \%$ frente a 2018.

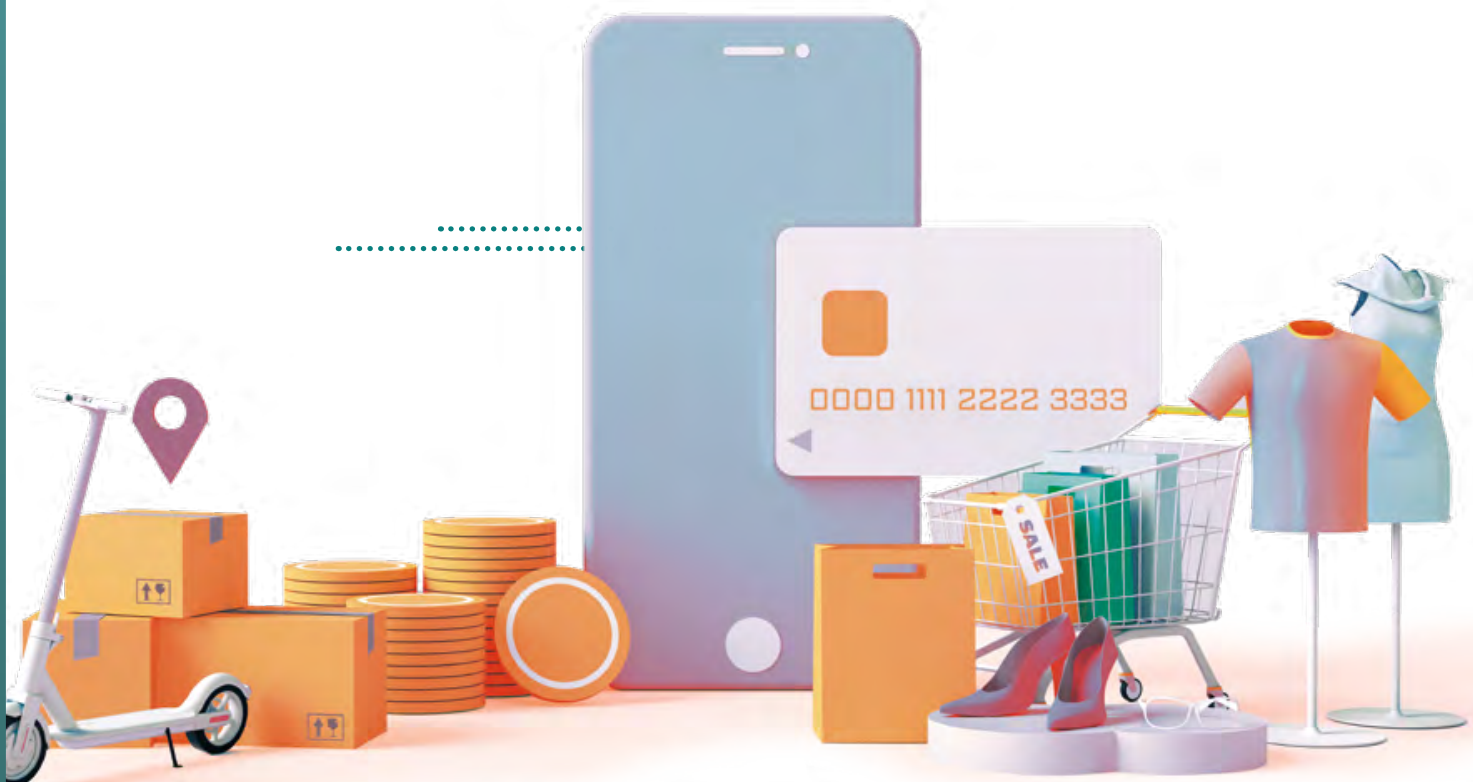




\section{Turismo y transporte son las categorias donde más se gasta en las compras online}

TABLA 4. 14. RESUMEN DEL GASTO EN COMERCIO ELECTRÓNICO Y OTROS INDICADORES

Ropa, calzado y complementos

Reserva de alojamiento y paquetes turísticos Entradas para espectáculos y eventos (cine, teatro, arte, deportes, ferias, etc.)

Billetes de transporte (avión, tren, autobús, barco, taxi, metro, etc.)

Comida a domicilio de restaurantes

Ocio, restaurantes, servicios personales y experiencias Salud y cuidado personal (cosmética, perfumería, farmacia, etc.)

Electrodomésticos, muebles, hogar, bricolaje y jardín

Teléfonos móviles, smartphones y accesorios relacionados Deporte y fitness (ropa deportiva, accesorios y otros productos)

Alimentación, bebidas y productos de limpieza del hogar

Ordenadores, tabletas, accesorios y otros productos de electrónica (sonido, fotografía y vídeo)

Juguetes y juegos de mesa

Libros, cómics, revistas y periódicos en formato físico

Servicios de Internet y telefonía (conexión a Internet, alojamiento web, tarifas y recarga móviles, etc.)

Descarga o servicio online de películas, música y videojuegos Material de oficina, papelería e imprenta

Mascotas (comida, higiene, complementos, animales, etc.)

Formación y cursos online

Libros, cómics, revistas y periódicos en formato electrónico (incluyendo descarga y suscripción) Joyería, bisutería y relojes

Películas, música y videojuegos para recibirlos en formato físico Servicios financieros y seguros

Programas, software y aplicaciones para móvil o tableta Juegos de azar, concursos, apuestas y lotería Vehículos de motor (alquiler y compra de vehículos, repuestos y accesorios, y vehículos eléctricos)

Artículos de coleccionismo y antigüedades

Contenido de pago en redes sociales, profesionales y de citas

Otros

\begin{tabular}{|c|r|r|r|r|r|}
\hline $\begin{array}{c}\% \\
\text { compradores compradores }\end{array}$ & $\begin{array}{c}\text { Gasto } \\
\text { medio } \\
(€)\end{array}$ & $\begin{array}{c}\text { № } \\
\text { medio } \\
\text { compras }\end{array}$ & $\begin{array}{c}\text { Gasto } \\
\text { total } \\
\text { (Mill. } € \text { ) }\end{array}$ & $\begin{array}{c}\% \text { sobre } \\
\text { gasto } \\
\text { total }\end{array}$ \\
\hline 59,2 & 14.364 .099 & 254 & 5,9 & 3.644 & 7,2 \\
\hline 52,1 & 12.646 .006 & 753 & 3,4 & 9.524 & 18,9 \\
\hline 49,0 & 11.892 .427 & 150 & 5,0 & 1.786 & 3,5 \\
\hline 45,3 & 10.995 .418 & 552 & 4,6 & 6.069 & 12,0 \\
\hline 38,5 & 9.332 .617 & 203 & 10,4 & 1.896 & 3,8 \\
\hline 33,6 & 8.152 .996 & 279 & 5,3 & 2.277 & 4,5 \\
\hline 32,4 & 7.873 .037 & 169 & 4,8 & 1.328 & 2,6 \\
\hline 30,5 & 7.393 .735 & 511 & 3,1 & 3.779 & 7,5 \\
\hline 30,3 & 7.361 .930 & 380 & 2,3 & 2.795 & 5,5 \\
\hline 24,6 & 5.967 .177 & 167 & 4,0 & 997 & 2,0 \\
\hline 23,7 & 5.753 .218 & 647 & 9,2 & 3.720 & 7,4 \\
\hline 22,6 & 5.477 .793 & 472 & 2,6 & 2.584 & 5,1 \\
\hline 22,2 & 5.389 .242 & 137 & 4,0 & 738 & 1,5 \\
\hline 20,4 & 4.947 .679 & 99 & 4,5 & 488 & 1,0 \\
\hline 19,7 & 4.769 .716 & 264 & 3,2 & 1.258 & 2,5 \\
\hline 18,5 & 4.479 .141 & 98 & 5,8 & 440 & 0,9 \\
\hline 17,7 & 4.306 .341 & 107 & 3,7 & 461 & 0,9 \\
\hline 16,2 & 3.940 .767 & 237 & 5,7 & 933 & 1,9 \\
\hline 15,0 & 3.640 .973 & 348 & 2,7 & 1.266 & 2,5 \\
\hline 14,3 & 3.480 .276 & 129 & 4,5 & 450 & 0,9 \\
\hline 13,6 & 3.309 .284 & 137 & 3,2 & 455 & 0,9 \\
\hline 12,1 & 2.945 .284 & 159 & 4,5 & 468 & 0,9 \\
\hline 12,1 & 2.928 .170 & 1.726 & 3,6 & 5.054 & \\
\hline 11,1 & 2.704 .042 & 114 & 3,9 & 308 & 0,6 \\
\hline 9,8 & 2.373 .033 & 187 & 13,2 & 443 & 0,9 \\
\hline 6,7 & 1.617 .986 & 1.075 & 3,7 & 1.739 & 3,5 \\
\hline 4,9 & 1.192 .468 & 250 & 5,0 & 298 & 0,6 \\
\hline 2,6 & 641.065 & 125 & 3,5 & 80 & 0,2 \\
\hline 1,4 & 342.221 & 463 & 8,3 & 158 & 0,3 \\
\hline & & & & & \\
\hline
\end{tabular}

Base: total internautas compradores online. / Fuente: Encuesta online de comercio electrónico, ONTSI. / *Se excluyen del cálculo los gastos en servicios financieros.

De los 50.382 millones de euros de gasto total de comercio electrónico B2C en 2019, la reserva de alojamientos y paquetes turísticos y los billetes de transporte, acumulan los mayores porcentajes de gasto total: $18,9 \%$ y $12 \%$, respectivamente.

Otras categorías con un peso importante dentro del gasto total son las destinadas al hogar: electrodomésticos, muebles, hogar, bricolaje y jardín (7,5\%), así como alimentación, bebidas y productos de limpieza del hogar (7,4\%), se llevan alrededor del 15\% del gasto total. Ropa, calzado y complementos, con un 7,2\% del gasto total, completa el Top 5 de categorías de productos en los que más se ha gastado en el canal online.

Cabe destacar que los servicios financieros y de seguros alcanzan un volumen de negocio algo superior a los 5.000 millones de euros. Sin embargo, esta partida no se incluye en el cálculo del montante total del B2C por su carácter no estrictamente comercial. 


\section{6. \\ FRECUENCIA DE COMPRA}

Los internautas han efectuado una media de 30 compras online en el año 2019, siendo los jóvenes, aquellos con estudios superiores, los que trabajan y las personas con ingresos por encima de $2.500 €$ mensuales quienes compran online con mayor frecuencia

TABLA 4. 15. № MEDIO DE ACTOS DE COMPRA, POR VARIABLES SOCIODEMOGRÁFICAS

\begin{tabular}{|c|c|c|c|}
\hline & & № COMPRAS AL MES & № COMPRAS AL AÑO \\
\hline \multicolumn{2}{|l|}{ TOTAL } & 2,5 & 29,5 \\
\hline \multirow{2}{*}{ GÉNERO } & Hombres & 2,4 & 29,2 \\
\hline & Mujeres & 2,5 & 29,9 \\
\hline \multirow{6}{*}{ EDAD } & 16-24 años & 2,4 & 28,9 \\
\hline & 25-34 años & 3,1 & 36,7 \\
\hline & 35-44 años & 2,9 & 35,2 \\
\hline & 45-54 años & 2,3 & 28,0 \\
\hline & 55-64 años & 1,9 & 22,4 \\
\hline & 65-74 años & 1,7 & 20,6 \\
\hline \multirow{6}{*}{$\begin{array}{l}\text { NIVEL DE } \\
\text { ESTUDIOS }\end{array}$} & Sin estudios & 1,1 & 12,9 \\
\hline & Primaria & 1,7 & 20,6 \\
\hline & Secundaria(ESO) & 2,0 & 23,6 \\
\hline & Secundaria (Bachillerato) & 2,1 & 25,2 \\
\hline & Formación profesional & 2,2 & 26,3 \\
\hline & Estudios superiores & 2,8 & 33,4 \\
\hline \multirow{5}{*}{$\begin{array}{l}\text { NIVEL DE } \\
\text { INGRESOS EN } \\
\text { EL HOGAR }\end{array}$} & Menos de 900 euros & 1,9 & 23,0 \\
\hline & Entre 900 y 1.599 euros & 2,1 & 24,8 \\
\hline & Entre 1.600 y 2.499 euros & 2,3 & 27,7 \\
\hline & Entre 2.500 y 2.999 euros & 3,0 & 35,8 \\
\hline & 3.000 euros o más & 3,3 & 39,5 \\
\hline \multirow{6}{*}{ OCUPACIÓN } & Estudiante & 2,3 & 27,5 \\
\hline & Ocupado/a por cuenta ajena & 2,7 & 32,7 \\
\hline & Ocupado/a por cuenta propia & 2,8 & 33,6 \\
\hline & Labores del hogar & 2,2 & 26,2 \\
\hline & Parado/a & 2,1 & 24,7 \\
\hline & Jubilado/a & 1,8 & 21,2 \\
\hline
\end{tabular}

Base: total internautas compradores online. / Fuente: Encuesta online de comercio electrónico, ONTSI.

Los internautas han llevado a cabo una media de 29,5 actos de compra online en el año 2019, lo que significa aproximadamente 2,5 compras online al mes de media.

De forma general, no se aprecian diferencias significativas en cuanto a la frecuencia de compra entre hombres y mujeres, pero sí se identifica una mayor frecuencia de compra entre los jóvenes.

Por otra parte, los internautas con estudios superiores son compradores frecuentes, aunque también hay una fuerte intensidad de compra entre la población con formación profesional o estudios secundarios.

Con relación al nivel de ingresos, se aprecia que, a mayor nivel adquisitivo, mayor frecuencia de compras se realizan. Algo similar ocurre en lo que a ocupación se refiere: queda claro que los internautas que con mayor frecuencia compran son los ocupados por cuenta propia y ajena. De todos ellos, los autónomos registran la media más alta de consumo online. 


\section{Las compras online más frecuentes son las vinculadas a los juegos de azar, concursos, apuestas y loterías}

TABLA 4. 16. № MEDIO DE ACTOS DE COMPRA ANUALES, POR CATEGORÍA DE COMPRA

\begin{tabular}{|c|c|}
\hline & $\begin{array}{c}\text { NNo MEDIO } \\
\text { DE COMPRAS }\end{array}$ \\
\hline Juegos de azar, concursos, apuestas y lotería & 13,2 \\
\hline Comida a domicilio de restaurantes & 10,4 \\
\hline Alimentación, bebidas y productos de limpieza del hogar & 9,2 \\
\hline Ropa, calzado y complementos & 5,9 \\
\hline Descarga o servicio online de películas, música y videojuegos & 5,8 \\
\hline Mascotas (comida, higiene, complementos, animales, etc.) & 5,7 \\
\hline Ocio, restaurantes, servicios personales y experiencias & 5,3 \\
\hline Entradas para espectáculos y eventos (cine, teatro, arte, deportes, ferias, etc.) & 5,0 \\
\hline Artículos de coleccionismo y antigüedades & 5,0 \\
\hline Salud y cuidado personal (cosmética, perfumería, farmacia, etc.) & 4,8 \\
\hline Billetes de transporte (avión, tren, autobús, barco, taxi, metro, etc.) & 4,6 \\
\hline as y periódicos en formato electrónico (incluyendo descarga y suscripción) & 4,5 \\
\hline Libros, cómics, revistas y periódicos en formato físico & 4,5 \\
\hline Películas, música y videojuegos para recibirlos en formato físico & 4,5 \\
\hline Juguetes y juegos de mesa & 4,0 \\
\hline Deporte y fitness (ropa deportiva, accesorios y otros productos) & 4,0 \\
\hline Programas, software y aplicaciones para móvil o tableta & 3,9 \\
\hline Material de oficina, papelería e imprenta & 3,7 \\
\hline quiler y compra de vehículos, repuestos y accesorios y vehiculos eléctricos) & 3,7 \\
\hline Servicios financieros y seguros & 3,6 \\
\hline Contenido de pago en redes sociales, profesionales y de citas & 3,5 \\
\hline Reserva de alojamiento y paquetes turísticos & 3,4 \\
\hline rnet y telefonía (conexión, alojamiento web, tarifas y recarga móviles, etc.) & 3,2 \\
\hline Joyería, bisutería y relojes & 3,2 \\
\hline Electrodomésticos, muebles, hogar, bricolaje y jardín & 3,1 \\
\hline 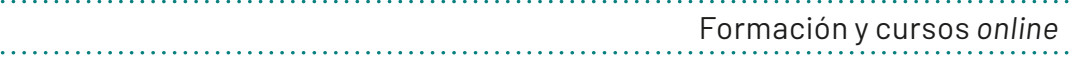 & 2,7 \\
\hline$a s, a c c e s o r i o s$ y & 2,6 \\
\hline Teléfonos móviles, smartphones y accesorios relacionados & 2,3 \\
\hline Otros & 8,3 \\
\hline
\end{tabular}

Base: total internautas compradores online. / Fuente: Encuesta online de comercio electrónico, ONTSI.

Los juegos de azar, concursos, apuestas y loterías, constituyen la categoría de productos con la mayor frecuencia de compra, 13,2 compras anuales. A continuación se sitúan los pedidos de comida a domicilio (10,4 compras anuales de media) y la compra de alimentación, bebidas y productos de limpieza del hogar (9,2 compras).

La media de compras anuales cae a 5 en materia de ropa, calzado y complementos; descargas o servicios online de películas, música y videojuegos; compras relacionadas con las mascotas (comida, higiene, complementos, animales, etc.) y el ocio, restaurantes, servicios personales y experiencias.

Las categorías de productos adquiridos con menor frecuencia corresponden a la formación, la electrónica y la telefonía móvil. 


\section{7. \\ COMERCIO ELECTRÓNICO ENTRE PARTICULARES C2C \\ Casi el $70 \%$ de los internautas utiliza las herramientas online de compraventa entre particulares}

Más allá de la compra que efectúan los particulares en tiendas online (business to client, B2C), también es interesante conocer en qué medida se utilizan las plataformas por Internet para la compraventa entre particulares, el denominado comercio electrónico entre particulares (client to client, C2C). Algunos ejemplos de este tipo de plataformas son Wallapop o Vinted.

El 69,4\% de los internautas ha hecho uso de este tipo de herramientas de compraventa online C2C durante 2019.

FIGURA 4. 32. ¿HACE USO DE ALGUNA HERRAMIENTA DE COMPRAVENTA ONLINE ENTRE PARTICULARES? POR PERFIL DE COMPRA ONLINE(\%)

\section{4,1}

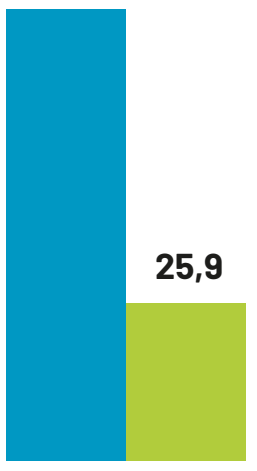

\section{5,2}

Compradores

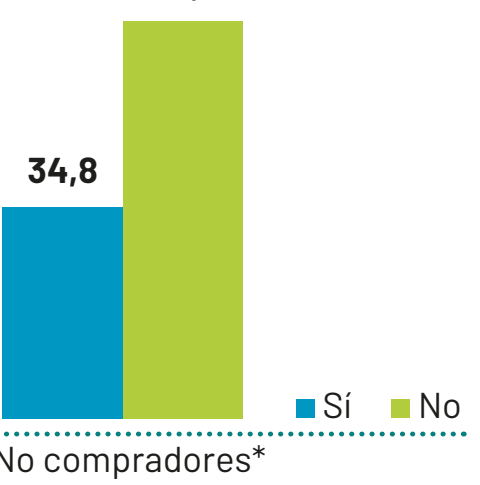

Base: total internautas compradores. / Base: total internautas no compradores. / Fuente: Encuesta online de comercio electrónico, ONTSI.

El uso de estas herramientas C2C es más habitual entre los usuarios que compran a través de Internet. De hecho, el 74,1\% de los compradores online las utilizan, frente al 34,8\% de los internautas no compradores.

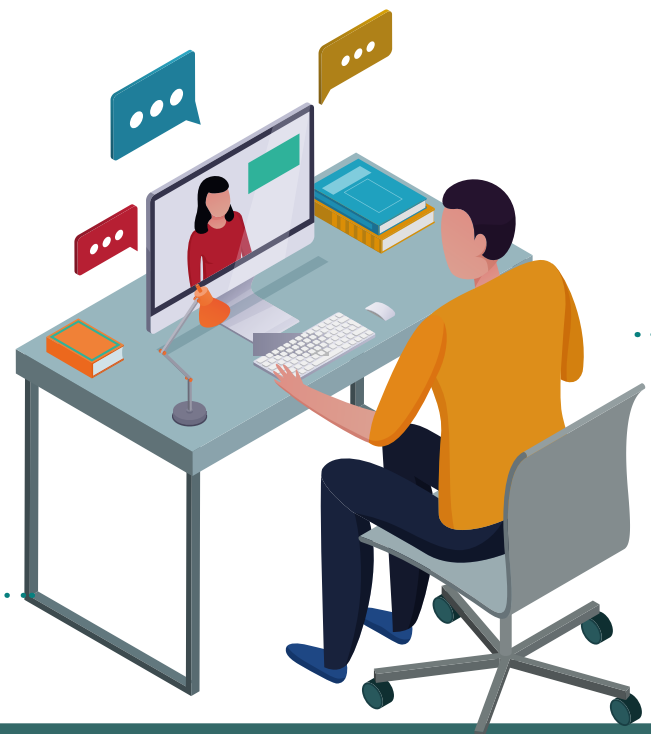




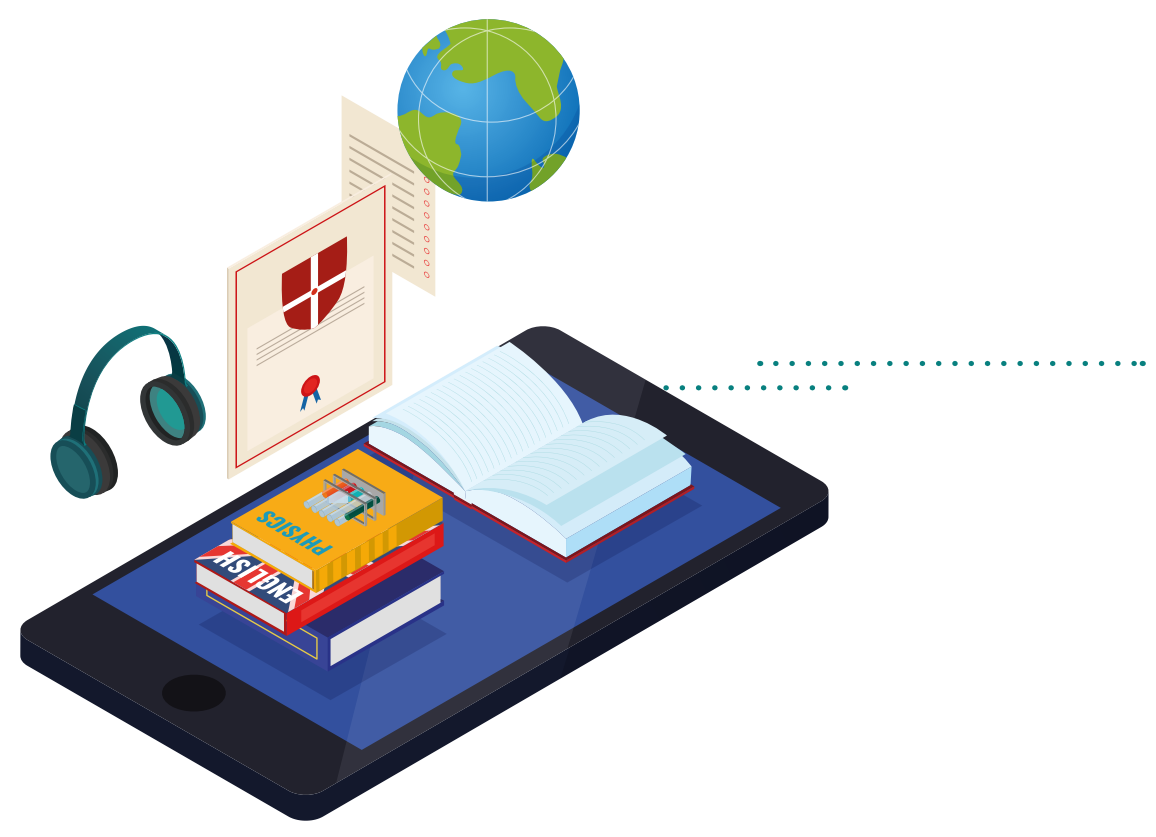

\section{Es más barato, es cómodo y permite vender artículos que ya no se usan: los tres factores clave del C2C}

FIGURA 4. 33. ¿POR QUÉ MOTIVOS USA HERRAMIENTAS DE COMPRAVENTA ONLINE ENTRE PARTICULARES? (\%) (RESPUESTA MÚLTIPLE)

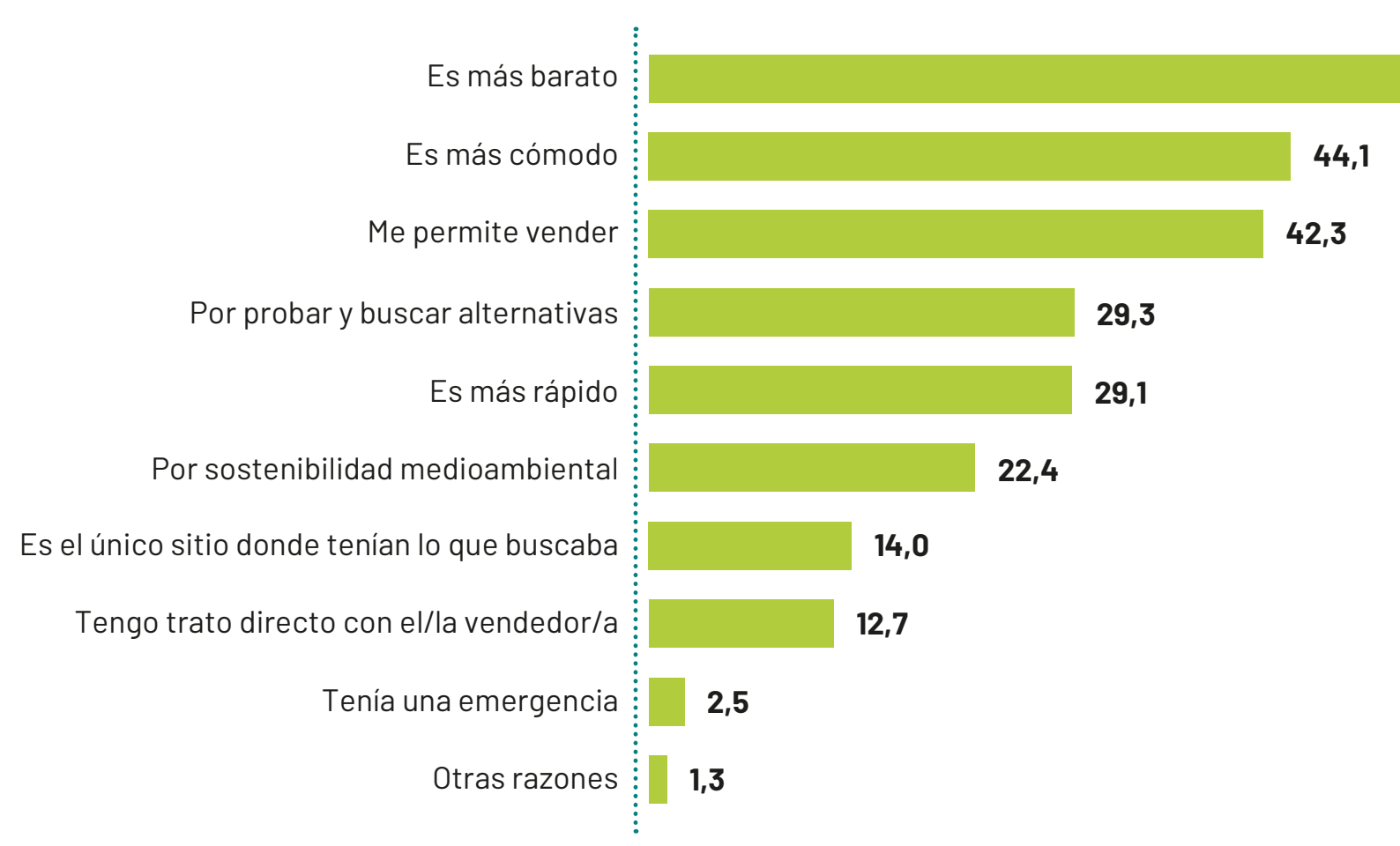

Los internautas señalan que las razones principales por las que utilizan herramientas de compraventa online C2C son el precio (52\%), la comodidad $(44,1 \%)$ y la posibilidad de poder vender productos $(42,3 \%)$. Otras opciones se vinculan a la curiosidad y a probar alternativas, así como la rapidez que ofrece este tipo de plataformas. 

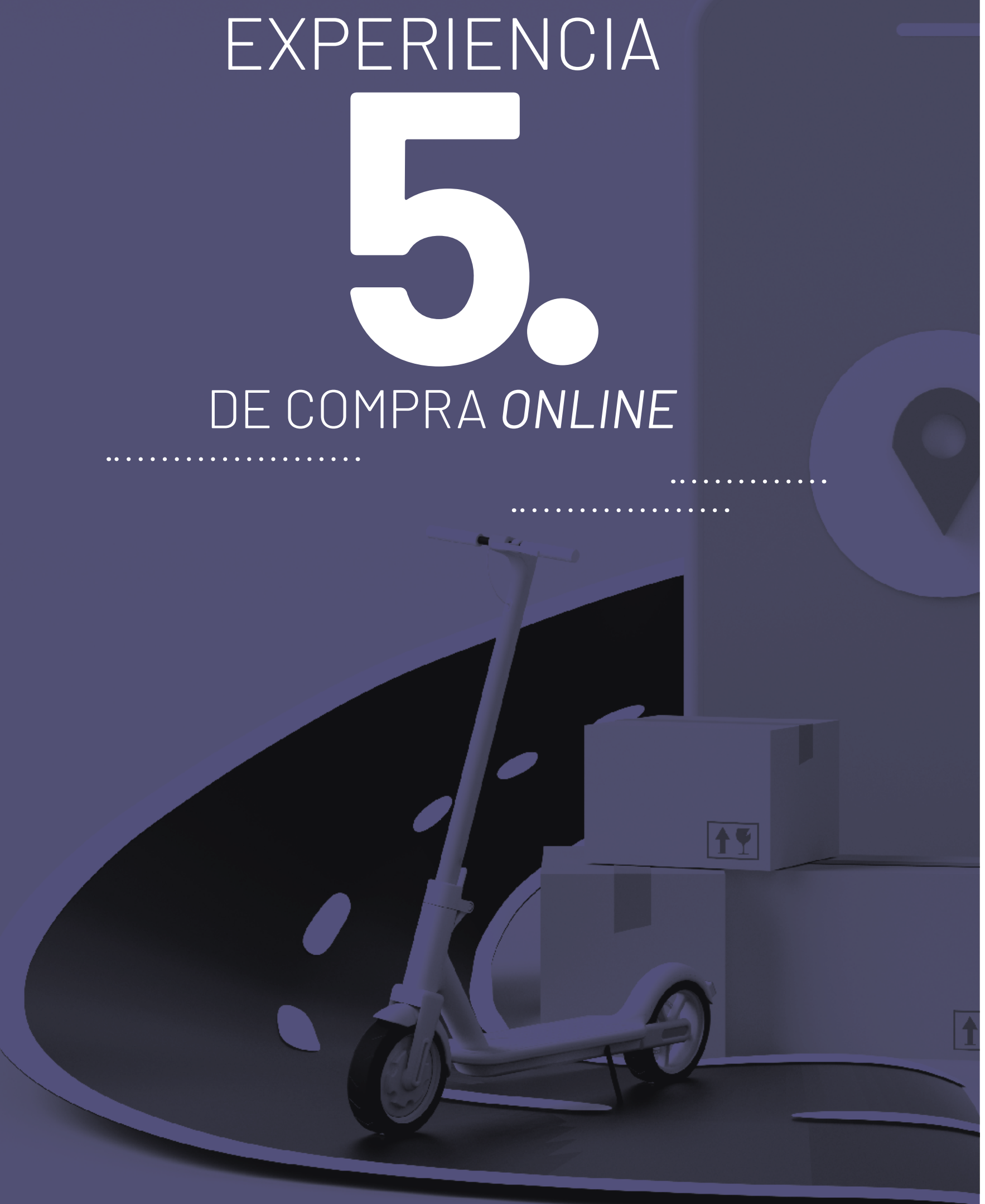


\section{1. FIDELIZACIÓN al cliente online}

Precios, seguridad y variedad fidelizan

FIGURA 5. 34. ¿POR OUUÉ RAZONES SUELE REPETIR COMPRAS EN EL MISMO SITIO WEB? (\%)(RESPUESTA MÚLTIPLE)

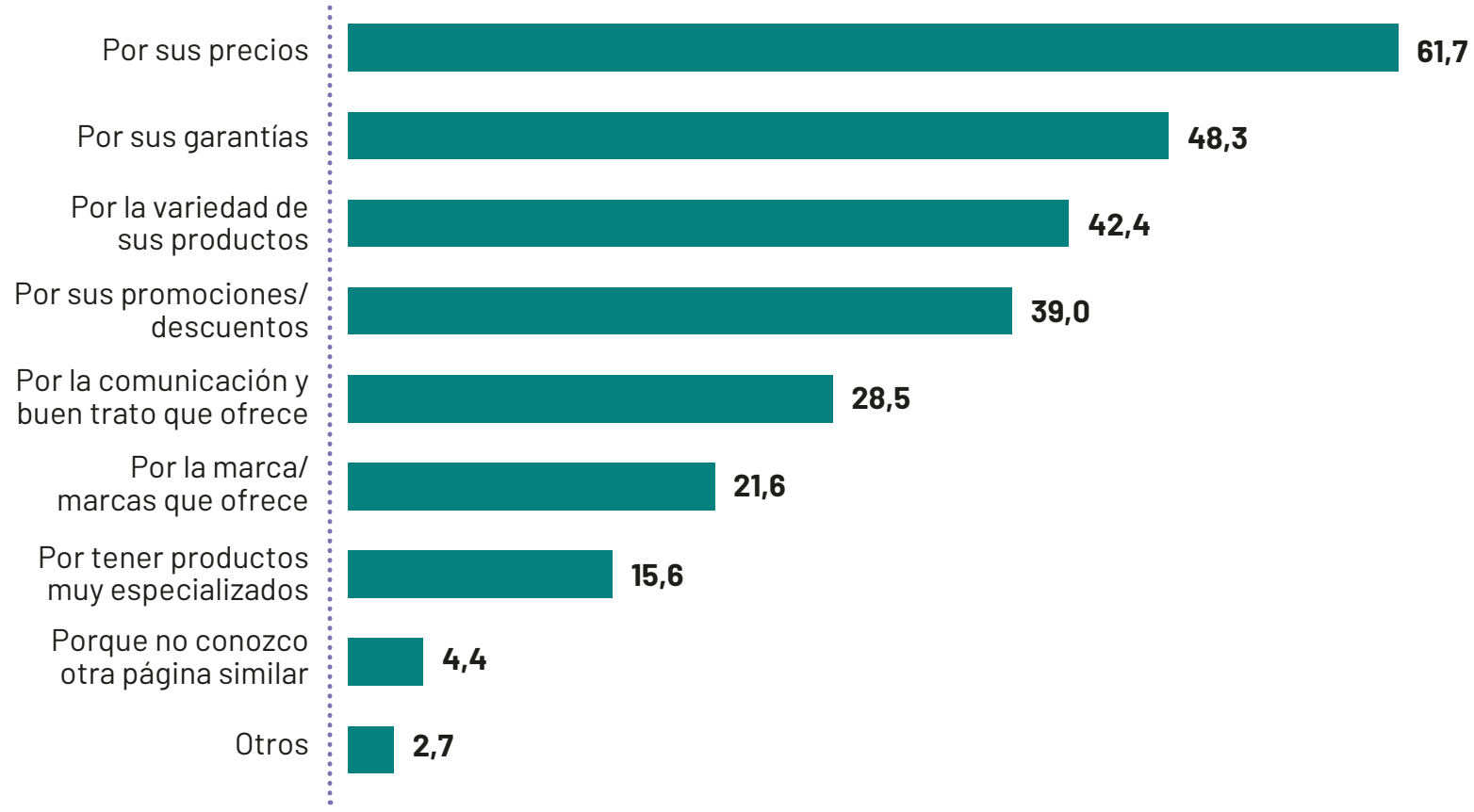

Base: compradores online que suelen repetir compras en los mismos sitios web. / Fuente: Encuesta online de comercio electrónico, ONTSI. / Nota metodológica: modificación del cuestionario respecto al año anterior, opción de respuesta múltiple.

El 96,1\% de los compradores online vuelve a comprar en la misma tienda online o sitio web. La mayoría regresa debido a sus precios $(61,7 \%)$, aunque también le estimulan la garantía del sitio web $(48,3 \%)$ y la variedad de productos que encuentra $(42,4 \%)$. Las promociones y descuentos, así como la comunicación y el buen trato al cliente, son otras dos razones que destacan los internautas compradores para repetir compras en la misma tienda online. En torno al $20 \%$ vuelve a comprar por las marcas ofrecidas, mientras que el nivel de especialización de la tienda online en un producto determinado representa el 15,6\% entre las razones argumentadas por los compradores para su fidelización.

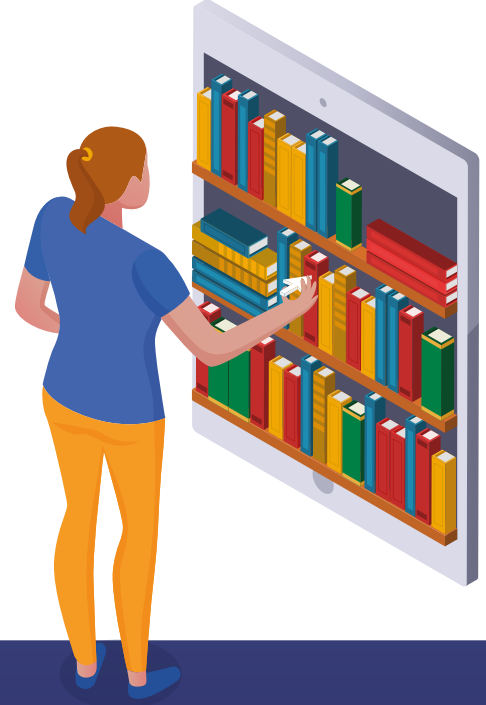




\section{2.}

\section{PROBLEMAS E INCIDENCIAS}

\section{Las incidencias afectan a casi el $20 \%$ de los compradores online, pero la tendencia interanual es decreciente}

TABLA 5. 17. INTERNAUTAS COMPRADORES OUE DECLARAN HABER TENIDO ALGÚN PROBLEMA EN LAS COMPRAS ONLINE, POR VARIABLES SOCIODEMOGRÁFICAS (\%)

\begin{tabular}{|c|c|c|}
\hline \multicolumn{2}{|l|}{ TOTAL } & 18,1 \\
\hline \multirow{2}{*}{ GÉNERO* } & Hombres & 16,9 \\
\hline & Mujeres & 19,3 \\
\hline \multirow{6}{*}{ EDAD* } & 16-24 años & 21,3 \\
\hline & 25-34 años & 20,0 \\
\hline & 35-44 años & 19,7 \\
\hline & 45-54 años & 18,1 \\
\hline & 55-64 años & 13,2 \\
\hline & 65-74 años & 15,0 \\
\hline \multirow{6}{*}{ NIVEL DE ESTUDIOS* } & Sin estudios & 16,7 \\
\hline & Primaria & 9,7 \\
\hline & Secundaria (ESO) & 20,1 \\
\hline & Secundaria (Bachillerato) & 20,2 \\
\hline & Formación profesional & 18,2 \\
\hline & Estudios superiores & 17,7 \\
\hline \multirow{5}{*}{$\begin{array}{l}\text { NIVEL DE INGRESOS } \\
\text { EN EL HOGAR* }\end{array}$} & Menos de 900 euros & 24,3 \\
\hline & Entre 900 y 1.599 euros & 19,2 \\
\hline & Entre 1.600 y 2.499 euros & 17,5 \\
\hline & Entre 2.500 y 2.999 euros & 17,6 \\
\hline & 3.000 euros o más & 13,8 \\
\hline
\end{tabular}

Base: total internautas compradores online. /*Base: total internautas compradores online por categoría sociodemográfica. / Fuente: Encuesta online de comercio electrónico, ONTSI.

El $18,1 \%$ de los consultados que compran por Internet manifiestan haber tenido algún tipo de problema en sus compras online durante 2019. Esta cifra es 6,3 p.p. inferior a la del año anterior, frenando la evolución creciente de los últimos años.

En cuanto a los perfiles de los internautas con incidencias, no se detectan especiales diferencias según género. Sí cabe destacar que las incidencias son más frecuentes entre los internautas más jóvenes, con estudios secundarios (ESO y Bachillerato) y con niveles de ingresos en el hogar inferiores a 900 euros. 


\section{Productos que no llegan o llegan con retraso son las incidencias más frecuentes en las compras online}

FIGURA 5. 35. ¿QUÉ TIPO DE PROBLEMAS TUVO EN SUS COMPRAS ONLINE? (\%)(RESPUESTA MÚLTIPLE)

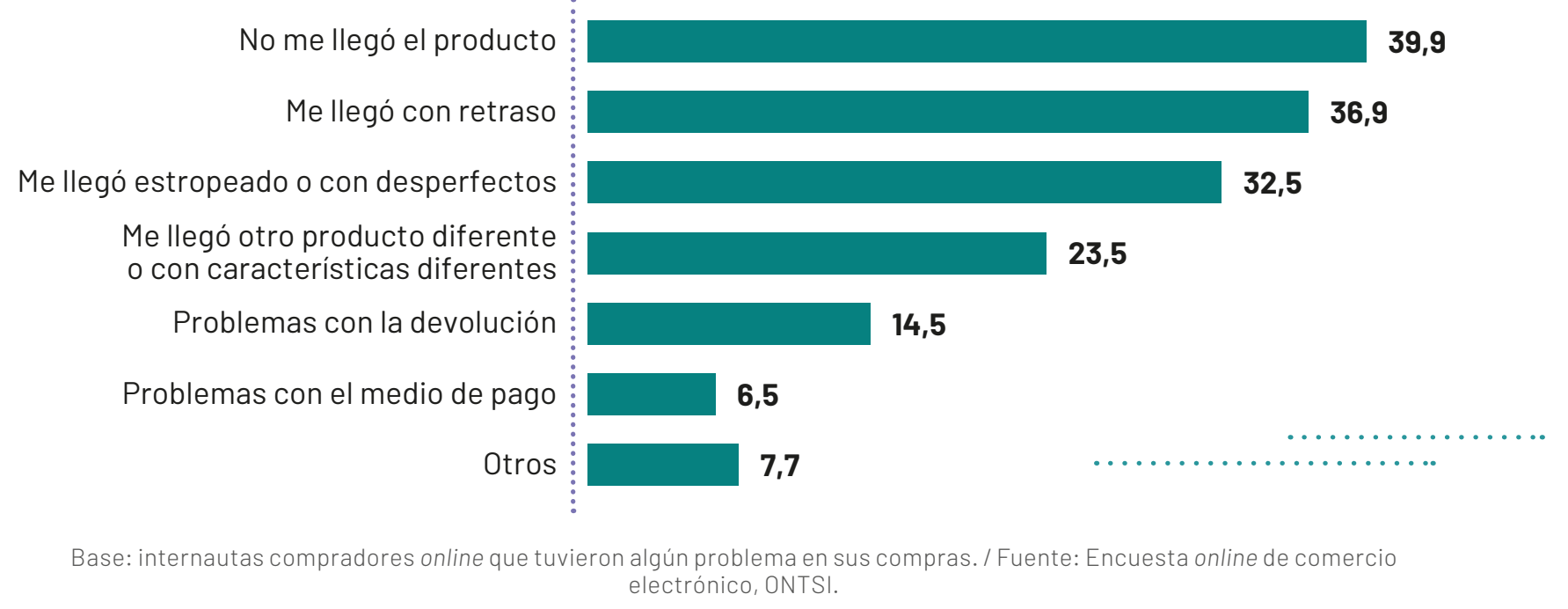

Los problemas más habituales que tienen los usuarios en la compra online están relacionados con el proceso de entrega del producto. En este sentido, cuatro de cada diez internautas compradores con incidencias afirman que alguna vez su producto o servicio no llegó a su destino.

Más del 30\% afirma que su compra llegó con retraso (36,9\%) o que el producto llegó estropeado o con desperfectos (32,5\%). Otro problema identificado es la entrega de un producto diferente al comprado o con características distintas (23,5\%).

El proceso de devolución, por su parte, está entre los que menos incidencias presenta $(14,5 \%)$, mientras que solo un 6,5\% tuvo problemas con el medio de pago.

\section{8 de cada 10 compradores han formulado alguna reclamación en 2019}

TABLA 5. 18. INTERNAUTAS OUE FORMULARON ALGUNA RECLAMACIÓN POR GÉNERO Y GRUPOS DE EDAD (\%)

\begin{tabular}{|c|c|c|c|c|c|c|c|c|c|}
\hline & \multirow{2}{*}{ TOTAL } & \multicolumn{2}{|c|}{ GÉNERO* } & \multicolumn{6}{|c|}{ EDAD* } \\
\hline & & Hombres & Mujeres & $\begin{array}{l}16-24 \\
\text { años }\end{array}$ & $\begin{array}{c}25-34 \\
\text { años }\end{array}$ & $\begin{array}{c}35-44 \\
\text { años }\end{array}$ & $\begin{array}{c}45-54 \\
\text { años }\end{array}$ & $\begin{array}{c}55-64 \\
\text { años }\end{array}$ & $\begin{array}{l}65-74 \\
\text { años }\end{array}$ \\
\hline Formuló alguna reclamación & 83,1 & 84,1 & 82,3 & 72,9 & 81,3 & 85,4 & 84,9 & 87,9 & 87,6 \\
\hline
\end{tabular}

Base: internautas compradores online que tuvieron algún problema en sus compras. /*Base: internautas compradores online que tuvieron algún problema en sus compras por categorías género y edad. / Fuente: Encuesta online de comercio electrónico, ONTSI.

\section{........................ Los compradores de 55 años y más son los que más reclaman en caso de incidencia}

De todos los compradores que han experimentado problemas, el 83,1\% ha planteado alguna reclamación en el año 2019. No se observa gran diferencia con relación al género de los compradores online que pusieron alguna reclamación, pero sí se percibe que son los mayores de 55 años los más propensos a realizarlas. 


\section{Prácticamente la mitad de los compradores soluciona las incidencias con las compras antes de tener que realizar una reclamación}

FIGURA 5. 36. ¿POR OUÉ MOTIVO NO REALIZÓ RECLAMACIÓN? (\%) (RESPUESTA MÚLTIPLE)

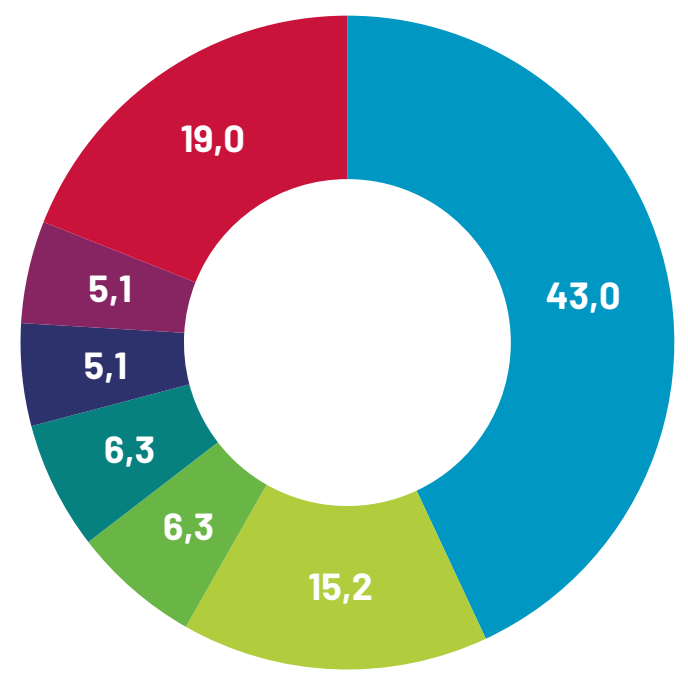

- Solucionaron finalmente la situación

- Desgana o desmotivación

- Imposibilidad de contactar con el vendedor o no le dieron la opción

- No sabía como hacerlo

- Falta de tiempo

- Era un importe pequeño

- Otros

Base: internautas compradores online que tuvieron algún problema en sus compras y no reclamaron. / Fuente: Encuesta online de comercio electrónico, ONTSI.

Entre los usuarios que han tenido algún problema en su compra online, cuatro de cada diez no han llegado a realizar la reclamación porque finalmente se solucionó el problema. Otros motivos para no presentar ninguna reclamación son de orden personal: la desgana o desmotivación(15,2\%), falta de conocimiento sobre cómo poner una reclamación (6,3\%) o falta de tiempo (5,1\%). Cabe destacar que un $6,3 \%$ de las personas que no reclaman, no lo hacen por la imposibilidad de contactar con el vendedor o por no hallar la opción para reclamar en la web vendedora.

\section{La vía de reclamación más frecuente es el servicio de atención al cliente o contacto directo con el vendedor, seguida por las redes sociales y foros}

FIGURA 5. 37. ¿A TRAVÉS DE OUÉ VÍA FORMULÓ LA OUEJA O RECLAMACIÓN?(\%)(RESPUESTA MÚLTIPLE)

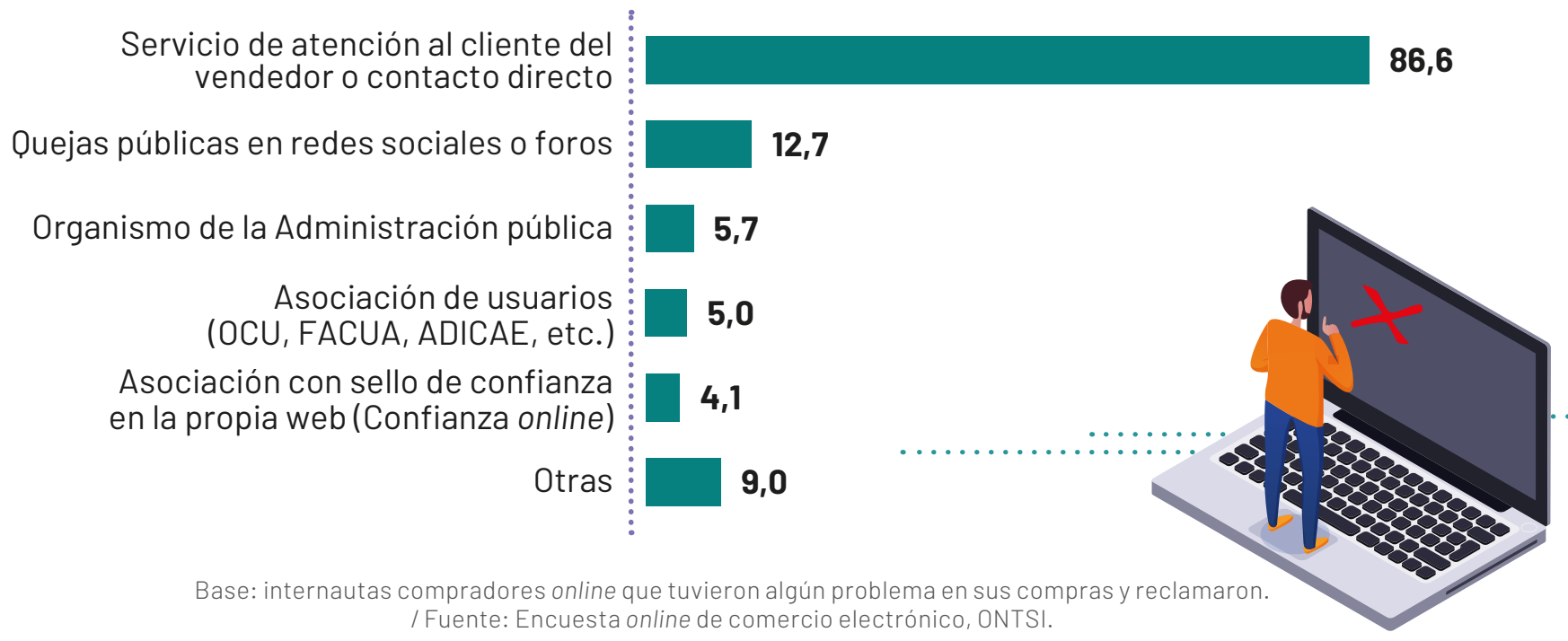


La mayoría de los compradores online con incidencias en sus compras electrónicas y que reclaman, lo hacen a través del servicio de atención al cliente de la tienda o sitio web donde ha comprado el producto o por contacto directo. Concretamente, el 86,6\% recurre a estas vías para presentar alguna reclamación, muy por delante de otras vías como las quejas públicas en redes sociales o foros $(12,7 \%)$.

Las vías menos utilizadas son las organizaciones de defensa al consumidor, públicas (5,7\%) o privadas $(5 \%)$.

\section{Las mujeres son las que más quejas y reclamaciones públicas escriben en redes sociales o foros}

TABLA 5. 19. VÍAS DE FORMULACIÓN DE RECLAMACIONES POR GÉNERO Y GRUPOS DE EDAD (\%)

\begin{tabular}{|c|c|c|c|c|c|c|c|c|c|}
\hline & \multirow[b]{2}{*}{ TOTAL } & \multicolumn{2}{|c|}{ GÉNERO* } & \multicolumn{6}{|c|}{ EDAD* } \\
\hline & & Hombres & Mujeres & $\begin{array}{l}16-24 \\
\text { años }\end{array}$ & $\begin{array}{l}25-34 \\
\text { años }\end{array}$ & $\begin{array}{l}35-44 \\
\text { años }\end{array}$ & $\begin{array}{l}45-54 \\
\text { años }\end{array}$ & $\begin{array}{l}55-64 \\
\text { años }\end{array}$ & $\begin{array}{l}65-74 \\
\text { años }\end{array}$ \\
\hline $\begin{array}{l}\text { Servicio de atención al } \\
\text { cliente o contacto directo }\end{array}$ & 86,6 & 88,7 & 84,8 & 79,1 & 90,2 & 85,8 & 90,8 & 82,1 & 88,4 \\
\hline $\begin{array}{r}\text { Quejas públicas en redes } \\
\text { sociales o foros }\end{array}$ & 12,7 & 10,8 & 14,3 & 16,4 & 13,7 & 15,1 & 3,9 & 21,7 & 7,7 \\
\hline $\begin{array}{r}\text { Asociación de usuarios (OCU, } \\
\text { FACUA, ADICAE, etc.) }\end{array}$ & 5,0 & 4,6 & 5,3 & 1,8 & 8,8 & 8,3 & 2,9 & 1,7 & 2,6 \\
\hline $\begin{array}{l}\text { Organismo de la } \\
\text { Administración pública }\end{array}$ & 5,7 & 6,0 & 5,5 & 8,1 & 8,9 & 3,7 & 3,9 & 6,9 & 5,1 \\
\hline $\begin{array}{r}\text { Asociación con Sello de } \\
\text { Confianza online }\end{array}$ & 4,1 & 4,0 & 4,2 & 5,5 & 5,6 & 2,8 & 6,3 & 1,7 & 0,0 \\
\hline Otras & 9,0 & 9,3 & 8,7 & 3,6 & 8,4 & 11,4 & 8,2 & 10,4 & 11,6 \\
\hline
\end{tabular}

Base: internautas compradores online que tuvieron algún problema en compras y reclamaron. / Base: internautas compradores online que tuvieron problemas en compras y reclamaron, por categorías género y edad. / Fuente: Encuesta online de comercio electrónico, ONTSI.

En cuanto a los perfiles de los compradores online y la vía utilizada para presentar reclamaciones, se observa que los hombres y en general las personas de 45 a 54 años son los que más utilizan el servicio de atención al cliente o contacto directo.

La queja pública en redes o foros es una vía mayormente preferida por mujeres y la mayoría de estas quejas las escriben personas de 55 a 64 años de edad.

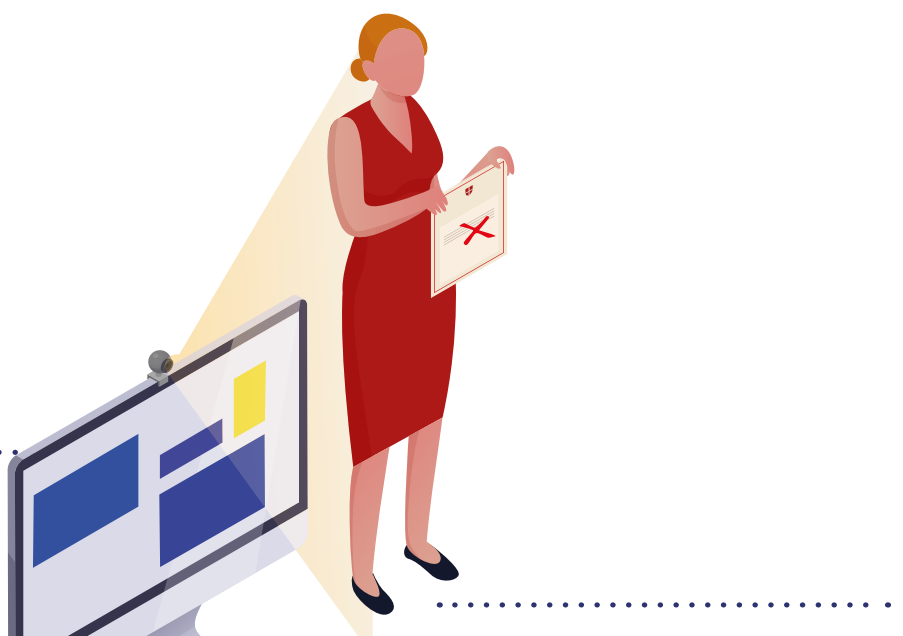




\section{3. \\ DEVOLUCIÓN DE PRODUCTOS \\ Alrededor de un $37 \%$ de los internautas ha devuelto productos o servicios comprados online en 2019}

TABLA 5. 20. ¿HA DEVUELTO ALGÚN PRODUCTO COMPRADO A TRAVÉS DE INTERNET? POR VARIABLES SOCIODEMOGRÁFICAS (\%)

\begin{tabular}{|c|c|c|}
\hline \multicolumn{2}{|l|}{ TOTAL } & 37,0 \\
\hline \multirow{2}{*}{ GÉNERO* } & Hombres & 35,6 \\
\hline & Mujeres & 38,4 \\
\hline \multirow{6}{*}{ EDAD* } & 16-24 años & 33,2 \\
\hline & 25-34 años & 43,9 \\
\hline & 35-44 años & 42,5 \\
\hline & 45-54 años & 36,8 \\
\hline & 55-64 años & 28,0 \\
\hline & 65-74 años & 33,4 \\
\hline \multirow{6}{*}{ NIVEL DE ESTUDIOS* } & Sin estudios & 34,6 \\
\hline & Primaria & 26,4 \\
\hline & Secundaria (ESO) & 30,0 \\
\hline & Secundaria (Bachillerato) & 31,2 \\
\hline & Formación profesional & 37,4 \\
\hline & Estudios superiores & 39,8 \\
\hline \multirow{6}{*}{ OCUPACIÓN* } & Estudiante & 33,3 \\
\hline & Ocupado/a por cuenta ajena & 38,8 \\
\hline & Ocupado/a por cuenta propia & 36,6 \\
\hline & Labores del hogar & 37,1 \\
\hline & Parado/a & 28,8 \\
\hline & Jubilado/a & 34,6 \\
\hline \multirow{5}{*}{ SITUACIÓN EN EL HOGAR* } & Vivo solo/a & 39,2 \\
\hline & Vivo con mi pareja & 38,7 \\
\hline & Vivo con familiares (no pareja o hijos) & 33,3 \\
\hline & Vivo con mi pareja e hijo/a/s & 38,0 \\
\hline & Vivo solo/a con mi hijo/a/s & 37,4 \\
\hline
\end{tabular}

Base: total internautas compradores online. /*Base: total internautas compradores online por categoría sociodemográfica / Fuente: Encuesta online de comercio electrónico, ONTSI.

\section{La tasa de devolución se incrementa 3,6 p.p.} respecto a 2018 y llega al $37 \%$

Durante 2019, un 37\% de los compradores online ha devuelto algún producto o servicio adquirido a través de Internet. Las cifras muestran que las mujeres devuelven productos o servicios en un porcentaje mayor que los hombres. La diferencia más acusada se percibe en la edad de los internautas; las personas de entre 25 y 44 años son las que más devoluciones realizan. 


\section{La moda aglutina la mayor parte de las devoluciones}

TABLA 5. 21. ¿QUÉ PRODUCTOS O SERVICIOS DEVOLVIÓ?(\%)

\begin{tabular}{|c|c|}
\hline & \% DEVOLUCIÓN \\
\hline Ropa, calzado y complementos & 33,5 \\
\hline Deporte y fitness & 15,9 \\
\hline Electrodomésticos, muebles, hogar, bricolaje y jardín & 15,6 \\
\hline Ordenadores, tabletas, accesorios y otros productos de electrónica (sonido, foto y vídeo) & 14,8 \\
\hline Teléfonos móviles, smartphones y accesorios relacionados & 9,4 \\
\hline Juguetes y juegos de mesa & 7,4 \\
\hline Material de oficina, papelería e imprenta & 7,3 \\
\hline Joyería, bisutería y relojes & 6,5 \\
\hline Películas, música y videojuegos para recibirlos en formato físico & 5,8 \\
\hline Vehículos de motor (alquiler y compra, repuestos y accesorios, y vehículos eléctricos) & 5,5 \\
\hline Programas, software y aplicaciones para móvil o tableta & 5,1 \\
\hline Libros, cómics, revistas y periódicos en formato electrónico (descarga y suscripción) & 4,7 \\
\hline Reserva de alojamiento y paquetes turísticos & 4,6 \\
\hline Contenido de pago en redes sociales, profesionales y de citas & 4,5 \\
\hline Salud y cuidado personal (cosmética, perfumeria, farmacia, etc.) & 4,5 \\
\hline Mascotas (comida, higiene, complementos, animales, etc.) & 4,0 \\
\hline Alimentación, bebidas y productos de limpieza del hogar & 3,7 \\
\hline Libros, cómics, revistas y periódicos en formato físico & 3,7 \\
\hline Ocio, restaurantes, servicios personales y experiencias & 2,9 \\
\hline Servicios de Internet y telefonía (conexión a Internet, alojamiento web, recarga móvil, etc.) & 2,4 \\
\hline Billetes de transporte (avión, tren, autobús, barco, taxi, metro...) & 2,4 \\
\hline Descarga o servicio online de películas, música y videojuegos & 2,1 \\
\hline Entradas para espectáculos y eventos (cine, teatro, arte, deportes, ferias, etc.) & 1,8 \\
\hline Servicios financieros y seguros & 1,6 \\
\hline Formación y cursos online & 0,9 \\
\hline Comida a domicilio de restaurantes & 0,9 \\
\hline Artículos de coleccionismo y antigüedades & 0,8 \\
\hline Juegos de azar, concursos, apuestas y lotería & 0,4 \\
\hline Otros & 0,1 \\
\hline
\end{tabular}

Base: internautas compradores online. La base de las categorías es la cantidad de individuos que compró cada categoría. / Fuente: Encuesta online de comercio electrónico, ONTSI.

La categoría que más devoluciones registra es la de ropa, calzado y complementos. El 33,5\% de los internautas compradores dice haber devuelto ropa, calzado o complementos en el año 2019, un porcentaje muy superior al de las siguientes categorías de compra, productos de deportes y fitness $(15,9 \%)$, electrodomésticos, muebles, hogar, bricolaje y jardín $(15,6 \%)$ y ordenadores, tabletas, accesorios y otros productos de electrónica (14,8\%).

Otros productos que también se devuelven con cierta frecuencia son los teléfonos móviles (9,4\%), juguetes y juegos de mesa $(7,4 \%)$ y material de oficina $(7,3 \%)$. 


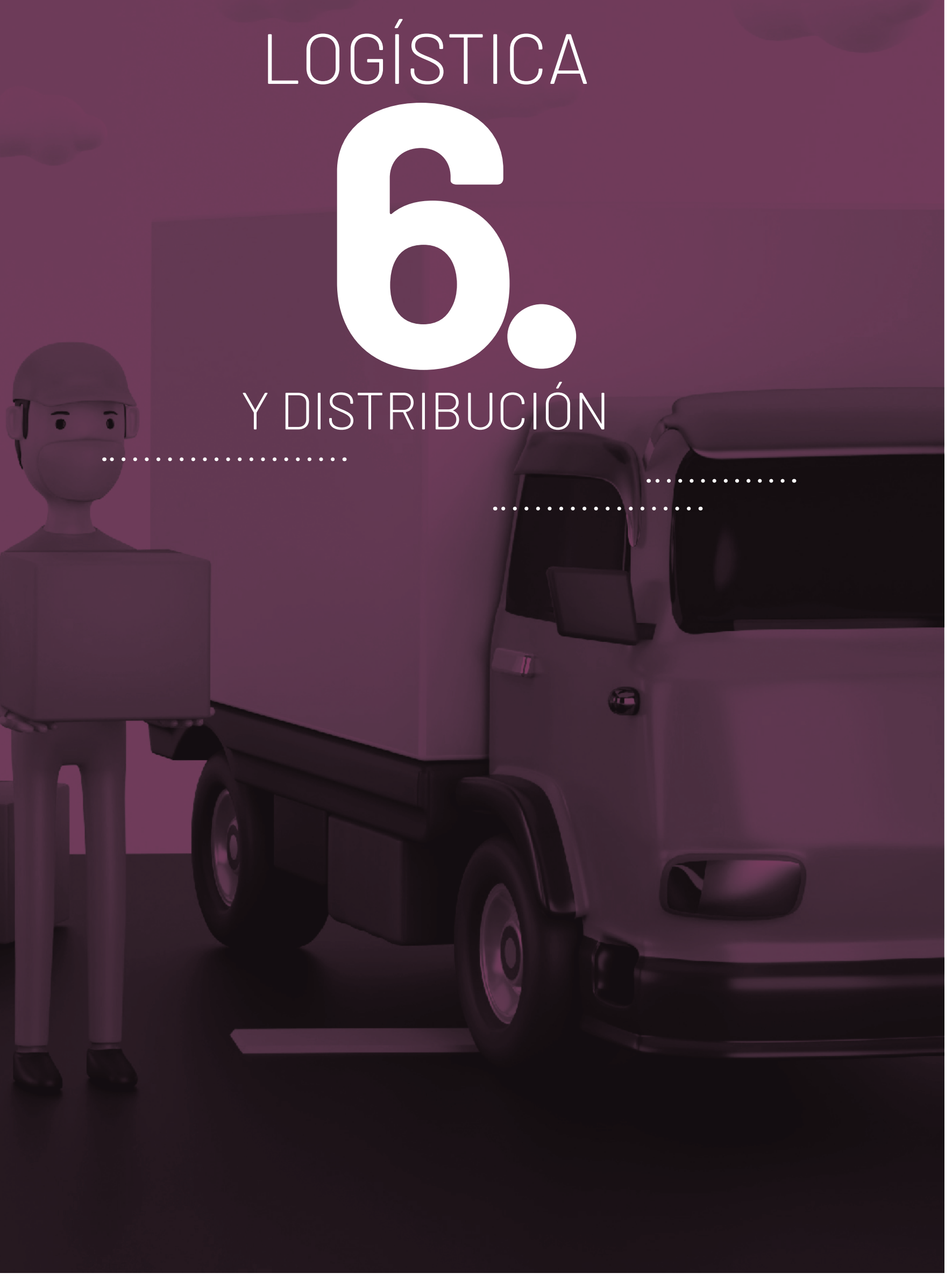




\section{Aumenta 2 millones el número de compradores de productos exclusivamente digitales}

TABLA 6. 22. INTERNAUTAS COMPRADORES, POR TIPO DE PRODUCTOS COMPRADOS (REOUIERAN ENVÍO O NO) (2018-2019) (\% Y NNo ABSOLUTO DE INTERNAUTAS COMPRADORES)

\begin{tabular}{|c|c|c|c|c|}
\hline \multirow[t]{2}{*}{ 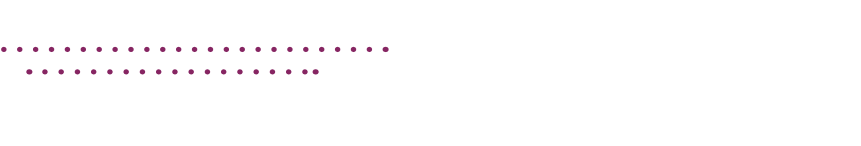 } & \multicolumn{2}{|c|}{ \% COMPRADORES } & \multicolumn{2}{|c|}{$\begin{array}{l}\text { № ABSOLUTO } \\
\text { DE COMPRADORES }\end{array}$} \\
\hline & 2018 & 2019 & 2018 & 2019 \\
\hline $\begin{array}{r}\text { Ha comprado algún producto físico } \\
\text { (que requiere envío) }\end{array}$ & 90,9 & 74,7 & 19.645 .061 & 18.116 .419 \\
\hline $\begin{array}{r}\text { Ha comprado exclusivamente productos } \\
\text { físicos (que requieren envío) }\end{array}$ & 4,1 & 5,5 & 886.495 & 1.342 .532 \\
\hline $\begin{array}{r}\text { Ha comprado exclusivamente productos } \\
\text { digitales (que no requieren envío) }\end{array}$ & 3,7 & 11,8 & 802.863 & 2.856 .354 \\
\hline No determinados* & 1,3 & 8,0 & 284.347 & 1.950 .890 \\
\hline
\end{tabular}

Base: total internautas compradores online. / Fuente: Encuesta online de comercio electrónico, ONTSI. /* Son considerados productos no determinados los incluidos en las categorías: "Otro tipo de productos" y "Vehículos de motor (incluyendo alquiler y compra de vehículos, repuestos y accesorios, y vehículos eléctricos)".

En 2019, el 80,2\% de los internautas ha comprado algún producto que requiere de servicios de logística y distribución para recibirlo.

Respecto a 2018, crece la compra exclusiva de productos con envío. Sin embargo, el mayor incremento se encuentra en el número de usuarios que compran únicamente productos digitales. Este grupo representaba el 3,7\% de las compras online en 2018, mientras que en 2019 concentra el $11,8 \%$ del total de compras online. El incremento en el volumen de compradores digitales puede deberse a que 4 de las 6 categorías que más compradores concentran en 2019 son categorías de productos que no requieren de envío (reserva de alojamiento y paquetes turísticos, entradas para espectáculos, billetes de transporte, así como ocio, restaurantes, servicios personales yexperiencias y eventos).

Por lo tanto, las adquisiciones online en 2019 vuelven a concentrarse en determinados tipos de productos incrementándose las compras exclusivas tanto de productos que requieren envío como los que no.

\section{El gasto total en productos físicos bate récords y, por primera vez, supera el gasto en productos y servicios digitales adquiridos online}

TABLA 6. 23. FRECUENCIA DE COMPRA, GASTO MEDIO Y \% SOBRE GASTO TOTAL DE LOS PRODUCTOS COMPRADOS ONLINE

\begin{tabular}{|c|c|c|c|c|}
\hline & $\begin{array}{c}\text { № compras al } \\
\text { año }\end{array}$ & $\begin{array}{l}\text { Gasto medio } \\
\text { anual }(€)\end{array}$ & $\begin{array}{l}\text { Gasto total } \\
\text { (Millones } € \text { ) }\end{array}$ & $\begin{array}{c}\text { \% sobre gasto } \\
\text { total (sin serv. } \\
\text { fin.) }\end{array}$ \\
\hline Productos físicos (requieren envío) & 4,9 & 262 & 24.584 & 48,8 \\
\hline Productos digitales (no requieren envío) & 5,0 & 250 & 23.901 & 47,4 \\
\hline No determinados* & 6,0 & 769 & 1.897 & 3,8 \\
\hline
\end{tabular}

Base: total internautas compradores online. / Fuente: Encuesta online de comercio electrónico, ONTSI. / *Son considerados productos no determinados los incluidos en las categorías: "Otro tipo de productos" y "Vehículos de motor (incluyendo alquilery compra de vehículos, repuestos y accesorios, y vehículos eléctricos)". 
El gasto total en productos que requieren de envío ha aumentado en 2019 y supera al gasto total en productos digitales (6.201 millones de euros más en 2019). De media, los consumidores online gastan $262 €$ en productos físicos frente a los $250 €$ desembolsados en productos digitales. La principal categoría de consumo es la de ropa, calzado y complementos, tratándose de productos físicos que requieren envío. Además, la comida a domicilio de restaurantes y los productos de alimentación, bebidas y productos de limpieza del hogar, son las categorías que más número de compras anuales concentran (10,4 y 9,2 compras anuales, respectivamente) y suponen el 11,1\% del gasto total.

\section{8 de cada 10 consumidores online se encargan personalmente de la recepción o recogida de los paquetes de sus compras}

FIGURA 6. 38. ¿SUELE SER USTED OUIEN RECOGE LOS PAOUETES DE LAS COMPRAS REALIZADAS A TRAVÉS DE INTERNET? (\%)

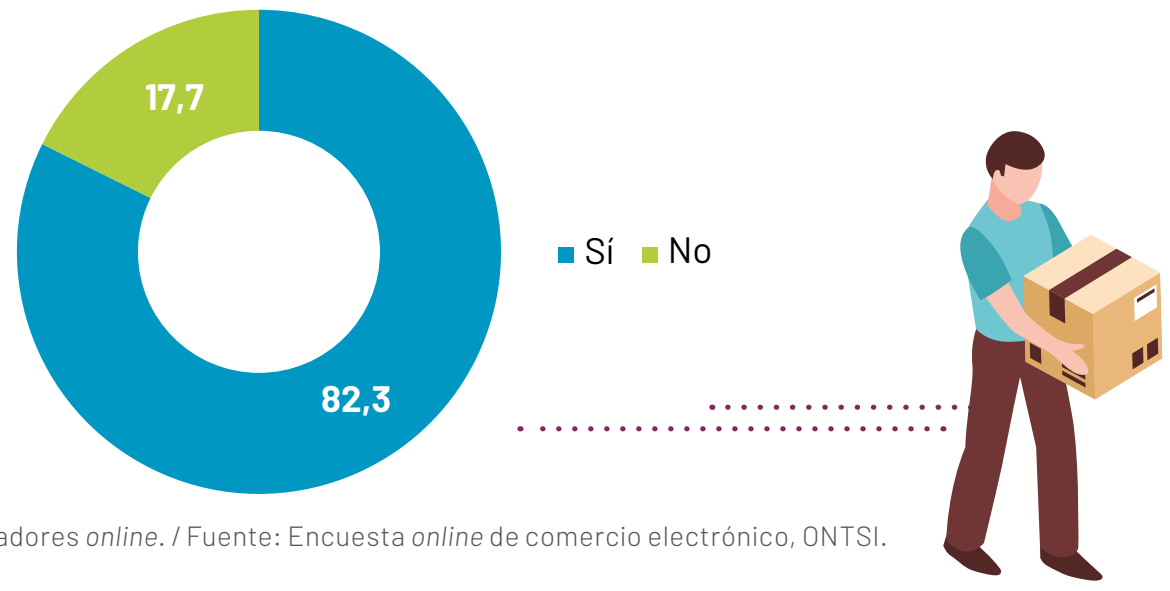

Más del $80 \%$ de los internautas compradores se encarga personalmente de la recepción o recogida de sus compras realizadas a través de Internet.

El incremento observado durante el pasado año parece haberse estancado, manteniendo un porcentaje similar al de 2018. Las empresas han incrementado las facilidades para que los consumidores puedanrecibir en persona sus pedidos, sin embargo, en ocasionesla incompatibilidad de horarios hace que una tercera persona sea la encargada de recibirlos.

\section{Los envios gratuitos continúan siendo la clave para la satisfacción de los consumidores con la entrega}

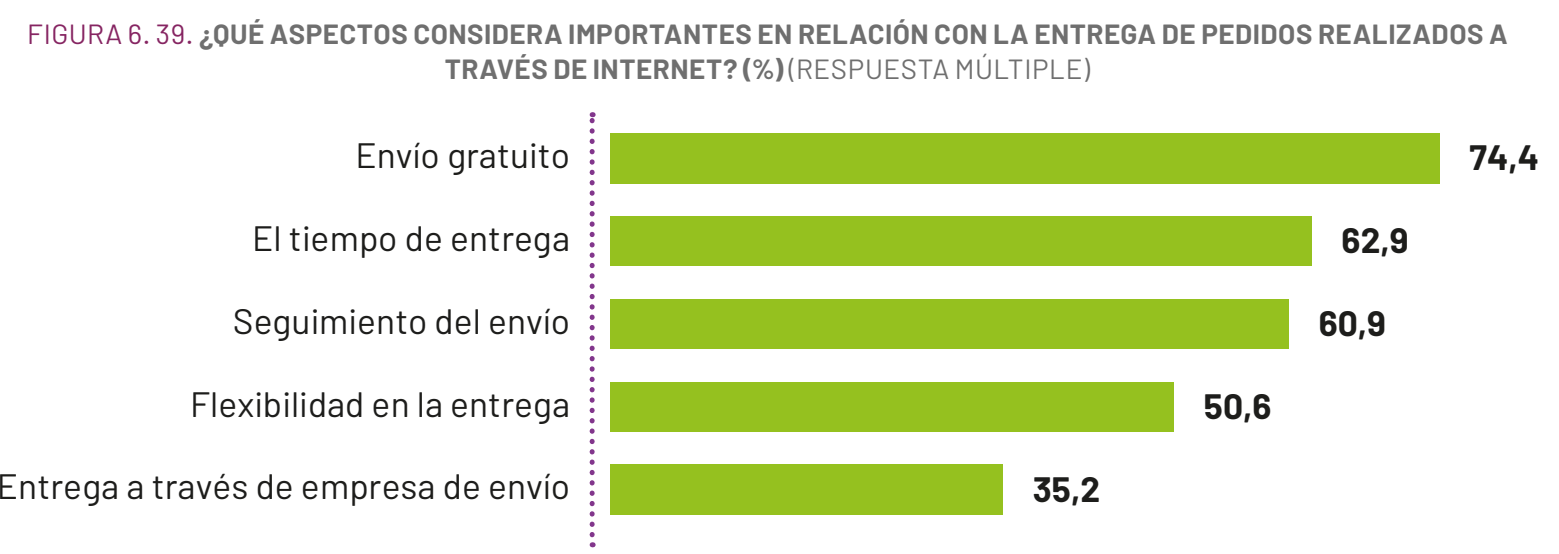


Gratis, rápido y localizable: estos son los principales factores para la satisfacción del cliente con la entrega de su compra online. El envío gratuito (74,4\%), seguido por el tiempo de entrega $(62,9 \%)$ y la posibilidad del seguimiento de envío $(60,9 \%$ ) son los aspectos a los que mayor importancia dan los internautas. Para los compradores, el aspecto menos influyente es que la entrega sea realizada por una empresa especializada (35,2\%).

La gratuidad, demora, seguimiento y flexibilidad son factores más importantes para las mujeres que para los hombres. Las empresas especializadas son un factor más relevante para los hombres.

En cuanto a la edad, los internautas más jóvenes, de 16 a 24 años de edad, priorizan la rapidez y el seguimiento del envío. La siguiente franja de edad situada entre 25 y 44 años, da mayor importancia a que los envíos sean gratuitos. Los grupos de edad más avanzada son los que más valoran una entrega flexible.

TABLA 6. 24. ASPECTO MÁS IMPORTANTE CON RELACIÓN A LA ENTREGA DE PEDIDOS REALIZADOS ................... A TRAVÉS DE INTERNET POR GÉNERO Y GRUPOS DE EDAD (\%)

\begin{tabular}{|c|c|c|c|c|c|c|c|c|c|}
\hline & \multirow[b]{2}{*}{ TOTAL } & \multicolumn{2}{|c|}{ GÉNERO* } & \multicolumn{6}{|c|}{ EDAD* } \\
\hline & & Hombres & Mujeres & $\begin{array}{r}16-24 \\
\text { años } \\
\end{array}$ & $\begin{array}{c}25-34 \\
\text { años } \\
\end{array}$ & $\begin{array}{c}35-44 \\
\text { años } \\
\end{array}$ & $\begin{array}{c}45-54 \\
\text { años } \\
\end{array}$ & $\begin{array}{c}55-64 \\
\text { años } \\
\end{array}$ & $\begin{array}{r}65-74 \\
\text { años } \\
\end{array}$ \\
\hline Envío gratuito & 74,4 & 70,9 & 77,9 & 72,0 & 79,1 & 76,9 & 72,9 & 71,4 & 73,0 \\
\hline El tiempo de entrega & 62,9 & 62,1 & 63,7 & 71,1 & 66,8 & 65,1 & 60,0 & 55,5 & 60,2 \\
\hline Seguimiento del envío & 60,9 & 58,4 & 63,3 & 66,1 & 62,8 & 61,6 & 59,2 & 54,7 & 63,6 \\
\hline Flexibilidad en la entrega & 50,6 & 49,4 & 51,8 & 47,5 & 51,4 & 53,9 & 54,4 & 49,7 & 37,3 \\
\hline $\begin{array}{c}\text { Entrega a través de empresa } \\
\text { de envío }\end{array}$ & 35,2 & 36,2 & 34,3 & 30,2 & 27,5 & 32,3 & 35,0 & 39,3 & 57,0 \\
\hline
\end{tabular}

Base: total internautas compradores online. / Base: total internautas compradores online por categorías género y edad. / Fuente: Encuesta online de comercio electrónico, ONTSI.

\section{Tres días es el plazo máximo de entrega que la mitad de los consumidores online considera razonable}

FIGURA 6. 40. ¿CUÁL CONSIDERA OUE ES EL PLAZO RAZONABLE DE ENTREGA DE PEDIDOS REALIZADOS POR INTERNET? (\%)

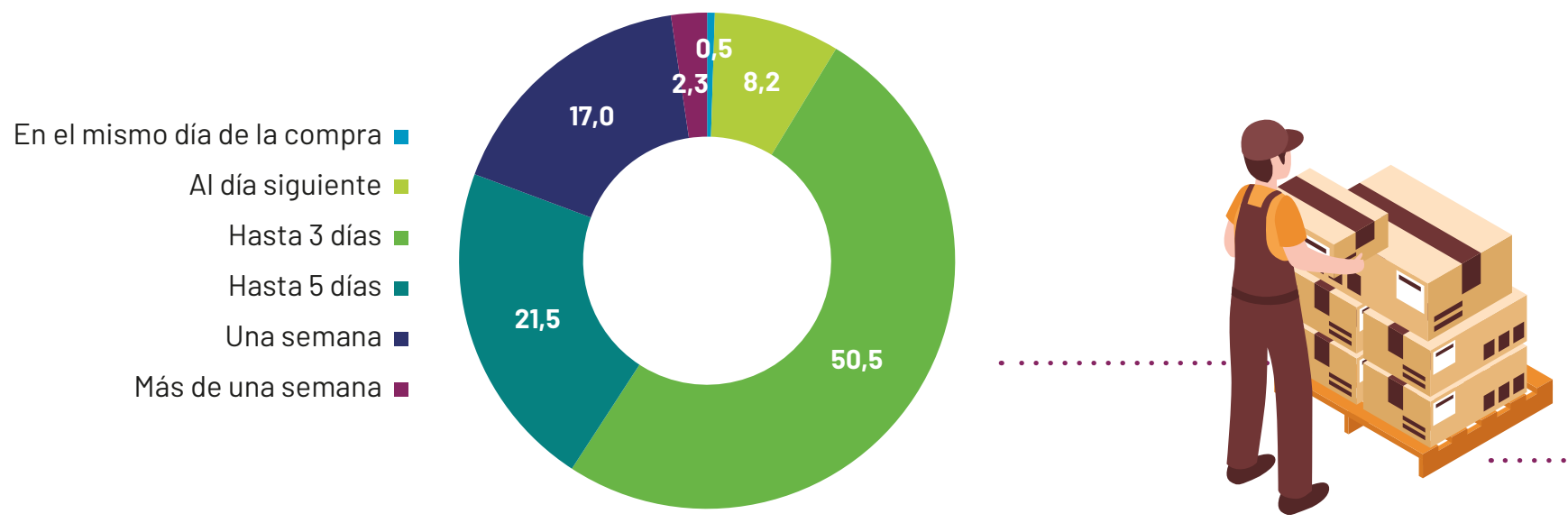

Base: total internautas compradores online. / Fuente: Encuesta online de comercio electrónico, ONTSI.

El $50,5 \%$ de los compradores online considera razonable que la entrega de sus productos se realice hasta 3 días después de su adquisición. Aunque los internautas, en general, prefieren plazos de entrega más cortos, un 19,3\% considera razonable un plazo de una semana o más para la recepción de los productos. 


$$
\begin{gathered}
\text { FRENOS } \\
\text { E IMPULSORES }
\end{gathered}
$$

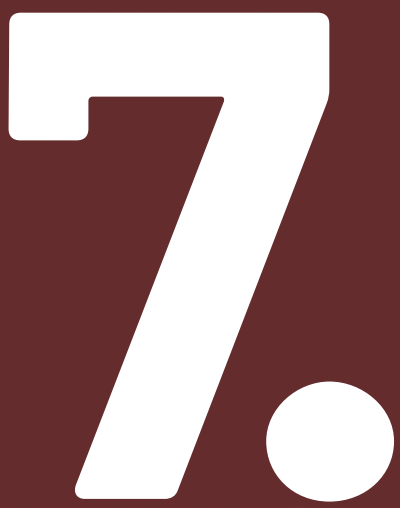

DEL COMERCIO ELECTRÓNICO 


\section{1. \\ ANÁLISIS DESDE LA PERSPECTIVA DE LOS NO COMPRADORES}

FRENOS PARA LA COMPRA ONLINE

\section{No haber tenido la necesidad o preferir visitar la tienda física, continúan siendo los principales motivos para no comprar online}

FIGURA 7. 41. ¿CUÁLES SON LAS RAZONES POR LAS OUE NO HA COMPRADO EN EL ÚLTIMO AÑO A TRAVÉS DE INTERNET? (\%) (RESPUESTA MÚLTIPLE)

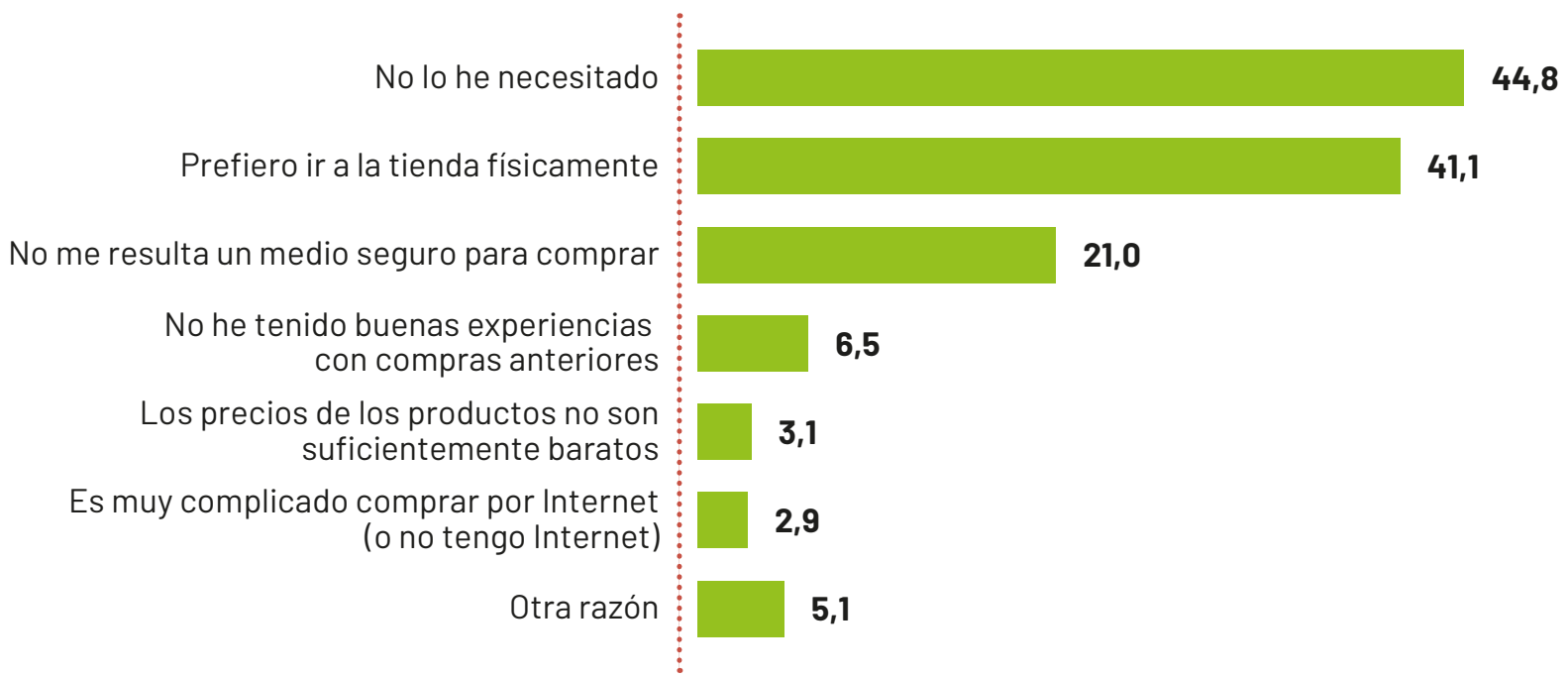

Base: total internautas no compradores online. / Fuente: Encuesta online de comercio electrónico, ONTSI. / Nota metodológica: modificación del cuestionario respecto al año anterior, opción de respuesta múltiple.

¿Es necesario comprar online? Esta parece ser la pregunta principal entre quienes no compran por Internet. La mayoría de los internautas que no han comprado online durante 2019 argumentan que no lo han necesitado (44,8\%). El 41,1\%, por su parte, prefiere visitar tiendas físicas. Por otro lado, para dos de cada diez no compradores, Internet no resulta un medio seguro de compra.

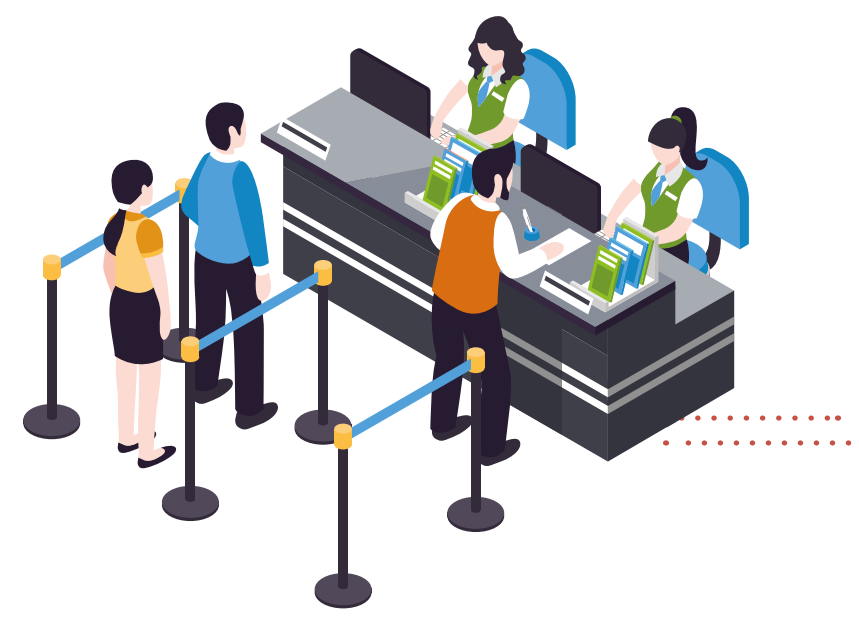




\section{El principal argumento de rechazo a la compra online entre los hombres es la falta de necesidad. Para las mujeres, visitar la tienda física y la inseguridad de Internet son los factores que se interponen a la compra online}

TABLA 7. 25. RAZONES POR LAS QUE NO HA COMPRADO A TRAVÉS DE INTERNET, POR GÉNERO (\%)

\begin{tabular}{|c|c|c|c|}
\hline \multirow[t]{2}{*}{$\cdots \cdots \cdots \cdots$} & \multirow{2}{*}{ TOTAL } & \multicolumn{2}{|c|}{ GÉNERO* } \\
\hline & & Hombres & Mujeres \\
\hline No lo he necesitado & 44,8 & 48,4 & 41,6 \\
\hline Prefiero ir a la tienda físicamente & 41,1 & 39,5 & 42,5 \\
\hline No me resulta un medio seguro para comprar & 21,0 & 19,2 & 22,5 \\
\hline No he tenido buenas experiencias con compras anteriores & 6,5 & 6,5 & 6,4 \\
\hline Los precios de los productos no son suficientemente baratos & 3,1 & 2,5 & 3,8 \\
\hline Es muy complicado comprar por Internet (o no tengo Internet) & 2,9 & 1,6 & 4,2 \\
\hline Otra & 5,1 & 7,6 & 2,8 \\
\hline
\end{tabular}

Base: total internautas no compradores online. / Base*: total internautas no compradores online por categoría de género. /

Fuente: Encuesta online de comercio electrónico, ONTSI.

Los hombres argumentan principalmente no haber comprado online porque no lo han necesitado (48,4\%), mientras que las mujeres prefieren realizar las compras en las tiendas físicas (42,5\%)y ven más dificultades relacionadas con el medio de compra online, tanto por falta de seguridad (22,5\%) como por complejidad en el proceso de compra (4,2\%).

\section{IMPULSORES DE LA COMPRA ONLINE}

\section{5 de cada 10 no consumidores online recurririan al comercio electrónico en caso de que no fuese posible el consumo offline}

FIGURA 7. 42. ¿CUÁLES SON LOS FACTORES DE LOS OUE DEPENDE OUE EN EL FUTURO COMPRE POR INTERNET? (\%) (RESPUESTA MÚLTIPLE)

Por necesidad o imposibilidad de comprar offline

Que encuentre algo verdaderamente interesante

Que mejore la accesibilidad o facilidad de compra

Que las transacciones sean más seguras o confiables Que los precios bajen

Que mis lugares habituales ofrezcan el servicio Que tenga conexión a Internet De que alguien me ayude o compre por mí Otro

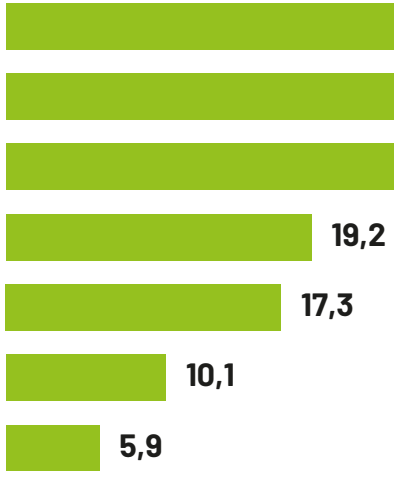

3,7

4,5

Base: total internautas no compradores online. / Fuente: Encuesta online de comercio electrónico, ONTSI. / Nota metodológica: modificación del cuestionario respecto al año anterior, opción de respuesta múltiple.

Además de la necesidad (49,9\%) y la posibilidad de encontrar algo de interés (38,2\%), mejorar la accesibilidad, facilidad $(24,7 \%)$ y seguridad en la compra $(19,2 \%)$ son factores determinantes para impulsar la compra online de los internautas no compradores. 


\section{2. \\ ANÁLISIS DESDE LA PERSPECTIVA DE LOS COMPRADORES}

PRINCIPALES RAZONES

PARA COMPRAR ONLINE

\section{La comodidad, principal razón por la que los internautas optan por comprar online}

FIGURA 7. 43. ¿CUÁLES SON LAS RAZONES POR LAS OUE HA COMPRADO EN EL ÚLTIMO AÑO A TRAVÉS DE INTERNET? (\%) (RESPUESTA MÚLTIPLE)

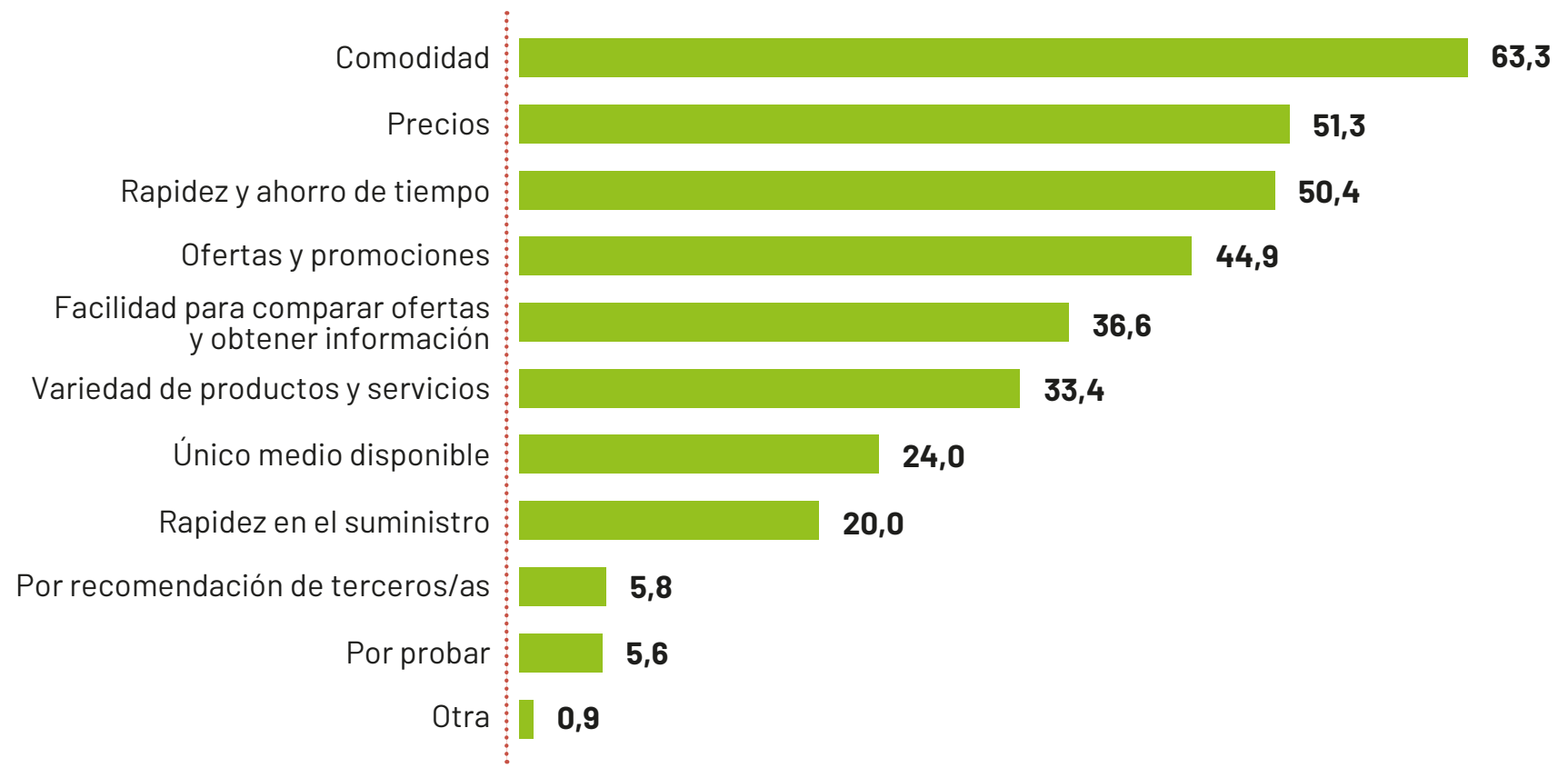

Base: total internautas compradores online. / Fuente: Encuesta online de comercio electrónico, ONTSI. / Nota metodológica: modificación del cuestionario respecto al año anterior, opción de respuesta múltiple.

En 2018, los compradores priorizaban los precios sobre la comodidad. Esto ha cambiado en 2019: la comodidad es el principal argumento de compra online (63,3\%), aunque los precios y la rapidez y ahorro de tiempo siguen siendo lo más importante para cinco de cada diez consumidores online.

Por otra parte, se valoran positivamente las ofertas y promociones (44,9\%), la facilidad para comparar y obtener información $(36,6 \%$ ) y la variedad de productos y servicios disponibles $(33,4 \%)$.

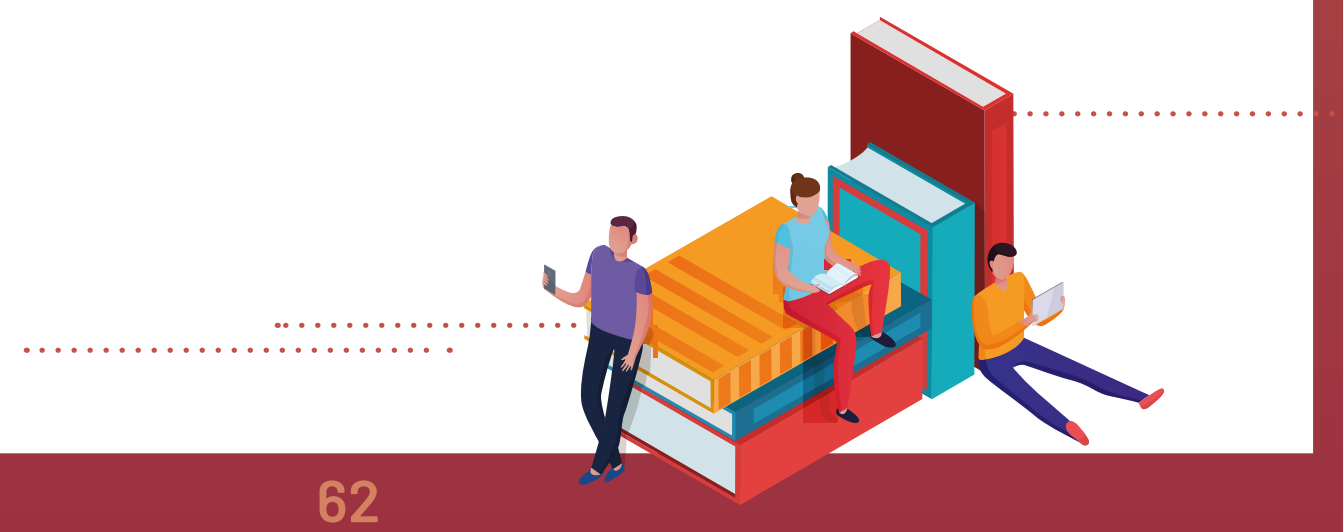




\section{Los hombres dan más importancia a los precios, mientras que las mujeres se inclinan a comprar por la rapidez y el ahorro de tiempo}

TABLA 7. 26. RAZONES PARA COMPRAR ONLINE EN LUGAR DE ACUDIR A UNA TIENDA FÍSICA, POR GÉNERO Y EDAD (\%)

\begin{tabular}{|c|c|c|c|c|c|c|c|c|c|}
\hline & \multirow[b]{2}{*}{ TOTAL } & \multicolumn{2}{|c|}{ GÉNERO* } & \multicolumn{6}{|c|}{ EDAD* } \\
\hline & & Hombres & Mujeres & $\begin{array}{l}16-24 \\
\text { años }\end{array}$ & $\begin{array}{c}25-34 \\
\text { años }\end{array}$ & $\begin{array}{l}35-44 \\
\text { años }\end{array}$ & $\begin{array}{l}45-54 \\
\text { años }\end{array}$ & $\begin{array}{l}55-64 \\
\text { años }\end{array}$ & $\begin{array}{l}65-74 \\
\text { años }\end{array}$ \\
\hline Comodidad & 63,3 & 63,3 & 63,3 & 60,7 & 59,1 & 64,1 & 63,2 & 64,0 & 71,3 \\
\hline Precios & 51,3 & 55,2 & 47,6 & 52,5 & 51,1 & 48,9 & 53,8 & 47,4 & 57,4 \\
\hline Rapidez y ahorro de tiempo & 50,4 & 46,7 & 54,0 & 52,5 & 59,8 & 53,3 & 46,7 & 45,5 & 41,6 \\
\hline Ofertas y promociones & 44,9 & 43,9 & 45,8 & 49,0 & 50,6 & 47,5 & 45,0 & 35,6 & 38,9 \\
\hline $\begin{array}{r}\text { Facilidad para comparar ofertas y } \\
\text { obtener información }\end{array}$ & 36,6 & 36,4 & 36,9 & 39,3 & 43,1 & 33,6 & 34,8 & 34,0 & 38,5 \\
\hline Variedad de productos y servicios & 33,4 & 35,6 & 31,2 & 36,3 & 36,3 & 30,5 & 34,8 & 30,3 & 33,3 \\
\hline Único medio disponible & 24,0 & 21,5 & 26,4 & 30,1 & 25,1 & 22,8 & 24,0 & 20,4 & 22,4 \\
\hline Rapidez en el suministro & 20,0 & 21,4 & 18,6 & 18,3 & 21,1 & 20,3 & 17,9 & 19,8 & 25,2 \\
\hline Por recomendación de terceros/as & 5,8 & 4,6 & 6,9 & 9,9 & 8,9 & 4,6 & 2,9 & 5,5 & 5,3 \\
\hline Por probar & 5,6 & 5,4 & 5,7 & 12,5 & 5,0 & 4,1 & 4,9 & 3,2 & 6,1 \\
\hline Otra & 0,9 & 0,5 & 1,4 & 0,8 & 0,9 & 1,5 & 0,7 & 0,4 & 1,0 \\
\hline
\end{tabular}

Base: total internautas compradores online. / *Base: total internautas compradores online por categoría de género y edad. / Fuente: Encuesta online de comercio electrónico, ONTSI.

Al comprar online los hombres son quienes dan más importancia a los precios (55,2\%), mientras que entre las mujeres prima la rapidez en la compra y el consecuente ahorro de tiempo (54\%), así como aprovechar ofertas y promociones (45,8\%).

En cuanto a la edad, los internautas de edad más avanzada prestan más atención a aspectos como la comodidad y los precios, mientras que los más jóvenes valoran la rapidez y ahorro de tiempo, las ofertas y promociones o la facilidad para comparar y obtener información.

\section{4 de cada 10 internautas que compran online tienen en cuenta los sellos de calidad o códigos éticos de confianza online}

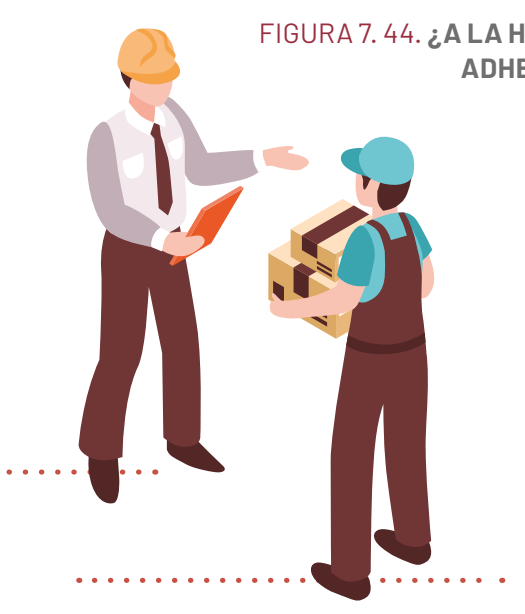
ADHERIDO A UN SELLO DE CALIDAD O CÓDIGOÉTICO DE CONFIANZA ONLINE? (\%)

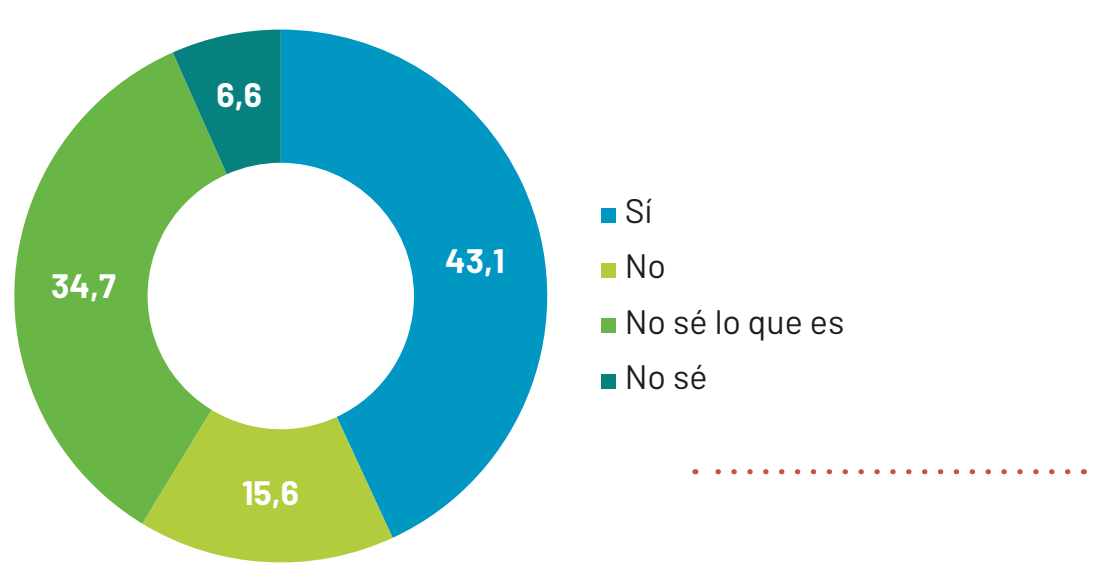

Base: total internautas compradores online. / Fuente: Encuesta online de comercio electrónico, ONTSI. / Nota: El sello de calidad en España está impulsado por Confianza Online, una asociación creada en 2003 por Autocontrol y Adigital para aumentar la confianza de los usuarios y la reputación de las empresas en Internet. A través del Sello, las webs pueden demostrar su compromiso con las buenas prácticas en Internet y con el sistema de tramitación de reclamaciones para el comercio electrónico y la publicidad digital. 
Durante 2019, el 43,1\% de los internautas que han comprado a través de Internet han tenido en cuenta que los sitios online dispongan de un sello de calidad o estén adheridos a algún tipo de código ético de confianza online. Sin embargo, tres de cada diez internautas afirman desconocer la existencia de este tipo de sellos o garantías de compra online y el 15,6\% declara que no lo tiene en cuenta a la hora de comprar.

FIGURA 7. 45. COMPRADORES OUE TIENEN EN CUENTA EL SELLO DE CALIDAD O CÓDIGO ÉTICO DE CONFIANZA ONLINE A LA HORA DE COMPRAR POR INTERNET (EVOLUCIÓN 2014-2019) (\%)
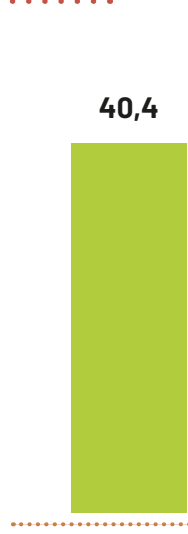

2014
40,5

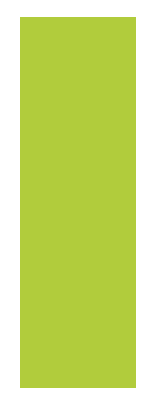

2015

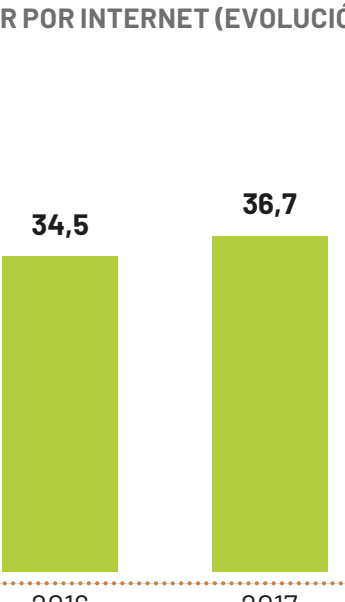

2016

2017
49,8

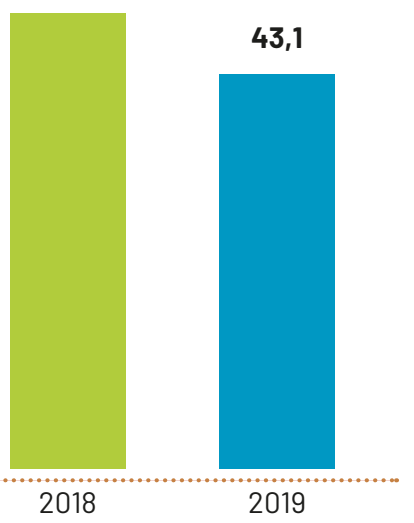

Base: total internautas compradores online. / Fuente: Encuesta online de comercio electrónico, ONTSI.

El porcentaje de compradores online que tienen en cuenta el sello de calidad o código ético ha experimentado un descenso respecto a 2018, aunque se mantiene por encima del $40 \%$. Este dato indica que a pesar del descenso, se mantiene la importancia otorgada a los elementos de calidad y confianza al presentar niveles superiores a los de años previos a 2018.

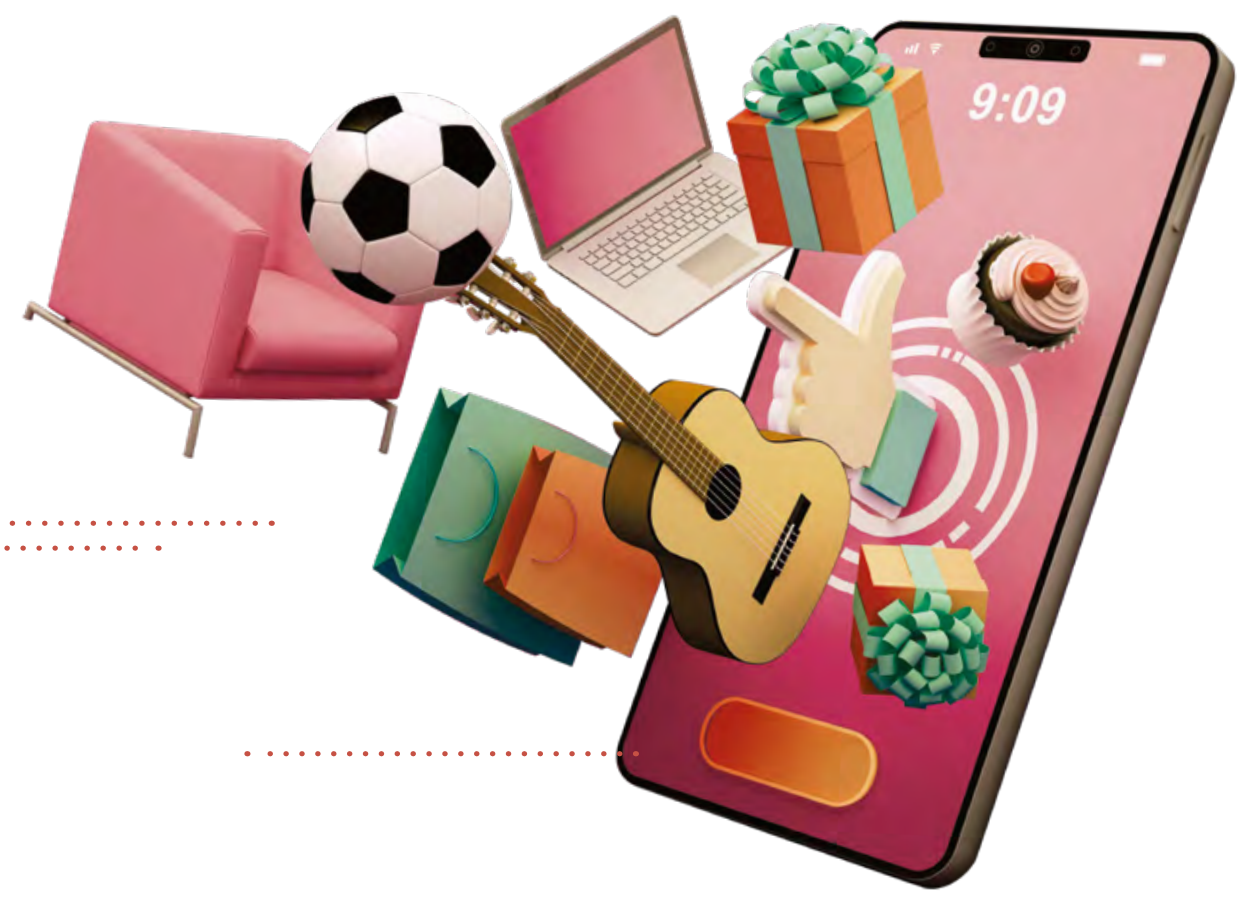




\section{ASPECTOS MEJORABLES \\ DEL COMERCIO ELECTRÓNICO B2C}

\section{El uso de los datos personales y los gastos de envio en el punto de mira de los consumidores online}

FIGURA 7. 46. ASPECTOS SATISFACTORIOS Y MEJORABLES DE LOS SITIOS DE COMPRA ONLINE(\%)

Sencillez del procedimiento de compra
Variedad de productos y servicios
Seguridad en los pagos
Calidad de la entrega de los productos
Información de los productos y opiniones

Base: total internautas compradores online por aspecto de los sitios de compra online. / Fuente: Encuesta online de comercio electrónico, ONTSI.

Lo mejor valorado del B2C entre los compradores es la sencillez del procedimiento de compra $(58,5 \%)$, la variedad de productos y servicios $(52,4 \%)$ y la seguridad en los pagos $(50,8 \%)$.

Estos tres aspectos han ganado valoraciones positivas en comparación a 2018: la sencillez en el procedimiento de compra se incrementa 6,3 puntos porcentuales, la variedad de los productos y servicios crece 5,6 puntos. Pero el factor que experimenta mayor incremento en el nivel de satisfacción es la seguridad en los medios de pago, con un crecimiento de 9,0 puntos porcentuales respecto a 2018.

El ahorro económico es el aspecto que más preocupa a los internautas: las ofertas y promociones son mejorables para el $74,8 \%$ de los compradores, los gastos de envío deberían reducirse para el $76,4 \%$ y los precios deberían bajar para el $71,7 \%$ de los compradores. También, consideran muy relevante mejorar la atención al cliente $(71,7 \%$ ) y el uso de los datos personales (69\%).

Las principales categorías que han empeorado su valoración respecto al año 2018 y, por lo tanto, acumulan un porcentaje mayor de compradores que demandan mejoras en su prestación son las ofertas y promociones disponibles (+ 5,5 p.p. mejorable y muy mejorable respecto a 2018) y el servicio de atención al cliente (+ 5,6 p.p. mejorable y muy mejorable respecto a 2018). 


\section{HÁBITOS \\ DE COMPRA ONLINE}

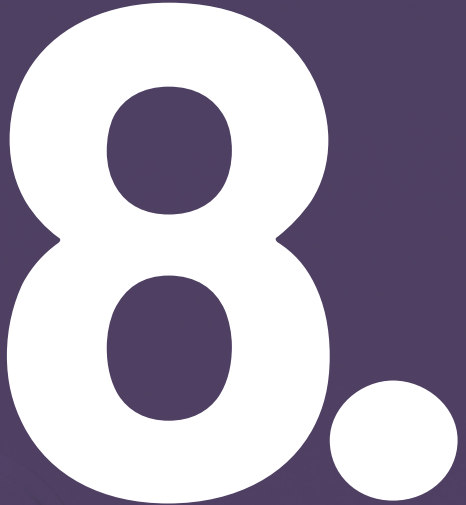

DURANTE EL CONFINAMIENTO 


\section{1. \\ CARACTERIZACIÓN DE LA COMPRA \\ DURANTE EL CONFINAMIENTO}

PERFIL DEL COMPRADOR

Y NO COMPRADOR ONLINE

\section{3 de cada 4 internautas han comprado online durante los meses de marzo a mayo de 2020}

FIGURA 8. 47. ¿HA REALIZADO COMPRAS DE PRODUCTOS O SERVICIOS POR INTERNET DURANTE EL CONFINAMIENTO? (\%)

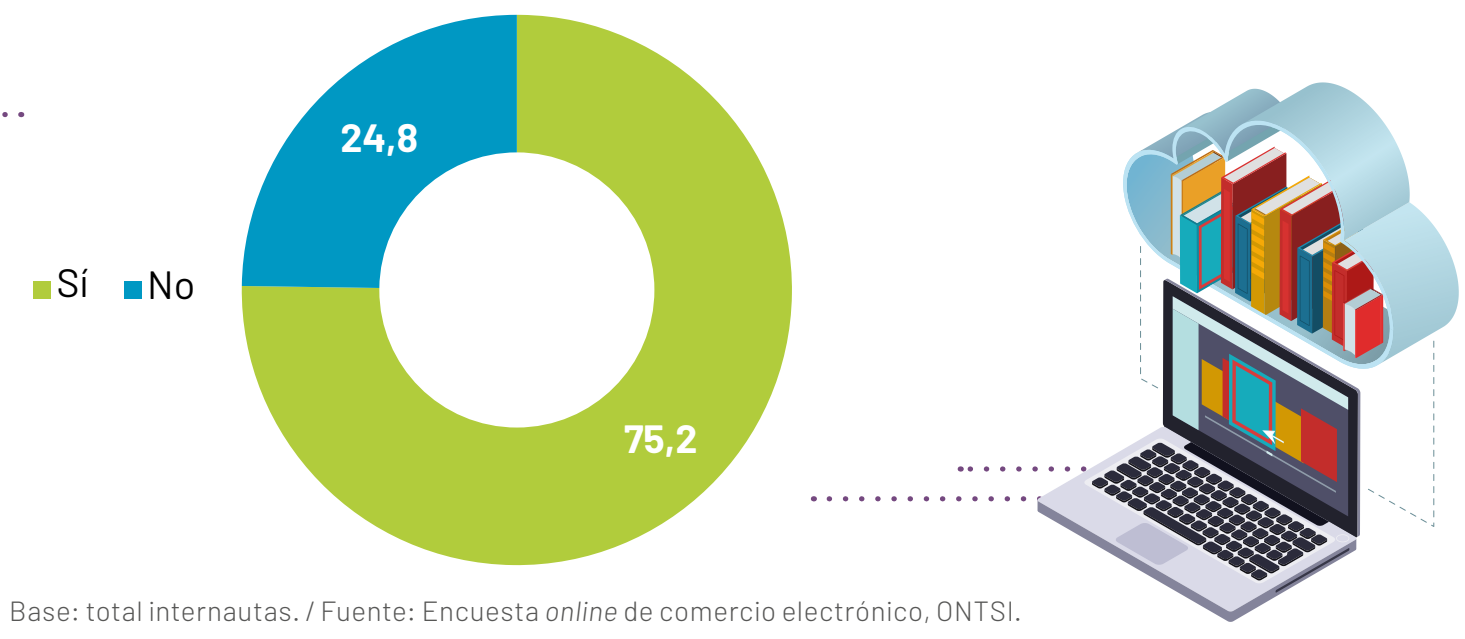

El aislamiento de la población en sus hogares, durante los meses de marzo a mayo de 2020, a causa de la crisis sanitaria por la COVID-19, ha impulsado la compra de productos y servicios online. Si bien en dicho periodo parte de la población ha optado por no comprar a través de Internet $(24,8 \%$ ), son más los que han utilizado esta opción como vía para satisfacer sus necesidades de consumo (75,2\%). En este apartado se realiza un análisis de la compra online a lo largo de estos meses de 2020.

\section{Durante el estado de alarma han comprado por Internet prácticamente el mismo número de personas que durante todo el año anterior 2019}

En comparación con el año 2019, prácticamente se ha registrado el mismo número de compradores durante algo más de 3 meses de duración del estado de alarma, que en todo el año anterior (76,4\% compradores durante el año 2019 frente al 75,2\% del confinamiento).

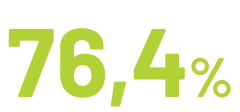

(24,3 MILLONES DE PERSONAS) DE INTERNAUTAS HAN COMPRADO ONLINE

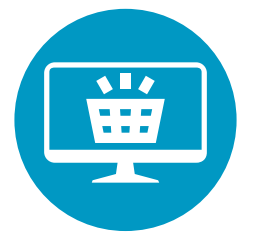

$75,2 \%$

(23 MILLONES DE PERSONAS)

HAN COMPRADO ONLINE DURANTE

LOS MESES DE CONFINAMIENTO

POR LA PANDEMIA DE 2020 


\section{Casi la mitad de los internautas que no han comprado durante 2019 se ha animado a comprar por Internet (47,2\%)}

FIGURA 8. 48. COMPRADORES ONLINE DURANTE EL CONFINAMIENTO, SEGÚN HÁBITOS DE COMPRA DURANTE 2019 (\%)

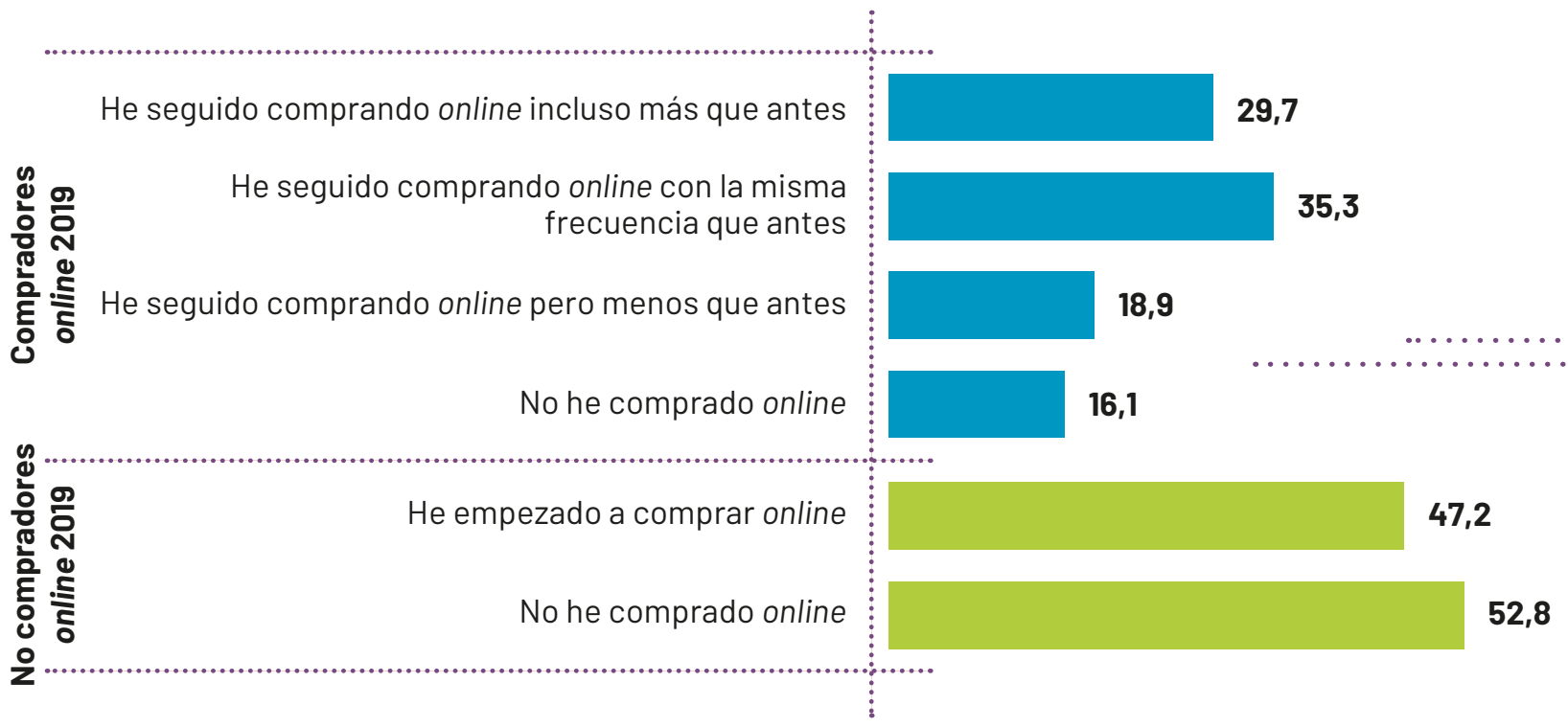

Base: total internautas compradores y no compradores online 2019. / Fuente: Encuesta online de comercio electrónico, ONTSI.

Casi la mitad de los internautas que no habían comprado online durante 2019 se ha decidido a hacerlo durante el estado de alarma (47,2\%). Entre las personas que ya venían realizando compras online durante 2019, el 83,9\% ha vuelto a comprar por Internet durante el período de marzo a mayo de 2020.

El 65\% de los compradores online durante 2019, ha seguido comprando online con la misma 0 superior frecuencia durante el aislamiento, concretamente tres de cada diez consumidores online habituales lo han hecho con mayor frecuencia.

Por el contrario, el 35\% ha optado por reducir sus compras online o incluso llegar a prescindir de ellas. En el apartado 8.2 Frenos e impulsores de la compra online durante el confinamiento, se profundiza en el análisis de los motivos que han llevado a los internautas a actuar de una manera u otra durante ese periodo de tiempo.

Según las variables socio demográficas, la compra online como consecuencia de la crisis sanitaria, fue más habitual entre las mujeres que entre los hombres, tanto si eran compradores durante el año 2019 como si no lo eran.

Por grupos de edad, los más jóvenes son los que más se han animado a comprar entre los no compradores en 2019. Entre los perfiles que venían realizando compras online durante el año 2019, el porcentaje de compradores online durante el periodo de aislamiento, en el grupo de edad de 16 a 44 años, ronda el 85\%, y el 88\% entre aquellos de 65 a 74 años.

Entre las personas menores de 45 años que no habían realizado compras online, el porcentaje de compra durante este periodo está entre el 50\% y el 60\%. Los mayores de 45 años, por su parte, integran el grupo mayoritario de quienes no compraron en 2019 y mantuvieron su negativa durante el confinamiento. 
TABLA 8. 27. COMPRADORES ONLINE DURANTE EL CONFINAMIENTO, SEGÚN GÉNERO Y EDAD (\%)

\begin{tabular}{|c|c|c|c|c|c|c|c|c|c|c|}
\hline & & \multirow{2}{*}{ TOTAL } & \multicolumn{2}{|c|}{ GÉNERO* } & \multicolumn{6}{|c|}{ EDAD* } \\
\hline & & & Hombres & Mujeres & $\begin{array}{l}16-24 \\
\text { años }\end{array}$ & $\begin{array}{l}25-34 \\
\text { años }\end{array}$ & $\begin{array}{c}35-44 \\
\text { años }\end{array}$ & $\begin{array}{l}45-54 \\
\text { años }\end{array}$ & $\begin{array}{l}55-64 \\
\text { años }\end{array}$ & $\begin{array}{r}65-74 \\
\text { años } \\
\end{array}$ \\
\hline \multirow{2}{*}{$\begin{array}{c}\text { COMPRADOR } \\
\text { ONLINE } 2019\end{array}$} & Compradores & 83,9 & 83,6 & 84,1 & 84,8 & 85,4 & 85,1 & 82,7 & 79,1 & 88,0 \\
\hline & No compradores & 16,1 & 16,4 & 15,9 & 15,2 & 14,6 & 14,9 & 17,3 & 20,9 & 12,0 \\
\hline \multirow{2}{*}{$\begin{array}{r}\text { NO COMPRADOR } \\
\text { ONLINE } 2019\end{array}$} & Compradores & 47,2 & 44,4 & 49,7 & 51,1 & 60,3 & 57,6 & 39,6 & 43,4 & 40,4 \\
\hline & No compradores & 52,8 & 55,6 & 50,3 & 48,9 & 39,7 & 42,4 & 60,4 & 56,6 & 59,6 \\
\hline
\end{tabular}

Base: total internautas /*Base: total internautas por categorías género y edad. / Fuente: Encuesta online de comercio electrónico, ONTSI.

\section{TIPO DE PRODUCTOS ADQUIRIDOS}

\section{Los productos de alimentación, bebidas y limpieza del hogar han registrado el principal incremento de ventas. 3 de cada 10 compradores han sumado estos productos a su cesta online}

TABLA 8. 28. ¿OUÉ TIPO DE PROCUTOS O SERVICIOS ADQUIRIÓ POR INTERNET DURANTE EL PERIODO DE CONFINAMIENTO? (\%)

\begin{tabular}{|c|c|c|}
\hline & \multicolumn{2}{|c|}{ PORCENTAJE DE COMPRADORES } \\
\hline & $\begin{array}{l}\text { DURANTE TODO } \\
\text { ELANOO } 2019 \\
\end{array}$ & $\begin{array}{c}\text { DURANTEEL } \\
\text { CONFINAMIENTO } \\
\end{array}$ \\
\hline Ropa, calzado y complementos & 59,2 & 38,5 \\
\hline Alimentación, bebidas y productos de limpieza del hogar & 23,7 & 30,5 \\
\hline Salud y cuidado personal & 32,4 & 27,2 \\
\hline Comida a domicilio de restaurantes & 38,5 & 21,2 \\
\hline Electrodomésticos, muebles, hogar, bricolaje y jardín & 30,5 & 21,0 \\
\hline Deporte y fitness & 24,6 & 15,7 \\
\hline Material de oficina, papelería e imprenta & 17,7 & 13,1 \\
\hline Mascotas & 16,2 & 12,3 \\
\hline Juguetes y juegos de mesa & 22,2 & 11,8 \\
\hline Libros, cómics, revistas y periódicos en formato físico & 20,4 & 11,3 \\
\hline s, tabletas, accesorios y otros productos de electrónica & 22,6 & 11,2 \\
\hline arga o servicio online de películas, música y videojuegos & 18,5 & 9,4 \\
\hline éfonos móviles, smartphones y accesorios relacionados & 30,3 & 9,4 \\
\hline os, cómics, revistas y periódicos en formato electrónico & 14,3 & 8,1 \\
\hline Formación y cursos online & 15,0 & 6,8 \\
\hline s, música y videojuegos para recibirlos en formato físico & 12,1 & 4,9 \\
\hline Joyería, bisutería y relojes & 13,6 & 4,6 \\
\hline Servicios de Internet y telefonía & 19,7 & 4,3 \\
\hline Reserva de alojamiento y paquetes turísticos & 52,1 & 3,6 \\
\hline Juegos de azar, concursos, apuestas y lotería & 9,8 & 3,4 \\
\hline Servicios financieros & 12,1 & 3,1 \\
\hline Programas, software y aplicaciones para móvil o tableta & 11,1 & 3,0 \\
\hline Artículos de coleccionismo y antigüedades & 4,9 & 2,4 \\
\hline hido de pago en redes sociales, profesionales y de citas & 2,6 & 1,0 \\
\hline $\begin{array}{l}\text { Otros tipos de producto }\end{array}$ & 1,4 & 2,7 \\
\hline
\end{tabular}

Base: total internautas compradores online, compradores durante el confinamiento y compradores durante 2019. / Fuente: Encuesta online de comercio electrónico, ONTSI.

Por categorías de productos y servicios, respecto a 2019, se observa un descenso generalizado en todos las compras, salvo en materia de alimentación, bebidas y productos de limpieza para el hogar. 


\section{Ropa, calzado y complementos han sido los productos preferidos para la compra online entre marzo y mayo de 2020}

La ropa, calzado y complementos (38,5\%), alimentación, bebidas y productos de limpieza del hogar $(30,5 \%)$ y salud y cuidado personal $(27,2 \%)$, fueron las categorías de productos más adquiridas durante el estado de alarma.

El descenso más significativo de compradores por categoría de producto o servicio durante este período, se observa en la compra relacionada con el ámbito turístico: el porcentaje de reservas de alojamiento y paquetes turísticos cae 48,5 puntos porcentuales.

\section{El aislamiento en los hogares ha impulsado en mayor medida las compras online en el sector de alimentación, bebidas y productos de limpieza del hogar}

La única categoría de compra que ha visto crecer su número de compradores es la alimentación, bebidasy productos de limpieza del hogarconun incremento de 7,9 p.p. en su porcentaje de compradores.

En función del género, se observa que los hombres han optado principalmente por adquirir productos de alimentación, bebidas y la limpieza del hogar (32\%); ropa, calzado y complementos (30,6\%) y electrodomésticos, muebles, hogar, bricolaje y jardín (22,7\%). Las mujeres, en cambio, se decantan por adquirir online principalmente ropa, calzado y complementos $(46,2 \%)$; productos para la salud y el cuidado personal $(31,7 \%$ ) y productos de alimentación, bebidas y para la limpieza del hogar (28,9\%).

FRECUENCIA DE COMPRA ONLINE

\section{Las compras online mensuales o semanales han sido la opción más frecuente para el $69,4 \%$ de los compradores, mientras que el $23,5 \%$ ha comprado de forma esporádica}

FIGURA 8. 49. ¿CON OUÉ FRECUENCIA COMPRÓ POR INTERNET DURANTE EL CONFINAMIENTO? (\%)
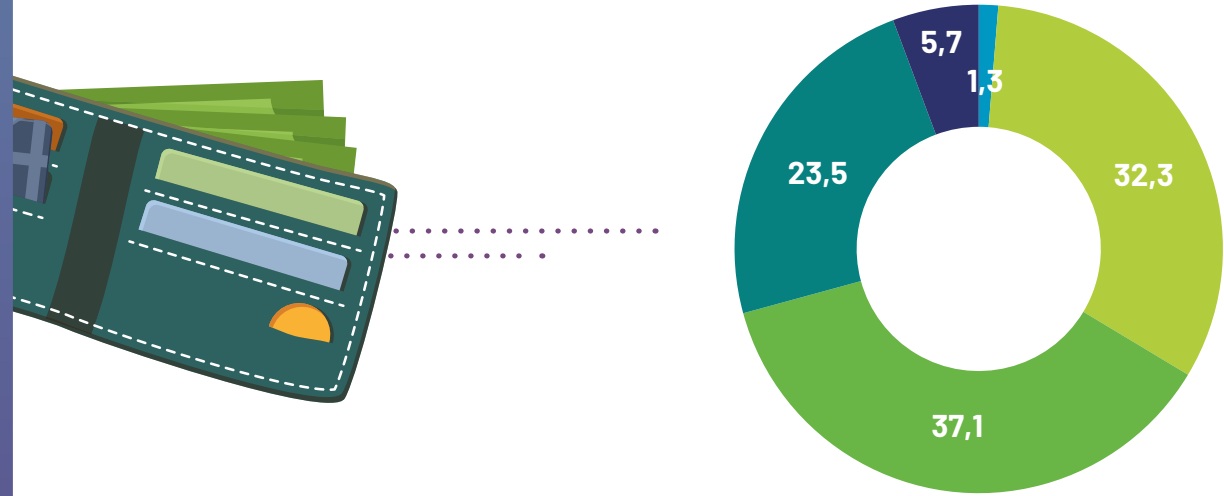

- Diariamente

- Semanalmente

- Mensualmente

- Con menor frecuencia

- No lo sé

Base: total internautas compradores online durante el confinamiento. / Fuente: Encuesta online de comercio electrónico, ONTSI

Ante un estado de alarma prorrogado durante algo más de tres meses, las compras online mensuales o semanales han sido la opción más frecuente para prácticamente siete de cada diez compradores, convirtiéndose en un hábito para la mayoría de los consumidores.

Los nuevos compradores surgidos durante este periodo, es decir, aquellos que no habían comprado nunca o no han comprado en 2019 han comprado mensualmente en un 26,8\% de los casos, pero han destacado los que han realizado compras con menor frecuencia $(44,4 \%)$. 
Por el contrario, los compradores que venían realizando compras con anterioridad y que afirman haber incrementado su volumen de compra online, han efectuado principalmente compras semanales $(62,3 \%)$. El resto de compradores que mantuvieron el volumen de compra respecto al año anterior se decantan principalmente por realizar compras mensuales $(49,6 \%)$ y los que han reducido su volumen de compras online prefieren las compras puntuales (48,4\%).

\section{GASTO DE LOS COMPRADORES ONLINE DURANTE EL CONFINAMIENTO}

\section{El $45 \%$ de los compradores ha gastado en compras online entre 101 y 500 euros}

FIGURA 8. 50. ¿CUÁNTO ESTIMA QUE HA SIDO EL GASTO TOTAL APROXIMADO EN SUS COMPRAS DURANTE EL CONFINAMIENTO?(\%)

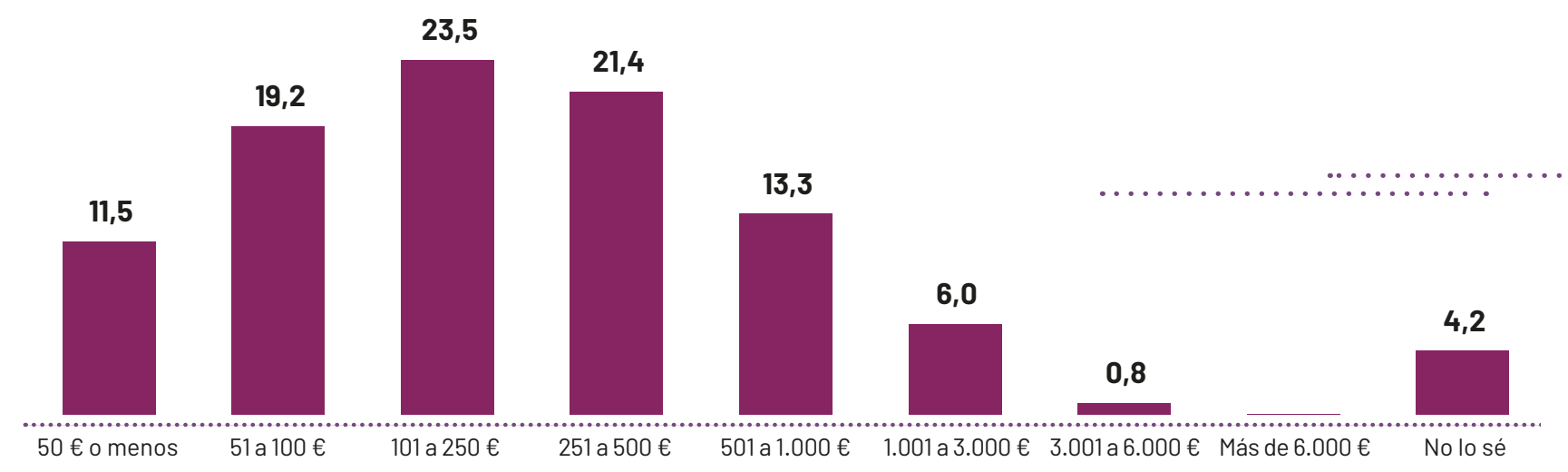

Base: total internautas compradores online durante el confinamiento. / Fuente: Encuesta online de comercio electrónico, ONTSI.

El gasto online por consumidor ha supuesto un desembolso menor o igual a 500 euros para el $75,6 \%$ de los consumidores.

Si se compara el gasto online durante el perío do que comprendió el estado de alarma y el indicado para todo el año 2019, el volumen de consumidores que indica haber gastado 501 euros o más ha pasado del 34\% durante el año 2019 al 20,1\% durante el periodo de aislamiento. Considerando la diferencia de meses entre ambos periodos, es importante el desembolso económico que han realizado los consumidores en el año 2020, tratándose de un periodo de tiempo mucho más reducido.

Las diferencias de gasto según género revelan un mayor porcentaje de hombres que gastan más de 500 euros ( $24,4 \%$ vs $16 \%$ de mujeres).

En cuanto a la edad, se aprecia que, de forma general, los más jóvenes han gastado menos que los compradores de edad más avanzada.

TABLA 8. 29. COMPARATIVA DE GASTO TOTAL ESTIMADO EN COMPRAS ONLINE DURANTE EL CONFINAMIENTO, SEGÚN GÉNERO Y EDAD (\%)

\begin{tabular}{|c|c|c|c|c|c|c|c|c|c|}
\hline & \multirow[b]{2}{*}{ TOTAL } & \multicolumn{2}{|c|}{ GÉNERO* } & \multicolumn{6}{|c|}{ EDAD* } \\
\hline & & Hombres & Mujeres & $\begin{array}{l}16-24 \\
\text { años }\end{array}$ & $\begin{array}{c}25-34 \\
\text { años }\end{array}$ & $\begin{array}{c}35-44 \\
\text { años }\end{array}$ & $\begin{array}{c}45-54 \\
\text { años }\end{array}$ & $\begin{array}{r}55-64 \\
\text { años }\end{array}$ & $\begin{array}{r}65-74 \\
\text { años }\end{array}$ \\
\hline Gasto total de 500 euros o menos & 75,6 & 72,1 & 79,0 & 87,7 & 79,9 & 74,9 & 73,4 & 69,4 & 68,6 \\
\hline Gasto total de 501 euros o más & 20,1 & 24,4 & 16,0 & 10,6 & 17,3 & 20,5 & 22,0 & 23,9 & 27,1 \\
\hline Nolo sé & 4,2 & 3,5 & 4,9 & 1,8 & 2,8 & 4,7 & 4,6 & 6,6 & 4,3 \\
\hline
\end{tabular}

Base: total internautas compradores online durante el confinamiento. / Base: total internautas compradores online durante el confinamiento, por categorías género y edad. / Fuente: Encuesta online de comercio electrónico, ONTSI. 


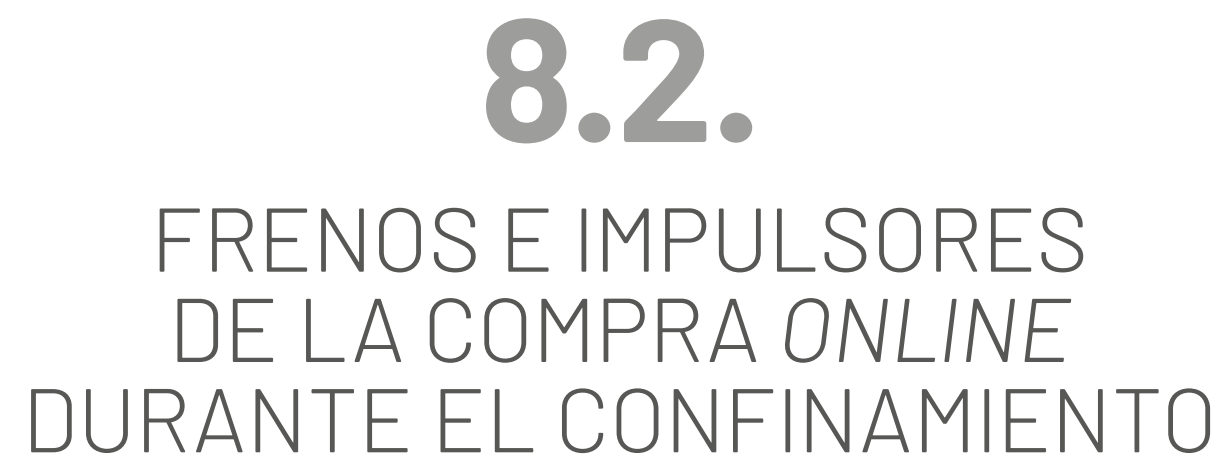

RAZONES PARA NO COMPRAR

ONLINE DURANTE EL CONFINAMIENTO

\section{La reducción de las compras a productos esenciales es el principal motivo por el que los internautas no han realizado compras online}

FIGURA 8. 51. ¿CÚALES SON LAS PRINCIPALES RAZONES POR LAS OUE NO HA COMPRADO O CONTRATADO ALGÚN PRODUCTO O SERVICIO ONLINE DURANTE EL CONFINAMIENTO? (\%)

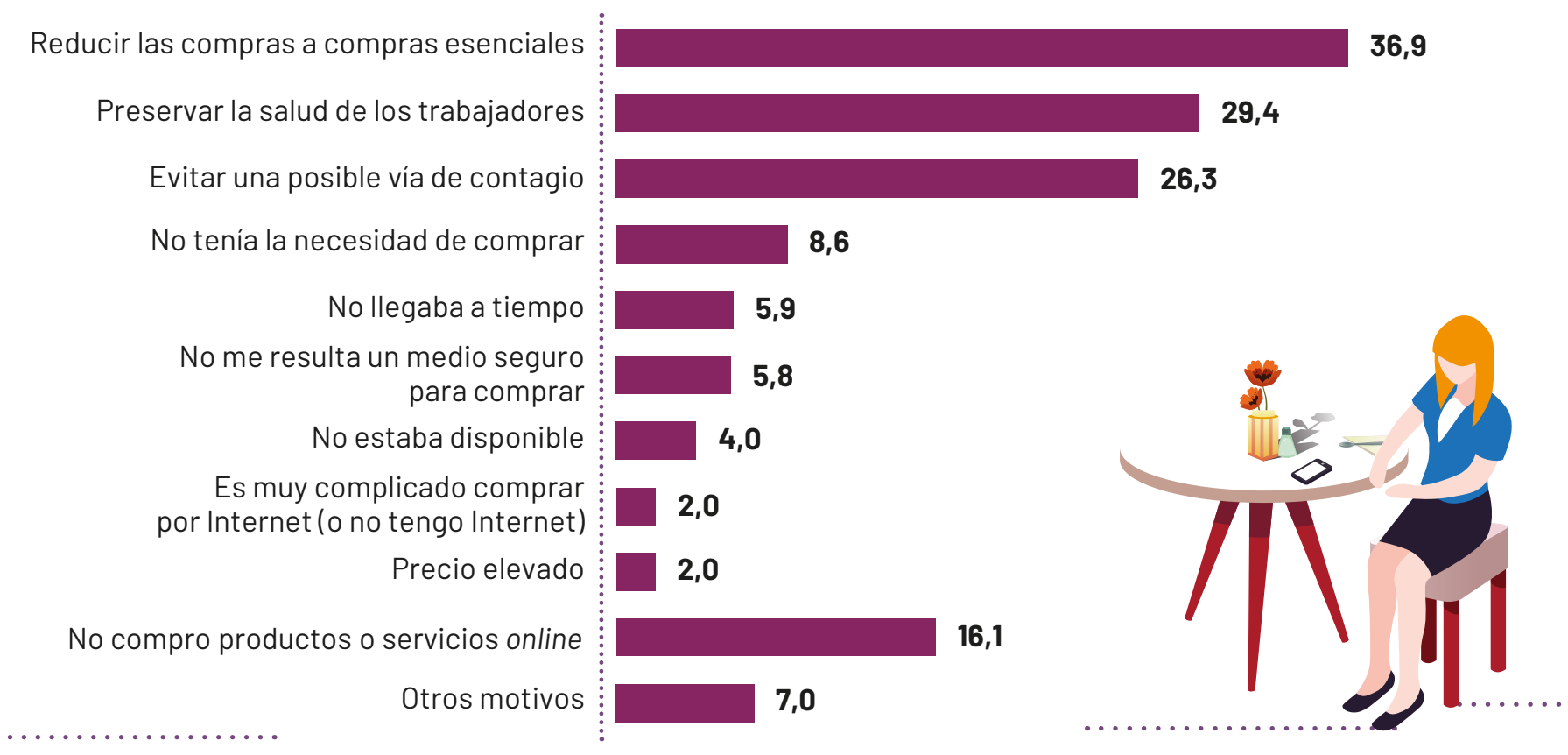

Base: total internautas no compradores online durante el confinamiento. / Fuente: Encuesta online de comercio electrónico, ONTSI.

Entre los motivos para no comprar online durante este período, destacan la reducción de las compras a las esenciales (36,9\%), querer preservar la salud de los trabajadores $(29,4 \%)$ o evitar una posible vía de contagio (26,3\%).

El resto de motivos están relacionados o bien con la falta de necesidad de hacer compras online $(8,6 \%)$ o bien a los asociados a la propia transacción de compra, como que no llegaba a tiempo el producto o servicio deseado (5,9\%), no estaba disponible (4\%), tenía un precio elevado (2\%) o dificultades (2\%) e inseguridades asociadas a la compra online (5,8\%).

Entre los otros motivos adicionales recogidos $(7 \%)$ se encuentran principalmente los relacionados con preferir comprar en tiendas de proximidad o la falta de recursos económicos. 
Si se atiende a la experiencia de compra previa al momento de la pandemia, se percibe que entre aquellos que no compraron durante 2019 las principales razones por las que no se ha adquirido algún producto o servicio durante el confinamiento difieren, pasando a ser la principal la no compra de productos o servicios online (30,6\%), seguido de la reducción de las compras a las esenciales $(28,8 \%)$. Entre los que sí han comprado online en 2019, destacan los tres principales motivos generales observados en el conjunto de los no compradores online durante el confinamiento.

\section{RAZONES PARA COMPRAR ONLINE DURANTE EL CONFINAMIENTO}

\section{La seguridad ante el contagio es la razón principal para el 46,1\% de los compradores para optar por el B2C} FIGURA 8. 52. ¿CÚALES SON LAS PRINCIPALES RAZONES POR LAS OUE HA COMPRADO O CONTRATADO ALGÚN PRODUCTO
O SERVICIO ONLINE DURANTE EL CONFINAMIENTO? (\%)

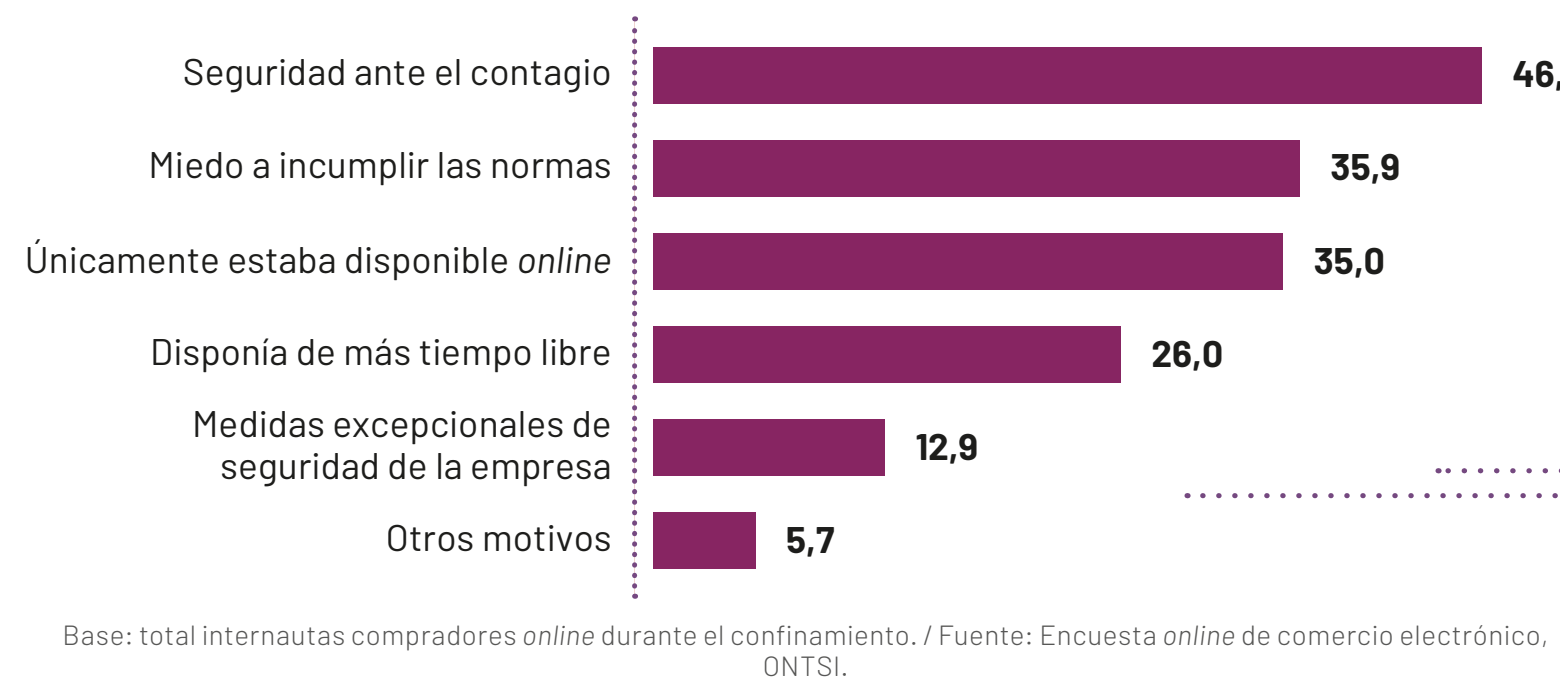
ONTSI.

Los principales motivos para comprar online durante este período han sido considerar la opción de compra online como la más segura para prevenir el contagio $(46,1 \%)$, el miedo a salir de casa e incumplir alguna normativa (35,9\%) o tratarse únicamente de productos disponibles vía online(35\%).

Entre los nuevos compradores online de esta etapa, la seguridad ante el contagio (35\%) y el miedo a incumplir la normativa en el caso de salir de casa $(34,3 \%)$ han sido las principales razones que los han llevado a comprar online por primera vez.

Entre los compradores más habituales, la percepción de la compra online como el medio más seguro ante el contagio ha sido la principal razón, tanto para quienes incrementaron sus compras durante el confinamiento (61\%) como para los que han continuado comprando en la misma medida (41,5\%).

Entre los que redujeron sus compras online, el principal motivo de compra indicado es que era la única vía disponible para adquirir los productos buscados (46,1\%).

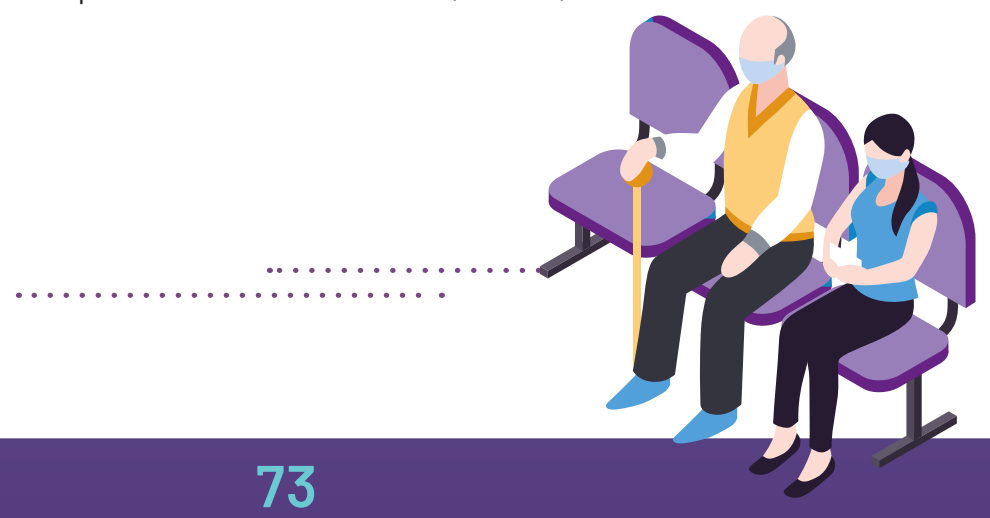




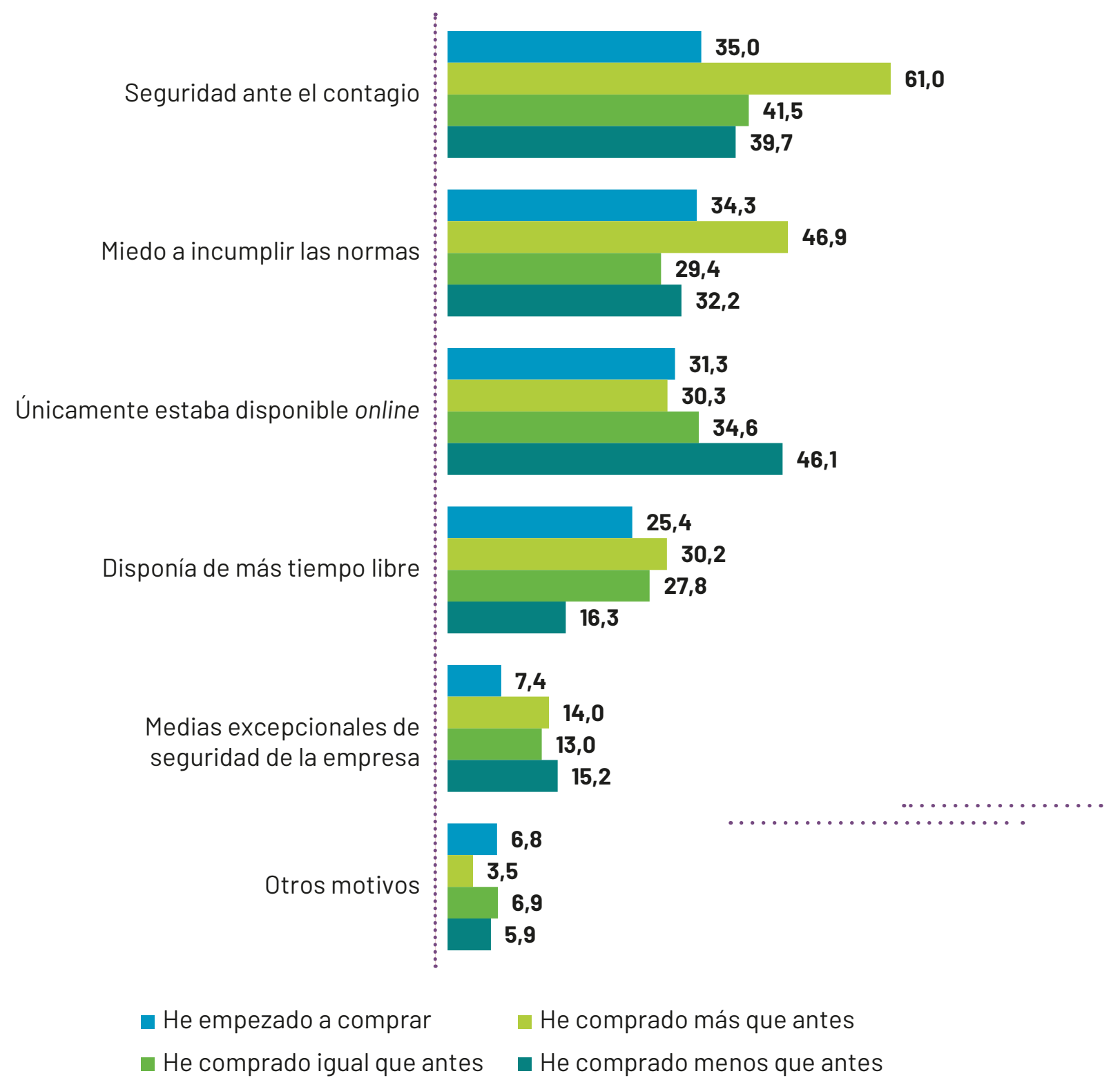

Base: internautas compradores online durante el confinamiento, según hábitos de compra durante 2019. / Fuente: Encuesta online de comercio electrónico, ONTSI.

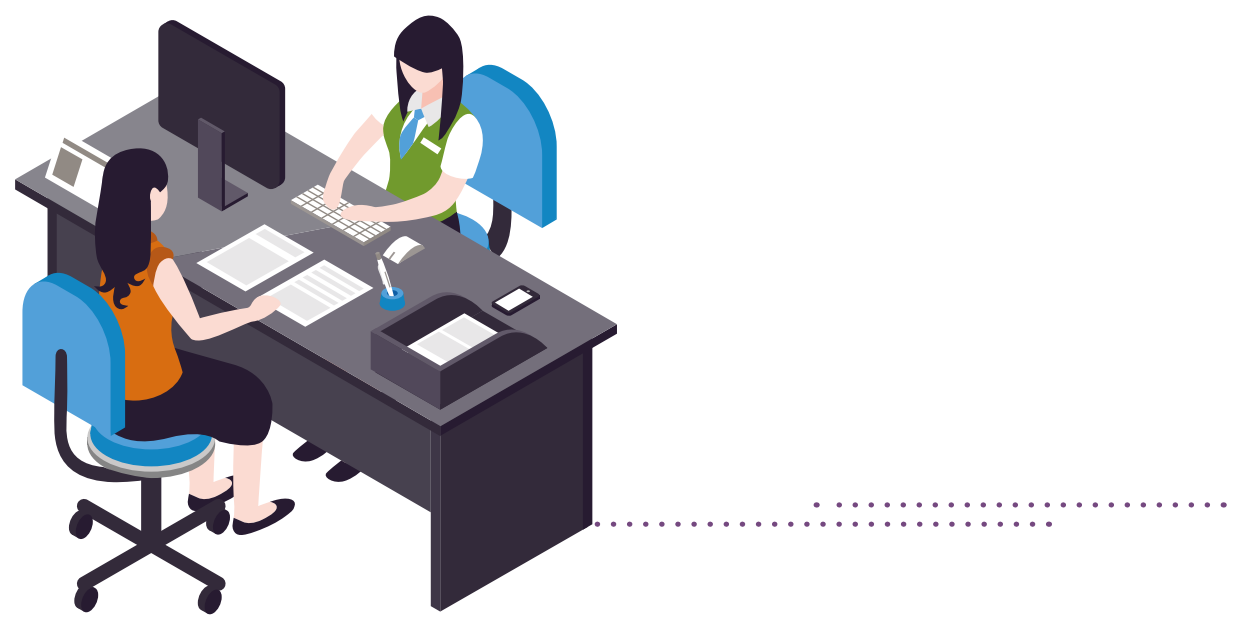




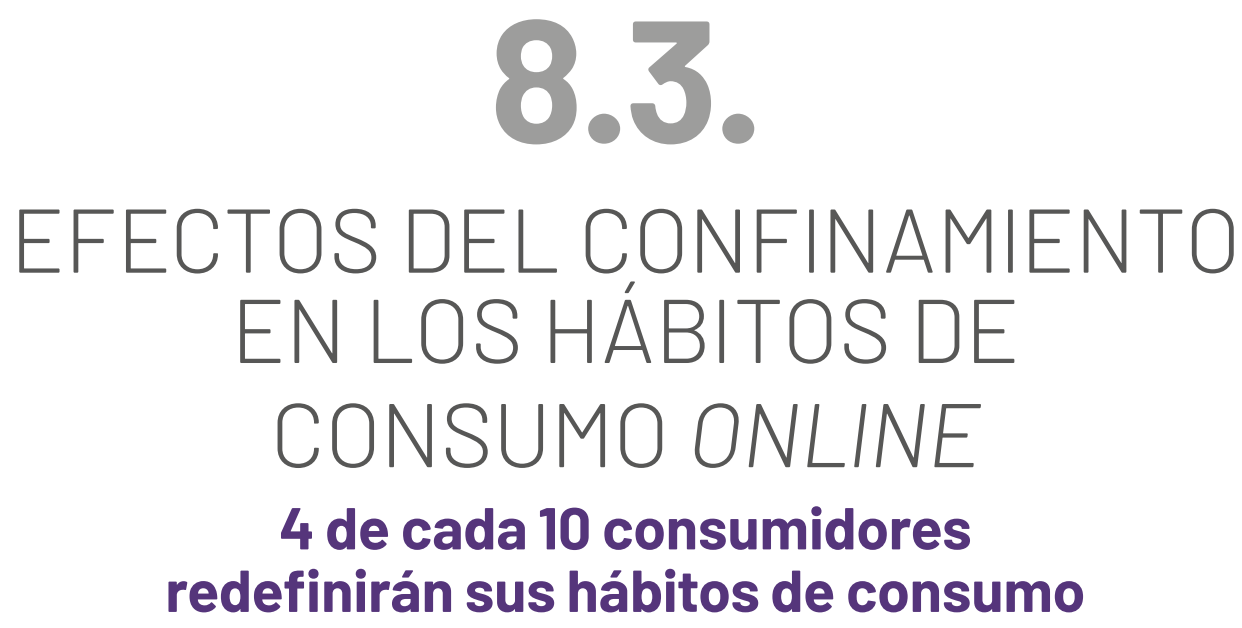

FIGURA 8. 54. ¿CONSIDERA OUE HABER VIVIDO ESTAS CIRCUNSTANCIAS ESPECIALES DE CONFINAMIENTO MODIFICARÁ SUS HÁBITOS DE CONSUMO ONLINE EN EL FUTURO? (\%)

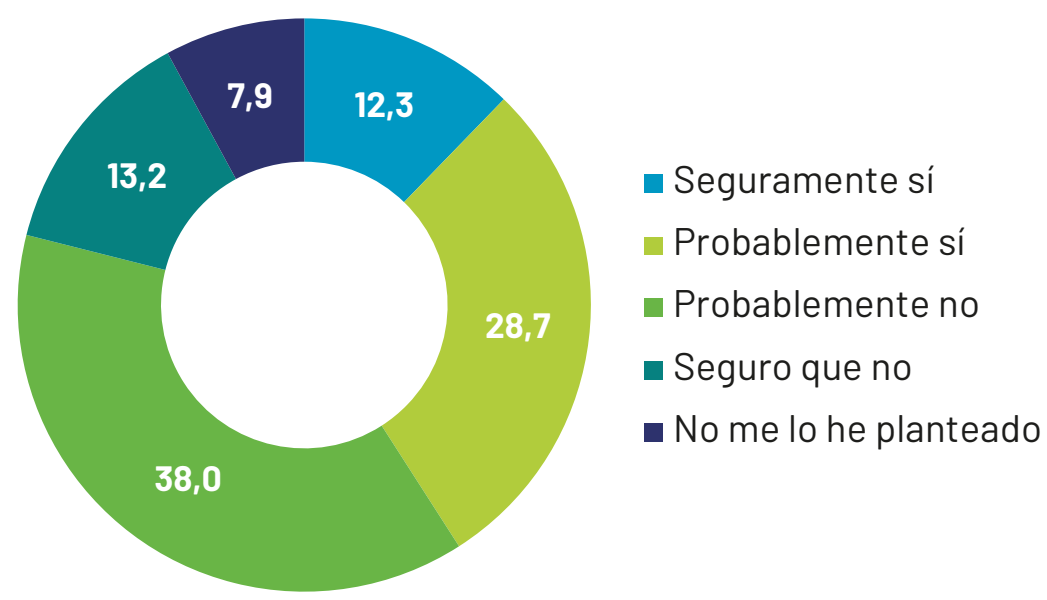

Base: total internautas compradores online durante el confinamiento. / Fuente: Encuesta online de comercio electrónico, ONTSI.

Se ha preguntado a los compradores online sobre tres escenarios con relación al futuro de su consumo online. Mientras el 7,9\% de quienes compraron durante el confinamiento no se ha planteado si modificará o no sus hábitos en un futuro, el $41 \%$ de los consumidores se posiciona en un escenario de posible cambio y el 51,2\% en un escenario en el que probablemente se mantengan sus hábitos.

Las mujeres son más proclives al cambio que los hombres. De hecho, el 46,1\% afirma que cambiará sus hábitos de consumo, mientras que los hombres ven menos probable que se produzcan cambios en un futuro $(57,7 \%)$.

Respecto a la variable sociodemográfica edad, conforme se incrementa la edad del consumidor, decrece la percepción de un posible cambio en sus hábitos de consumo. El 64,7\% de los consumidores, que tienen entre 65 y 74 años, afirma que no cambiará sus hábitos.

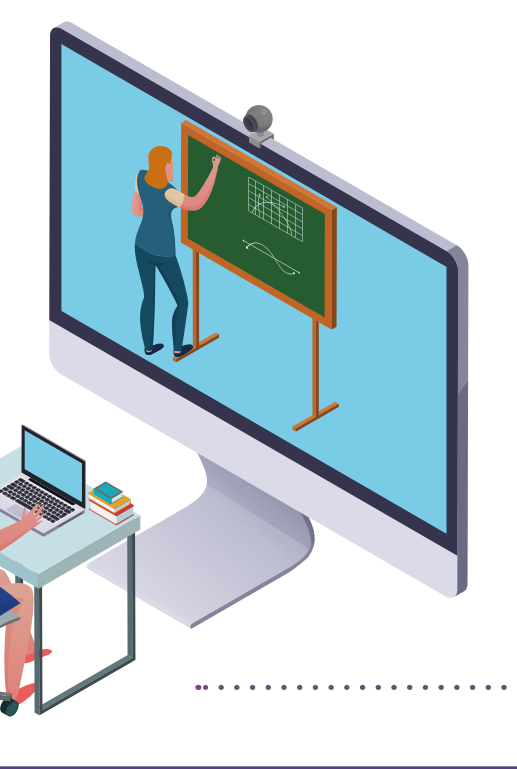




\section{La doble naturaleza del cambio en el consumo: el aumento de las compras online o la compra en el pequeño comercio de proximidad}

FIGURA 8. 55. ¿CÓMO CONSIDERA OUE SE MODIFICARÁN SUS HÁBITOS DE CONSUMO?(\%)

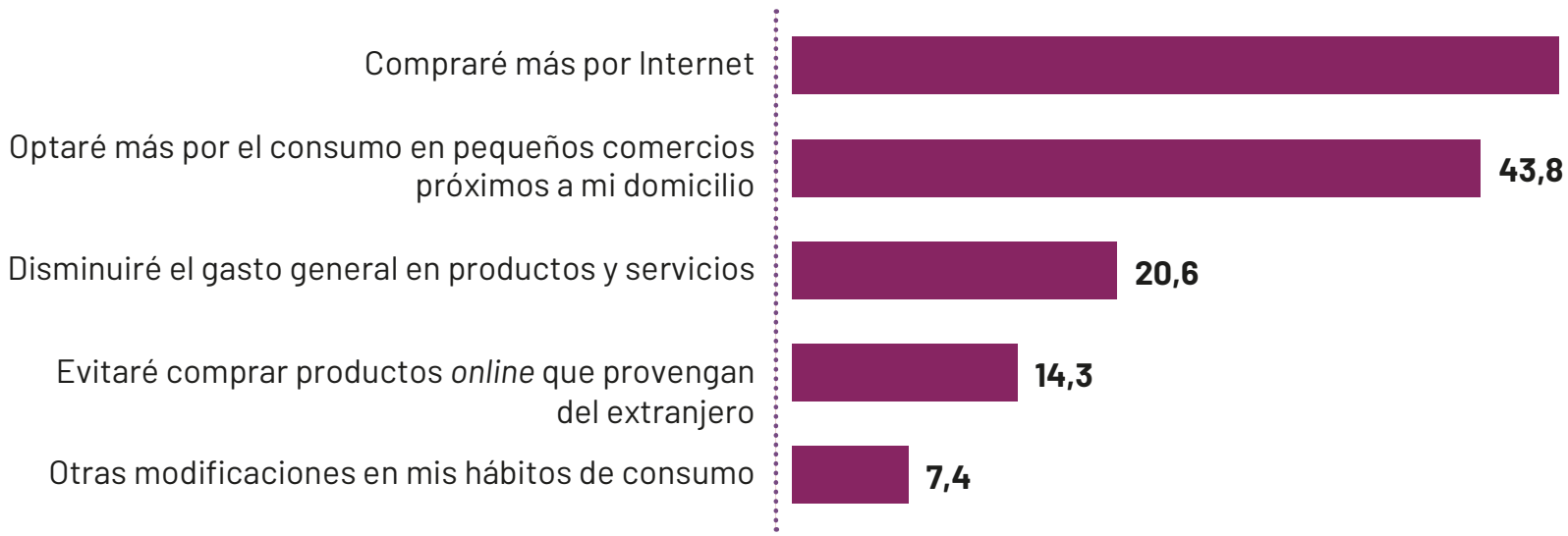

Base: internautas compradores online durante el confinamiento que consideran que cambiaran sus hábitos de consumo. I Fuente: Encuesta online de comercio electrónico, ONTSI.

El incremento de las compras online es el principal cambio previsto por los consumidores, tras la experiencia vivida durante la crisis sanitaria (48,7\%). Le acompaña un incremento de las compras en pequeños comercios de proximidad (43,8\%), probablemente como instrumento para facilitar la recuperación económica de los negocios de su entorno más cercano.

Por otro lado, dos de cada diez internautas compradores durante el confinamiento, reducirán el gasto general en productos y servicios, probablemente debido al efecto económico de la crisis y la necesidad de reducir el consumo para adaptarse a la nueva situación económica.

Finalmente, evitar el consumo de productos procedentes del extranjero es uno de los posibles cambios indicados por el 14,3\% de los internautas que esperan modificar sus hábitos.

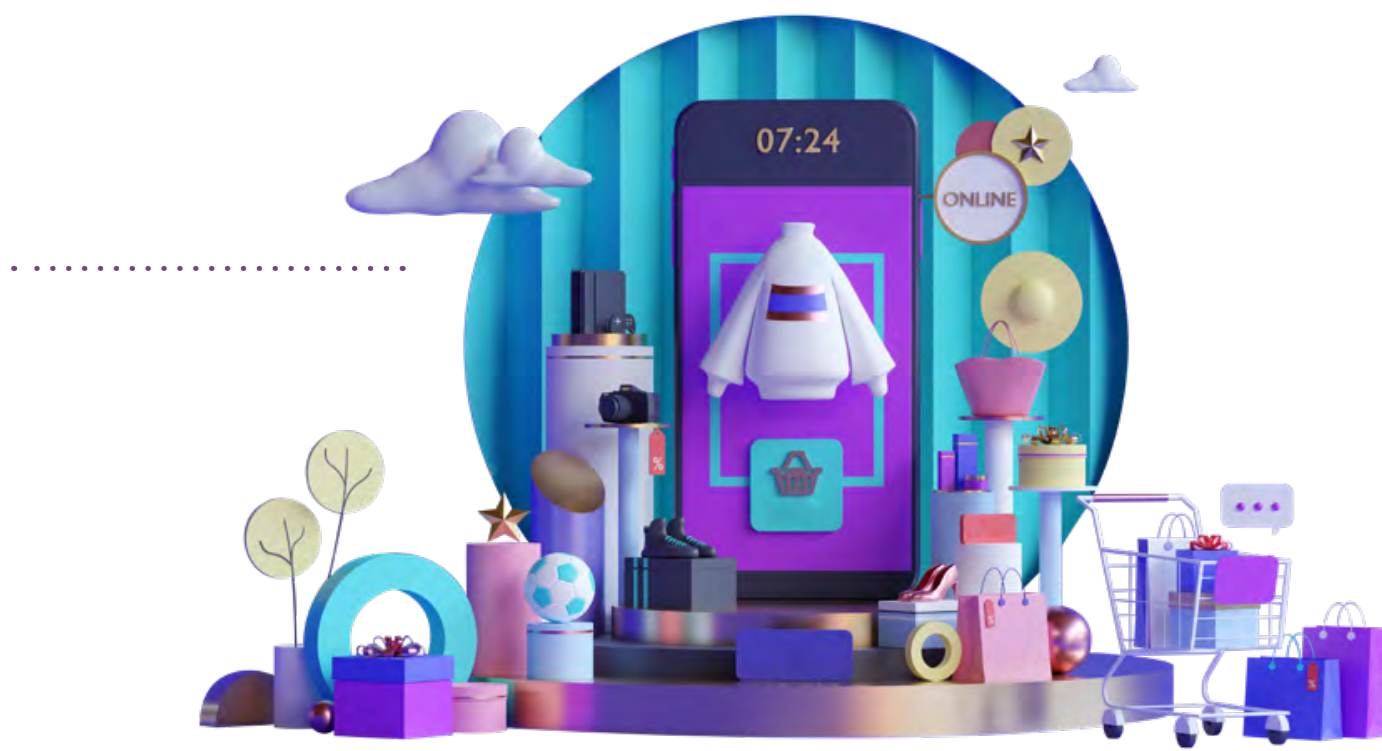




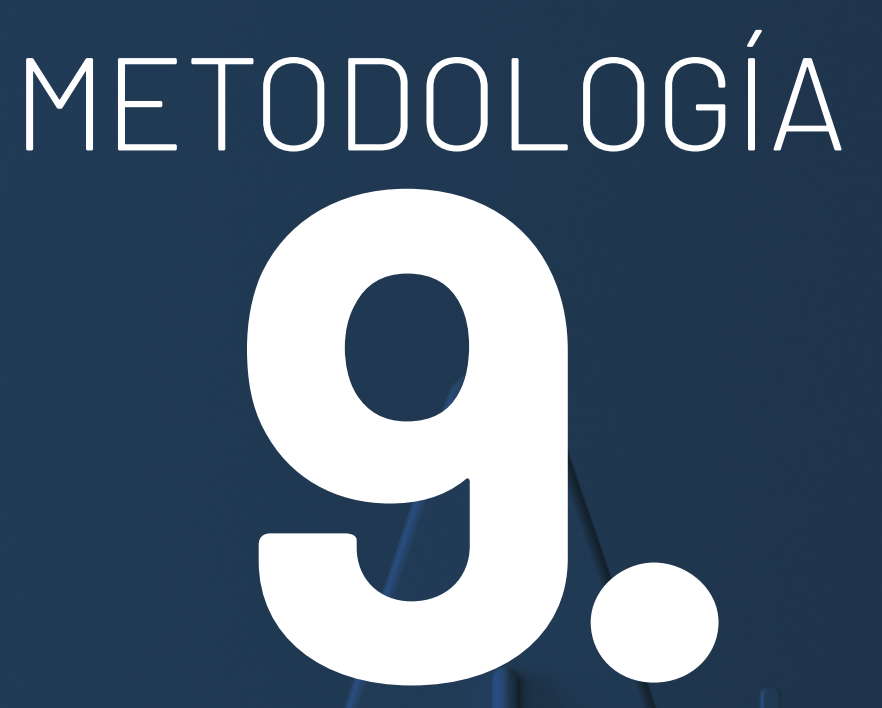




\section{1. \\ CAMBIOS RESPECTO \\ A LA EDICIÓN ANTERIOR}

En la edición 2020 del informe se han implementado algunos cambios en el cuestionario, con el fin de incorporar preguntas relacionadas con los hábitos de compra de bienes y servicios a través de Internet durante el periodo de confinamiento derivado del estado de alarma que entró en vigor en España el pasado 15 de marzo de 2020 y se extendió durante aproximadamente 3 meses y que ha conllevado importantes restricciones de movilidad a la ciudadanía.

La incorporación de este nuevo bloque de preguntas ha provocado que durante esta edición se haya prescindido de algunos aspectos que se venían analizando durante años anteriores, como la compra de productos offline. Esto ha permitido mantener una duración media del cuestionario acorde a la técnica de investigación planteada, evitando posibles dificultades en la captación o en la recogida de información.

Además, con el fin de mitigar el efecto reactivo del panel online en los resultados (se supone un uso más intensivo de Internet por parte de los encuestados, basándonos en los resultados obtenidos durante la pasada edición de 2019) y obtener una muestra de la población más próxima al internauta dentro de la población general, se ha introducido en el muestreo como variable de control la frecuencia de uso de Internet del encuestado. Con esto se ha tratado de obtener una representación de la muestra en lo referido a la frecuencia de uso de Internet, más próxima a los resultados de la «Encuesta sobre Equipamiento y Uso de Tecnologías de la Información y Comunicación en los Hogares» (utilización de productos TIC por las personas, uso de Internet y frecuencia de uso) del INE.

Es posible que determinadas comparativas de resultados con la edición de 2019, como por ejemplo la intensidad de compra por categorías de producto, se hayan visto afectadas por la incorporación de la variable de control de frecuencia de uso de Internet al muestreo. Durante esta edición del estudio se observa que los resultados han seguido una tendencia evolutiva más próxima a los análisis realizados durante la edición de 2018, siendo por lo tanto una muestra más próxima a la población general a pesar del cambio metodológico introducido el pasado año.

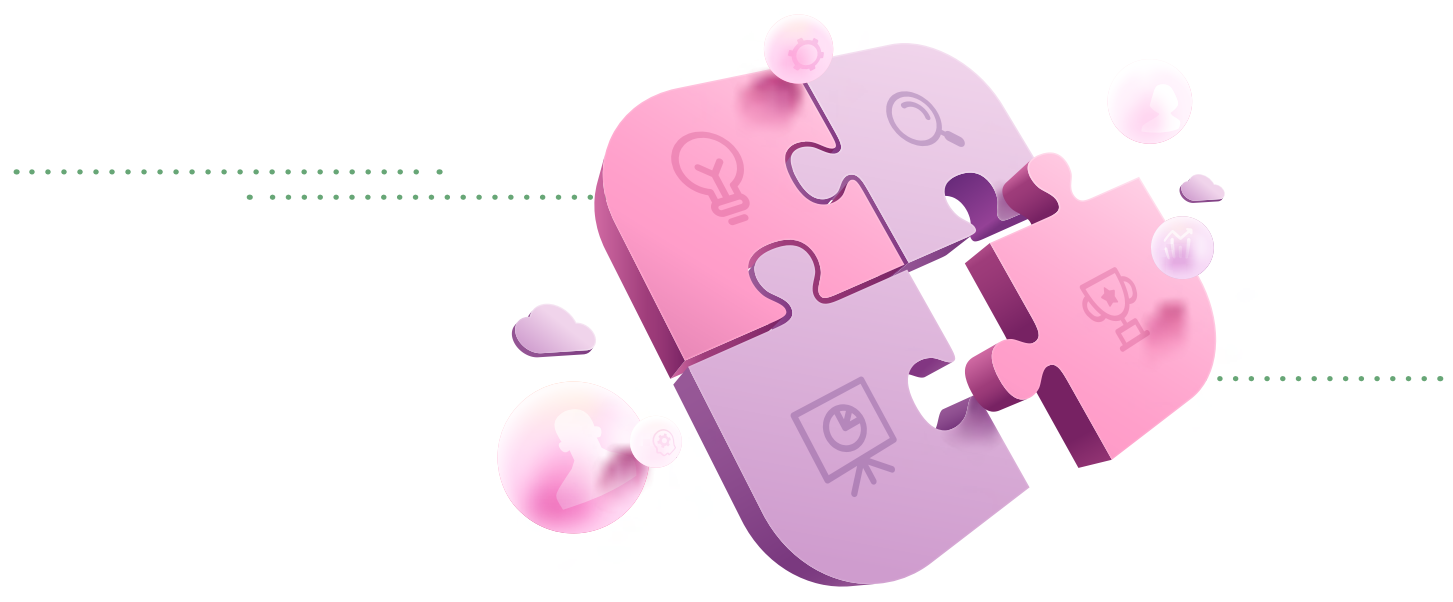




\section{2. \\ FICHA TÉCNICA}

La metodología implementada para la realización del estudio consiste en una fase cuantitativa, basada en la realización de una encuesta a usuarios de un panel online.

\begin{tabular}{|c|c|}
\hline ÁMBITO & Nacional (Península, Baleares y Canarias). \\
\hline UNIVERSO & $\begin{array}{l}\text { Población internauta de } 16 \text { a } 74 \text { años ( } 34.910 .798 \text { individuos, según datos del INE: } \\
\text { Encuesta sobre equipamiento y uso de tecnologías de información y comunicación en } \\
\text { los hogares). }\end{array}$ \\
\hline TÉCNICA DE RECOGIDA & Encuesta online (CAWI), a través de panel online. \\
\hline TAMAÑO DE LA MUESTRA & 2.900 personas. \\
\hline MUESTREO & $\begin{array}{l}\text { Se han establecido cuotas por género, edad y tamaño de hábitat, según datos del INE. } \\
\text { Se ha incorporado como variable de control para la selección de los encuestados la } \\
\text { frecuencia de uso de Internet (+-5\% sobre el total de resultados), según la «Encuesta } \\
\text { sobre Equipamiento y Uso de Tecnologías de la Información y Comunicación en los } \\
\text { Hogares» (utilización de productos TIC por las personas, uso de Internet y frecuencia } \\
\text { de uso). }\end{array}$ \\
\hline PONDERACIÓN & $\begin{array}{l}\text { Los resultados han sido ponderados para corregir las posibles desviaciones de la } \\
\text { variable frecuencia de uso de Internet, considerando las variables género y edad. }\end{array}$ \\
\hline $\begin{array}{l}\text { NIVEL DE CONFIANZA } \\
\text { Y MARGEN DE ERROR }\end{array}$ & Nivel de confianza del $95 \%(p=q=50 \%)$ y margen de error de $\pm 1,82 \%$. \\
\hline FECHA DE CAMPO & 30 de junio al 14 de julio de 2020 \\
\hline
\end{tabular}
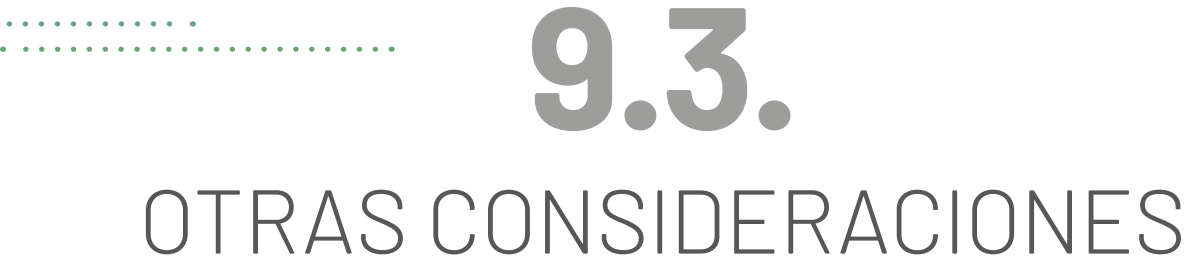

- Base de compradores: se ha continuado manteniendo el criterio definido durante la pasada edición del estudio. Se considera comprador online al individuo que ha realizado compras por Internet con una frecuencia mínima de una vez cada seis meses, ya que se entiende que los compradores con una periodicidad inferior han utilizado el medio de forma esporádica y por lo tanto no responde a un hábito o necesidad. Esta forma de consideración se ha utilizado para analizar las variables de número de compradores online, gasto, compras por categoría y nuevos compradores. Para el resto de los análisis planteados, se considera comprador online al individuo que ha realizado compras online independientemente de la frecuencia.

- Cálculo del volumen de gasto: al igual que en la edición del estudio del año anterior, el volumen de gasto se calcula a partir de un ajuste respecto a los datos aportados por la CNMC en relación con el volumen de negocio de las transacciones de comercio electrónico en España.

- Recodificación de las variables gasto y frecuencia de compra: la recodificación en ambos casos se ha mantenido igual respecto a años anteriores con el fin de facilitar la comparativa de los resultados. 


\section{ÍNDICE DE TABLAS}

TABLA 3. 1.

DISTRIBUCIÓN DE INTERNAUTAS POR PERFIL SOCIODEMOGRÁFICO (\%)

15

TABLA 3. 2. ¿CON QUÉ FRECUENCIA ACCEDE A INTERNET? POR GÉNERO Y GRUPOS DE EDAD (\%) .......................... 17

TABLA 3.3. ¿CON QUÉ FRECUENCIA ACCEDE A INTERNET? POR COMPRADORES Y NO COMPRADORES $(\%)$.............. 17

TABLA 3. 4. INTERNAUTAS COMPRADORES Y NO COMPRADORES ONLINE POR VARIABLES SOCIODEMOGRÁFICAS RELATIVAS AL HOGAR Y LA CONVIVENCIA(\%).....

TABLA 3. 5. INTERNAUTAS QUE NO COMPRARON EN 2019 PERO SÍ EN AÑOS ANTERIORES, POR GÉNERO Y GRUPOS DE EDAD (\%)

TABLA 3. 6. INTENCIÓN DE COMPRA ONLINE EN LOS PRÓXIMOS MESES DE LOS NO COMPRADORES POR GÉNERO Y GRUPOS DE EDAD(\%)

22

TABLA 4. 7. SEGÚN GÉNERO Y EDAD ¿CUÁL DE LAS SIGUIENTES ACCIONES REALIZA GENERALMENTE ANTES DE HACER COMPRAS ONLINE? POR GÉNERO Y GRUPOS DE EDAD (\%)(RESPUESTA MÚLTIPLE).

TABLA 4. 8. USO DE PAYPAL Y TARJETA COMO FORMA DE PAGO ONLINE, POR GÉNERO Y GRUPOS DE EDAD(\%)........ 30

TABLA 4. 9. BIENES Y SERVICIOS ADQUUIRIDOS POR INTERNET (\% Y № ABSOLUTO DE INTERNAUTAS COMPRADORES).. 31

TABLA 4. 10. BIENES Y SERVICIOS ADQUIRIDOS POR INTERNET (\%) 32

TABLA 4. 11. SUSCRIPCIONES A SERVICIOS Y CONTENIDOS DIGITALES, POR GÉNERO Y GRUPOS DE EDAD (\%)........... 34

TABLA 4. 12. APLICACIONES ADQUIRIDAS SEGÚN DISPOSITIVOS, POR GÉNERO Y GRUPOS DE EDAD (\%) .................... 38

TABLA 4. 13. ¿CUÁL FUE EL GASTO TOTAL APROXIMADO EN SUS COMPRAS POR INTERNET EN 2019? (2017-2019)(\%) .. 41

TABLA 4. 14. RESUMEN DEL GASTO EN COMERCIO ELECTRÓNICO Y OTROS INDICADORES ...................................... 42

TABLA 4. 15. № MEDIO DE ACTOS DE COMPRA, POR VARIABLES SOCIODEMOGRÁFICAS ........................................ 43

TABLA 4. 16. № MEDIO DE ACTOS DE COMPRA ANUALES, POR CATEGORÍA DE COMPRA .......................................... 44

TABLA 5. 17. INTERNAUTAS COMPRADORES QUE DECLARAN HABER TENIDO ALGÚN PROBLEMA EN LAS COMPRAS ONLINE, POR VARIABLES SOCIODEMOGRÁFICAS $(\%)$......

TABLA 5. 18. INTERNAUTAS QUE FORMULARON ALGUNA RECLAMACIÓN POR GÉNERO Y GRUPOS DE EDAD(\%) .........50

TABLA 5. 19. VIIAS DE FORMULACIÓN DE RECLAMACIONES POR GÉNERO Y GRUPOS DE EDAD(\%)......

TABLA 5. 20. ¿HA DEVUELTO ALGÚN PRODUCTO COMPRADO A TRAVÉS DE INTERNET? POR VARIABLES SOCIODEMOGRÁFICAS (\%). 53

TABLA 5. 21. ¿QUÉ PRODUCTOS O SERVICIOS DEVOLVIÓ?(\%). 54

TABLA 6. 22. INTERNAUTAS COMPRADORES, POR TIPO DE PRODUCTOS COMPRADOS (REQUIERAN ENVÍO O NO) (2018-2019)(\% Y № ABSOLUTO DE INTERNAUTAS COMPRADORES).

TABLA 6. 23. FRECUENCIA DE COMPRA, GASTO MEDIO Y \% SOBRE GASTO TOTAL DE LOS PRODUCTOS COMPRADOS ONLINE.

TABLA 6. 24. ASPECTO MÁS IMPORTANTE CON RELACIÓN A LA ENTREGA DE PEDIDOS REALIZADOS A TRAVÉS DE INTERNET POR GÉNERO Y GRUPOS DE EDAD(\%)......

TABLA 7. 25. RAZONES POR LAS QUE NO HA COMPRADO A TRAVÉS DE INTERNET, POR GÉNERO (\%)......

TABLA 7. 26. RAZONES PARA COMPRAR ONLINE EN LUGAR DE ACUDIR A UNA TIENDA FÍSICA, POR GÉNERO $Y \operatorname{EDAD}(\%)$

TABLA 8. 27. COMPRADORES ONLINE DURANTE EL CONFINAMIENTO, SEGÚN GÉNERO Y EDAD(\%)...... 69

TABLA 8. 28. ¿QUÉ TIPO DE PROCUTOS O SERVICIOS ADQQUIRIÓ POR INTERNET DURANTE EL PERIODO DE CONFINAMIENTO? (\%)

TABLA 8. 29. COMPARATIVA DE GASTO TOTAL ESTIMADO EN COMPRAS ONLINE DURANTE EL CONFINAMIENTO, SEGÚN GÉNERO Y EDAD $\%$ ).........

(7)

7




\section{ÍNDICE DE FIGURAS}

FIGURA 3. 1. VOLUMEN DE NEGOCIO DEL COMERCIO ELECTRÓNICO B2C EN ESPAÑA(EVOLUCIÓN 2009-2019)

(MILLONES €)

FIGURA 3. 2. GASTO MEDIO ANUAL POR INTERNAUTA COMPRADOR EN COMERCIO ELECTRÓNICO B2C EN ESPAÑA

(EVOLUCIÓN 2009-2019)(€).

FIGURA 3. 3. INTERNAUTAS EN ESPAÑA(EVOLUCIÓN 2009-2019)(\%)...... 14

FIGURA 3. 4. ¿CUÁL ES LA SITUACIÓN EN SU HOGAR? (\%) ............................................................................. 16

FIGURA 3.5. ¿ES USTED EL/LA PRINCIPAL RESPONSABLE DE LAS COMPRAS PARA EL HOGAR? (\%) ......................... 16

FIGURA 3. 6. DISTRIBUCIÓN DE INTERNAUTAS COMPRADORES POR PERFIL SOCIODEMOGRÁFICO (\%) ....................... 18

FIGURA 3. 7. DISTRIBUCIÓN DE INTERNAUTAS COMPRADORES POR GÉNERO (\%) .............................................. 18

FIGURA 3. 8. DISTRIBUCIÓN COMPRADORES ONLINE POR RESPONSABILIDAD EN LA COMPRA Y GÉNERO $(\%)$............. 19

FIGURA 3. 9. ¿CON QUÉ FRECUENCIA COMPRÓ POR INTERNET DURANTE 2019? ( \% ) ................................................ 20

FIGURA 3. 10. DISTRIBUCIÓN DE LOS INTERNAUTAS COMPRADORES ONLINE POR MOMENTO DE COMPRA

(ANTIGUOS Y NUEVOS) (\%).....

FIGURA 3. 11. DISTRIBUCIÓN DE INTERNAUTAS NO COMPRADORES POR PERFIL SOCIODEMOGRÁFICO $(\%)$................ 21

FIGURA 3. 12. A PESAR DE NO HABER REALIZADO COMPRAS A TRAVÉS DE INTERNET EN EL AÑO 2019, ¿TIENE INTENCIÓN DE HACERLO EN LOS PRÓXIMOS MESES? (\%)

FIGURA 3. 13. ¿TIENE INTENCIÓN DE COMPRAR A TRAVÉS DE INTERNET EN LOS PRÓXIMOS MESES? POR PERFIL DE COMPRA ONLINE ANTERIOR A $2019(\%)$

FIGURA 4. 14 ¿CUÁL DE LAS SIGUIENTES ACCIONES REALIZA GENERALMENTE ANTES DE HACER COMPRAS ONLINE? (\%)(RESPUESTA MÚLTIPLE)

FIGURA 4. 15. DISPOSITIVOS UTILIZADOS PARA COMPRAS ONLINE, POR GÉNERO (\%) (RESPUESTA MÚLTIPLE) ............ 26 FIGURA 4. 16. DISPOSITIVOS UTILIZADOS PARA COMPRAS ONLINE, POR GRUPOS DE EDAD(\%)(RESPUESTA MÚLTIPLE) .. 27 FIGURA 4. 17. ¿DÓNDE SUELE COMPRAR EN INTERNET?(\%) (RESPUESTA MÚLTIPLE)............................................28

FIGURA 4. 18. ¿QUÉ MOTIVOS LE LLEVAN A RECURRIR A UN MARKETPLACE PARA SUS COMPRAS ONLINE? (\%) (RESPUESTA MÚLTIPLE)

FIGURA 4. 19. ¿POR QUÉ MOTIVOS NO RECURRE A UN MARKETPLACE PARA SUS COMPRAS ONLINE?(\%)

(RESPUESTA MÚLTIPLE)

FIGURA 4. 20. ¿QUÉ FORMAS DE PAGO SUELE UTILIZAR EN SUS COMPRAS ONLINE?(\%)(RESPUESTA MÚLTIPLE) ........ 30 FIGURA 4. 21. ¿ESTÁ SUSCRITO A ALGÚN SERVICIO O CONTENIDO DIGITAL (VÍDEO, MÚSICA, VIDEOJUEGOS, ETC.)? (\%).. 33

FIGURA 4. 22. ¿AA QUÉ SERVICIOS DIGITALES ESTÁ SUSCRITO Y A TRAVÉS DE QUÉ DISPOSITIVOS ACCEDE? (\%) (RESPUESTA MÚLTIPLE).

FIGURA 4. 23. SERVICIOS Y CONTENIDOS DIGITALES QUE SE COMPARTEN CON TERCERAS PERSONAS (\%)...... 35

FIGURA 4. 24. COMPRA DE PRODUCTOS O SERVICIOS A TRAVÉS DE INTERNET USANDO DISPOSITIVOS MÓVILES, POR GÉNERO Y GRUPOS DE EDAD (\%).....

FIGURA 4. 25. ¿QUÉ PORCENTAJE REPRESENTAN LAS COMPRAS MÓVILES SOBRE EL TOTAL DE LAS COMPRAS QUE REALIZA A TRAVÉS DE INTERNET?(\%)

FIGURA 4. 26. ¿CUÁLES SON LAS PRINCIPALES RAZONES POR LAS QUE REALIZA COMPRAS ONLINE A TRAVÉS DE MÓVIL? (\%)(RESPUESTA MÚLTIPLE).....

FIGURA 4. 27. ¿POR QUÉ RAZONES NO REALIZA COMPRAS ONLINE A TRAVÉS DE MÓVIL O PREFIERE NO HACERLO?(\%)(RESPUESTA MÚLTIPLE)

FIGURA 4. 28. ¿PARA QUÉ TIPO DE DISPOSITIVO ADQUIRIÓ ALGUNA APLICACIÓN DE PAGO?(\%)...... 
FIGURA 4. 29. TIPOLOGÍA DE APLICACIONES ADQUUIRIDAS (\%)

FIGURA 4. 30. ¿ ¿CUÁL FUE EL GASTO TOTAL APROXIMADO EN SUS COMPRAS POR INTERNET EN 2019? (2017-2019)(\%).... 40

FIGURA 4. 31. EVOLUCIÓN DEL GASTO MEDIO ANUAL EN COMPRAS ONLINE, POR GÉNERO (2009-2019)(€)................. 40

FIGURA 4. 32. ¿HACE USO DE ALGUNA HERRAMIENTA DE COMPRAVENTA ONLINE ENTRE PARTICULARES? POR PERFIL DE COMPRA ONLINE $(\%)$.....

FIGURA 4. 33. ¿POR QUÉ MOTIVOS USA HERRAMIENTAS DE COMPRAVENTA ONLINE ENTRE PARTICULARES? (\%) (RESPUESTA MÚLTIPLE).

FIGURA 5. 34. ¿POR QUÉ RAZONES SUELE REPETIR COMPRAS EN EL MISMO SITIO WEB? (\%)(RESPUESTA MÚLTIPLE) .. 48 FIGURA 5. 35. ¿QUÉ TIPO DE PROBLEMAS TUVO EN SUS COMPRAS ONLINE?(\%)(RESPUESTA MÚLTIPLE).................... 50

FIGURA 5. 36. ¿PPOR QUÉ MOTIVO NO REALIZÓ RECLAMACIÓN?(\%)(RESPUESTA MÚLTIPLE)).......................................51

FIGURA 5. 37. ¿A TRAVÉS DE QUÉ VÍA FORMULÓ LA QUEJA O RECLAMACIÓN? (\%)(RESPUESTA MÚLTIPLE)................. 51

FIGURA 6. 38. ¿SUELE SER USTED QUIEN RECOGE LOS PAQUETES DE LAS COMPRAS REALIZADAS A TRAVÉS DE INTERNET? $(\%)$

FIGURA 6. 39. ¿QUÉ ASPECTOS CONSIDERA IMPORTANTES EN RELACIÓN CON LA ENTREGA DE PEDIDOS REALIZADOS A TRAVÉS DE INTERNET? (\%)(RESPUESTA MÚLTIPLE)

FIGURA 6. 40. ¿¿CUÁL CONSIDERA QUE ES EL PLAZO RAZONABLE DE ENTREGA DE PEDIDOS REALIZADOS POR INTERNET?(\%).

FIGURA 7. 41. ¿CUÁLES SON LAS RAZONES POR LAS QUE NO HA COMPRADO EN EL ÚLTIMO AÑO A TRAVÉS DE INTERNET? (\%)(RESPUESTA MÚLTIPLE)

FIGURA 7. 42. ¿CUÁLES SON LOS FACTORES DE LOS QUE DEPENDE QUE EN EL FUTURO COMPRE POR INTERNET? (\%)(RESPUESTA MÚLTIPLE)......

FIGURA 7. 43. ¿ ¿CUÁLES SON LAS RAZONES POR LAS QUE HA COMPRADO EN EL ÚLTIMO AÑO A TRAVÉS DE INTERNET?(\%)(RESPUESTA MÚLTIPLE).

FIGURA 7. 44. ¿AA LA HORA DE DECIDIRSE A COMPRAR EN UN DETERMINADO SITIO WEB, TIENE EN CUENTA SI ESTÁ ADHERIDO A UN SELLO DE CALIDAD O CÓDIGO ÉTICO DE CONFIANZA ONLINE? (\%)

FIGURA 7. 45. COMPRADORES QUE TIENEN EN CUENTA EL SELLO DE CALIDAD O CÓDIGO ÉTICO DE CONFIANZA ONLINE A LA HORA DE COMPRAR POR INTERNET (EVOLUCIÓN 2014-2019)(\%)

FIGURA 7. 46. ASPECTOS SATISFACTORIOS Y MEJORABLES DE LOS SITIOS DE COMPRA ONLINE (\%).........................65

FIGURA 8. 47. ¿HA REALIZADO COMPRAS DE PRODUCTOS O SERVICIOS POR INTERNET DURANTE EL CONFINAMIENTO?(\%)

FIGURA 8. 48. COMPRADORES ONLINE DURANTE EL CONFINAMIENTO, SEGÚN HÁBITOS DE COMPRA DURANTE $2019(\%)$

FIGURA 8. 49. ¿CON QUÉ FRECUENCIA COMPRÓ POR INTERNET DURANTE EL CONFINAMIENTO?(\%)

FIGURA 8. 50. ¿CUÁNTO ESTIMA QUE HA SIDO EL GASTO TOTAL APROXIMADO EN SUS COMPRAS DURANTE EL CONFINAMIENTO?(\%)

FIGURA 8. 51. ¿CÚALES SON LAS PRINCIPALES RAZONES POR LAS QUE NO HA COMPRADO O CONTRATADO ALGÚN PRODUCTO O SERVICIO ONLINE DURANTE EL CONFINAMIENTO? (\%)

FIGURA 8. 52. ¿CÚALES SON LAS PRINCIPALES RAZONES POR LAS QUE HA COMPRADO O CONTRATADO ALGÚN PRODUCTO O SERVICIO ONLINE DURANTE EL CONFINAMIENTO?(\%).....

FIGURA 8. 53. PRINCIPALES RAZONES POR LAS OUE HA COMPRADO O CONTRATADO ALGÚN PRODUCTO O SERVICIO ONLINE DURANTE EL CONFINAMIENTO, SEGÚN HÁBITOS DE COMPRA DURANTE $2019(\%)$

FIGURA 8. 54. ¿CONSIDERA QUE HABER VIVIDO ESTAS CIRCUNSTANCIAS ESPECIALES DE CONFINAMIENTO MODIFICARÁ SUS HÁBITOS DE CONSUMO ONLINE EN EL FUTURO?(\%). 75

FIGURA 8. 55. ¿CÓMO CONSIDERA QUE SE MODIFICARÁN SUS HÁBITOS DE CONSUMO?(\%) 76 